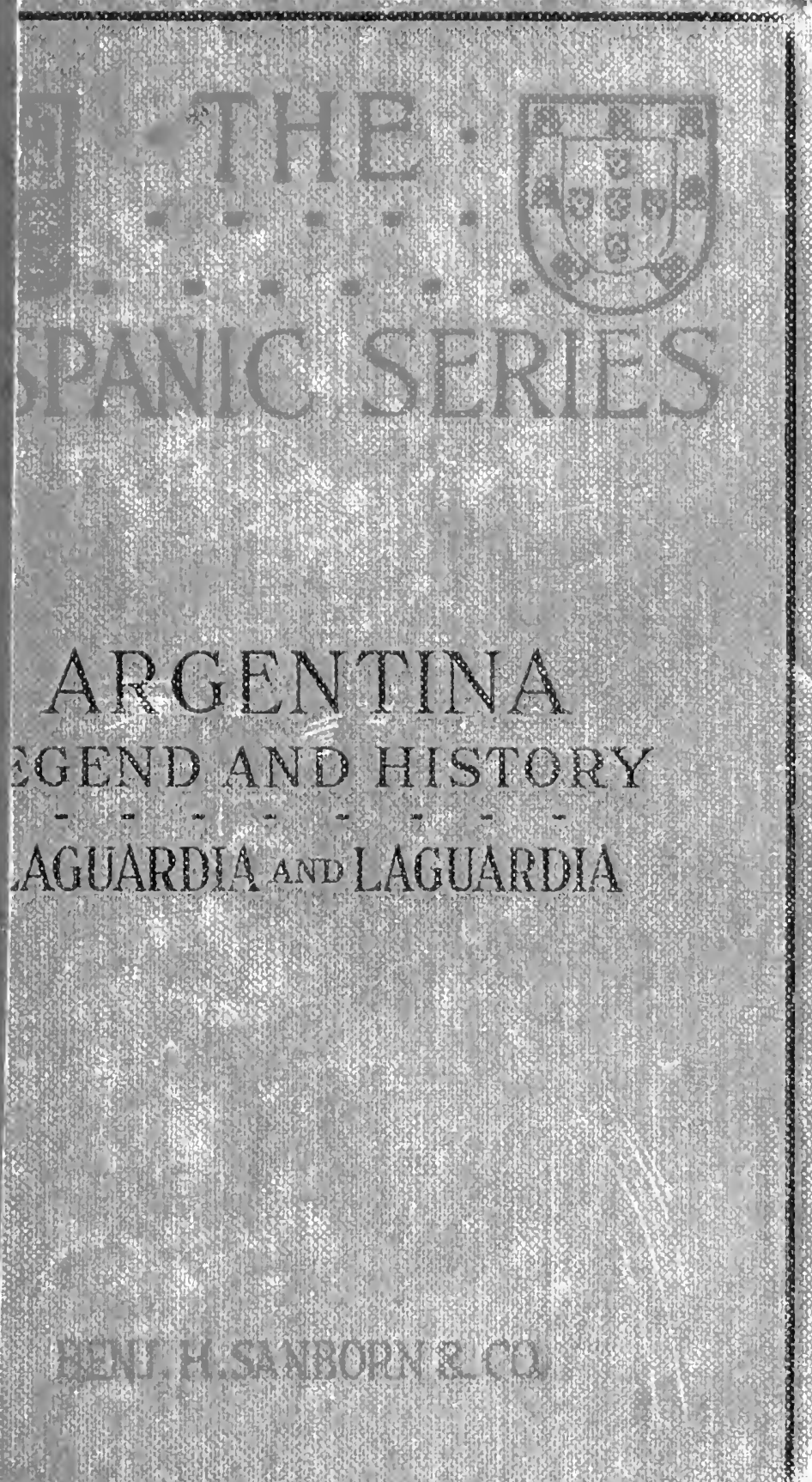



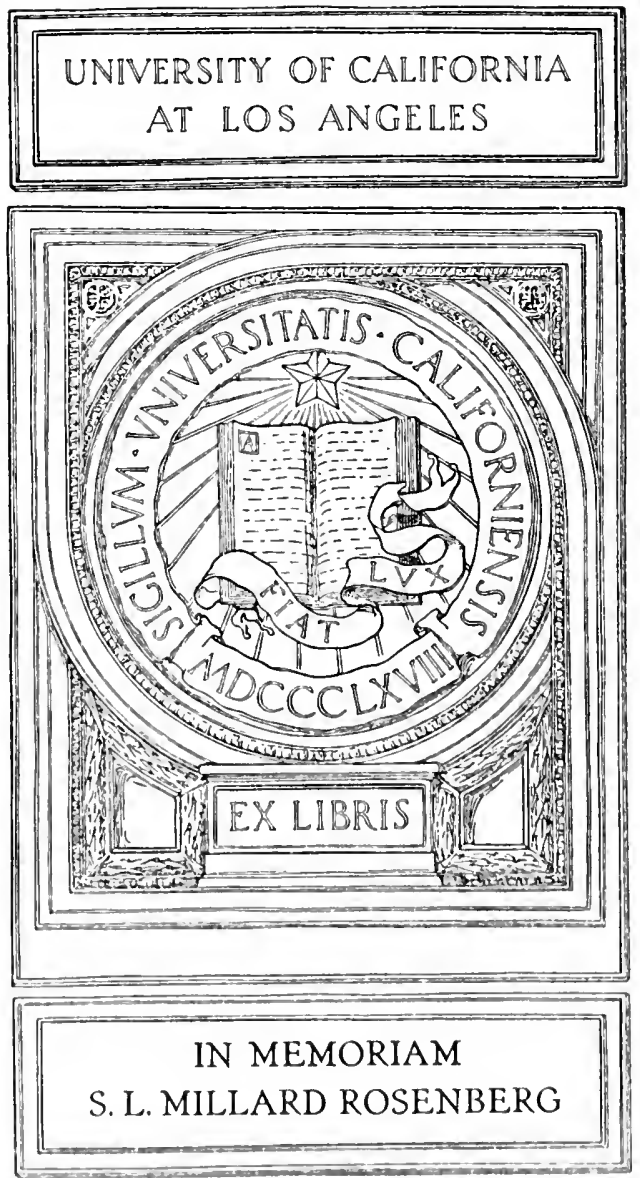



\title{
THE HISPANIC SERIES
}

UNDER THE EDITORSHIP OF

\author{
John D. Fitz-Geralo, Phi.I).
}

PROFESSOR OF SPANISH, UNIVERSITY OF ILLINOIS MEMBER OF THE HISPANIC SOCIETY OF AMERICA CORRESPONDIENTE DE LAS REALES ACADEMIAS ESPAÑOLA, DE LA HISTORIA DE MADRIL, Y DE HUENAS LETRAS DE BARCELONA

\section{ARGENTINA \\ LEGEND AND HISTORY}




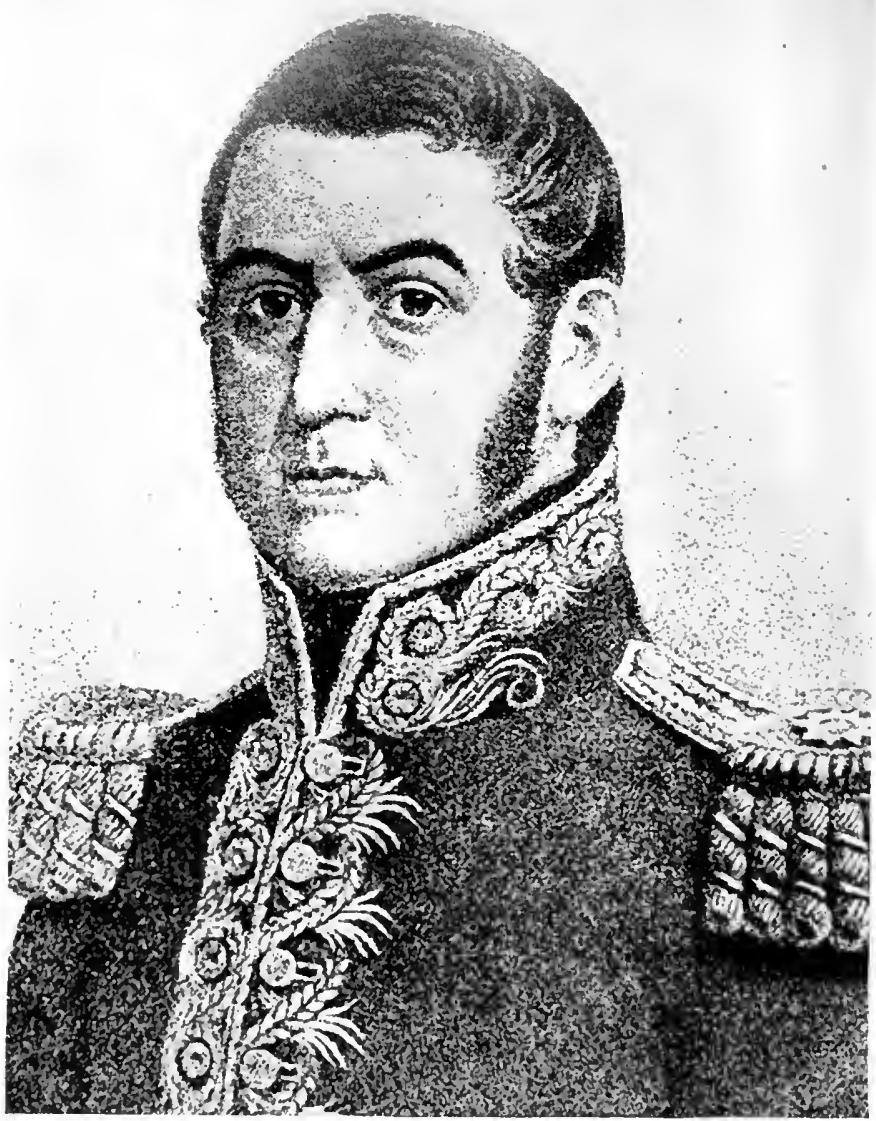

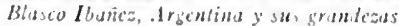

JOSE DE SAN MARIÍN 


\title{
A R G E N T I N A
}

LEGEND AND HISTORY

\author{
READINGS SELECTED AND EDITED
}

BY

GARIBALDI G. B. LAGUARDIA, A.M.

AND

CINCINATO G. B. LAGUARDIA, A.B.

OF THE UNITED STATES NAVAL ACADEMY

BENJ. H. SANBORN \& CO. 
Copyright, igig,

By BENJ. H. SANBORN \& CO.

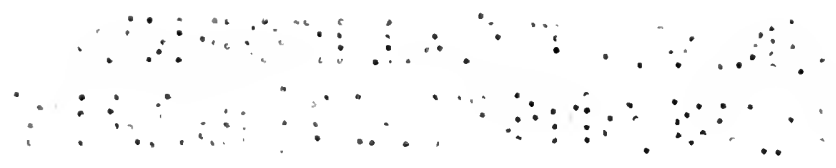

Norwood 扔ress

1. S. Cushing ('). liserwick of sinth (").

Nurwoul, Mass., I'.A.A. 


\section{A I \\ NOSTRI GENITORI}

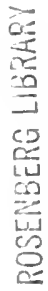


Digitized by the Internet Archive in 2008 with funding from Microsoft Corporation 


\section{PREFACE}

In this book, the editors offer reading material which will give the student some idea of the history of Argentina, of her great men, of her development since the dawn of independence, and of her wonderful possibilities, as shown in Blasco Ibáñez's Con Rumbo a la Esperanza.

The choice of material has necessarily been restricted, but within that limited field, the editors have selected what was representative and typical and best adapted to the purpose in view.

The book has been arranged to suit the needs of third-year high school work, or second-year college Spanish. It was taken for granted that the student would be familiar with the underlying principles of Spanish grammar before taking up this book; and yet, grammatical explanations have been given wherever they were deemed necessary, and translations of difficult passages have been suggested. The Introduction gives a brief historical sketch of Argentina, which will furnish a background on which to locate the specific events related in the book. Considerable detailed information conceming the authors represented and the institutions and customs of Argentina and her people will be found in the vii 
Biographical Notes and in the annotations to the selections.

If the book succeeds in arousing a sympathetic interest in the struggles for Argentine independence and her subsequent progress, the editors will feel more than repaid. Upon that sympathetic interest must rest the ever growing Pan-American ideal to bring both Americas closer to each other.

The editors gratefully acknowledge their obligation to the Pan-Annerican Union, Washington, D.C., to The Hispanic Society of America, New York, and to Doubleday, Page \& Co., New York, for their courtesy in permitting the reprinting of the article on the Congreso de Tucumán, taken from the July, I9I6, number of La Revista del Mundo. To their colleague, Mr. Julian MorenoLacalle, the editors are sincerely grateful for valuable suggestions and for many kindnesses, which have made the work easier to accomplish. Thanks also are due to Professor F. B. Luquiens (of Yale), Messrs. H. K. Stone (of Grinnell College, Iowa), O. d'Amato (of the University of Illinois), and J. Pittaro (of the Stuyvesant High School, New York).

\section{Garibaldi G. B. Inguardia Cincinato G. B. Laguardia}

[Titlil) States Naval. Academy

AnNAPOLIS, Marylani) 


\section{CONTENTS}

PAGE

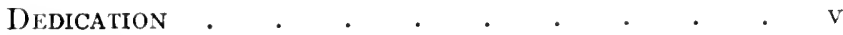

PREFACE. . . . . . . . . . . vii

INTRODUCTION . $\quad$. . . . . . . . . XV

Biographical Notes . . . . . . . . . . . 1

Himo Nacional Argentino . . . . . . I

Vicente López y Planes

El Gaucho Argentino . . . . . . . . 7

Vicente Fidel López

Originalidad y Caracteres Argentinos . . . 22

Domingo F. Sarmiento

I. El Rastreador . . . . . . . . 36

II. El Baquiano . . . . . . . . 40

III. El Gaucho Malo . . . . . . . 46

IV. El Cantor . . . . . . . . . 49

ASOCIACIÓN . . . . . . . . . . 56

Domingo F. Sarmicnto

La Pulpería . . . . . . . ${ }_{56}$

Leyendas del País de la Selya • • • 74

C. O. Bunge (Según Ricardo Rojas)

I. El País de la Selva, Sus Leyendas y Trovadores . 74

II. Zupay . . . . . . . . . .

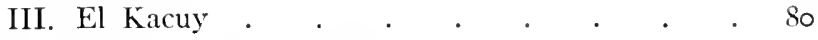

La Leyenda de Santos Vega . . . . . 86 ,

C. O. Bunge 
PAGE

La Tradición de Lucía Miranda • . . . 9 I C. O. Bunge

El Lucero del Manantial: Episodio de la Dictadura

de don Juan Manuel Rosas . . . . $9 S$ Manucla Gorriti

I. Naría . . . . . . . . . . . . . .

II. Un Sueño . . . . . . . . . . 100

III. El Encuentro . . . . . . . 101

IV. Amor y Agravio . . . . . . 102

V. Dieciséis Años Después . . . . . . . I03

VI. Madre e Hijo . . . . . . . . IoS

VII. En la Sala de Representantes . . . . I Io

VIII. EI Terrible Drama . . . . . . . I12

IX. Conclusión . . . . . . . . Itt

Los 3000 PESOS DE DORREgo . . . . . I16

C.O. Bunge

Cumplar la CONSIGNa

C. O. Bunge (Según Juán M. Esspora)

LA I.EALTAD DE SAN MARTÍN

C. O. Bunge (Según Juán M. Espora)

I A WALE EN RÍO BAMBA

Pedro Lacasa

EL OMBú

Marcos Sustre

liN LA CORDILLERA

Iuln Marin Gutiêrres

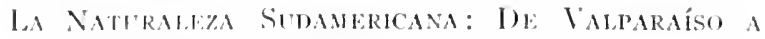
BuFves deres

Jumu Maria Ciulierez 
Linters y la Reconquista de Buenos Aires . . I 8 C. O. Bunge (Según P. Groussac)

I. Los Preparativos y la Marcha hacia Buenos Aires $I_{4} 8$

II. La Reconquista . • • • • • • I53

El Negro Falucho . . . . . . . i6 I Bartolomé Mitre

La Abdicación de San Martín . . . . . 166 Bartolomé Hitre

El General Belgrano. . . . . . . I 77 Bartolomé Mitre

El General Las Heras . . . . . . 184 Bartolomé Hitre

Don Juan Martín de Pueyredón • • • · I 90 V.F. López

Mariano Moreno . 195 Juan Maria Gutiêrrez

GüEMES

Bartolomé Mitre

Facundo Quiroga

Domingo F. Sarmiento

Esteban Echeverría

Pedro Goyena

El Congreso de Tucumán: i 816-igi6 222 Ernesto Nelson

Buenos AIRes FN I8I5. - 243

Vicente Fidel López 


\section{xii LIST OF MAPS AND ILLUSTRATIONS}

Buenos Aires: Las Tiendas Antiguas . . . 25 I Lucio $\mathrm{V}$. López

Con Rumbo a la Esperanza (from La Argentina y sus

$$
\text { grandezas) . . . . . . . . . . } 255
$$

Vicente Blasco Ibánes

El Ministro Drago al Ministro García MÉrou • 292 Luis M. Drago

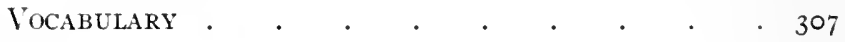

\section{LIST OF MAPS AND ILLUSTRATIONS}

José de San Martín . • • . . . Frontispiece

República Argentina (mapa) . . . . . xiv

El 25 de Mayo de I8Io . . . . . . xxii

Belgrano ex Tucumín . . . . . . xxix

La Bahía de Montevideo en I8 825 . . . . xxxii

El PASO de los ANdes . . . . . . xxxV

los Treinta y Tres Orientales . . . . xliii

Chioza de Gaucho en la Pampa. . . . . i i

Vista de un Pago de Gauchos . . . . . . 15

Domingo F. Sarmiento . . . . . . 23

Estancia en las Pampas . . . . . . 43

UNa purpería en la Campo . . . . . 60

Gaucho fen ho Acto de arrojar ux tiro de Bolas 65

Ricardo Rojas, Jovex Escritor Argentino . . 77

Una Payad de Contrapuxto . . . . . 87

Carlos Octaho Bunge . . . . . . . 92

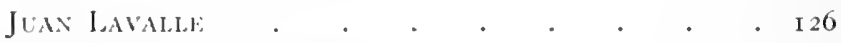

UNA VISTA DE LA PAMPA . • . • • . I 29

UN Омич́ . . . . . . . . . 130 
SUD-AMÉrICA $(m u p u)$. . . . . facing I4I Santiago Antonio de Liniers . . . . . I50 Paul Groussac . . . . . . . . . 154 Buenos Aires y Sus Contornos (mapa) . . . ${ }_{156}$ Avance de los Ingleses sobre: Buenos Aires . . I 58 Estatua al Negro Falucho en Buenos Aires. . 163

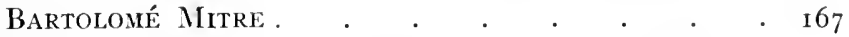

Estatua Ecuestre del General San Martín, Plaza

San Martín, Buenos Aires . . . . . . I69 San Martín y Bolívar en Guayaquil • • • 174 Manuel Belgrano . . . . . . . . 179 Juan Gregorio de Las Heras . • • . . 187 Juan Martín de Pueyrredón • • • • • . ig I Mariano Moreno . . . . . . . . . . 197 Martín GüEmes . . . . . . . . . . . 204 Juan Facundo Quiroga . . . • . . . 2 I I Casa donde se Reunió el Congreso de Tucumán • 224 Ernesto Nelson . . . . . . . . . 232 Vista del Puerto de Buenos Aires . . . . 265 Vicente Blasco IbÁÑez . . . . . . 273 Buenos Aires: Los Elevadores . . . . $\quad 285$ Buenos Aires: La Avenida de Mayo . . . 291 Luis M. Drago . . . . . . . . 295 


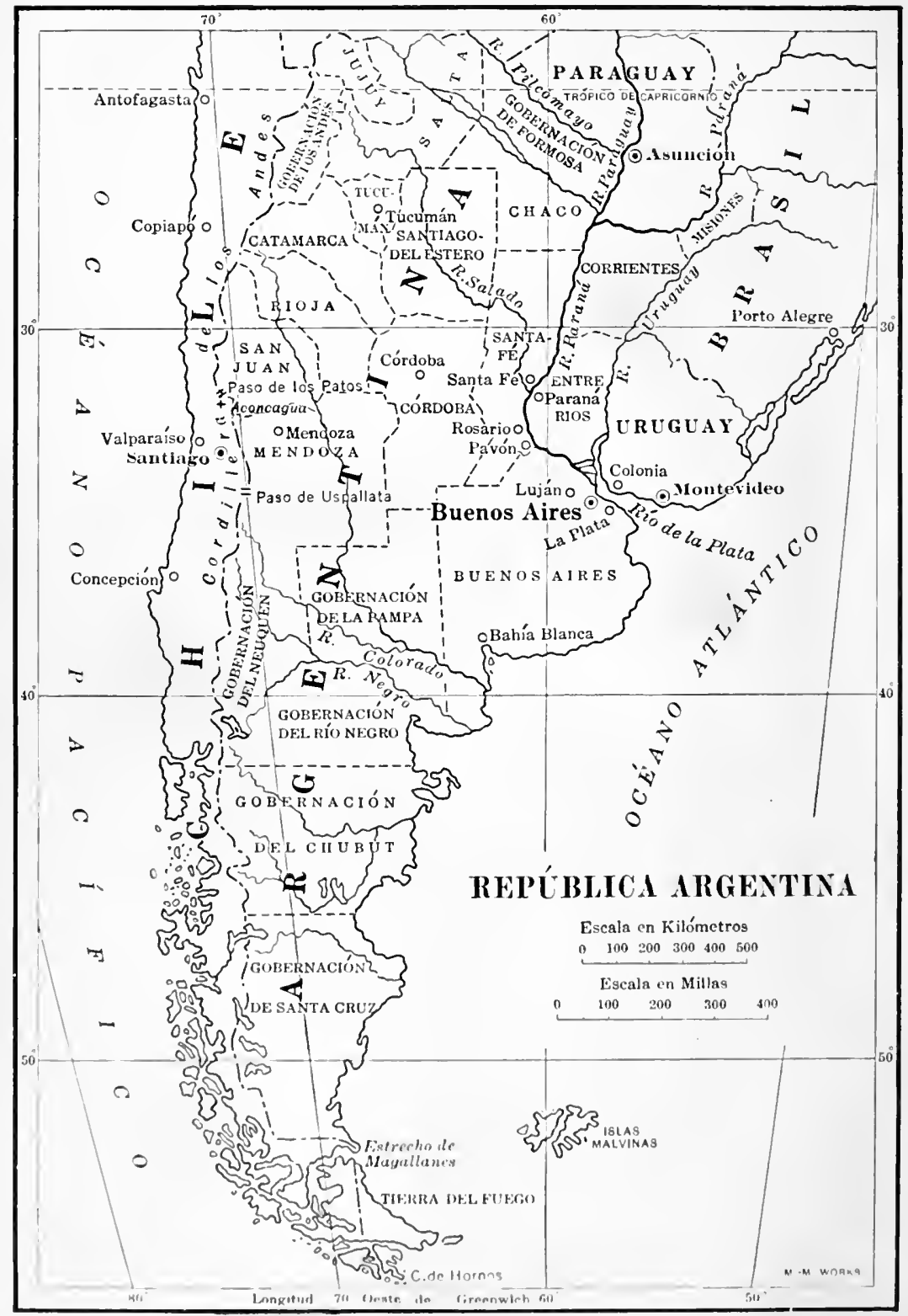




\section{INTRODUCTION}

THE material of which this textbook is composed must be so new to the vast majority of both teachers and students of Spanish in this country, that the need of an introduction has been deemed imperative by the editors.

Americans have of late been growing more and more alive to the urgent necessity of gaining a better knowledge of the vast continent and the peoples to the south of them. Argentina, as the most prosperous of the South American republics, has claimed no small share of this newly awakened interest. It is hoped that this book will aid in promoting and strengthening this interest, and that this introduction, in its turn, will be of aid in elucidating and furnishing a proper background for the material herein presented.

If we wish to understand Argentina, we must begin first of all by familiarizing ourselves with one pivotal sentiment that has permeated and controlled every aspect of Argentine life and development since colonial days. This sentiment is an exalted and haughty patriotism, so intense, indeed, that the tone with which an Argentine says "Soy argentino", is no whit less assertive and proud than that in which citizens of ancient Rome were wont to say "Civis Romanus sum". 
Whatever the origin of this sentiment, the evidences of it are irrefutable. Argentina has today about nine million inhabitants: of these, fully two thirds are of recent foreign origin, mainly Italian and Spanish, and to a much smaller extent, English, French, and German. Argentina, in other words, has relatively a much larger population of recent foreign extraction than the United States. Nevertheless, the hyphen does not exist in Argentina; and the terms Italo-Argentine, Hispano-Argentine, Franco-Argentine, etc., are entirely unknown. The jealous and uncompromising patriotism of the Argentine makes hyphenated national designations impossible. If we turn from the evidence of purely popular sentiment to the more sober and more controlled evidence of literature, we find the same thing. Take away from the literature of Argentina the theme of patriotism, and you have taken away its most distinctive and its greatest life-giving element. It has been said, and justly, that the Italian literature of the nineteenth century centered entirely about the theme of Italian unification, voicing during the first half of the century the aspirations of her great men for a united Italy, and during the second half intoning the paan of joy at the accomplishment of those aspirations. The same may be said of Argentine literature. The names of the great leaders of her immortal Revolution, both against the mother country 
and later against the internal caudillo tyrants - the most important of whom was Rosas - and the deeds that they performed, recur again and again through the pages of her men of letters, whatever be the form of literature they engage in, narrative, dramatic, or poetic.

It is for this reason that for the proper understanding of the Argentine temperament, as evidenced by her literature as well as by her popular ideals, the knowledge of her political history, beginning with the time of the English invasions in I 806 (when the latent nationalism of the then Viceroyalty of the Plata first manifested itself in action), is a requisite of prime importance.

Until the year 1776, Argentina had been but a negligible part of the Spanish possessions in South America, being a dependency of the Viceroyalty of Peru. Despite, however, the short-sighted commercial policy of Spain, which forbade the colonies from trading with any European country, save the mother country, and then by restricted routes and through specific Spanish ports, Buenos Aires, towards the end of the eighteenth century, had far outstripped all other colonial cities with the exception of Lima. By royal decree, therefore, on the 8th of August, I776, the Viceroyalty of the Plata River was established with Buenos Aires as its capital. It included what is today Argentina, Uruguay, Paraguay, Bolivia, and the province of Rio Grande, belonging now to Brazil. 
The first Viceroy was Don Pedro de Ceballos, a soldier of ability and an administrator of unusual talent. As a result of the war he waged against the Portuguese, who had taken possession of northern Uruguay and the harbor of La Colonia, this port was won back to the Viceroyalty of the Plata. It may be said that the driving out of the Portuguese from La Colonia marks the first of a series of events that finally led to the independence of Argentina; for, if Buenos Aires had been able to grow commercially, it had been due, in no small measure, to the clandestine trade that was carried on through the port of La Colonia. Its capture forced the Viceroy to assume a very grave responsibility; namely, to change on his own authority the trade regulations then in force. His permission to allow certain forejgn merchandise to come into Buenos Aires, an act which was later approved by the Crown, was the first recognition of the needs of the new Viceroyalty, as well as of the pressure that the colonists could bring to bear upon the mother country.

Of the Viceroys that followed Ceballos till the period of the English invasions, there is but one that deserves to be recalled here. He was Don Juan José de Vértiz, under whose administration still greater commercial freedom was granted to Buenos Aires. To take the place of the schools of the Jesuits, who were at this time expelled from Spain and the colonies, Vertiz founded in 
Buenos Aires the Colegio de San Carlos. It was also during his administration that the famous brothers Biedma explored Patagonia, and that the settlement of this immense region was begun, forestalling thus the plans contemplated by the English as a result of the voyages of Thomas Falkner.

The decay into which Spain had fallen towards the beginning of the nineteenth century, and the rule of the seas that England gained as a result of the battle of Trafalgar (I805), led the English to attempt the conquest of the Viceroyalty of the Plata, of whose great possibilities Falkner, upon his return to England, had given a glowing account. Sir Home Popham, therefore, who had coöperated with Sir David Baird in the occupation of the Cape, put I 635 men under the orders of General W. Beresford for the purpose of capturing Buenos Aires. The English expedition landed at Quilmes, not far from Buenos Aires, the $25^{\text {th }}$ of June, I806. The Viceroy at that time was Don Rafael de Sobremonte, one of the weakest men who had occupied that important office since the establishment of the Viceroyalty of the Plata. Instead of leading the colonies against the invader, he fled to the interior with whatever moneys he was able to gather from the treasury. Under these circumstances the English force, small as it was, easily took possession of Buenos Aires. Meanwhile, the people under 
the leadership of Don Santiago de Liniers and Don Juan Martín Pueyrredón, prepared to drive out the invader, and it was not long before Liniers, with the aid of forces from Montevideo, and Pueyrredón, with forces hastily raised in the province, forced Beresford to surrender unconditionally. In recognition of the valor and ability displayed by Liniers, the people chose him as their leader, forcing Sobremonte to surrender his power. This was the second time that the colonists imposed their will; the time was not distant when they should do so forever.

In July, I 807 , another British expedition, composed of I 2,000 soldiers, under General Whitelock, attempted to reconquer Buenos Aires. But Liniers was fully prepared to meet the new and increased forces sent to take possession of the colony. In less than a year he had been able to reorganize the scanty and demoralized forces that protected the capital. Whitelock, having effected a landing, marched upon Buenos Aires; but after much fierce street fighting, in which women and children took part, he was forced to capitulate with the loss of over 3000 of his effectives. The heroism of the people of Buenos Aires on this occasion is well attested by the testimony of Whitelock himself, who said: "Each home was a castle, and each soldier a hero.'

These signal victories, which the colonists were 
able to obtain without any aid from the home government, coupled with their ancient dissatisfaction over the trade restrictions forced upon Buenos Aires, had a double effect : first, they inspired the colonists with a new sense of self-reliance and confidence; secondly, they heightened the old discontent, and gave rise to thoughts of independence. When, therefore, Napoleon, in I810, dethroned Ferdinand VII, and crowned his own brother Joseph King of Spain, the occasion presented itself for the colonists to translate those sentiments of dissatisfaction into actual revolt.

- Liniers was at this time Viceroy, the choice of the people having received the official sanction of the royal government. As a Frenchman, however, he was distrusted, and in his place Don Baltasar Cisneros was appointed in July, I809. One of his first acts, the throwing open of the commerce of the Viceroyalty to all nations, quieted for a while the general discontent, and gained for the new Viceroy a certain measure of popularity. But his harshness in repressing an outbreak that took place in La Paz (Bolivia), in February of I 8 IO, lost him at once the prestige he had at first won.

The minds of the multitude were irrevocably bent on separation; men like Belgrano, Castelli, Chiclana, Paso, Rodríguez Peña, were secretly working for the independence of the provinces. 
On the 25th of May, ISIo, after news had been received of the complete subjugation of Spain, the people en masse demanded the deposition of Cisneros, and a committee presided over by Cornelio

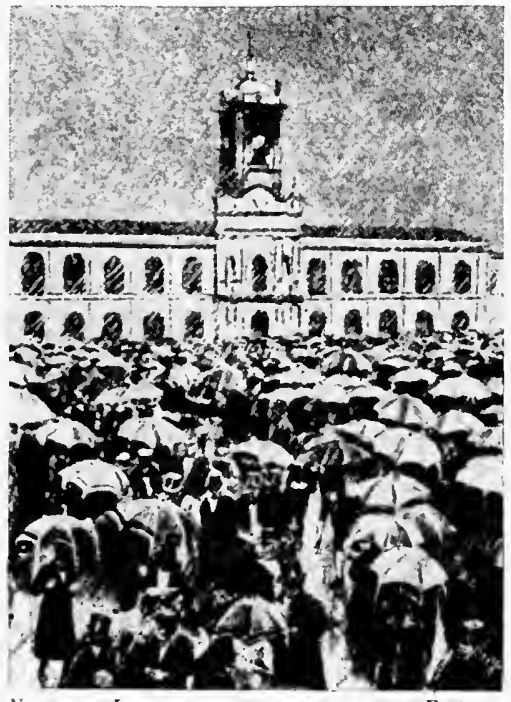

Navarro y Lamarca

II istoria general de A mérica
Saavedra was appointed to take the reins of government. Castelii, Belgrano, Azcuénaga, Alberti, Matheu y Larra, were the other members of this Junta, and Paso and Moreno were its secretaries. Thus the change in government was carried out, in form at least, by a mass meeting of the population of Buenos Aires.

The task of the newly established government was indeed an arduous one; for, not only did it have to defend its authority against Spain, but also to make its power felt and obeyed by the provinces of the interior. 'The first task was accomplished when the Spaniards were finally driven 
from South America; the carrying out of the second task brought on a second revolution, a fratricidal strife, which came very near establishing in Argentina a number of petty and insignificant states instead of a united, strong nation. In this second struggle, though in principle the battle was lost for Buenos Aires (since the federal form of government is the one that obtains today in Argentina), the leadership of the capital remained unquestionably established so far as initiative and spiritual ascendancy are concerned.

Buenos Aires set out, as Rome had done, to expand politically from a city-state into a vast republican state. She partly failed in this, as is evidenced by the withdrawal of Paraguay, Uruguay, and Bolivia from the old Viceroyalty of the Plata, but, as we have said, she succeeded in establishing, if not the political hegemony of the Plata, the undisputed spiritual leadership, and the proud claim of being the second largest and wealthiest Latin city in the world, and the greatest in all the Southern Hemisphere.

We shall attempt to trace briefly : first, the steps by which the Spaniards were expelled from the South American countries; second, the steps by which the provinces of the Plata emerged from the chaos of civil strife, and came, after the battle of Pavón, to enjoy the sweet fruits of peace.

After the deposition of Cisneros, the provisional 
Junta sent out circulars to the provinces, asking for their recognition of its authority. The provinces, save Uruguay and Paraguay, signified their support of the new government. From the very beginning, then, these two provinces showed a tendency not to accept the leadership of Buenos Aires. Furthermore, not long thereafter, when it became known that the Junta aimed at separation, the province of Córdoba anc' those of Alto Perú (Bolivia) joined with Uruguay and Paraguay in their opposition to the provisional government. The "Tory" reaction was thus not long in manifesting itself.

Montevideo, led by the newly appointed Viceroy, Javier de Elío, made ready a fleet to attack Buenos Aires; Gutiérrez de la Concha, Governor of Córdoba, appointed Liniers to lead its forces against the Junta; and in Alto Perú, General Goyeneche, appointed president of Cuzco by the Viceroy of Peru, took charge of the resistance to the Revolution. The gravity of the reaction that set in, the increasing number of forces that were being arrayed against the new government, demanded firm and instant action. Happily for the independence of Argentina, there was in the Junta a leader of force and vision. He was Mariano Moreno, the secretary of the Junta; he was the soul of the revolutionary movement in its early stages; he was the pilot that steered it safely through the perilous shoals of the dawn of 
independence. It is in recognition of these great services that Argentina acclaims him today as one of her greatest champions, ranking with San Martín, Belgrano, and Rivadavia.

: To meet these dangers, two expeditions were sent out: one against Córdoba and Alto Perú, under the orders of Ortiz de Ocampo; and another against Paraguay, under the orders of General Belgrano.

Liniers and Concha were taken prisoners, and by order of the Junta were put to death. Thus died Santiago de Liniers, defender of Buenos Aires during the English invasions. Many historians and writers have denounced this act of the Junta as ruthless and unnecessarily severe; practically as many others have defended it in view of the inexorable need for sternness demanded by the conditions of the times. We mention it as the first instance of internecine struggle, and as typical of the unrelenting character of the Revolution that came later. The expedition continued its northward march, under the orders of Balcarce, and defeating the Royalists at Suipacha, soon had control of the north as far as the Desaguadero, the boundary between the Viceroyalties of Peru and of the Plata. Here we shall leave it for a while in order to follow the campaign against Paraguay.

Heartened by the successes of Balcarce, the Junta decided to hasten the expedition against 
Paraguay under the orders of Belgrano. But, whereas the expeditionary force of Alto Perú had met until then with remarkable success, Belgrano, after having his communications impeded by the control of the Paraná, which the Royalists held, and taking part in two unsuccessful engagements, was glad to sign an agreement whereby he was allowed to withdraw unmolested from Paraguay with all his forces. Though this expedition failed of its purpose to bring Paraguay under the control of the Junta, it helped in no small degree to create a separatist movement in Paraguay which led in a few years to the defeat of the Spaniards and the establishment of an independent government.

By this time also the situation in Uruguay called for the attention of the Junta. The people of the country, despite the pro-Spanish sentiment prevalent in Montevideo, were manifesting signs of revolt against the Spaniards, and when Artigas, the Uruguayan leader, came to Buenos Aires to enlist the aid of the provisional government, the forces of Belgrano that had returned from Paraguay were intrusted to Rondeau to coöperate with Artigas in Uruguay. With the aid of these troops from Buenos Aires, Artigas obtained a signal victory against the Spaniards at Las l'iedras, which enabled him to lay siege to Montevideo.

With the exception of Belgrano's expedition to 
Paraguay, which, though unsuccessful in its attempt to bring that province under the control of the Junta, had nevertheless caused no serious military loss, the forces of the Revolution were everywhere successful. Unfortunately, the stinging defeat of Huaquí that the army of Alto Perú met at the hands of Goyeneche in I8II, on the boundary between Bolivia and Peru, threatened for a moment to reëstablish the power of Spain. Had the Argentine forces been successful, Bolivia and Uruguay would never have become separate republics. The complete independence of South America would have been attained ten years before the battle of Ayacucho (1824), and, very likely, with its victorious armies, Buenos Aires would have been able to avoid the terrible civil struggle that, through the lack of a wise and strong central government, lasted till the downfall of Rosas. As it was, the siege of Montevideo had to be abandoned at a time when its garrison was on the point of surrendering; and it was only through the energetic and skillful leadership of Pueyrredón, who was put in command after Huaquí, that of the 23,000 men who composed the original Army of the North, one thousand succeeded in reaching Tucumán. From a purely military point of view, the disaster of Huaquí meant the passing of the initiative from the revolutionary Army to the forces of Spain. In fact, not until I817, when San Martín crossed the Andes and 
defeated the Royalists in Chile, were the provinces once more on the offensive. It meant also that the way for a decisive blow at the Spaniards through the north was forever barred; that the attack had to be carried through the west to Chile, first, and then by sea to the heart of Spanish power in Lima; that while troops were being prepared slowly and patiently for this purpose, the constant pressure of the victorious Spanish armies from the north had to be withstood; and last, but by no means least, it emphasized the need for the presence of a strong man to bolster up the provisional government in Buenos Aires itself, which, after the death of Mariano Moreno, was left without a leader of ability and strength commensurate with the magnitude of the task to be accomplished.

Fortunately for the independence of the provinces of the Plata, there arose, at this critical juncture, men like Belgrano, who by his victories of Tucumán and Salta, stemmed the flood of Spanish invasion after Huaquí; San Martín, who by his conquest of Chile and Lima, was to force the Spaniards into the fastnesses of the mountains of Peru, where his veteran troops, delivered by one of the greatest acts of self-denial in the record of history into the hands of Bolivar, sounded the knell of Spanish dominion on the battlefields of Junin and Ayacucho; Güemes, who after the battle of Sipe-Sipe, a disaster comparable only to 
Huaquí, was able, with the aid of his intrepid gauchos, to protect the communications of the army that was being prepared by San Martín in Mendoza; Rivadavia and Pueyrredón, without the stimulus of whose leadership the provisional

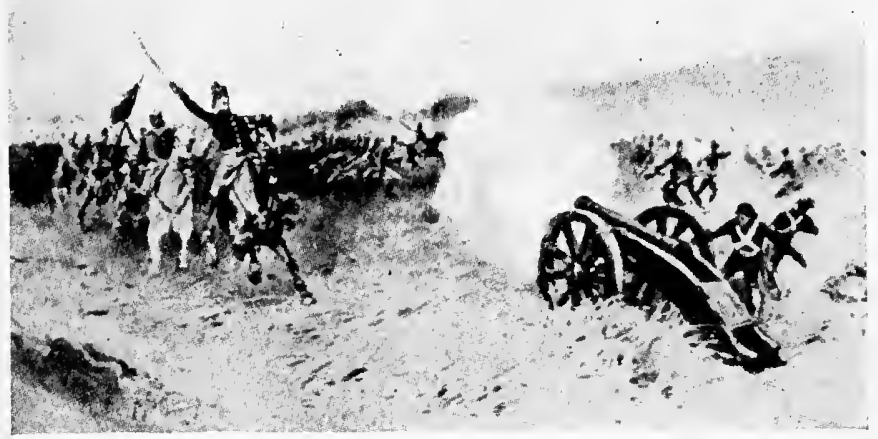

Vavirro y Limarca, II istoria general de América

Fortuny

Belgrano en Tucumán

government would have succumbed under the weight of the responsibilities it had assumed.

Immediately after the victory of Tucumán, obtained by Belgrano against the Spanish forces that invaded northern Argentina after the defeat of Huaqui, the siege of Montevideo was begun once more, both as a result of that victory and of negotiations with Brazil, whereby the troops of that empire, which had come to the aid of the Spaniards, were to withdraw from Uruguay. 
The patriots were soon able, in spite of the friction that arose between Artigas and the Argentine troops, to pin the Spanish forces within the inner circle of the defenses of Montevideo. It was in connection with this campaign against Montevideo that San Martín in I8I3 won his first victory against the Spaniards, at San Lorenzo, on the shores of the Paraná. By this victory an end was put to the foraging expeditions that the beleaguered garrison of Montevideo sent to the province of Entre Ríos. Thus the only immediate avenue for the supplying of provisions was closed. The desertion, however, of Artigas, and the harassing by his Uruguayan bands of the besieging forces, threatened once more to bring about the abandonment of the siege. The defeat of the naval forces of Spain in the Plata River by Admiral Brown, an Irish sailor in the service of the government of Buenos Aires, came at this time most opportunely to close all avenues of replenishing, and the garrison was forced to capitulate. The taking of Montevideo was an event of the utmost importance for the Revolution, since it made possible the concentrating of all forces for an attack upon Peru, the heart of Spanish power in South America.

Undeterred by the disastrous results of the first Army of the North at Huaquí, the provisional government decided upon a second expedition to Alto Perú. In addition to the strategic difficulties 
of this plan, new obstacles arose from the jealousies and ill-feeling caused by the ambition of General Alvear. He has truly been called the Alcibiades of Argentina. Handsome, young, accomplished, and erratically brilliant in the conception of his military plans, he was consumed by a disproportionate ambition to be the leading military hero of the Revolution. It was in order to satisfy this inordinate craving for glory that he had himself appointed general-in-chief of the besieging forces of Montevideo, at a moment when that city was doomed to fall, thus depriving Rondeau of a victory which in reality was his. As in the case of the campaign of Montevideo, Rondeau was first selected to command the second Army of the North, but Alvear intended to keep him in command only until the time should come for decisive action, when he himself, aided by the ascendancy he had gained with the provisional government, would assume command and reap the fruits of victory. In accordance with this plan, he attempted to supplant Rondeau towards the end of the year i 8 I 4 . This time, however, Rondeau refused to deliver his command to Alvear, and, as his troops supported him, Alvear was forced to return to Buenos Aires. The great popularity that he enjoyed in the capital raised him to the supreme honor of Director of the United Provinces, but his harshness in dealing with opposing political parties, and his weakness 


\section{$\mathrm{xxxii}$}

ARGENTINA

in meeting the rebellion of Artigas, combined with the opposition of both the Army of the North and the army that San Martín was quietly getting together in Mendoza for the invasion of Chile, made his tenure of office very short-lived, and he

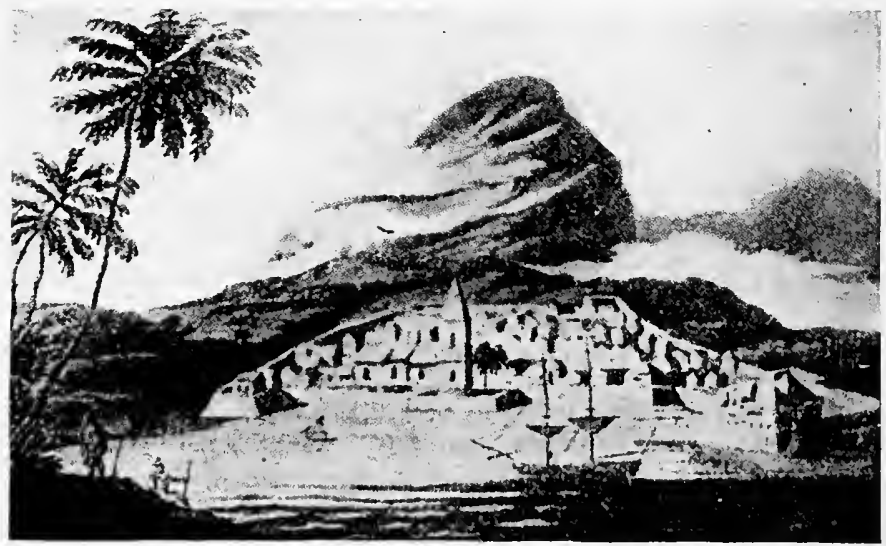

Luvarro y Lamarca, Historias general de A mérica

La Bahí de Montevideo en 1825

was forced to surrender the reins of government and flee to Rio Janeiro. This was the first serious defection among the makers of the Revolution, if we except the work of the Uruguayan leader, Artigas, who by his constant opposition to the provisional government of Buenos Aires delayed and prevented the unification of forces necessary to bring about the fall of Spanish power, but who 
at least worked for the independence of Uruguay, whereas Alvear sought primarily to aggrandize himself. It was not surprising therefore that the Army of the North, its discipline shaken by the recent rebellion caused by Alvear's ambition, and confronted, as it was, by the naturally difficult task of attacking Peru by a road which had been marked by the previous defeat of Huaquí, met a second disastrous defeat at Sipe-Sipe. So complete was this defeat that the Army of the North ceased to exist entirely, never to be reorganized again as it had been after Huaquí. What Belgrano did for the defense of the provinces after the defeat of the first Army of the North, the caudillo Güemes accomplished after Sipe-Sipe. With his swift band of gauchos he conducted such an effective guerrilla warfare against the victorious Spanish army, that they were unable to derive the full benefit of their great victory.

The fortunes of the Revolution had never sunk so low as after the battle of Sipe-Sipe. Yet, it was immediately after this disaster that the Congress of Tucumán, on the 9th of July, i816, proclaimed officially the independence of the United Provinces of the Plata. This was an artificial way of reviving the hopes of the Revolution, for what was wanted then was action, not words. Withal it did serve to rouse the failing enthusiasm of the people. Moreover, to substantiate the rhetorical enthusiasm of the Declara- 
tion of Independence, there soon came from an unexpected quarter deeds of such magnitude as to destroy for all time the power of Spain in America.

A few months after the meeting of the Congress of Tucumán, San Martín started on his great liberating campaign of Chile, after more than two years of patient preparation. Left to his own resources in the province of Cuyo (today, Mendoza, San Luis, and San Juan), unaided for a long time by the central government, who saw in him only a mediocre soldier (mistaking his modesty, his stoic disregard for the glamour of popularity, and above all his stanch insistence on systematic and careful preparation, for lack of military genius and dash), San Martín never lost heart, but bided his time till the rise to power in Buenos Aires of Pueyrredón assured him of support. On the i 7 th of January, ISI7, the Army of the Andes set out by the now historic passes of Los Patos and Uspallata on the expedition which was to win for democracy half a continent.

The crossing of the snow-capped Andes was rapidly and successfully accomplished, and on the rth of February, I8I7, the Spanish Army, commanded by General Maroto, was completely defeated on the slopes of Chacabuco, not far from Santiago. Maroto himself was captured, and San Martin entered Santiago de Chile with his army on the r th of liebruary. Meantime, the 
remaining Spanish forces fled to Talcahuano, where, having been reënforced by 3000 fresh troops from Peru, they attacked the detachment under Las Heras that San Martín had sent in their pursuit. The siege of Talcahuano had to be raised, and Las Heras withdrew in 1818 to join the corps of the main army. On the rgth of March, San Martín was again closely pressing

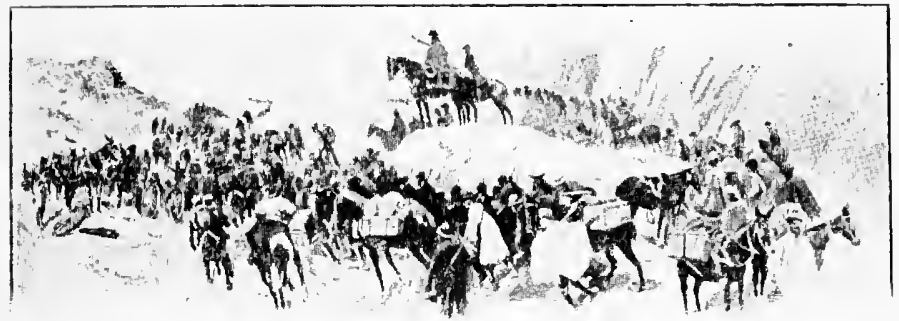

Navarro y Lamarca, Historia general de America

Forltuny

El Paso de los Andes

the enemy, and after a cavalry skirmish the Spaniards sought the protection of the city of Talca. The Argentine forces encamped outside of the city, and the Spaniards, surprising the patriots at night, charged their bivouac, dispersing and killing many of the patriot troops. This night attack is known as the battle of Cancha Rayada. It came very close to wrecking the long-prepared and carefully thought-out plans of San Martin. His coolness and the indomitable courage of his generals, particularly Las Heras, 
saved the day, and hardly two weeks later, on the $5^{\text {th }}$ of April, he was able to meet the Spaniards on the shores of the River Maipú or Maipo, defeating them decisively, and sealing forever the independence of Chile.

Now, San Martín was able to carry out his longcherished plan of attacking Peru from the Chilean side, transporting his army by water to Pisco. With the aid of Lord Thomas Cochrane, an English sailor in the service of Chile, he was able to clear the seas of Spanish ships, and on the 7 th of September, I820, he landed his forces in the Bay of Paracas. San Martín drove the Spaniards before him, and Lima and Callao were captured in quick succession. The former was evacuated by La Serna, Spanish viceroy of Peru, the rgth of July, I82I, and Callao was surrendered on the 2 Ist of September of the same year. Once in Lima, the first thing that San Martín did was to call together an assembly to find out the wishes of the people of Peru. The Junta met and notified the Protector, the title given to San Martín by the Peruvians, that the unanimous wish of all was the independence of Peru. At a great demonstration, held in the Plaza Mayor of Lima, San Martin rose before the assenbled multitude and unfolding for the first time the national flag of Peru, created by San Martin himself, he exclaimed amid the thunderous applause of the people: "Peru is from this moment free and in- 
dependent, by the will of its people and the justness of its cause, which God defends.'

San Martín had insured the independence of Argentina, which then included Bolivia, had driven the Spaniards from Chile, and now declared the independence of Peru. But the last remnants of the Spanish forces that had fled to the mountains of northern Peru had still to be vanquished before his task could be said to be fully accomplished. As the Argentine historian Mitre says, San Martín might have attempted this task with the forces at his command, unaided by either Chile or Argentina, which were then in the throes of civil discord, but he had too much at heart the independence of those lands in whose cause he had been fighting for over ten years. He preferred to take no chances. He invoked the coöperation of Simón Bolivar, who had done for Colombia and Venezuela what he himself had done for Argentina, Chile, and Peru. On the 26th of July, I822, therefore, there took place at Guayaquil, Ecuador, a famous interview between the two greatest generals of South America. What took place at that meeting has been wrapped in mystery, though the results are known full well. San Martín delivered his armies into Bolivar's hands, so that he might strike the last blow in behalf of the independence of South America. The combined forces of Colombia and Argentina under the command of General Sucre, Bolivar's lieu- 
tenant, won a brilliant victory at Ayacucho in I824, which crowned once for all the efforts of the peoples of South America to obtain their independence.

Thus, first by the military prowess of her greatest son, San Martín, and later by his greatness of soul and self-denial, worthy of the best traditions of Rome, Argentina insured the independence of South America. Though the words exchanged between Bolivar and San Martín at Guayaquil are not known, acquainted as we are with the natures of both, we can easily surmise what took place. Bolivar was a brilliant military genius, but like Alvear, was consumed by an unquenchable thirst for power, save that he surpassed Alvear in ambition in the same ratio that his military ability was superior to that of the Argentine Alcibiades. San Martín was a thorough military leader, leaving nothing to chance, a great disciplinarian, and once his plans were completed, as powerful in their execution as he had been patient in their preparation; but above all, San Martin was preëminently a man of lofty ideals and high moral worth. He may not have been endowed with the keen intuitive military genius of Bolivar; he was averse to all dramatic appeal and display, and hence never became popular in the sense that Bolívar and Alvear were popular; but in the unselfish qualities of devotion to a cause, even to the point of self-effacement, he stands the 
equal of the greatest men in history, a worthy peer of Cincinnatus and Regulus.

After the conference with Bolivar in Guayaquil, San Martín returned to Peru to find that the people whose independence he had declared were hostile to him. He immediately called a meeting of the constitutional congress, and, on the 2oth of September, I822, resigned his title of Protector.

Coming to Chile, he met with equal, if not greater, hostility. He retired to the province of Mendoza in Argentina, where for a while he devoted himself to farming, and then made a voyage to Buenos Aires, then torn by contending factions, to meet there, in his own country, with indifference and disregard. San Martín clearly saw that despite his devotion to the cause of independence, despite his mighty accomplishments in behalf of his country, his presence, if anything, would only lead to greater strife. Stoically, therefore, and without a murmur, he betook himself to voluntary exile in France, where he died in poverty, in 1850 , forgotten by his countrymen, attended only by his daughter, who faithfully remained by his side throughout the long years of his exile. Once only, in I 829 , he returned to Buenos Aires; but the newspapers of the times published this insulting paragraph: "Ambiguities - General San Martín has returned to his country after an absence of five years, but only after knowing that 
peace has been signed with the Emperor of Brazil." Even after this crowning insult San Martín uttered no plaint, but quietly returned to France to devote his time to the cultivation of flowers of his native land. His was not the Marian temperament; no messenger was ever sent by him to his fellow-countrymen to tell them that their liberator had been seen in France eating the bitter bread of exile.

“A truly great man...", Shakespeare has said of Cæsar. Much more aptly could that apply to San Martín in point of pure manhood. Argentina, today, has made reparation for the oblivion with which she requited her greatest man during his lifetime, by erecting imposing monuments to his memory; but, above all, by enshrining his name in the heart of every one of her sons.

But to return to Argentina herself: thanks to San Martin, the Revolution was successful, both at home and abroad. Even as early as I 820, however, the discordant elements that were to delay her progress almost half a century were clearly patent, not only in thought, but also in action. Each province had its caudillo, who was fiercely jealous of any limitations upon his power. Thus, Ramírez in Entre Ríos, Güemes in Salta, Facundo Quiroga (known for his cruelty as "El Tigre de los Llanos") in La Rioja, López in Santa Fé, Ibarra in Santiago, were practically 
overlords of independent provinces, ready to make common cause against Spain, but just as ready to quarrel with each other. The situation was similar to that of the colonies in North America, which, though willing to unite against England, resented any attempt at interference in their internal affairs by a central government. Buenos Aires, the city, as the center of Argentine wealth, culture, and civilization, was the exponent of a unitarian form of government, that is, a strong, centralized government with Buenos Aires at the head. Naturally, the caudillos resented any interference on the part of Buenos Aires. In 1820 , the first important battle between these two antagonistic elements took place at Cepeda, on the borders of Santa Fé and Buenos Aires. Here Rondeau, representing Buenos Aires and the unitarian principle, suffered defeat at the hands of Ramírez, known as "El Supremo Entrerriano”.

Varying fortunes attended the civil strife which went on between these two factions. In I822, a pact was entered upon by Buenos Aires and the caudillos of Entre Ríos, Santa Fé, and Corrientes, by the terms of which common cause was to be made against an expected Spanish invasion, which never materialized, and the other provinces were to be urged to join the Confederation.

Rivadavia now appears on the scene in Buenos Aires as Minister of Education, and later, as President of the Confederation in 1826 . He 
introduced many noteworthy reforms, founded libraries and universities, and attempted to establish the government on a firm unitarian basis with Buenos Aires as the capital. He resigned in 1827 , following the treaty which his envoy signed with Brazil in the same year, after the battle of Ituzaingó. Despite the victory of Argentine arms, Uruguay had been ceded to Brazil.

As far back as I680, Uruguay had been a bone of contention between Portugal and Spain, but at the outbreak of the Revolution in 1810 , the country was Spanish and was an integral part of the Viceroyalty of the Plata. Montevideo became, as we have seen, the center of Spanish resistance to the movement of independence, and following Artigas' victory at Las Piedras, was besieged by his troops and the Argentine forces under Rondeau. The city would have fallen, but news of the defeat at Huaquí reached Buenos Aires, and the besiegers were recalled to protect the Argentine soil. Civil strife between Buenos Aires and Artigas ensued because the latter stood for a federal republic, while Buenos Aires, of course, was unitarian, and wished to retain her supremacy over the provinces. In i 8 :7, Artigas became embroiled with the Portuguese, who routed him and captured Montevideo. Rivera, Oribe, and Lavalleja, lieutenants of Artigas, and later famous in the history of Uruguaty, had to take refuge in the interior. Artigas himself re- 
tired to Paraguay and died there of old age in I850. By I82 I all resistance to Brazil was at an end. Rivera and many of the other caudillos had accepted commissions in the Brazilian army of occupation. Uruguay itself had become the cispla-

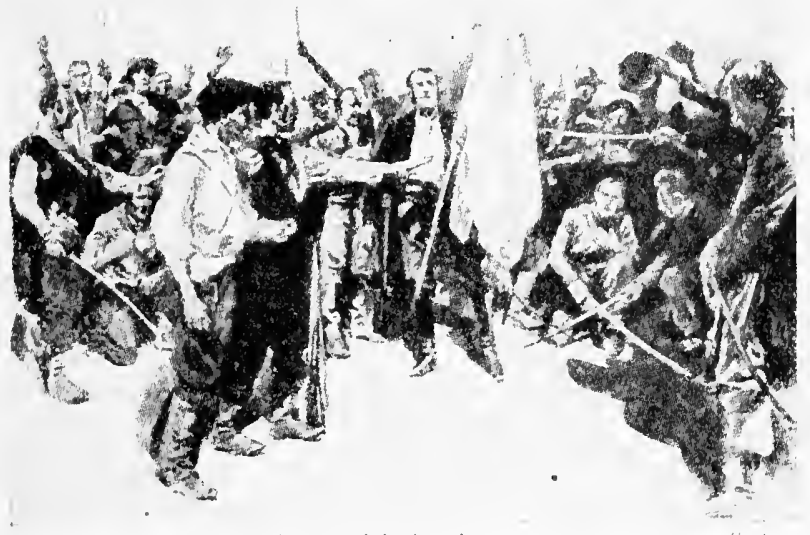

vavarro y Lamara, Histuria general de América

furluny

Los Treinta y Tres Orientales

tine province of Brazil, and so matters stood until the igth of April, is 85 , when Lavalleja gathered the famous "Treinta y Tres", a band of thirtythree Uruguayan patriots, and landed in Uruguay from the Argentine province of Entre Ríos. So great was their success that by May of that year, the whole country was in revolt against the Brazilians, and the forces of the Empire were 
confined within Montevideo and La Colonia. The patriot victory at Sarandí under Lavalleja and Rivera caused Argentina to declare formally that Uruguay was again a part of the Argentine Confederation. War between Argentina and Brazil was declared and at Ituzaingó, far within the Brazilian territory, the Brazilians suffered a terrible defeat in I827. This, as we saw above, happened during Rivadavia's presidency, and led to his resignation because of the peace signed by his envoy. The upshot of the whole matter was that both Brazil and Argentina gave up all claims to Uruguay and guaranteed its independence as a separate republic for five years. Argentina was being torn by federalist and unitarian dissensions, and could not press her claim. In Uruguay itself there were rival factions led by Rivera and Lavalleja, who held the presidency in turn, Rivera becoming the first official head of the nation in 1830 .

In Argentina, after Rivadavia's resignation, Dorrego, leader of the federalists in Buenos Aires, became Director. The chief names until I829, date of the advent of Rosas, are La Paz and Lavalle, as unitarians; Dorrego and the caudillos from the various provinces, as federalists. Lavalle, who had been the hero of Ituzaingó, put himself at the head of the unitarians and forced Dorrego to Hee, capturing him later and putting him to death. It is now that Rosas comes to the 
fore, although Quiroga and the other caudillos all joined forces to help defeat Lavalle, who retired to Uruguay. La Paz, however, more than managed to hold his own in the provinces of the interior, defeating Quiroga twice with terrific slaughter. But he, too, was finally defeated and taken prisoner in I83 I. Since I829, Rosas had become the provisional governor of Buenos Aires, that is, the head, in so far as there was any head, of the Argentine government. One of his first acts as governor of Buenos Aires was to carry on an expedition against the Indians to the south of Buenos Aires, and extend the frontiers of the whites down to the Río Negro.

And now for a few words on Rosas himself. He is referred to as the Argentine tyrant and has been compared to Nero for his wanton cruelty. True it is that he committed many deeds of cruelty, yet the times and conditions in which he lived were such that stern measures were necessary. He was of noble family and one of the wealthiest men in Argentina. From his own estancias he could raise a cavalry corps of gauchos and keep it in the field. He made it a point to afford shelter to outlaw gauchos, and gathered about him a band of adventurous spirits ready to dare anything. His victories against the Indians increased his prestige, and in 1835 he was given supreme power by the Legislature in Buenos Aires. His control of the supreme power lasted until 1852 . 
Immediately upon his assuming command, federalists were put in office everywhere instead of unitarians, who were forced to flee into exile. In the course of his long career, Rosas waged war for the re-annexation of Uruguay, which had become independent in I 827, after the battle of Ituzaingó. He incurred the enmity of France and England, and had to put down many revolts against his power. Lavalle played an important part in one of these and met his death at the hands of Oribe, who had aligned himself with Rosas. Throughout Rosas' reign, for such was his administration, Argentine exiles kept alive the hope of overthrowing the tyrant. Sarmiento founded a newspaper, El Progreso, in Copiapó, Chile, which had for its object a campaign against Rosas. In it Sarmiento published for the first time in serial form his Facundo, selections from which are given in this book.

Rosas' attempt to re-annex Uruguay deserves special mention. 'The five-year period of Uruguayan independence agreed upon by Argentina and Brazil had come to an end when Rosas came into power. Argentina was free to solicit the incorporation of Uruguay into the Argentine Confederation. Oribe, whom we remember as one of Artigas' lieutenants, had become president of Irugualy after Rivera, and allied himself to Rosas ayainst the Rivera faction, which had the support of the Argentine unitarian exiles. Oribe 
had to abandon Montevideo, which fell into Rivera's hands only to be besieged by Rosas and Oribe. The war that ensued has been called the Great War. It lasted for eight years, from 1843 to $\mathrm{I} 85 \mathrm{I}$, and the entire burden of the struggle centered around the siege of Montevideo, one of the longest in history. During this long eightyear siege, Montevideo received the help of many adventurers and lovers of liberty, as Rosas and Oribe were regarded as oppressors who sought to dominate a weaker country. Garibaldi, famous in Italian history, played a prominent part in the defense of the beleaguered city as leader of a famous foreign legion composed of Italians and Frenchmen.

Eventually Rosas brought about his own downfall. Although a federalist, he slowly centralized all power in himself, thereby gaining the distrust of the other caudillos. Urquiza, the caudillo from Entre Ríos, led the revolt against Rosas, and at the battle of Caseros, in I $85 \mathrm{I}$, completely routed the forces of the tyrant. Flight was Rosas' only resource, and he took refuge, with his daughter Manuela, on board the English frigate Centaur. He ended his days in England.

But not yet were discords at an end. The victor of Caseros convened a constituent congress at Santa Fé, to which Buenos Aires failed to send delegates, remaining a sovereign state in the same manner that Rhode Island did when she 
refused to become a party to the Constitution of the United States. Naturally, Urquiza became president, and the provinces prospered under his administration. Such a situation, however, could not endure for long.

Buenos Aires chafed under certain customs restrictions on her exports to the rest of the nation, and in I859, under the leadership of Mitre, Buenos Aires attacked the confederation of provinces established by the congress at Santa Fé. As in I820, Cepeda again marked the defeat of Buenos Aires at the hands of the federalists, although Mitre managed to save the army of Buenos Aires. With the mediation of Paraguay, a peace was patched up between the warring elements. Buenos Aires became a member of the Confederation, and her customs houses were put in the control of the federal government, and in 1860 , Derqui succeeded Urquiza as president. In the meanwhile, troubles in the province of San I,uis led to friction once more between Buenos Aires and the federalists. The rupture became open when Buenos Aires sent deputies elected according to local law and not according to the Constitution, and sent them to the congress convened by Derqui. Buenos Aires was declared in state of siege, and at Pavón, in 1861 , Mitre led the forces of the capital to victory. 'The many wars had tired the nation, and all the provinces willingly gave Mitre the power to con- 
voke a congress to settle all differences. This congress met on the $2 \mathrm{~d}$ of May, I 862, and it was agreed that the city of Buenos Aires should be the seat of the federal government, as well as of the province of Buenos Aires itself. The election of Mitre to the presidency marked the beginning of a period of prosperity and solidarity for the country. 


\section{BIOGRAPHICAL NOTES}

López y Planes (Vicente), an Argentine poet, was born in Buenos Aires in I784: He served as a volunteer during the English invasions and wrote a rhymed chronicle of the events of that stirring period. In ISIO he was attached to the Army of the North as secretary to its general, Ortiz de Ocampo, and took an active part in all the great movements of the Revolutionary Era. At the foundation of the University of Buenos Aires, he became the organizer and director of classical studies. He was the founder of the Bureau of Statistics and President of the Republic in 1827 . Until 1852 he was the president of the Supreme Court. After the battle of Caseros, General Urquiza intrusted to him the organization of a provisional government, and he became governor of the province of Buenos Aires. Though he is best known as the author of the Argentine National Hymn, he is hardly less to be remembered for the many services he rendered his country in various official capacities from the time of the founding of the Republic to his death in 1856 .

López (Vicente Fidel), Argentine jurisconsult, writer, and orator, was born in Buenos Aires in 1814 . He was the son of the famous author of the Argentine National Hymn, lópez y Planes. like many other Argentineans, he left his country during Rosas' reign, returning in 1852 to devote himself untiringly to the 
work of regeneration. Among his works are to be found, both purely literary and historical writings, such as: I.a Noria del IIereje o la Inquisición, his monumental work on the Conquista, an erudite and scientific work, and his Tratado del Derecho Romano. He also wrote a series of articles on the Argentine Revolution for the Revista del Rio de la Plata. In 1874 he succeeded Gutiérrez as president of the University of Buenos Aires. He died in 1903 after a life devoted to the service of his country.

Sarmiento (Domingo F.) was born in San Juan in $\mathbf{I} 8 \mathbf{I} \mathbf{I}$ of humble parents. His father fought under San Martín in Chile. From early childhood he was left to his own resources, and has very often been called the Lincoln of Argentina. His love of books, his keen habits of observation, and a brilliant mind raised him from the humble position of clerk in a country store to the presidency of the Republic. During Rosas' rule, he joined the great army of Argentine refugees in Chile, founding schools there and taking an active part in the political life of the country as the editor of $\mathrm{El}$ Mercurio and El Nacional, two important organs of the press. His first book was a primer, and his El Monitor de las Escuelas was the first educational periodical in South America. In 1842 he founded the first normal school on the Pacific coast, directing it for three years. Through the pages of El Progreso and El Heraldo Argentino he carried on a tireless campaign against the tyrant Rosas. His impetuous character and the violence of his attacks made him many enemies, and, on the advice of President Montt of Chile, he undertook a series of travels through Europe, northern Africa, and the United States. He became a great admirer of the 
institutions and government of the United States, and particularly of the educational ideas of Horace Mann, with whom he came into close contact. Together with Mitre he returned to Argentina on the eve of the battle of Caseros, in which he fought under the orders of Urquiza. During the years that Buenos Aires was separated from the rest of the Confederation, he was director of public instruction. After the battle of Pavón, he was ambassador to Chile and Peru, and later to the United States, where he wrote Las Escuelas, base de la prosperidad de los Estados Unidos, and published an educational review entitled Ambas Américas. Upon the completion of Mitre's term of office in 1868 , and while still an ambassador to the United States, he was elected to the presidency of Argentina. His administration was free from civil discord, and he carried out great reforms that made for the prosperity and progress of Argentina. $\mathrm{He}$ is especially remembered for the great impetus he gave to public education in Argentina. It can be said of him that he is one of Argentina's greatest writers, and South America's greatest educator. Among his most important works are: Facundo o Civilización y Barbarie, Recuerdos de Provincia, Ambas Américas, and Viajes en Europa, Africa y América. His death in I 888 was mourned all over South America, and was felt as a distinct loss among intellectual circles the world over.

Bunge (Carlos Octavio) is a very modern Argentine writer. Among his works may he mentioned: Nuestra América, Ensayo de Psicología Individual y Social, La Noevela de la Sangre, La Poesía Popular Argentina, and Nuestra Patria. an anthology for use in the Argentine schools, containing, besides extracts from other 
Argentine authors, many episodes written by Bunge himself. Of him, Blasco Ibáñez, in his La Argentina y sus grandezas, says: "Carlos Octavio Bunge es el más fecundo de los escritores jóvenes. Tiene un talento proteico que se ejercita con facilidad en todos los géneros.

II a escrito un cuento, La Sirena, de una originalidad sólo comparable a la de Poë, y que basta para la reputación de un autor." Bunge died May 22, 1918.

Gorriti (Manuela), an Argentine writer of note, was born in Salta in I819. She was married to General Manuel Isidro Belzú, one time president of Bolivia. Her life was full of misfortunes, but she never ceased to write. She displays in her writings unusual power of imagination. In 1865 her complete works appeared in Buenos Aires in two volumes, entitled Sueños y Realidades. In the later years of her life until I874, the date of her death, she devoted herself to education, being directress of a college in Lima.

Sastre (Marcos), an Argentine educator and didactic author, was born in Montevideo in I809. Among his more important works are Anagnosia, Guia del Preceptor, and specially, El Temple Argentino, a vivid and graphic description of the enchanting islands of the Paraná, their scenery, flora, and fauna.

Gutiérrez (Juan María) was born in Buenos Aires. He was a lawyer by profession, but is best known for his writings. Like Sarmiento, he fled to Chile to escape the tyranny of Rosas, and devoted himself to journalism, public education, and the publication of didactic works. In I 846 he was appointed director of the Naval Academy of Valparaíso, introducing during his term very important reforms. From 1845 to 1849 he edited a collection of poems by José Joaquín Olmedo, 
another collection, entitled América Poética, El Arauco Domado by Pedro de Ona, and textbooks such as $E l$ Lector Americano, La I ida de Franklin, Elementos de Geometria. He returned to Argentina in I852, after Rosas' defeat at the battle of Caseros, lending his efforts to the advancement of education, as he had done in Chile. He was appointed president of the University of Buenos Aires, and entirely revised its obsolete curriculum and faculty. In addition to being one of Argentina's foremost educators, he has the distinction of being her first literary critic of note. Among his works on literary criticism may be mentioned the following: Artículos Críticos y Literarios (1860); Estudios Biográficos y Críticos sobre Algunos Poetas Sur Americanos Anteriores al Siglo XIX (I865); Apuntes Biográficos de Escritores, Oradores, y Hombres de Estado de la República Argenina. His style is characterized by correctness and precision. In 1873 he was made president emeritus of the University of Buenos Aires. He died the following year.

Lacasa (Pedro) was born in Buenos Aires in I8Io. Early in life he gave up his studies to devote himself to agriculture. When the revolution of i 839 broke out, he took part in it, and rose to the rank of colonel. In 1865 he took part in the war against Paraguay. He died in Jujuy in $\mathbf{1} 869$. His son, Pedro Lacasa, published in I 870 a volume containing his poems, a biography of General Lavalle, and one of General Miguel Soler.

Mitre (Bartolomé) was born in Buenos Aires in I $\$ 2 \mathbf{I}$. In 1838 , when hardly seventeen years old, he beame known as a soldier and poet by taking part in the siege of Montevideo as a captain, and by publishing a collection 
of poems. In the second siege of Montevideo he rose to the rank of lieutenant-colonel. When the campaign in Uruguay was ended, he went first to Bolivia and then to Chile, where he was editor of El Mercurio. This was not his first experence in journalism, for he had already been the director of La Nueva Era and El Nacional in Montevideo, and La Época in Bolivia. His articles in El Mercurio were a bitter attack against the government, and he was forced to leave the country, living in Peru for a time. In I 852 he returned to Chile, but, hearing of the revolt against the tyrant Rosas, he hastened back to his native country, and took an active part in the battle of Caseros, being in command of the Uruguayan artillery. From that time dates the rise of his political power in Argentina. As we have seen, he was defeated at Cepeda (I 859) in his fight against Urquiza, but in I86I, at Pavón, he led the forces of Buenos Aires to victory, becoming president of Argentina from I 862 to $\mathrm{I} 868$. The rapid strides Argentina has made in the last fifty years date from Mitre's presidency. He encouraged the construction of railroads, the establishment of telegraphic communication throughout the republic, and the founding of schools. During the war against Paraguay (1865-I870), which rendered difficult the carrying out of Mitre's beneficial plans to the fullest measure, he distinguished himself as the commander-in-chief of the allied armies, that is, those of Argentina, Brazil, and Uruguay. He was editor of La Nación, which shares with the famous $L a$ Prensa the distinction of being the leading newspaper of South America.

When we consider the political and military events in Mitre's life, the quantity and quality of his literary 
work are really astonishing. We wonder where he found time to write his remarkable histories of San Martín and Belgrano (in nine octavo volumes), his various volumes of poems, his translations from Longfellow and Dante, and his extensive correspondence. As a poet and orator, he ranks among the first in Argentina; and, as an historian, he remains to this day the great fountain source to which all those who desire to know the history of Argentina must turn. He is perhaps the greatest man of letters Argentina has produced. As versatile as Sarmiento, though not so voluminous, he displays in general a juster appreciation of facts and a greater equipoise and a more even excellence in literary form.

Goyena (Pedro), an Argentine lawyer and publicist, was born in Buenos Aires in $\mathrm{I}_{4} \mathrm{I}$. He was the editor of La Revista Argentina and professor of Roman law at the University of Buenos Aires. His style, both as writer and orator, is known for its purity and brilliancy.

Nelson (Ernesto) is a man well known in Argentina in educational circles. He was born in Buenos Aires in 1875 and was educated there. He has spent ten years in this country studying educational movements. He was recently Director General de Enseñanaa Secundaria y Especial in Argentina. Among his publications are Recopilaciones de Correspondencia de la Nación, IIacia la Universidad Futura, and numerous articles. He represented his country at the St. Louis Exposition in I904; took his doctor's degree at Columbia University, after four years of residence; and was a member of the Argentine Commission at the Panama-lacific Exposition, San Francisco, in 1915, and a delegate to the Second Pan-American Scientific Congress in Wash- 
ington in $1915^{-16}$. He has edited for use in this country a Spanish-American Reader, the first book of its kind, dealing, as it does, with all phases of South American life and customs.

López (Lucio V.), the son of Vicente Fidel López, is a contemporary Argentine political writer and critic. He was born in 1857 , and was professor of political law in the University of Buenos Aires in I89o, when President Juárez Celmán was turned out of office. He was among the leaders of that movement. He enjoys a great reputation as a keen observer and writer on political events in Argentina.

Blasco Ibáñez (Vicente) was born in Valencia in i $867^{\circ}$. $\mathrm{He}$ is one of the leaders among contemporary Spanish novelists. Prior to the recent war, he resided in Argentina, where he received a tract of land from the Argentine government as a compensation, in part, for his book, written at the request of the Argentine government, La Argentina y sus grandezas. At present (1919), he is in France, occupied in writing a history of the war. His book Los Cuatro Jinetes del Apocalipsis, published during the recent war, deals in the first part with life on the Pampas, in the last with the war. It is considered one of the best books brought out by the war in any language. Among his works, these are best known: La Barraca, Cañas y Barro, La Horda, Sangre y Arena, Los Muertos Mandan, and El Intruso. His works have been translated into practically every European language.

Drago (Luis Maria) is a contemporary Argentine jurist and writer on international affairs. He has given his name to the Drago doctrine, a corollary to the Monroe doctrine. One of his earliest works, IIombres de Presa, a study on criminology, was translated into 
Italian by Lombroso, the famous Italian criminologist. In 1902 he was elected to the Argentine Congress, and shortly after he was appointed minister of foreign affairs by the then President of the Republic, Julio Roca. In December of that year he sent his famous note to the government of the United States, protesting against the use of force on the part of England, Germany, and Italy for the collection of debts the Venezuelan government had incurred with private subjects of those nations. He was the Argentine delegate to the Second Peace Conference, and is a member of the Permanent Court of Arbitration at The Hague. In 1912, Columbia University conferred upon him the degree of Doctor of Laws, honoris causa. That he is interested not only in legal matters is shown by his publication La Literatura del Slang. 


\section{ARGENTINA \\ LEGEND AND HISTORY}





\section{ARGENTINA}

\section{LEGEND AND HISTORY}

\section{HIMNO NACIONAL ARGENTINO}

Vicente López y Planes

\section{Coro}

Sean eternos los laureles que supimos conseguir: coronados de gloria vivamos o juremos con gloria morir.

1. Oíd mortales el grito sagrado:

¡ Libertad! ; Libertad! ¡ Libertad!

¡ Oíd el ruido de rotas cadenas!. . .

Ved en trono a la noble Igualdad.

Se levanta a la faz de la tierra una nueva y gloriosa Nación, coronada su sien de laureles y a sus plantas rendido un León.

12. Leôn, an allusion to the lion on the Spanish coat of arms. 
2. De los nuevos campeones los rostros

Marte mismo parece animar:

la grandeza se anida en sus pechos;

a su marcha todo hace temblar.

Se conmueven del Inca las tumbas

$y$ en sus huesos revive el ardor, lo que ve renovando a sus hijos de la Patria el antiguo esplendor.

3. Pero sierras y muros se sienten retumbar con horrible fragor: todo el país se conturba por gritos de venganza de guerra y furor.

4. su, i.e., de los campeones.

4. hace. The subject is Marte in line 2.

5. Inca. When the Spanish Conquistadores came to America, all of Peru, Bolivia, Eeuador, and northwestern Argentina were inhabited by the Quichua Indians. These Indians were divided into seven tribes, from one of which came the Incas who became the rulers of the vast territory occupied by the Quichuas. The Inca was the head of the ruling class and consequently the emperor of all the Quichuas. The reference here is to Atahualpa, the last Inca, who was strangled in 1533 by order of Pizarro, conqueror of Peru.

6. sus, i.e., del Inca.

7. lo que, trans., as: As he sees his sons renewing the old splendor of the Fatherland. Vide Ballo-Cuervo, Gramatica, $\$ 976,977$; and Cuervo, Apuntaciones criticas, 337.

9. se sienten, are heard. The student should exercise special care in noting the difference between the use of the reflexive as a substitute for the passive voice and the true use of the reflexive; the first nse is enfined almost entirely to the third person, singular and plural. 
En los fieros tiranos la envidia escupió su pestífera hiel; su estandarte sangriento levantan provocando a la lid más cruel.

4. ¿No los veis sobre Méjico y Quito arrojarse con saña tenaz, y cuál lloran bañados en sangre Potosí, Cochabamba y la Paz? ¿No los veis sobre el triste Caracas luto, llantos y muerte esparcir?

5. Méjico. From I 8 Io to 1820 the Mexicans fought bravely, but with scant success, to free themselves from the Spanish yoke. During that period three great leaders of Mexican independence were captured and shot by the Spaniards: the priest Miguel Hidalgo, in I 8 I I ; the priest Morelos, in 1815 ; and Francisco Xavier Minas, in 1817 . Under the leadership of Santa Ana, in I823, the Mexicans were finally successful in driving out the Spaniards and establishing a republican form of government.

5. Quito. Until the beginning of the sixteenth century the present republic of Ecuador was the kingdom of Quito, ruled over by the Incas. After Pizarro's conquest in 1533 it became the Audiencia of Quito, subject to the rule of the Viceroy of Peru. Ecuador was the last South American country to obtain its independence from Spain. From I8Io to 1822 , when the Spaniards were defeated at the battle of Pichincha, it was the scene of much ruthless and fierce fighting.

7. cuál, trans., how.

8. Potosí, Cochabamba, la Paz, cities in Bolivia. Most of the fighting against the Spaniards in Bolivia took place in the triangle formed by those three cities. V. map.

9. Caracas, capital of Venezucla, the first South Ameri- 
No los veis devorando cual fieras todo pueblo que logran rendir?

5. A vosotros se atreve, argentinos, el orgullo del vil invasor: vuestros campos ya pisa contando tantas glorias hollar vencedor. Mas los bravos que unidos juraron su feliz libertad sostener, a esos tigres sedientos de sangre fuertes pechos sabrán oponer.

6. E El valiente argentino a las armas corre ardiendo con brío y valor! El clarín de la guerra cual trueno, en los campos del Sud resonó. Buenos Aires se pone a la frente de los pueblos de la inclita unión, y con brazos robustos desgarran al íberico altivo león.

7. San José, San Lorenzo, Suipacha, ambas Piedras, Salta y Tucumán, La Colonia y las mismas murallas

can country to declare its independence from Spain, in isir. About that time the terrors of an earthquake, which destroyed the greater part of the city, were ardded to those of war.

I. cual, trans., like.

3. a, trans., againsl.

6. vencedor, trans., as a conqueror; note absolute construction.

19-21. San Josê, Piedras, La Colonia, battles fought by 
del tirano en la Banda Oriental, son letreros eternos que dicen: “Aquí, el brazo argentino triunfó : aquí, el fiero opresor de la Patria su cerviz orgullosa dobló.’

8. La Victoria al guerrero argentino con sus alas brillantes cubrió, $\mathrm{y}$ azorado a su vista el tirano con infamia a la fuga se dió. Sus banderas, sus armas, se rinden por trofeos a la libertad, y sobre alas de gloria alza el pueblo trono digno a su gran majestad.

the Uruguayans in coopperation with the Argentineans. At Las Piedras there were two engagements, hence ambas Piedras.

San Lorenzo, name of the first battle fought by San Martin against the Spaniards.

Suipacha, Salta, Tucumán. General Balcarce defeated the Spaniards at Suipacha, as did General Belgrano at the battles of Salta and Tucumán.

I. la Banda Oriental, popular name for the republic of Uruguay. Until the period of the Revolution, Uruguay was one of the Provinces of the Plata, and from its location on the eastern bank of the Uruguay River it received the name of "Eastern District."

8. su, i.e., del guerrero argentino.

ro. sus, i.e., del tirano.

II. por, trans., $a s$.

13. su, i.e., de la libertad. 
9. Desde un polo hasta el otro resuena de la fama el sonoro clarín, y de América el nombre enseñando les repite: “¡ Mortales, oíd!

Ya su trono dignísimo alzaron las Provincias Unidas del Sud." Y los libres del mundo responden: " Al gran pueblo argentino, salud!"

4. les, i.e., a los hombres.

j. trono dignísimo, i.e., independence from Spain.

8. i. . . , salud! hail! 


\section{EL GAUCHO ARGENTINO}

\section{Vicente Fidel López}

A uno y otro lado del Uruguay, desde el delta del Paraná a las fronteras del Brasil, y desde el Paraguay a las riberas del Atlántico, se extendian campañas de una belleza incomparable, de una fertilidad exuberante, y de un clima que, aunque 5 templado, no relaja el vigor de los temperamentos. Esas campañas estaban incultas en manos de la España. Arroyos innumerables y muchos ríos caudalosos, acompañados en una y otra ribera de selvas tupidísimas, distribuían por todas partes to una masa enorme de aguas puras y saludables, que alimentaban pastizales inmensos, donde los ganados y el hombre crecían y se multiplicaban libres y salvajes. El hombre tenía allí la carne, el fuego y el agua, sin ningún trabajo, con un ${ }_{5}$ cielo espléndido de luz y de transparencia. El atraso moral de la metrópoli, la incuria de su gobierno, su absoluta falta de industria, su impotencia caduca para educar y para llevar la vida civil al seno de los desiertos americanos, habían 20 extenuado todas las facultades de la España, rindiéndola en una indolente holgazanería a mediados del Siglo XVII. Era imposible, pues, 
que el aliento creador de los intereses económicos, que sólo se levantan en la vida urbana, hubiese podido penetrar en nuestros campos. Así es que la población errante que se había apoderado ${ }_{5}$ de ellos, había crecido desparramada, inculta y vagabunda. La extensión indefinida que ocupaba, hacía que el derecho de la propiedad raíz fuese inútil para sus habitantes, y hasta se puede decir que era desconocido. Donde cada hombre podía roobtener el derecho nominal de llamarse dueño de cincuenta o más leguas de terreno, sin otro trabajo que denunciarlo, abonando veinte o cincuenta pesos a la tesorería del Rey, era imposible que la posesión fuese verdadera delante de la ley, para ${ }_{5} 5$ responder al título de la propiedad. De modo que el gaucho argentino no necesitaba de semejante título para tener tierras y para satisfacer sus necesidades; $y$ en un estado semejante, era natural que no le fuese fácil concebir que los demás zohombres tuviesen razón y justicia para privarle de la facultad de ocupar el desierto, como cosa suya, y de poner su rancho donde mejor le conviniera. Sin peligro del hombre, sin miedo del aislamiento, porque la rápida carrera de su caballo ${ }_{25}$ lo trasportaba en un momento a las aldeas de la costa, y dueño de los ganados que pacían por los campos, era claro que no tenía necesidad ninguna

14. para responder al título de la propiedad, 10 insure claim 11 the property. 
de pedir a la tierra ese fruto sabroso de la agricultura, que civiliza por el trabajo y por la influencia de las leyes que rigen las producciones del suelo. El hombre civilizado de nuestros campos había retrogradado verdaderamente, a un estado semi- 5 bárbaro, por causa de su aislamiento relativo. Pero estaba muy léjos de haber perdido las tradiciones de la civilización de que había tomado origen, como algunos observadores poco discretos lo han dicho; y sus condiciones no eran las so de un estado pastoril, análogo al de los patriarcas del Asia. Éstos necesitaban, por lo menos, de la propiedad de los rebaños, gobernaban como patricios la tribu numerosa de sus parientes, $y$ vagaban por las áridas sequedades del África, ${ }_{15}$ buscando un pozo de agua y' un poco de hierba para ellos y para sus bestias.

El gaucho argentino vivía absoluto e independiente, con un individualismo propio y libre. Se emancipaba de sus padres apenas enpezaba a 20 sentir las primeras fuerzas de la juventud; y vivía abundantemente de las volteadas de los

15. sequedades, abstract noun used as a concrete noun; trans., sterile lands.

18. absoluto, taken in its literal sense here, apart, by himself.

22. volteadas, Argentinism; separation and selection of cattle without previously rounding them up; hasty selection of cattle. Cf. Darwin's The Voyage of the Beagle: "About two leagues beyond this curious tree we halted for the night; at this instant an unfortunate cow was spied by 
animales que Dios creaba en el desierto. Armado del lazo, podía echar mano del primer potro que le of recía mejores condiciones para su servicio; escogía, por su propio derecho, la vaca más gorda s para mantenerse; y si necesitaba algún dinero, para procurarse alguno de los objetos comerciales que apetecía, derribaba cuantos toros quería, les sacaba los cueros, e iba a venderlos en las aldeas de las costas, a los mercaderes que traficaban ıo con ellos, para surtir el escasísimo comercio que teníamos con la Europa. La ley civil o política no pesaba sobre él; y aunque no había dejado de ser miembro de una sociedad civilizada, vivía sin sujeción a las leyes positivas del conjunto. I5 Tomaba a una mujer de su clase, libre como él, sumisa y buena, sin cuidarse mucho de las formas con que se unía a ella. Plantaba una choza en la rinconada de un arroyo, bien cerca del agua para evitarse el trabajo de acarrearla; y como ${ }_{20}$ los prebostes de la hermandad solían tener la ocurrencia de atravesar los campos, con cincuenta o sesenta blandengues, ahorcando expeditivamente bandoleros, el gaucho tenía buen cuidado de levantar esa choza cubierta por el bosque, y ${ }_{25}$ con sendas o vados que le eran conocidos, para

the lynx-eyed gauchos, who set off in full chase, and in a few minutes dragged her in with their lazos, and slaughtered her."

14. leyes positivas, estailished laws.

25. con sendas o vados, etc., i.e., cerca de su choza, nearby. 


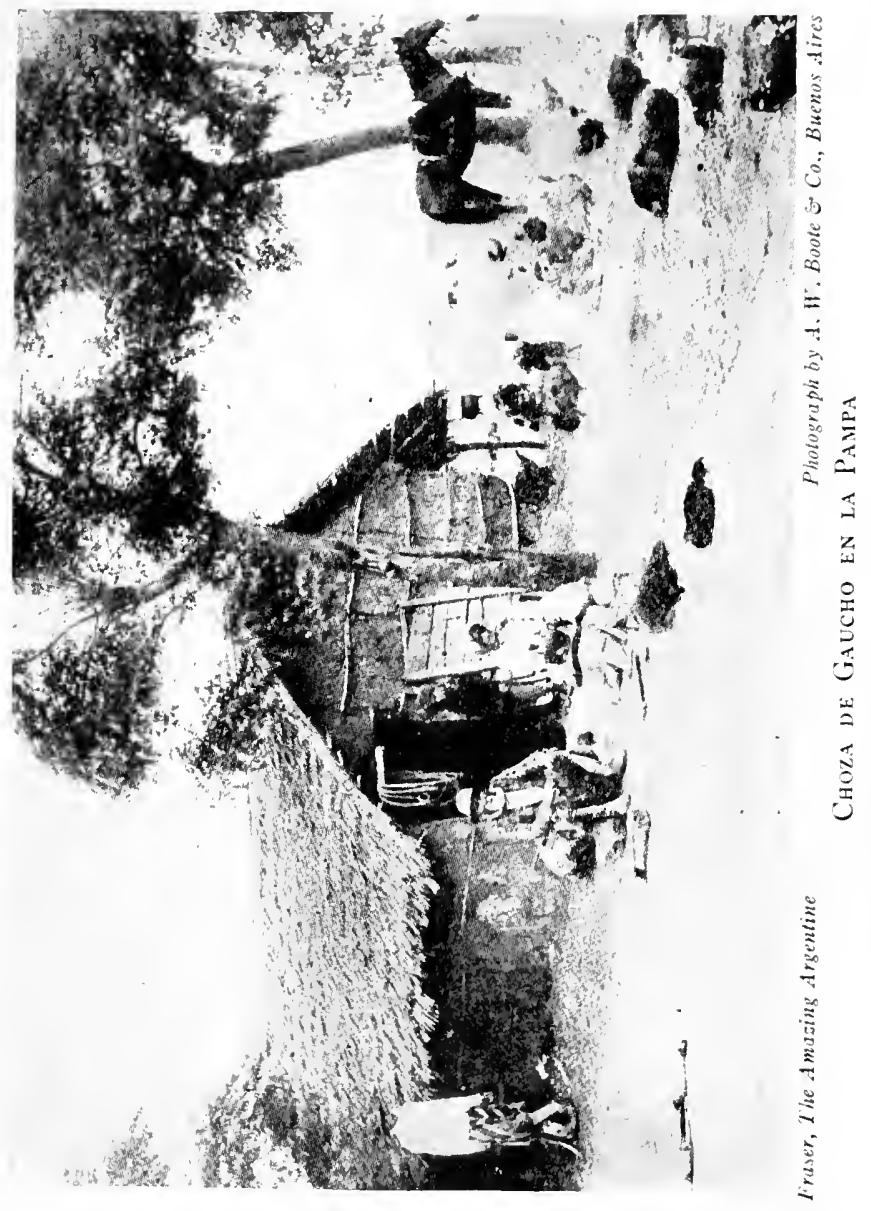


evitar que le encontrasen desprevenido; porque la justicia del Rey no era muy solícita en distinguir a los inocentes de los vagos; ni él mismo sabía bien entre cuáles se había de clasificar.

5 A todos estos rasgos, propios del género de vida que hacían, los gauchos agregaban las dotes de un temperamento fuerte, nervioso e inquieto. El clima en que vivían les permitía viajar a la intemperie, bajo las influencias, templadas al1ogunas veces, rígidas otras veces, de la naturaleza $\mathrm{y}$ del espacio. Acostumbrados al peligro, y ariscos, por decirlo de una vez, estaban siempre prontos a pelear a la justicia del Rey, cuando los sorprendía; y como ella no usaba de procedimientos muy ${ }_{15}$ cuidadosos para determinar sus fallos y sus castigos, los gauchos la evitaban, siempre que podían, como se evita un peligro grave, o como se huye de un yugo incómodo.

Su cuerpo era por consiguiente muy ágil. Sus 20 miembros mostraban, por su esbeltez y delicadeza, que, de una generación en otra, se habían críado sueltos de las tareas abrumadoras y serviles de la agricultura o de la industria. Esa constante gimnasia del caballo les daba una destreza 25 admirable para sorprender con la velocidad de un gato las furias del potro salvaje, y sentarse gallardamente en sus lomos, con un equilibrio que la fiera nunca descomponía, aunque brincase

5. género de vida que hacian, kind of life they led. 
y se revolviese con demencia para deshacerse del jinete que la domaba. Su porte era elegante $y$ cauto; sus maneras serias; y aunque parecían mansas, lo hacían impenetrable y digno al mismo tiempo. Algunas veces, fiero e impetuoso, 5 daba rienda suelta a sus pasiones; otras, era hidalgo y generoso. Pero siempre era difícil y desigual, como los seres bravíos que se crían en las soledades de la tierra. Era bello como ellos, por el temple y por los rasgos pronunciados de so su tipo.

En general, el gaucho tenía a pecho ser amigable y hospitalario en su cabaña. Recto en el cumplimiento de su palabra, no se excusaba jamás de proteger con nobleza a los que reclamaban $\mathrm{su}_{\mathrm{i} 5}$ amparo, aunque hubiesen sido sus enemigos. Hablaba tranquilo, y con una voz cubierta que podría parecer dulce, si no fuese que sus palabras eran siempre escasas, ambiguas o taimadas. Cuando encontraba algo de que burlarse, su 20 ironía era profunda, pero siempre disimulada con la doblez del sentido, con el monosílabo o con un acento particular que daba a sus expresiones. El enojo no le arrancaba gritos ni gestos; y ya en las dificultades del peligro, o dominado por la ${ }_{25}$ ira, era siempre concentrado, guardando las apa-

4. lo hacian . . tiempo, gave him an air of mystery and dignity at the same time.

17. voz cubierta, soft voice.

22. con el monosílabo, by a monosyllabic remark. 
riencias de una moderación que era amenazante por su propio laconismo.

Destituído de toda creencia en la fatalidad de los sucesos, ponía su personalismo sobre todos los 5 intereses de la vida y sobre todas las influencias religiosas; así es que siempre estaba pronto para reaccionar en defensa de su persona o de su libertad, y aun reducido al último trance, marchando, por ejemplo, al suplicio entre filas de ro enemigos, ocultaba bajo un aire resignado la atención más vigilante al menor azar, al menor descuido de sus verdugos, para tirarse al fondo de un río, salvar un precipicio, o saltar sobre un caballo y desaparecer como una sombra entre los Is arcabuces y sablazos de sus perseguidores. Verdad es, que nunca le faltaba entre estos mismos un cómplice, o un aparcero que se interesase por su suerte, y que preparase el lance dejándole los riesgos de la ejecución.

20 Todos estos contrastes hacían del gaucho argentino un hombre libre y civilizado en medio de la semibarbaric en que vivía, o más bien, en que vagaba. Porque aunque distante de la vida urbana de los europeos, no era ajeno, sin embargo, 25 a la vida política; y ya sea por la raza, ya por las ideas, o por los móviles morales, estaba unido al orden fundamental de la asociación colonial; puede decirse que era un europeo que había caido en la vida errante de los desiertos americanos; y .30 que habiendo conservado su personalismo absoluto 


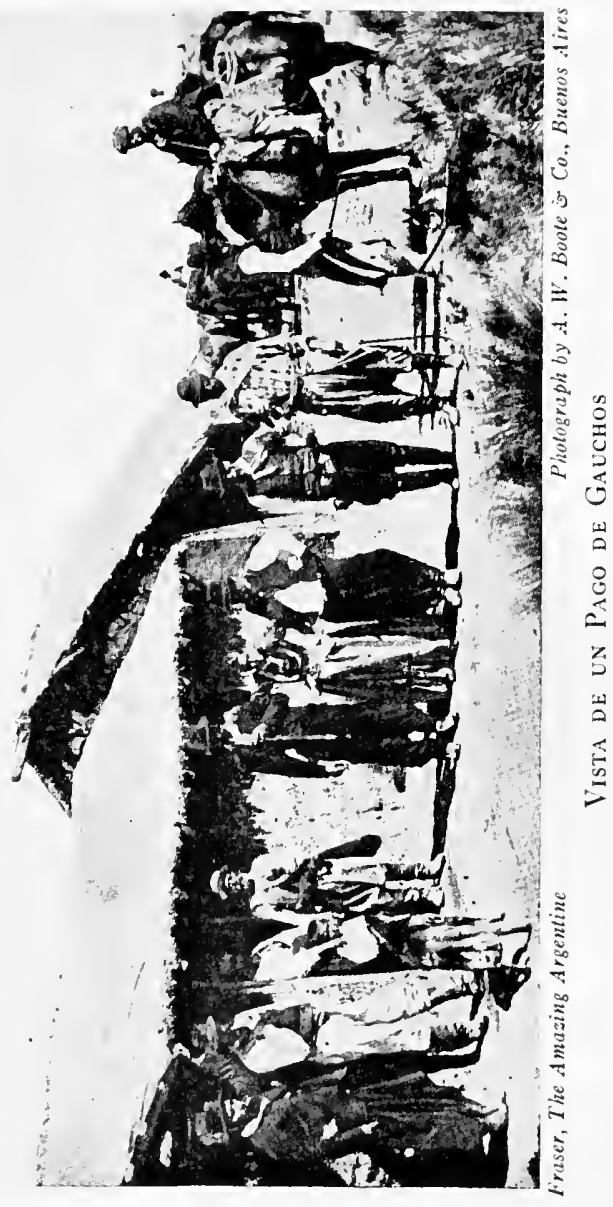


e independiente, había venido a constituir un tipo especial, que reunía todos estos contrastes, con un sello indefinido de identidad y de originalidad a la vez; y si fuese posible dar claridad a cosas que 5 parecerán tan contradictorias, yo diría que los gauchos de las campañas argentinas, tomados en masa, fueron el germen preparado para producir las evoluciones constitucionales de nuestro organismo, y que a pesar de que, cuando arrojaron su ro influencia decisiva en las vicisitudes de nuestra historia, se hallaban hundidos en un estado cercano al de la barbarie, eran, con todo, un pueblo libre, que lleno de la conciencia de sus intereses y de sus derechos políticos, introdujo una revolución is social en el seno de la revolución política de mayo, moviéndola en un sentido verdaderamente democrático y en busca de una civilización liberal sin las trabas del pasado.

La vida de los gauchos no tuvo jamás ninguno 20 de los accidentes de la vida de las tribus. Ellos constituían una población homogénea, señalada con un mismo tipo, con unos mismos hábitos, con unas mismas pasiones; y que poséa todas las aptitudes $y$ las formas de una nacionalidad 25 política, distinta y peculiar. Aunque los gauchos nunca vivían aglomerados, estaban sin embargo espontáneamente distribuídos en pagos, de acuerdo

14. introdujo una revolución social, i.e., the internal revolution that followed immediately upon the heels of the struggle for independence. 
con la configuración que el curso de los ríos, los montes y los accidentes limítrofes, le daban a cada porción de la campaña. Reconocían entre sí, por esto, una cierta cohesión geográfica análoga a la que tienen los diversos vecindarios, si es 5 que la idea de vecindad puede aplicarse a las partes incultas de un vasto territorio. Tenían por lo mismo una especie de patriotismo local sumamente apasionado, con entidades dominantes o caudillejos que surgían por el coraje, por el ro acierto, por la audacia de sus empresas y por los crímenes que cometían o por otros mil de esos accidentes, que en todas partes concurren para formar personajes populares a la altura del medio social en que nacen y en que se nutren.

El gaucho argentino no reconocía por jefe, ni prestaba servicio militar, sino al caudillo que él mismo elegía por su propia inclinación; porque ante todo se tenía por hombre libre, y como tal usaba de su criterio y de su gusto individual con 20 absoluta independencia de todo otro influjo. Eso sí, cuando se había decidido por una bandera, su adhesión no tenía límites y podía contarse con

4. por esto, on this account.

5. vecindarios. This word means both district or ward of a town, and vicinity : hence the statement that follows.

5. si es que, i.e., si es verdad que.

14. a la altura... se nutren, on a par with the social milieu in which they are born and grow.

21. Eso si, Of course, Most assuredly. 
ella para toda la vida; no economizaba sacrificio alguno, y su constancia, sobre todo en las luchas políticas, llegaba hasta el heroísmo. Tomaba partido por sentimiento propio y por pasión, 5 jamás por interés, ni con la mira de obtener el menor provecho directo como premio de sus esfuerzos. Lo único que le movía eran las afinidades de los hábitos y de las tendencias entre su persona y la de los jefes a quienes servía; es decir, un ro patriotismo a su modo, pero que en resumidas cuentas era un sentimiento politíco y moral que tenía causas puras y libres en su misma voluntad.

Cuando el acaso terrible de la lesa lo había apresado para el servicio de los ejércitos veteranos de ${ }_{15}$ la patria, se debatía, como un animal bravío por escapar a la presión y a la esclavitud de la disciplina rigurosísima de San Martín o de Belgrano. Desertaba apenas podía, y se escondía en las entrañas de la tierra. Pero si le volvían a cazar, se zodaba más o menos pronto según su carácter más o menos indómito: Y cuando una campaña feliz,

3. Tomaba partido .... y por pasión, Ile took sides, guided by his personal sentiments and emotions.

ro. a su modo, peculiar to himself.

15. por escapar, lit., for the sake of escaping; translate as if it were para escapar. There is very little difference between por and para when followed by an infinitive: para is by far the commoner preposition used.

i7. San Martín, Belgrano, the two greatest military leaders of Argentina during the period of the struggle for independence. 
una batalla ganada o perdida, venían a darle la pasión del cuerpo en que servía, se convertía en un soldado ejemplar, como no creo que tuviese mejor ninguna otra nación civilizada. Era sobrio, sufrido, bravo y experto: ni el hambre, ni la des- 5 nudez lo indignaban o lo abatían.

Entregado siempre a la voluntad de sus jefes, con una alegría templada que jamás desmentía, servía animado del amor de la patria y con el orgullo militar del ciudadano libre que tiene fe ro en su causa, y que se considera con la obligación personal de vencer. Toda su filosofía se reducía a saber que servía a la patria, y que la patria esperaba ser salvada por sus soldados: la doctrina era lacónica, pero tan cierta, que apelo al testi- ${ }_{5}$ monio de cuantos hayan conocido al gaucho argentino, convertido en granadero de a caballo, o en voltigero del ejército de los Andes, para que digan si esto era verdad.

En cuanto al sentimiento religioso, el gaucho 20 estaba tan lejos del árabe, que es imposible hallar entre ellos punto alguno de contacto. En las cosas de su persona, de su casa, de sus relaciones, o de sus negocios, la religión y sus ministros no valían ni pesaban un ápice para él. El árabe 25 es ante todo tétrico, fatalista y creyente. Vive dominado por un panteísmo religioso que dirige todas sus ideas: habla directamente con Dios, en la nube que pasa, en las estrellas que brillan en los cielos, en todos los fenómenos del desierto y en so 
cada uno de los acontecimientos que tejen el hilo fatídico de su vida. Su ferocidad, sus crímenes $y$ hasta sus virtudes, son hijos de su fanatismo. Al gaucho argentino no se le ocurrió jamás nada ${ }_{5}$ de esto. Su alma había florecido libre de todo cuerpo de doctrina y batida sólo por los intereses de la vida material: era alegre de espíritu y vivía independiente en un país bellísimo, lleno de recursos, bien regado, fértil, abundante, y que ro no tenía ningún punto de contacto con la adusta e imponente severidad del clima abrasador del Árica, en donde sólo la noche y las sombras dan expansión al alma de los mortales y de las fieras. El gaucho era en el fondo un ser completamente ${ }_{15}$ descreído: su religión era un deísmo sui generis que se reducía a figurar una cruz con los dedos, o a besar el escapulario que llevaba al pecho, en los momentos difíciles de la vida. Una vez que lo hacía, se teińa por salvado en el cielo, si moría; 200 por amparado del poder y del favor de Dios, si se salvaba. Después, y a no volvía a acordarse de sus deberes religiosos, sino para saludar los símbolos del catolicismo, si los encontraba a su paso: una cruz de un sepulcro, un fraile, o la puerta ${ }_{25}$ de una iglesia. Con esto, se tenía por católico romano y papal, sin entender palabra de la cosa, y sin procurar entenderla tampoco; porque todo lo

6. cuerpo de doctrina, system of dogmas.

15. sui generis, Latin for a su modo. V. note 18, 10. 
demás era para él asunto puro de tradición, de que no se daba otra cuenta sino como de un hecho superior, que le venía impuesto por el asentimiento vago del pueblo, por una tradición que, aunque desprovista de doctrina, dominaba en 5 las campañas y en las chozas donde criaba a su familia.

I. de que no se daba otra cuenta . . superior, lit., of which he gave himself no other account save as of a superior fact, i.e., of which he knew nothing save that it was a divine fact.

3. le venia impuesto, was imposed upon him. Venir is here used as an auxiliary for the passive voice instead of ser.

5. doctrina. Notice the use of a general term for a concrete term. What is meant here by doctrina is not teaching but teachers. 


\section{ORIGINALIDAD Y CARACTERES ARGENTINOS}

$\underset{\text { Cantor }}{\text { El Rastreador - El Baquiano - El Gaucho Malo - El }}$

\section{Domingo F. Sarmiento}

Ainsi que l'océan les steppes remplissent l'esprit du sentiment de l'infini

Si de las condiciones de la vida pastoril, tal como la han constituído la colonización y la incuria, nacen graves dificultades para una organización política cualquiera, y muchas más para el 5 triunfo de la civilización europea, de sus instituciones, y de la riqueza y de la libertad, que son sus consecuencias, no puede, por otra parte, negarse que esta situación tiene su costado poético, fases dignas de la pluma del romancista. Si un rodestello de la literatura nacional puede brillar momentáneamente en las nuevas sociedades americanas, es el que resultará de la descripción de las grandiosas escenas naturales, y sobre todo de la lucha entre la civilización europea y ${ }_{i 5}$ la barbarie indígena, entre la inteligencia y la

MotTo. The steppes, like the ocean, fill the soul with the feeling of the infinite. Taken from Humboldt's Voyages aux régions équinoxiales du noureau continent.

7. no puede... negarse, it cannot be denied. Cf. 2, 9. 
ORIGINALIDAD Y CARACTERES ARGENTINOS

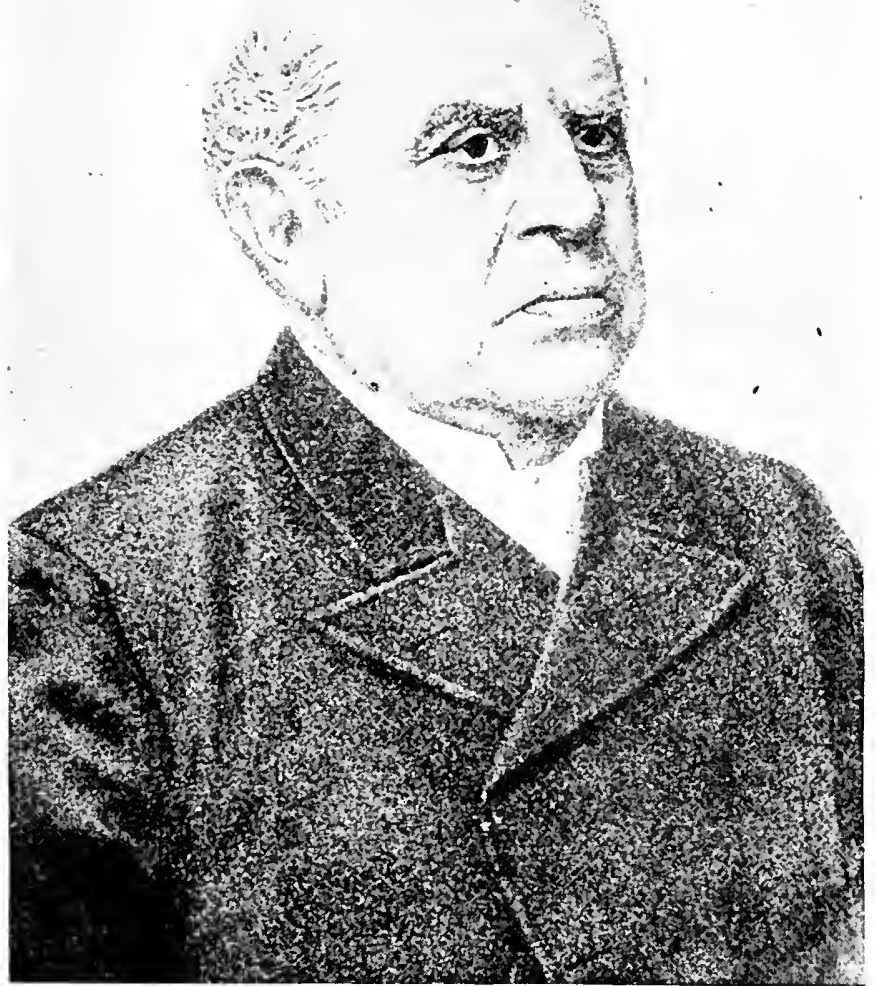

Blaseo Ibânes, Argentina y sus grandezas

Doningo F. Sarmiento 
materia: lucha imponente en América, y que da lugar a escenas tan peculiares, tan características y tan fuera del círculo de ideas en que se ha educado el espíritu europeo. . .

El único romancista norteamericano que haya logrado hacerse un nombre europeo, es Fenimore Cooper, y eso, porque transportó la escena de sus descripciones fuera del círculo ocupado por los plantadores, al limite entre la vida bárbara y la ro civilizada, al teatro de la guerra que las razas indígenas y la raza sajona están combatiendo por la posesión del terreno.

No de otro modo nuestro joven poeta Echeverría ha logrado llamar la atención del mundo literario is español con su poema titulado La Cautiva. Este bardo argentino dejó a un lado a Dido y Argía, que sus predecesores los Varelas trataron con maestría clásica y estro poético, pero sin suceso y

I. lucha imponente. The indefinite article is regularly omitted in Spanish with nouns in apposition.

II. están combatiendo. The first edition of Sarmiento's Facundo, the work from which this extract is taken, appeared in 1845 ; hence the use of the present.

13. Echeverria, one of Argentina's foremost poets.

15. La Cautiva, name of the poem for which Echeverria is best known. It marks a departure from Spanish classical traditions, depicting a struggle typical of the pampas, its scenery, its inhabitants, and its poetry.

16. Dido and Argia, the titular heroines of dramas by Juan Cruz Varela, the foremost Argentine poet of the classical school; the first is based on the fourth book of Virgil's Aneid; the second on Alfieri's Antigone. 
sin consecuencia, porque nada agregaban al caudal de nociones europeas, y volvió sus miradas al desierto, y allá en la inmensidad sin límites, en las soledades en que vaga el salvaje, en la lejana zona de fuego que el viajero ve acercarse cuando los 5 campos se incendian, halló las inspiraciones que proporciona a la imaginación el espectáculo de una naturaleza solemne, grandiosa, inconmensurable, callada; y entonces el eco de sus versos pudo hacerse oír con aprobación aun por la península ro española.

Hay que notar de paso un hecho que es muy explicativo de los fenómenos sociales de los pueblos. Los accidentes de la naturaleza producen costumbres y usos peculiares a estos accidentes, ${ }_{15}$ haciendo que donde estos accidentes se repiten, vuelvan a encontrarse los mismos medios de parar a ellos, inventados por pueblos distintos. Esto me explica por qué la flecha y el arco se encuentran en todos los pueblos salvajes, cualesquiera que 20 sean su raza, su origen y su colocación geográfica. Cuando leía en El Último de los Mohicanos de Cooper, que Ojo de Halcón y Uncas habían perdido el rastro de los Mingos en un arroyo, dije para mí :

7. proporciona. The subject is el espectáculo.

17. a ellos. The use of the prepositional object pronoun adds emphasis to the sentence.

23. Ojo de Halcón, Hawkeye, character in Cooper's The Last of the Mohicans.

24. Mingos, epithet applied to the Huron Indians in Cooper's Leatherstocking Tales. 
“van a tapar el arroýo". Cuando en La Pradera el Trampero mantiene la incertidumbre y la agonía mientras el fuego los amenaza, un argentino habría aconsejado lo mismo que el Trampero s sugiere al fin, que es, limpiar un lugar para guarecerse, e incendiar a su vez, para poderse retirar del fuego que invade sobre las cenizas del que se ha encendido. Tal es la práctica de los que atraviesan la pampa para salvarse de los incendios ro del pasto. Cuando los fugitivos de La Pradera encuentran un río, y Cooper describe la misteriosa operación del Pawnie con el cuero de búfalo que recoge, - va a hacer la pelota, me dije a mí

I. " van a tapar el arroyo," "they are going to dam the brook." Cf. Chapter XXI of The Last of the Mohicans.

I. La Pradera, Cooper's novel, The Prairie.

2. el Trampero, the Trapper: known also in the other works of Cooper's Leatherstocking Tales as Deerslayer, Hawkeye, Pathfinder, Settler.

4. lo mismo que el Trampero sugiere. Cf. The Prairie, Chapter XXIII.

9. los incendios del pasto. The dangers from such fires will be evident when it is known that not infrequently grass grows so tall in the pampas as to cover a man on horseback.

rx. la misteriosa operación del Pawnie. Cf. The Prairie, Chapter XXIV. The Pawnie is an Indian character in The Prairie, friend of the Trapper.

13. A cowhick, fashioned so as to give it huoyancy, is of ten used in the pampas to cross streams. An improvised craft of this type is called a pelota, i.e., ball. Though the pelota is often mentioned and described by Argentine travelers and 
mismo: lástima es que no haya una mujer que la conduzca, que entre nosotros son las mujeres las que cruzan los ríos con la pelota tomada con los dientes por un lazo. El procedimiento para asar una cabeza de búfalo en el desierto, es el mismo que 5 nosotros usamos para batear una cabeza de vaca o un lomo de ternera. En fin, mil otros accidentes que omito, prueban la verdad de que modificaciones análogas del suelo traen análogas costumbres, recursos y expedientes. No es otra la ra-ıo zón de hallar en Fenimore Cooper descripciones de usos y costumbres que parecen plagiadas de la pampa; así, hallamos en los hábitos pastoriles de la América, reproducidos hasta los trajes, el semblante grave y hospitalidad árabes.

Existe, pues, un fondo de poesía que nace de los accidentes naturales del país y de las costumbres

explorers, nowhere other than in this passage of Sarmiento have the editors read that they were towed by women. Cf. The Prairie, Chapter XXIV.

3. con la pelota ... lazo, with the pelota towed by means of a rope seized between the teeth.

4. El procedimiento para asar una cabeza de búfalo. For reference V. The Prairie, Chapter IX. Sarmiento has evidently made a mistake here, meaning not the head but the hump of a buffalo.

7. En fin, ... In his Voyage of the Beagle, Chapter III, Darwin, writing almost contemporaneously of conditions on the pampas, says: "It is curious how similar circumstances produce such similar results in manners. At the Cape of Good Hope the same hospitality, and very nearly the same points of etiquette, are universally observed." 
excepcionales que engendra. La poesía, para despertarse, porque la poesía es, como el sentimiento religioso, una facultad del espíritu humano, necesita el espectáculo de lo bello, del poder sterrible, de la inmensidad de la extensión, de lo vago, de lo incomprensible; porque sólo donde acaba lo palpable y vulgar, empiezan las mentiras de la imaginación, del mundo ideal. Ahora, yo pregunto: ¿qué impresiones ha de dejar en el rohabitante de la República Argentina el simple acto de clavar los ojos en el horizonte, y ver . . . no ver nada? Porque cuanto más hunde los ojos en aquel horizonte incierto, vaporoso, indefinido, más se aleja, más lo fascina, lo confunde y lo ${ }_{15}$ sume en la contemplación y la duda. ¿ Dónde termina aquel mundo que quiere en vano penetrar? ¡No lo sabe! ¿Qué hay más allá de lo que ve? Ia soledad, el peligro, el salvaje, la muerte. He aquí ya la poesía. El hombre que se 2o mueve en estas escenas, se siente asaltado de temores e incertidumbres fantásticas, de sueños que lo preocupan despierto.

De aquí resulta que el pueblo argentino es poeta

7. acaba. The verb is in the singular because lo palpable $y$ vulgar are taken to be one and the same thing.

14. se aleja. The subject of this verb and the following verbs of the sentence is horizonte.

22. despierto, with concessive force, though axtake.

23. es poeta, is poefical. Notice the use of a noun with the force of an adjective. 
por carácter, por naturaleza. ¿ $Y$ cómo ha de dejar de serlo, cuando en medio de una tarde serena y apacible, una nube torva y negra se levanta sin saber de dónde, se extiende sobre el cielo mientras se cruzan dos palabras, y de repente ${ }_{5}$ el estampido del trueno anuncia la tormenta que deja frío al viajero, y reteniendo el aliento por temor de atraerse un rayo de los mil que caen en torno suyo? La obscuridad sucede después a la luz; la muerte está por todas partes; un poder 10 terrible, incontrastable, le ha hecho en un momento reconcentrarse en sí mismo, y sentir su nada en medio de aquella naturaleza irritada: sentir a Dios, por decirlo de una vez, en la aterrante magnificencia de sus obras. ¿Qué más colores 15 para la paleta de la fantasía? - Masas de tinieblas que anublan el día, masas de luz lívida, temblorosa, que ilumina un instante las tinieblas y muestra la pampa a distancias infinitas, cruzándolas vivamente el rayo, en fin, símbolo del poder.- Estas 20

I. y cómo ha de dejar de serlo, and how can it help being so. Lo refers to the previous statement, es poeta.

5. mientras se cruzan dos palabras, in the twinkling of an eve.

8. atraerse. The reflexive is here the indirect object of the verb.

I6. Masas de tinieblas... masas de luz lívida, in loose apposition with colores of the preceding sentence.

I8. y muestra . . poder, and shows the limitless stretches of the pampa as they are vividly pierced by the lightning, the symbol of power. 
imágenes han sido hechas para quedarse hondamente grabadas. Así cuando la tormenta pasa, el gaucho se queda triste, pensativo, serio, y la sucesión de luz y tinieblas se continúa en su 5 imaginación, del mismo modo que, cuando miramos fijamente el sol, nos queda por largo tiempo su disco en la retina.

Preguntadle al gaucho a quién matan con preferencia los rayos, y os introducirá en un romundo de idealizaciones morales y religiosas, mezcladas de hechos naturales, pero mal comprendidos, de tradiciones supersticiosas y groseras. Añádase que si es cierto que el flúido eléctrico entra en la economía de la vida humana, y es el mismo Is que llaman flúido nervioso, el cual excitado subleva las pasiones y enciende el entusiasmo, muchas disposiciones debe tener para los trabajos de la imaginación el pueblo que habita bajo una atmósfera cargada de electricidad hasta el punto

\section{Añâdase, Let it be alled.}

18. una atmósfera cargada de electricidad. "On a second night we witnessed a splendid scene of natural fireworks; the masthead and yard arm ends shone with St. Elmo's light; and the form of the vane could almost be traced, as if it had been rubbed with phosphorus. The sea was so highly luminous that the tracks of the penguins were marked by a fiery wake, and the darkness of the sky was momentarily illuminated by the most vivid lightning." - DARwin, The Foyage of the Beagle, describing the cntrance to the estuary of the Plata. 
que la ropa frotada chisporrotea como el pelo contrariado del gato.

¿ Cómo no ha de ser poeta el que presencia esas escenas imponentes?

- "Gira en vano, reconcentra

Su inmensidad y no encuentra

La vista en su vivo anhelo

Do fijar su fugaz vuelo,

Como el pájaro en el mar.

Doquier campo y heredades

Del ave y bruto guaridas;

Doquier cielo y soledades

De Dios sólo conocidas,

Que Él sólo puede sondar."

¿O el que tiene a la vista esta naturaleza is engalanada?

- "De las entrañas de América

Dos raudales se desatan :

El Paraná, faz de perlas,

Y el Uruguay, faz de nácar.

Los dos entre bosques corren

O entre floridas barrancas,

Como dos grandes espejos

Entre marcos de esmeraldas.

I. como el pelo contrariado del gato, like a cat's hair when stroked the curong way.

7. la vista, subject of the verbs gira, reconcentra, encuentra, in the preceding lines.

I9. Paraná and Uruguay (next line). Two rivers. V. map. 
Salúdanlos en su paso

La melancólica pava,

El picaflor y el jilguero,

El zorzal y la torcaza.

5

Como ante reyes se inclinan

Ante ellos ceibos y palmas,

$Y$ les arrojan flor del aire,

Aroma y flor de naranja;

Luego en el Guazú se encuentran

10

$Y$ reuniendo sus aguas,

Mezclando nácar y perlas

Se derraman en el Plata."

Pero ésta es la poesía culta, la poesía de la ciudad; hay otra que hace oír sus ecos por los I 5 campos solitarios: la poesía popular, candorosa y desaliñada del gaucho.

También nuestro pueblo es músico. Ésta es una predisposición nacional que todos los vecinos le reconocen. Cuando en Chile se anuncia por zola primera vez un argentino en una casa, lo invitan al piano en el acto, o le pasan una vihuela,

7. arrojan. Strictly speaking, the subject is ceibos y palmas, though the meaning is clearly that all the trees overhanging the banks, i.e., the aromo and the orange tree, shower their flowers.

7. flor del aire, focver of the air: popular name for a plant of the genus Tillandsia, very common in Argentina. There are many varietics, with flowers of different colors. The striking characteristic of this plant is that it will grow without having its roots in the ground, getting its sustenance from the air when tied to or suspended from anything.

9. Guazú, onc of the rivers of the l'araní delta. 
$y$ si se excusa diciendo que no sabe pulsarla, lo extrañan, y no le creen, " porque sięndo argentino", dicen, "debe ser músico". Ésta es una preocupación popular que acusa nuestros hábitos nacionales. En efecto, el joven culto de las 5 ciudades toca el piano o la flauta, el violín o la guitarra; los mestizos se dedican casi exclusivamente a la música, y son muchos los hábiles compositores e instrumentistas que salen de entre ellos. En las noches de verano se oye sin cesar ıo la guitarra en la puerta de las tiendas, y tarde de la noche, el sueño es dulcemente interrumpido por las serenatas y los conciertos ambulantes.

El pueblo campesino tiene sus cantares propios: el triste, que predomina en los pueblos del I $5_{5}$ Norte, es un canto frigio, plañidero, natural al hombre en el estado primitivo de barbarie, según Rousseau; la vidalita, canto popular con coros,

16. es un canto frigio. The well-known archeologist, Sir William Mitchell Ramsay, in his article on Phrygia in the Encyclopadia Britannica says : "The scenery is generally monotonous; even the mountainous districts rarely show striking features or boldness of character; where the landscape has beauty it is of a subdued melancholy character. The circumstances of the country are well calculated to impress the inhabitants with a sense of the overwhelming power of nature and of their complete dependence on it. Their mythology, so far as we know it, has a melancholy and mystic tone, and their religion partakes of the same character."

18. Rousseau (Jean Jacques), the celebrated French philosopher of the eighteenth century (1712-1778), in his 
acompañado de la guitarra y un tamboril, a cuyos redobles se reune la muchedumbre y va engrosando el cortejo y el estrépito de las voces. Este canto me parece heredado de los indígenas, porque 5 lo he oído en una fiesta de indios en Copiapó en celebración de la Candelaria, y como canto religioso debe ser antiguo, y los indios chilenos no lo han de haber adoptado de los españoles argentinos. La vidalita es el metro popular en ro que se cantan los asuntos del día, las canciones guerreras; el gaucho compone el verso que canta, y lo populariza por las asociaciones que su canto exige.

Así, pues, en medio de la rudeza de las costum${ }_{15}$ bres nacionales, estas dos artes que embellecen la vida civilizada $y$ dan desahogo a tantas pasiones generosas, están honradas y favorecidas por las masas mismas que ensayan su áspera musa en composiciones líricas y poéticas. El joven Eche2o verría residió algunos meses en la campaña en I 8 40, y la fama de sus versos sobre la pampa le había precedido ya; los gauchos lo rodeaban con respeto y afición, y cuando un recién venido mostraba señales de desdén hacia el cajetilla, alguno le

youth wrote a Dissertation on Modern Music, in which he attempted to introduce a new system of musical notation.

5. Copiapó, city in Chile. V. map.

8. no lo han de haber adoptado, cannot have adopted it.

12. y lo populariza ... exige, and popularizes it by the audiences which his song gathers. 
insinuaba al oído: "es poeta," y toda prevención hostil cesaba al oír este título privilegiado.

Sabido es, por otra parte, que la guitarra es el instrumento popular de los españoles, y que es común en América. En Buenos Aires, sobre 5 todo, está todavía muy vivo el tipo popular español, el majo. Descúbresele en el compadrito de la ciudad y en el gaucho de la campaña. El jaleo español vive en el cielito; los dedos sirven de castañuelas. Todos los movimientos de los io hombros, los ademanes, la colocación del sombrero, hasta la manera de escupir por entre los colmillos, todo es un andaluz genuino.

Del centro de estas costumbres y gustos generales se levantan especialidades notables, que un día ${ }_{15}$ embellecerán y darán un tinte original al drama y al romance nacional. Yo quiero sólo notar aquí algunos que servirán para completar la idea de

13. andaluz genuino. Most of the Spanish colonizers of Argentina were Andalusians. To this day their influence is noticeable in the pronunciation of Spanish throughout South America. The most striking difference in the pronunciation of the Castilians and that of the Andalusians is that the latter pronounce the $\mathrm{z}$, and the $\mathbf{c}$ when followed by e or i, like an s. The Andalusians do not make the $\mathbf{s}$ as sibilant as the Castilians; with them it is very often a light aspirate sound.

18. algunos refers to especialidades in the preceding sentence. It is made masculine because the word is used to denote males, i.e., the tipos and caracteres which are described in detail later on. 
las costumbres, para trazar en seguida el carácter, causas y efectos de la guerra civil.

\section{El Rastreador}

El más conspicuo de todos, el más extraordinario, es el rastreador. Todos los gauchos del interior 5 son rastreadores. En llanuras tan dilatadas en donde las sendas y caminos se cruzan en todas direcciones, y los campos en que pacen o transitan las bestias son abiertos, es preciso saber seguir las huellas de un animal, y distinguirlas de entre mil; so conocer si va despacio o ligero, suelto o tirado, cargado o vacio. Ésta es una ciencia casera y popular. Una vez caía yo de un camino de encrucijada al de Buenos Aires, y el peón que me conducía echó, como de costumbre, la vista is al suelo. "Aquí va, dijo luego, una mulita mora, muy buena . . ésta es la tropa de don Zapata . . es de muy buena silla . . va ensillada . . . ha pasado ayer. . ." Este hombre venía de la sierra de San Luis, la tropa volvia de Buenos

2. guerra civil. The revolutionary struggle between Buenos Aires and the provinces of the interior, which broke out close upon the heets of Argentine independence, is referred to here. $V$. Introduction.

17. es de muy buena silla, she is a sery good mount.

18. ha pasado ayer. A Spaniard would say here pasó ayer. This use of the perfect instead of the preterite is a common Gallicism in South America.

19. sierra de San Luis, in the province of San Luis. V. $111 \mathrm{al}$ \%. 
Aires, y hacía un año que él había visto por última vez la mulita mora cuyo rastro estaba confundido con el de toda una tropa en un sendero de dos pies de ancho. Pues esto que parece increíble, es con todo, la ciencia vulgar; 5 éste era un peón de arria, y no un rastreador de profesión.

El rastreador es un personaje grave, circunspecto, cuyas aseveraciones hacen fe en los tribunales inferiores. La conciencia del saber ıo que posee, le da cierta dignidad reservada y misteriosa. Todos lo tratan con consideración : el pobre, porque puede hacerle mal, calumniándolo o denunciándolo; el propietario, porque su testimonio puede fallarle. Un robo se ha ejecutado ${ }_{15}$ durante la noche; no bien se nota, corren a buscar una pisada del ladrón, y encontrada, se cubre con algo para que el viento no la disipe. Se llama en seguida al rastreador, que ve el rastro y lo sigue sin mirar sino de tarde en tarde el suelo, como si 20 sus ojos vieran de relieve esa pisada que para otro es imperceptible. Sigue el curso de las calles, atraviesa los huertos, entra en una casa, y señalando un hombre que encuentra, dice fríamente: “ ¿Éste es!" El delito está probado, y raro es el 25 delincuente que resiste a esta acusación. Para él, más que para el juez, la deposición del rastreador

15. fallarle, pass sentence against him. Le is dative of disadvantage. 
es la evidencia misma; negarla sería ridículo, absurdo. Se somete, pues, a este testigo que considera como el dedo de Dios que lo señala. Yo mismo he conocido a Calíbar, que ha ejercido 5 en una provincia su oficio durante cuarenta años consecutivos. Tiene ahora cerca de ochenta años; encorvado por la edad, conserva, sin embargo, un aspecto venerable y lleno de dignidad. Cuando le hablan de su reputación fabulosa, ro contesta: “ ya no valgo nada; ahí están los niños ;" los niños son sus hijos, que han aprendido en la escuela de tan famoso maestro. Se cuenta de él que durante un viaje a Buenos Aires le robaron una vez su montura de gala. Su mujer ${ }_{15}$ tapó el rastro con una artesa. Dos meses después Calíbar regresó, vió el rastro ya borrado e imperceptible para otros ojos, y no se habló más del caso. Año y medio después Calíbar marchaba cabizbajo por una calle de los suburbios, entra en zo una casa, y encuentra su montura ennegrecida ya, y casi inutilizada por el uso. ¡ Había encontrado el rastro de su raptor después de casi dos años! El año I 830, un reo condenado a muerte se había escapado de la cárcel. Calíbar fué en${ }_{25}$ cargado de buscarlo. El infeliz, previendo que sería rastreado, había tomado todas las precauciones que la imagen del cadalso le sugirió. ¡Precauciones inútiles! Acaso sólo sirvieron para

2. que, object of considera. 
perderle; porque, comprometido Calíbar en su reputación, el amor propio ofendido le hizo desempeñar con calor una tarea que perdía a un hombre, pero que probaba su maravillosa vista. El prófugo aprovechaba todas las desigualdades del suelo para 5 no dejar huellas; cuadras enteras había marchado pisando con la punta del pie; trepábase en seguida a las murallas bajas, cruzaba un sitio, y volvía para atrás. Calíbar lo seguía sin perder la pista; si le sucedía momentáneamente extra-ı viarse, al hallarla de nuevo exclamaba: “ $¡$ Dónde te mi-as-dir!" Al fin llegó a una acequia de agua en los suburbios, cuya corriente había seguido aquél para burlar al rastreador. . . i Inútil! Calíbar iba por las orillas, $\sin$ inquietud, $\sin 15$ vacilar. Al fin se detiene, examina unas hierbas, y dice: "Por aquí. ha salido; no hay rastros, pero estas gotas de agua en los pastos lo indican." Entra en una viña; Calíbar reconoció las tapias que la rodeaban, y dijo: "Adentro está." La 20 partida de soldados se cansó de buscar, y volvió a dar cuenta de la inutilidad de las pesquisas. "No ha salido", fué la breve respuesta que sin moverse, sin proceder a nuevo examen, dió el rastreador. No había salido en efecto, y al día siguiente 25

Io. si le sucedia momentáneamente extraviarse, if he happened to lose the track for a moment.

I I. "i Dônde te mi-as-dir!" stands for "i Dónde te me has de ir!" Where do you think you will get away from me?

16. unas hierbas, some blades of grass. 
fué ejecutado. En I830 algunos reos políticos intentaban una evasión: todo estaba preparado, los auxiliares de afuera prevenidos; en el momento de efectuarla, uno dijo: "¿ Y Calíbar? - ¡ Cierto! ${ }_{5}$ - contestaron los otros anonadados, aterrados, ¡Calíbar!”

Sus familias pudieron conseguir de Calíbar que estuviese enfermo cuatro días contados desde la evasión, y así pudo efectuarse sin inconveniente.

ı ¿Qué misterio es éste del rastreador? ¿Qué poder microscópico se desenvuelve en el órgano de la vista de estos hombres? ¡Cuán sublime criatura es la que Dios hizo a su imagen y semejanza!

\section{El Baquiano}

I5 Después del rastreador, viene el baquiano, personaje eminente y que tiene en sus manos la suerte de los particulares y la de las provincias. El baquiano es un gaucho grave y reservado, que conoce a palmo veinte mil leguas cuadradas de ${ }_{20}$ llanuras, bosques y montañas. Es el topógrafo más completo; es el único mapa que lleva un

15. baquiano, atso spelled baqueano. This adjective is derived from the verb vaquear, which in Argentina means to round up cattle. In the course of their work, the baquianos, or cattemen, acquired an intimate knowledge of the country, and it was only natural, therefore, that the pathfinders, the sense in which the word is used here, should come from their midst. Today it is also used to denote a person who is an expert in anything. 
general para dirigir los movimientos de su campaña. El baquiano va siempre a su lado. Modesto y reservado como una tapia, está en todos los secretos de la campaña; la suerte del ejército, el éxito de una batalla, la conquista de 5 una provincia, todo depende de él.

El baquiano es casi siempre fiel a su deber; pero no siempre el general tiene en él plena confianza. Imaginaos la posición de un jefe condenado a llevar un traidor a su lado, y a pedirle ro los conocimientos indispensables para triunfar. Un baquiano encuentra una sendita que hace cruz con el camino que lleva: él sabe a qué aguada remota conduce; si encuentra mil, y esto sucede en un espacio de cien leguas, él las conoce todas, ${ }_{15}$ sabe de donde vienen y adonde van. Él sabe el vado oculto que tiene un río, más arriba o más abajo del paso ordinario, y esto en cien ríos o arroyos; él conoce en los ciénagos extensos un sendero por donde pueden ser atravesados $\sin 20$ inconveniente, y esto en cien ciénagos distintos.

En lo más obscuro de la noche, en medio de los bosques o en las llanuras sin límites, perdidos sus compañeros, extraviados, da una vuelta en círculo de ellos, observa los árboles; si no los hay, se 25 desmonta, se inclina a tierra, examina algunos

9. Imaginaos. The final $\mathrm{d}$ of the second person plural imperative is dropped in reflexive verbs.

13. el camino que lleva, the road he is following.

25. si no los hay, if there aren't any. 
matorrales y se orienta de la altura en que se halla ; monta en seguida, y les dice para asegurarlos: "Estamos en dereceras de tal lugar, a tantas leguas de las habitaciones; el camino ha de ir al 5 Sur" - y se dirige hacia el rumbo que señala, tranquilo, sin prisa de encontrarlo, y sin responder a las objeciones que el temor o la fascinación sugiere a los otros.

Si aun esto no basta, o si se encuentra en la ro pampa y la obscuridad es impenetrable, entonces arranca pastos de varios puntos, huele la raíz y la tierra, los masca, y después de repetir este procedimiento varias veces, se cerciora de la proximidad de algún lago, o arroyo de agua salada, o Is dulce, y sale en su busca para orientarse fijamente. El general Rosas, dicen, conoce por el gusto el pasto de cada estancia del sur de Buenos Aires.

Si el baquiano lo es de la pampa, donde no hay caminos para atravesarla, y un pasajero le pide

4. el camino ha de ir al Sur, the road must be to the south.

14. lago o arroyo de agua salada o dulce. Salt streams and lakes are common in Argentina, particularly in the central provinces. "One day I rode to a large salt lake, or salina, which is distant fifteen miles from the town. During the winter it consists of a shallow lake of brine, which in summer is converted into a field of snow-white salt. . . . One of these brilliantly white and level expanses, in the midst of the brown and desolate plain, offers an extraordinary spectacle." - Darwin, The l'oyage of the Beagle.

16. El general Rosas. V. Introduction.

18. 10. Cf. 29,2 . 


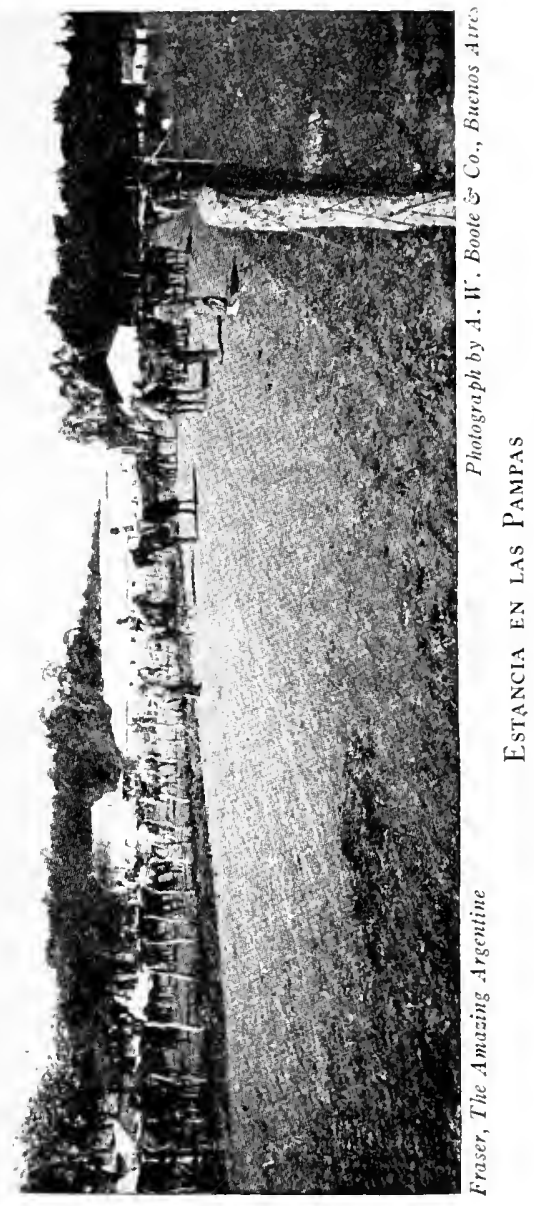


que lo lleve directamente a un paraje distante cincuenta leguas, el baquiano se para un momento, reconoce el horizonte, examina el suelo, clava la vista en un punto y se echa a galopar con la rec5 titud de una flecha, hasta que cambia de rumbo por motivos que sólo él sabe, y galopando día y noche, llega al lugar designado.

El baquiano anuncia también la proximidad del enemigo ; esto es, diez leguas, y el rumbo por rodonde se acerca, por medio del movimiento de los avestruces, de los gamos y guanacos que huyen en cierta dirección. Cuando se aproxima, observa los polvos, y por su espesor cuenta la fuerza: "son dos mil hombres", dice - "quinientos", ${ }_{15}$ " doscientos", y el jefe obra bajo este dato, que casi siempre es infalible. Si los cóndores y cuervos revolotean en un círculo del cielo, él sabrá decir si hay gente escondida, o es un campamento recién abandonado, o un simple animal muerto. El ba20 quiano conoce la distancia que hay de un lugar a otro; los días y las horas necesarias para llegar a él, y además una senda extraviada e ignorada por donde se puede llegar de sorpresa en la mitad del tiempo; así es que las partidas de montoneras 25 emprenden sorpresas sobre pueblos que están a cincuenta leguas de distancia, y que casi siempre

12. Cuando se aproxima. The subject is el enemigo.

12. observa los polvos, obserees the clouds of dust.

15. el jefe obra bajo este dato, the chief makes his plans in occordance with this information. 
las aciertan. ¿Creeráse exagerado? ¡No! El general Rivera, de la Banda Oriental, es un simple baquiano que conoce cada árbol que hay en toda la extensión de la República del Uruguay. No la hubieran ocupado los brasileños sin su auxilio, 5 y no la hubieran libertado sin él los argentinos. Oribe, apoyado por Rosas, sucumbió después de tres años de lucha con el general baquiano, y todo el poder de Buenos Aires, hoy con sus numerosos ejércitos que cubren toda la campaña del ıo Uruguay, puede desaparecer destruído a pedazos, por una sorpresa, por una fuerza cortada mañana, por una victoria que él sabrá convertir en su provecho, por el conocimiento de algún caminito que cae a retaguardia del enemigo, o por otro accidente 5 inadvertido o insignificante.

El general Rivera principió sus estudios del terreno el año ISo4, y haciendo la guerra a las autoridades, entonces como contrabandista, a los contrabandistas después como empleado, al 20 rey en seguida como patriota, a los patriotas

I. las aciertan, succeed in them.

I. Creeráse. The object pronoun is placed after the verb for stylistic effect. The student should avoid this use.

I. El general Rivera. José Fructuoso Rivera (17901854), famous gaucho leader of the revolutionary movement in Uruguay. He was twice elected to the presidency of his country. Defeated in $18+5$ by Urquiza, he Hed to Brazil.

2. Banda Oriental. V. 5 , I.

7. Oribe (Manuel), one of the famous "Thirty-three" liberators of Uruguay. V. Introduction. 
más tarde como montonero, a los argentinos como jefe brasileño, a éstos como general argentino, a Lavalleja como presidente, al presidente Oribe como jefe proscrito, a Rosas, en fin, aliado de ${ }_{5}$ Oribe, como general oriental, ha tenido sobrado tiempo para aprender un poco de la ciencia del baquiano.

\section{El Gaucho Malo}

Éste es un, tipo de ciertas localidades, un outlaw, un squatter, un misántropo particular. Es el ıo Ojo del Halcón, el Trampero de Cooper, con toda su ciencia del desierto, con toda su aversión a las poblaciones de los blancos; pero sin su moral natural $y$ sin sus conexiones con los salvajes. Llámanle el Gaucho Malo, sin que este epíteto le ${ }_{15}$ desfavorezca del todo. La justicia lo persigue desde muchos años; su nombre es temido, pronunciado en voz baja, pero sin odio y casi con respeto. Es un personaje misterioso; mora en la pampa, son su albergue los cardales; vive de zoperdices y de mulitas; si alguna vez quiere regalarse con una lengua, enlaza una vaca, la voltea

3. Lavalleja (Juan Antonio), leader of the liberating expedition of the "Thirty-three".

ro. con toda su ciencia. The possessive adjective su refers to Ojo de Halcón and el Trampero, which are different names for the hero in Cooper's Leatherstocking Tales.

15. La justicia, i.e., its cmissaries, the police.

2r. enlaza una vaca ... This is hardly so today, save perhaps occasionally in the deptlss of the pampas. But in 
solo, la mata, saca su bocado predilecto, y abandona lo demás a las aves montesinas. De repente se presenta el Gaucho Malo en un pago de donde la partida acaba de salir; conversa pacíficamente con los buenos gauchos, que lo rodean y lo admiran ; 5 se provee de los vicios, y si divisa la partida, monta tranquilamente en su caballo, y lo apunta hacia el desierto, sin prisa, sin aparato, desdeñando volver la cabeza. La partida rara vez lo sigue; mataría inútilmente sus caballos, porque el que so monta el Gaucho Malo es un parejero pangaré, tan célebre como su amo. Si el acaso lo echa alguna vez de improviso entre las garras de la justicia, acomete lo más espeso de la partida, y a merced de cuatro tajadas que con su cuchillo ha is abierto en la cara o en el cuerpo de los soldados, se hace paso por entre ellos, y tendiéndose sobre el lomo del caballo para sustraerse a la acción de balas que lo persiguen, endilga hacia el desierto, hasta que, poniendo espacio conveniente entre 20 él y sus perseguidores, refrena su trotón y marcha tranquilamente. Los poetas de los alrededores agregan esta nueva hazaña a la biografía del héroe del desierto, y su nombradía vuela por toda la vasta campaña. A veces se presenta a la puerta 25

the days of Sarmiento it was far from being an uncommon event. Cf. 9, 22.

6. se provee de los vicios. He supplies himself with tobacco and mate. In the simple life of the gaucho, tobacco and mate are luxuries, vices (!). 
de un baile campestre con una muchacha que ha robado; entra en baile con su pareja, confúndese en las mudanzas del cielito, y desaparece sin que nadie lo advierta. Otro día se presenta en la ${ }_{5}$ casa de la familia ofendida, hace descender de la grupa a la niña que ha seducido, y desdeñando las maldiciones de los padres que lo siguen, se encamina tranquilo a su morada sin límites.

Este hombre divorciado con la sociedad, prosro crito por las leyes; este salvaje de color blanco, no es en el fondo un ser más depravado que los que habitan las poblaciones. El osado prófugo que acomete una partida entera, es inofensivo para con los viajeros. El Gaucho Malo no es ${ }_{15}$ un bandido, no es un salteador; el ataque a la vida no entra en su idea, como el robo no entraba en la idea del Churriador; roba, es cierto, pero ésta es su profesión, su tráfico, su ciencia: roba caballos. Una vez viene al real de una tropa zodel interior; el patrón propone comprarle un caballo de tal pelo extraordinario, de tal figura, de tales prendas, con una estrella blanca en la paleta. El gaucho se recoge, medita un momento, y después de un rato de silencio, contesta: "No ${ }_{25}$ hay actualmente caballo así." ¿ Qué ha estado

2. entra en baile con su pareja, confúndese en las mudanzas del cielito, joins in the dance with his partner, mingles swith the others in the steps of the cielito.

8. su morada $\sin$ límites, i.e., los cardales, the thistle fields of the pampat. 
pensando el gaucho? En aquel momento ha recorrido en su mente mil estancias de la pampa, ha visto y examinado todos los caballos que hay en la provincia, con sus marcas, color, señas particulares, y se ha convencido de que no hay ninguno 5 que tenga una estrella en la paleta: unos la tienen en la frente, otros una mancha blanca en el anca.

¿Es sorprendente esta memoria? ¡No! Napoleón conocía por sus nombres a doscientos mil soldados, y recordaba, al verlos, todos los 10 hechos que a cada uno de ellos se referían. Si no se le pide, pues, lo imposible, en día señalado, en un punto dado del camino, entregará un caballo tal como se le pide, sin que el anticiparle el dinero sea un motivo de faltar a la cita. Tiene sobre 15 este punto el honor de los tahures sobre la deuda. Viaja a veces a la campaña de Córdoba, a Santa Fé. Entonces se le ve cruzar la pampa con una tropilla de caballos por delante; si alguno lo encuentra, sigue su camino sin acercársele, a menos 20 que él lo solicite.

\section{El Cantor}

Aquí tenéis la idealización de aquella vida de revueltas, de civilización, de barbarie, y de peli-

4. en la provincia, i.e., in whichever province the gaucho malo may be living, or better, roving.

II. Si no se le pide, If he is not asked.

20. a menos que él lo solicite. Él refers to alguno; 10, to acercársele; trans., unless the traveler wishes the gaucho to approach him. 
gros. El Gaucho Cantor es el mismo bardo, el vate, el trovador de la Edad Media, que se mueve en la misma escena, entre las luchas de las ciudades y del feudalismo de los campos, entre la vida que 5 se va y la vida que se acerca. El cantor anda de pago en pago, de “tapera en galpón”, cantando sus héroes de la pampa, perseguidos por la justicia, los llantos de la viuda a quien los indios han robado sus hijos en un malón reciente, la derrota ro y la muerte del valiente Rauch, la catástrofe de Facundo Quiroga, y la suerte que cupo a Santos Pérez. El cantor está haciendo candorosamente el mismo trabajo de crónica, costumbres, historia, biografía, que el bardo de la Edad Media; y sus 15 versos serían recogidos más tarde como los documentos y datos en que habría de apoyarse el historiador futuro, si a su lado no estuviese otra sociedad culta, con superior inteligencia de los acontecimientos que el infeliz despliega en sus zorapsodias ingenuas. En la República Argentina se ven a un tiempo dos civilizaciones distintas en un mismo suelo: una naciente, que $\sin$ cono-

Io. valiente Rauch, popular hero and gaucho leader; comparable to Custer in American history.

Io. catástrofe de Facundo. Reference to the assassination of this rival of Rosas. He was murdered by the outlaw gaucho Santos P'érez at the instigation of Rosas. His death was a favorite theme of the cantores.

19. el infeliz, a term of mild contempt, the poor felloxi. 
cimiento de lo que tiene sobre su cabeza, está remedando los esfuerzos ingenuos y populares de la Edad Media; otra que, sin cuidarse de lo que tiene a los pies, intenta realizar los últimos resultados de la civilización europa: el siglo XIX y el 5 siglo XII viven juntos; el uno dentro de las ciudades, el otro en las campañas.

El cantor no tiene residencia fija: su morada está donde la noche le sorprende: su fortuna en sus versos y en su voz. Dondequiera que el ro cielito enreda sus parejas $\sin$ tasa, dondequiera que se apura una copa de vino, el cantor tiene su lugar preferente, su parte escogida en el festín. El gaucho argentino no bebe, si la música y los versos no lo excitan, ${ }^{1}$ y cada pulpería tiene su 15 guitarra para poner en manos del cantor, a quien el grupo de caballos estacionados a la puerta

${ }^{1}$ No es fuera de propósito recordar aquí las semejanzas notables que presentan los argentinos con los árabes. En Argel, en Orán, en Máscara y en los aduares del desierto, 20 ví siempre a los árabes reunidos en cafés, por estarles prohibido el uso de los licores, apiñados en derredor del cantor, generalmente dos que se acompañan de la vihuela a duo, recitando canciones nacionales plañideras como nuestros

I. de lo que tiene sobre su cabeza, i.e., the cultured city element.

3. de lo que tiene a los pies, i.e., the semicivilized gaucho element of the country.

ro. Dondequiera que, Wherever.

20. Orán, port in Algeria.

20. Máscara, town in Algeria, to the southeast of Orín. 
anuncia a lo lejos donde se necesita el concurso de su gaya ciencia.

El cantor mezcla entre sus cantos heroicos la relación de sus propias hazañas. Desgraciada5 mente, el cantor, con ser el bardo argentino, no está libre de tener que habérselas con la justicia. También tiene que dar cuenta de sendas puñaladas que ha distribuído, una odos desgracias (i muertes!) que tuvo, y algún caballo o muchacha que robó. ro El año i 8 +o, entre un grupo de gauchos y a orillas del majestuoso Paraná, estaba sentado en el suelo y con las piernas cruzadas un cantor que tenía azorado y divertido a un auditorio con la larga y animada historia de sus trabajos $y$ aventuras. is Había ya contado lo del rapto de la querida, con los trabajos que sufrió; lo de la desgracia, y la disputa que la motivó; estaba refiriendo su en-

tristes. La rienda de los arabes es tejida de cuero y con azotera, como las muestras; el freno de que usamos es el 20 freno árabe, $y$ muchas de nuestras costumbres revelan el contacto de nuestros padres con los moros de la Andalucía. De las fisonomías no se hable: algunos árabes he conocido que jurara haberlos visto en mi país. - El Autor.

5. con ser, though being.

5. no está libre de..., is not fré from hasing some accounts to settle with the police.

15. Io del rapto, the story of the abdurtion.

19. azotera. In Argentima reins are often made longr enough so that the cnds may be used as a whip; these constitute the azotera.

22. no se hable, let us not speak. 
cuentro con la partida y las puñaladas que en su defensa dió, cuando el tropel y los gritos de los soldados le avisaron que esta vez estaba cercado. La partida, en efecto, se había cerrado en forma de herradura; la abertura quedaba hacia el Paraná, 5 que corría veinte varas más abajo, tal era la altura de la barranca. El cantor oyó la grita sin turbarse: viósele de improviso sobre el caballo, y echando una mirada escudriñadora sobre el círculo de soldados con las tercerolas preparadas, vuelve io el caballo hacia la barranca, le pone el poncho en los ojos y clávale las espuelas. Algunos instantes después se veía salir de las profundidades del Paraná, el caballo sin freno, a fin de que nadase con más libertad, y el cantor tomado de la cola, is volviendo la cara quietamente, cual si fuera en un bote de ocho remos, hacia la escena que dejaba en la barranca. Algunos balazos de la partida no estorbaron que llegase sano y salvo al primer islote que sus ojos divisaron.

II. el poncho. The poncho used by the gauchos is a thick woolen blanket of oblong shape, with a slit in the center so that it may fall over the wearer's shoulders. It is an inseparable accouterment of the gaucho. It is his winter coat, his raincoat, and his shield to boot, for in his dueling, to which he is much given, the gaucho fights with the knife in one hand and the poncho wrapped around the other hand and arm.

13. se veía salir, there was seen emerging.

I5. tomado de la cola, clinging to the tail. 
Por lo demás, la poesía original del cantor es pesada, monótona, irregular, cuando se abandona a la inspiración del momento: más narrativa que sentimental, llena de imágenes tomadas de la vida 5 campestre, del caballo, y de las escenas del desierto, que la hacen metafórica y pomposa. Cuando refiere sus proezas o las de algún afamado malévolo, parécese al improvisador napolitano, desarreglado, prosaico de ordinario, elevándose a la altura poéro tica por momentos, para caer de nuevo al recitado insípido y casi sin versificación. Fuera de esto, el cantor posee su repertorio de poesías populares, quintillas, décimas y octavas, diversos géneros de versos octosilábicos. Entre éstas hay muchas ${ }_{15}$ composiciones de mérito, y que descubren inspiración y sentimiento.

Aun podría añadir a estos tipos originales muchos otros igualmente curiosos, igualmente locales, si tuviesen, como los anteriores, la pecu2oliaridad de revelar las costumbres nacionales, $\sin$ lo cual es imposible comprender nuestros personajes políticos, ni el carácter primordial y americano de la sangrienta lucha que despedaza a la República Argentina. Andando esta historia, el ${ }_{25}$ lector va a descubrir por sí solo dónde se encuentra el rastreador, el baquiano, el gaucho malo y el

23. la sangrienta lucha, i.e., the struggle between the unitarians and federalists. V. Introduction.

24. Andando esta historia, As this history goes on. 


\section{ORIGINALIDAI Y CARACTERES ARGENTINOS 55}

cantor. Verá en los caudillos cuyos nombres han traspasado las fronteras argentinas, y aun en aquellos que llenan el mundo con el horror de su nombre, el reflejo vivo de la situación interior del país, sus costumbres y su organización. 


\section{ASOCIACIÓN}

\section{Domingo F. Sarmiento}

Le gaucho vit de privations, mais son luxe est la liberté. Fier d'une indépendence sans bornes, ses sentiments, sauvages comme sa vie, sont pourtant nobles et bons. - HEAD

\section{La Pulpería}

En el capítulo primero hemos dejado al campesino argentino en el momento en que ha llegado a la edad viril, tal cual lo ha formado la naturaleza y la falta de verdadera sociedad en que vive. Le ${ }_{5}$ hemos visto hombre independiente de toda necesidad, libre de toda sujeción, sin ideas de gobierno, porque todo orden regular y sistemado se hace de todo punto imposible. Con estos hábitos de incuria, de independencia, ra a entrar en otra escala

Moтто. The gaucho liwes amid privations, but his luxury is freedom. Proud of the boundless independence he enjoys, his sentiments, as wild as his life, are nevertheless noble and good. Taken from Croquis des Pampas, written in 1826 by Sir Francis Bond Head, after his return to England from his mission as director of a mining company in the provinces of the l'lata.

I. En el capitulo primero, i.r., of the author's Facundo, from which this and the preceding selection are taken. 
de la vida campestre, que, aunque vulgar, es el punto de partida de todos los grandes acontecimientos que vamos a ver desenvolverse muy luego.

No se olvide que hablo de los pueblos esencialmente pastores ; que en éstos tomo la fisonomía fun- 5 damental, dejando las modificaciones accidentales que experimentan, para indicar a su tiempo los efectos parciales. Hablo de la asociación de estancias que, distribuídas de cuatro en cuatro leguas, más o menos, cubren la superficie de una provincia. ı

Las campañas agrícolas subdividen y diseminan también la sociedad, pero en una escala muy reducida; un labrador colinda con otro: y los aperos de labranza y la multitud de instrumentos, aparejos, bestias, que ocupa, lo variado de susis productos y las diversas artes que la agricultura llama en su auxilio, establecen relaciones necesarias entre los habitantes de un valle y hacen indispensable un rudimento de villa que les sirva de centro. Por otra parte, los cuidados y faenas 20 que la labranza exige, requieren tal número de brazos, que la ociosidad se hace imposible, y los varones se ven forzados a permanecer en el recinto de la heredad. Todo lo contrario sucede en esta

4. No se olvide, Let it not be forgotten.

5. que en éstos. Translate as if it were y que en éstos.

7. a su tiempo, at the proper time.

I5. ocupa. The subject is labrador.

I5. lo variado, the variety.

24. Todo lo contrario, Just the opposite. 
singular asociación. Los límites de la propiedad no están marcados; los ganados, cuanto más numerosos son, menos brazos ocupan; la mujer se encarga de todas las faenas domésticas y fabriles; ${ }_{5}$ el hombre queda desocupado, sin goces, sin ideas, sin atenciones forzosas; el hogar doméstico lo fastidia, lo expele, digámoslo así. Hay necesidad, pues, de una sociedad facticia para remediar esta desasociación normal. El hábito contraído desde so la infancia de andar a caballo, es un nuevo estímulo para dejar la casa.

Los niños tienen el deber de echar caballos al corral apenas sale el sol; y todos los varones, hasta los pequeñuelos, ensillan su caballo, aunque Is no sepan qué hacerse. El caballo es una integrante del argentino de los campos; es para él lo que la corbata para los que viven en el seno de las ciudades. El año $4 \mathrm{I}$, el Chacho, caudillo de los I lanos, emigró a Chile. - ¿Cómo le va amigo ?, 2o-le preguntaba uno. - i Cómo me ha de ir!-, contestó con el acento del dolor y de la melancolía. - ¡ En Chile . . y a pie! Sólo un gaucho

I. Los límites de la propiedad no están marcados. Later on, when Sarmiento became president, he introduced wire fences to indicate the boundary lines of the estancias.

14. aunque no sepan qué hacerse, though they may not know what to do with themselves.

17. la corbata. To a gaucho the cravat is the mark of the city man.

18. El a ño $4 \mathrm{I}$, i.e., 184 .

20. ¿Cómo me ha de ir! IIow do you suppose! 
argentino sabe apreciar todas las desgracias y todas las angustias que estas dos frases expresan.

Aquí vuelve a aparecer la vida árabe, tártara. Las siguientes palabras de Victor Hugo parecen escritas en la pampa:

" No podría combatir a pie! no hace sino una sola persona con su caballo." - ( Le Rhin)

Salen, pues, los varones sin saber fijamente adónde. Una vuelta a los ganados, una visita a una cría o a la querencia de un caballo predilecto, to invierte una pequeña parte del día; el resto lo absorbe una reunión en una venta o pulpería. Allí concurren cierto número de parroquianos de los alrededores; allí se dan y adquieren noticias sobre los animales extraviados; trázanse en el ${ }_{15}$ suelo las marcas del ganado, sábese dónde se caza el tigre, dónde se le han visto rastros al león: allí en fin, está el cantor; allí se fraterniza por el circular de la copa y las prodigalidades de los que poseen.

2. estas dos frases, i.e., i En Chile! i y a pie! In a foreign land! and on foot! Chile, moreover, being a mountainous country, ill suits the gaucho accustomed as he is to the plains of Argentina. Being horseless is of course always a calamity for a gaucho, whether in the pampa or far from it.

14. se dan. V. 2, 9 .

17. dónde se le han visto rastros al león, where the tracks of the lion (puma) have been seen.

18. se fraterniza, lit., it is fraternised; trans., there drinking and the prodigality of those with means induce comradeship. 


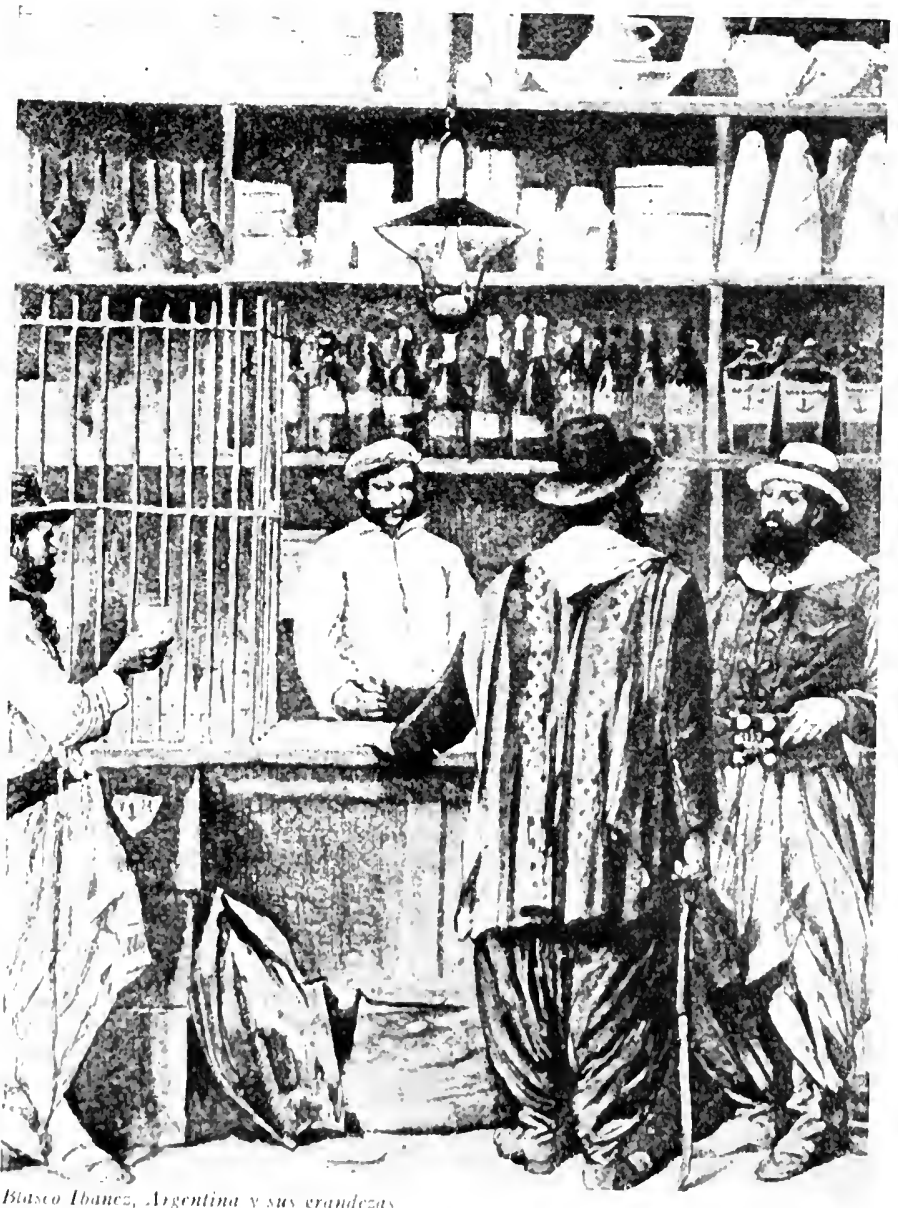

UNA PUIRRII IN II. (IIIM) 
En esta vida tan sin emociones, el juego sacude los espíritus enervados, el licor enciende las imaginaciones adormecidas. Esta asociación accidental de todos los días viene, por su repetición, a formar una sociedad más estrecha que la de donde 5 partió cada individuo; y en esta asamblea, sin objeto público, sin interés social, empiezan a echarse los rudimentos de las reputaciones que más tarde, y andando los años, van a aparecer en la escena política. Ved cómo.

El gaucho estima, sobre todas las cosas, las fuerzas físicas, la destreza en el manejo del caballo y, además, el valor. Esta reunión, este club diario, es un verdadero circo olímpico en que se ensayan y comprueban los quilates del mérito de 15 cada uno.

El gaucho anda armado del cuchillo, que ha heredado de los españoles; esta peculiaridad de la Península, este grito característico de Zaragoza, iguerra a cuchillo!, es aquí más real que en España. 20 El cuchillo, a más de un arma, es un instrumento que le sirve para todas sus ocupaciones; no puede

7. empiezan a echarse, begin to be laid.

19. la Península, i.e., Spain.

20. iquerra a cuchillo! war to the knife! The Spanish general. José Palafox Melfi, defender of the city of Zaragoza against the besieging troops of Napoleon (1808-1809), being asked by the French general to surrender, answered with the famous words above mentioned. For this heroic defense of Zaragoza he was made Duke of Zaragoza.

21. a más de un arma, besides being a weapon. 
vivir sin él; es como la trompa del elefante, su brazo, su mano, su dedo, su todo. El gaucho, a la par de jinete, hace alarde de valiente y el cuchillo brilla a cada momento, describiendo 5 círculos en el aire a la menor provocación, sin provocación alguna, sin otro interés que medirse con un desconocido; juega a las puñaladas como jugaría a los dados. Tan profundamente entran estos hábitos pendencieros en la vida íntima del ıo gaucho argentino, que las costumbres han creado sentimientos de honor y una esgrima que garantiza la vida. El hombre de la plebe de los demás países toma el cuchillo para matar, y mata; el gaucho argentino lo desenvaina para pelear, y ${ }_{15}$ hiere solamente. Es preciso que esté muy borracho, es preciso que tenga instintos verdaderamente malos o rencores muy profundos, para que atente contra la vida de su adversario. Su objeto es sólo marcarlo, darle una tajada en la cara, de20 jarle una señal indeleble. Así se ve a estos gauchos llenos de cicatrices, que rara vez son profundas. La riña, pues, se traba por brillar, por la gloria del vencimiento, por amor a la reputación. Ancho

2. a la par de jinete. After the words a la par the words de hacer alarde are understood and ser is understood before jinete and valiente.

Ir. una esgrima, a form of dueling.

20. Así se ve a estos gauchos, thus these gauchos are seen.

22. por brillar. V. 18,15 . 
círculo se forma en torno de los combatientes, y los ojos siguen con pasión y avidez el centelleo de puñales, que no cesan de agitarse un momento. Cuando la sangre corre a torrentes, los espectadores se creen obligados en conciencia a separarlos. Sis sucede una desgracia, las simpatías están por el que se desgració; el mejor caballo le sirve para alejarse a parajes lejanos, y allí lo acoge el respeto o la compasión. Si la justicia le da alcance, no es raro que haga frente, y si corre a la partida, ıo adquiere un renombre desde entonces que se dilata sobre una ancha circunferencia. Transcurre el tiempo, el juez ha sido mudado, y ya puede presentarse de nuevo en su pago sin que se proceda a ulteriores persecuciones; está absuelto. I5 Matar es una desgracia, a menos que el hecho se repita tantas veces que inspire horror el contacto del asesino. El estanciero Don Juan Manuel de Rosas, antes de ser hombre público, había hecho de su residencia una especie de asilo para los 20 homicidas, sin que jamás consintiese en su servicio a los ladrones; preferencias que se explicarían fácilmente por su carácter de gaucho propietario, si su conducta posterior no hubiese revelado afinidades que han llenado de espanto al mundo.

10. si corre a la partida, if he gets the better of the rural guards.

24. si su conducta posterior..., i.e., Rosas protected murderers because he himself turned out to be the greatest of murderers later on when he became dictator. 
En cuanto a los juegos de equitación, bastaría indicar uno de los muchos en que se ejercitan, para juzgar del arrojo que para entregarse a ellos se requiere. Un gaucho pasa a todo escape por 5 enfrente de sus compañeros. Uno le arroja un tiro de bolas, que en medio de la carrera maniata el caballo. Del torbellino de polvo que levanta éste al caer vese salir al jinete corriendo seguido del caballo,

I. En cuanto a los juegos de equitación. Darwin, speaking of the horsemanship of the gaucho, says: "General Rosas is also a perfect horseman - an accomplishment of no small consequence in a country where an assembled army elected its general by the following trial: a troop of unbroken horses, being driven into a corral, were let out through a gateway, above which was a crossbar; it was agreed that whoever should drop from the bar on one of these wild animals, as it rushed out, and should be able, without saddle or bridle, not only to ride it, but also to bring it back to the door of the corral, should be their general. The person who succeeded was accordingly elected; and doubtless made a fit general for such an army. This extraordinary feat has also been performed by Rosas."

5. Uno le arroja un tiro de bolas, Some one takes a shot at him with the bolas. The bolas used by the gauchos to catch cattle and game are of two kinds; they may consist of two round stones covered with leather and united by a leather thong about seren or eight feet long: or they may consist of three halls united to a common center. The balls differ in size and weight, depending on the kind of game the galuchos wish to catch. Ther are twirled around the head and hurled at the feet of the Hecing animal. Light bolas of the first hind are called lives. ('f. $82,12$.

8. vese salir al jinete corriendo, the rider is seen to emerge running. 


a quien el impulso de la carrera interrumpida hace avanzar obedeciendo a las leyes de la física. En este pasatiempo se juega la vida, y a veces se pierde.

Creeráse que estas proezas y la destreza y la 5 audacia en el manejo del caballo son la base de las grandes ilustraciones que han llenado con su nombre la República Argentina y cambiado la faz del país? Nada es más cierto, sin embargo. No es mi ánimo persuadir a que el asesinato y el so crimen hayan sido siempre una escala de ascensos. Millares son los valientes que han parado en bandidos oscuros; pero pasan de centenares los que a esos hechos han debido su posición. En todas las sociedades despotizadas, las grandes dotes is naturales van a perderse en el crimen; el genio romano que conquistara el mundo, es hoy el terror de los Lagos Pontinos, y los Zumalacárregui, los Mina españoles, se encuentran a centenares en Sierra Leona. Hay una necesidad para el hombre

II. que han parado en bandidos, who have ended by becoming bandits.

15. van a perderse en el crimen, are lost in crime.

16. que conquistara, trans., that once conquered.

17. Lagos Pontinos, the Pontine Marshes, the low country surrounding Rome.

17. los Zumalacárregui, los Mina. Tomás de Zumalacárregui (1788-1835) and Javier Mina (1789-1817) were intrepid guerrilla fighters who distinguished themselves in the Peninsular War against Napoleon, and later died in struggles against their own compatriots.

19. Sierra Leona, British colony on the western coast of Africa, between french Guinea and Liberia. 
de desenvolver sus fuerzas, su capacidad y su ambición, que cuando faltan los medios legítimos, él se forja un mundo con su moral y sus leyes aparte, y en él se complace en mostrar que había nacido Napoleón o César.

Con esta sociedad, pues, en que la cultura del espíritu es inútil o imposible, donde los negocios municipales no existen, donde el bien público es una palabra sin sentido, porque no hay público, el hombre dotado eminentemente se esfuerza por ıo producirse, y adopta para ello los medios y caminos que encuentra. El gaucho será un malhechor o un caudillo, según el rumbo que las cosas tomen en el momento en que ha llegado a hacerse notable.

Costumbres de este género requieren medios ${ }_{15}$ vigorosos de represión, y para reprimir desalmados se necesitan jueces más desalmados aún. Lo que al principio dije del capataz de carretas, se aplica exactamente al juez de campaña. Ante toda otra cosa, necesita valor: el terror de su 20 nombre es más poderoso que los castigos que aplica. El juez es naturalmente algún famoso de tiempo atrás, a quien la edad y la familia han llamado a

2. que, apocopated form of porque.

18. capataz de carretas, foreman of a train of ox-carts. For boldness and ruggedness these foremen may well be compared with the American pioneers who crossed the prairies in the forties.

22. algún famoso de tiempo atrás, some one famous in former days. 
la vida ordenada. Por supuesto, que la justicia que administra es de todo punto arbitraria; su conciencia o sus pasiones lo guían, y sus sentencias son inapelables. A veces suele haber jueces de ${ }_{5}$ éstos, que lo son de por vida, y que dejan una memoria respetada. Pero la conciencia de estos medios ejecutivos, $y$ lo arbitrario de las penas, forman ideas en el pueblo sobre el poder de la autoridad, que más tarde vienen a producir sus ro efectos. El juez se hace obedecer por su reputación de audacia temible, su autoridad, su juicio sin formas, su sentencia, un yo lo mando, y sus castigos inventados por él mismo. De este desorden, quizá por mucho tiempo inevitable, resulta is que el caudillo que en las revueltas llega a elevarse, posee sin contradicción, y sin que sus secuaces duden de ello, el poder amplio y terrible que sólo se encuentra hoy en los pueblos asiáticos. El caudillo argentino es un Mahoma que pudiera a su zo antojo cambiar la religión dominante $y$ forjar

I. Por supuesto, que. The que is redundant.

4. suele haber, there are cent to be.

5. 10. Cf. 29,2 .

7. lo arbitrario, the arhitrariness.

16. sin que sus secuaces duden de ello, without his followers dowiting it. The student must bear in mind that, whereas athoul in English is used only as a preposition, in Spanish its equivalent $\sin$ is used as a conjunction when, as in this case, it is followed by que. Spanish clauses introduced by sin que, therefore, must be translated by the preposition scithout plus the gerund of the verb. 
una nueva. Tiene todos los poderes: su injusticia es una desgracia para su víctima, pero no un abuso de su parte; porque él puede ser injusto; más todavía, él ha de ser injusto necesariamente; siempre lo ha sido.

Lo que digo del juez es aplicable al comandante de campaña. Éste es un personaje de más alta categoría que el primero, $y$ en quien han de reunirse en más alto grado las cualidades de reputación y antecedentes de aquél. Todavía una circuns- ro tancia nueva agrava, lejos de disminuir, el mal. El gobierno de las ciudades es el que da el título de comandante de campaña; pero como la ciudad es débil en el campo, sin influencias y sin adictos, el gobierno echa mano de los hombres que más 15 temor le inspiran para encomendarles este empleo, a fin de tenerlos en su obediencia; manera muy conocida de proceder de todos los gobiernos débiles, y que alejan el mal del momento presente, para que se produzca más tarde en dimensiones 20 colosales. Así el gobierno papal hace transacciones con los bandidos, a quienes da empleos en

6. comandante de campaña, an officer exercising both civil and military authority in the country; trans., country prefect.

Io. Todavía una circunstancia nueva, Still another circumstance.

I7. en su obediencia. Su refers to el gobierno.

21. Así el gobierno papal. The pontificate of Gregory XVI (I83I-I846) was notoriously ill-advised. 
Roma, estimulando con esto el vandalaje y creándole un porvenir seguro: así el sultán concedía a Mehemet Alí la investidura de Bajá de Egipto, para tener que reconocerlo más tarde ${ }_{5}$ rey hereditario a trueque de que no lo destronase. Es singular que todos los caudillos de la revolución argentina han sido comandantes de campaña: López e Ibarra, Artigas y Güemes, Facundo y Rosas. Es el punto de partida para todas las ro ambiciones. Rosas, cuando hubo apoderádose de la ciudad, exterminó a todos los comandantes que lo habían elevado, entregando este influyente cargo a hombres vulgares, que no pudiesen seguir el camino que él había traído: Pajarito, Cela${ }_{15}$ rrayán, Arbolito, Pancho el Nato, Molina, eran

2. el sultán. Mustafa IV in 1806 , by imperial firman, ratified the election of Mehemet Ali by the sheiks to the pashalik of Egypt. Mehemet Ali (I769-I 849), pasha and afterwards viceroy of Egypt, though an illiterate of humble birth, was an extraordinarily clever and astute man. It was only through the intervention of the powers that in I 849 , after the rout of the Ottoman forces at the battle of Nezib, he was forced to be satisfied with only the hereditary Viceroyalty of Egypt.

5. destronase. The subject is Mehemet Alí.

6. revolución, i.e., the social revolution after the war of independence.

8. López e Ibarra, Artigas y Güemes, Facundo y Rosas. V. Introduction.

II. la ciudad, i.e., Buenos Aires.

14. el camino que él había traído, the path he had followed. 
otros tantos comandantes de que Rosas purgó al país.

Doy tanta importancia a estos pormenores, porque ellos servirán a explicar todos nuestros fenómenos sociales, y la revolución que se ha 5 estado obrando en la República Argentina: revolución que está desfigurada por palabras del diccionario civil, que la disfrazan y ocultan creando ideas erróneas: de la misma manera que los españoles, al desembarcar en América, daban un ro nombre europeo conocido a un animal nuevo que encontraban, saludando con el terrible de león, que trae al espíritu la magnanimidad y fuerza del rey de las bestias, al miserable gato llamado puma, que huye a la vista de los perros, y tigre 15 al jaguar de nuestros bosques. Por deleznables e innobles que parezcan estos fundamentos que quiero dar a la guerra civil, la evidencia vendrá luego a mostrar cuán sólidos e indestructibles son. La vida de los campos argentinos, tal como la he 20 mostrado, no es un accidente vulgar; es un orden de cosas, un sistema de asociación, característico, normal, único, a mi juicio, en el mundo, y él solo basta para explicar toda nuestra revolución. Había antes de I 8 Io en la República Argentina dos 25 sociedades distintas, rivales e incompatibles; dos civilizaciones diversas: la una española, europea,

I. otros tantos, so many. The naming of such worthless men as those mentioned to the post of prefect was the equivalent of eliminating that number of prefects. 
culta ; y la otra bárbara, americana, casi indígena ; y la revolución de las ciudades sólo iba a servir de causa, de móvil, para que estas dos maneras distintas de ser de un pueblo se pusiesen en pre5 sencia una de otra, se acometiesen, y después de largos años de lucha, la una absorbiese a la otra. He indicado la asociación normal de la campaña, la desasociación, peor mil veces que la tribu nómada; he mostrado la asociación ficticia roen la desocupación, la formación de las reputaciones gauchas - valor, arrojo, destreza, violencia y oposición a la justicia regular, a la justicia civil de la ciudad. Este fenómeno de organización social existía en 1810 , existe aún modificado ${ }_{15}$ en muchos puntos, modificándose lentamente en otros, e intacto en muchos aún. Estos focos de reunión del gauchaje valiente, ignorante, libre y desocupado, estaban diseminados a millares en la campaña. La revolución de i 8 Io llevó a to20 das partes el movimiento y el rumor de las armas. La vida pública que hasta entonces había faltado a esta asociación árabe-romana, entró en todas las ventas, y el movimiento revolucionario trajo al fin la asociación bélica en la montonera 25 provincial, hija legítima de la venta y de la estan-

2. la revolución de las ciudades, i.e., against the Spaniards.

8. la desasociación, i.e., de la campaña.

10. en la desocupación, originating in idleness.

16. Estos focos, i.e., la pulpería, la estancia, la venta. 
cia, enemiga de la ciudad y del ejército patriota revolucionario. Desenvolviéndose los acontecimientos, veremos las montoneras provinciales con sus caudillos a la cabeza; en Facundo Quiroga, últimamente triunfante en todas partes, la cam- 5 paña sobre las ciudades, y dominadas éstas en su espíritu, gobierno, civilización, formarse al fin el gobierno central, unitario, despótico, del estanciero Don Juan Manuel de Rosas que clava en la culta Buenos Aires el cuchillo del gaucho y des- so truye la obra de los siglos, la civilización, las leyes y libertad.

4. en Facundo Quiroga, ... For translation rearrange the sentence thus: últimamente en Facundo Quiroga veremos (understood) la campaña triunfante en todas partes sobre las ciudades, y éstas, siendo (understood) dominadas en su espíritu, gobierno, civilización, veremos (understood) formarse, al fin, el gobierno, etc. In the series espiritu, gobierno, civilizacion the conjunction y is omitted by asyndeton. 


\section{LEYENDAS DEL PAÍS DE LA SELVA}

\section{O. Bunge (Según Ricardo Rojas)}

\section{El País de la Selva, Sus Leyendas y Trovadores}

Llamo País de la Selva a la región argentina que se extiende, en el interior de la república, desde la cuenca de los grandes ríos hasta las primeras ondulaciones de la montaña, es decir, ${ }_{5}$ entre las llanuras bañadas por el Paraná y sus afluentes y los contrafuertes iniciales de la cordillera de los Andes. A esa región central correspondíale en los tiempos del coloniaje el nombre de Tucumán, y abarcaba, más o menos, rolas actuales provincias de Tucumán, Santiago del Estero y Córdoba. En los tiempos anteriores a la conquista estuvo ella poblada por varias razas $y$ pueblos indígenas, entre los cuales descollaran los Lules, por haber recibido y adoptado ${ }_{15}$ del Cuzco la cultura quichua o incásica.

4. montaña, i.e., the Andes.

Io. Santiago del Estero. V. map.

13. descollaran, had excelled.

15. Cuzco, city in P'eru, capital of the ancient empire of the Incas. V. map. 
No hay en toda la República Argentina territorio alguno donde existan más tradiciones y leyendas locales que en el País de la Selva. Los mitos y argumentos legendarios de la antigua cultura indígena han persistido hasta los tiempos 5 actuales, mezclándose y amalgamándose a veces, curiosa y originalmente, a las ideas y sentimientos aportados por la conquista española. Es sobre todo en la provincia de Santiago del Estero, que se diría el corazón del País de la Selva, donde io mayormente se conservan las antiguas leyendas indiocoloniales, siendo las más populares la de Zupay y la.del Kacuy.

Transmitense las leyendas verbalmente en quichua, de padres a hijos. Pero la Selva tiene 15 también sus trovadores, que saben cantar su poesía. La poesía y la música se hallan unidas en las costumbres de la Selva, cual lo estuvieron en la Grecia clásica. Siendo éstas las manifestaciones estéticas más genuinas del país, los trova- 20 dores, generalmente, cultivan las dos. La melodía acompaña y sostiene la copla, y ambas se integran en la danza por un ritmo común.

Ninguna de las fiestas del país se realiza sin la presencia del trovador, especie de sacerdote de la 25 alegría y de la muerte. Es su escenario la selva toda, recorrida por él en vida vagabunda. Hoy

26. Es su . . vagabunda, The entire forest traversed by him in his wanderings is the scene of his actirities. 
le llevan a velorios, mañana a una trinchera de carnestolendas, después a pesebres, luego a holgorios de boda, más tarde a bailes tradicionales. $\therefore$ Él es el órgano expresivo de todos los 5 sentimientos del pueblo. El agasaja al viajero, al caudillo, al magistrado, o simplemente al patrón. Él anima las reuniones carnavalescas o nupciales; él plañe en torno al féretro de los difuntos monótonas alabanzas, $y$ junto al cadáver ro de los párvulos musita las letanías de los ángeles, - pues allí donde no llega la acción sacramental de la iglesia, no sólo realiza su misión profana de la alegría báquica, sino las ceremonias de un verdadero culto religioso. . . .

15 Ninguna particular indumentaria singulariza la indumentaria del cantor; pero el instrumento del cual se acompaña, completa su figura. Cultiva ante todo el amor de su vihuela. Protégela de la humedad y del sol; quiérela como si fuera una zo mujer. . . Y Y la vihuela corresponde tanto a sus amores, que la trova dice:

Las cuerdas de mi guitarra gimen conmigo a la par y me ayudan a llorar el dolor que me lastima. . . ¡Si parece que la prima hubiese aprendido a hablar!

26. Si parece que, etc., It seems indeed as if the treble string, elc. 


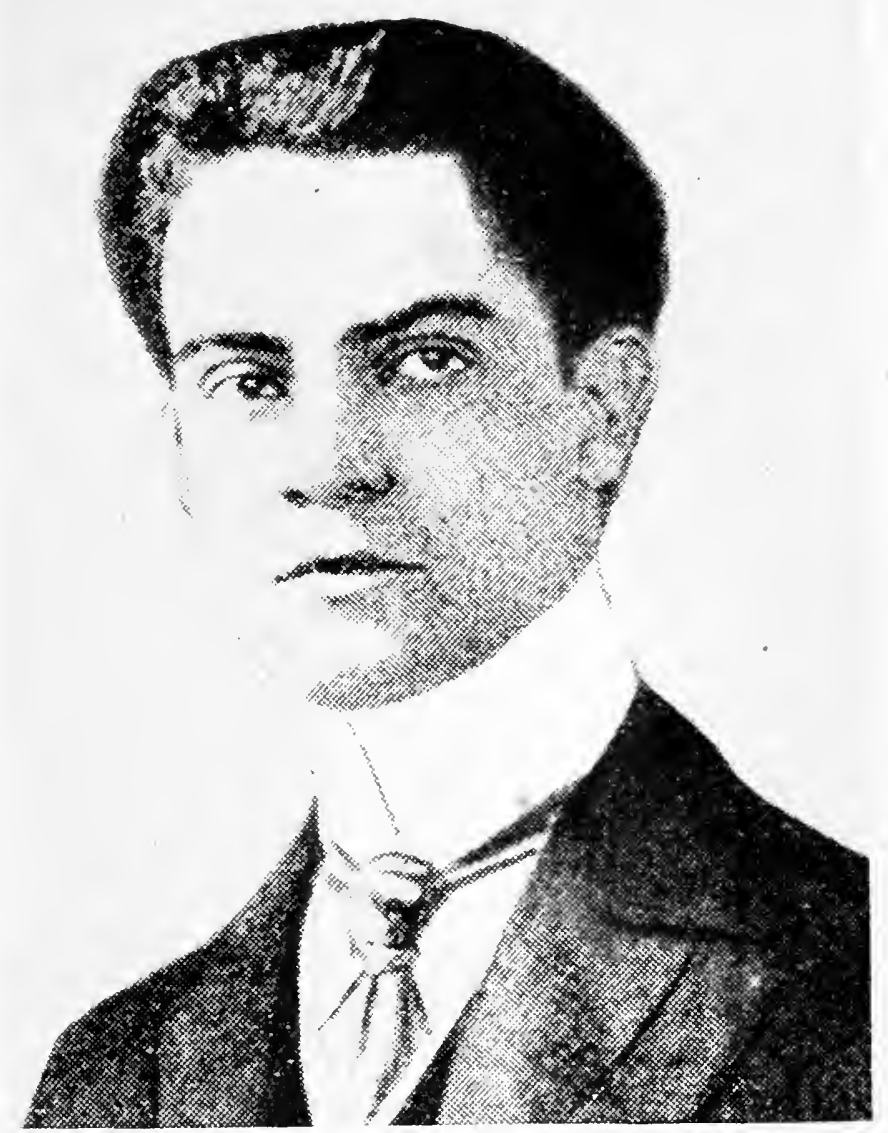

Blasco Ibánez, Argenlina y sus grandezas

Ricardo Rojas, Joven Escritor Argentino 


\section{Zupay}

Entre los mitos del país Zupay es, sin duda, la encarnación más potente del misterio selvático. Zupay es el Diablo de la Selva; y, como tal, no es producto genuino del espíritu quichua, ni 5 la tradición incontaminada del demonio español. Más bien es una resultante del uno y del otro. En su estado primordial es un genio latente $y$ maligno; es el genio de todo lo adverso que aflige a los hombres y el enemigo de Nuestro Señor. ro Puede estar en el agua, en el fuego, en la atmósfera; y sabe, al par, dirigir estos elementos para sembrar en la Selva pestes, inundaciones, sequías, catástrofes. . . .

El mito de Zupay se relaciona tanto con los de is la hechicera y la Salamanca, que constituyen inseparable unidad. Los poderes de la bruja provienen de un pacto con Zupay, y la Salamanca no es sino la academia subterránea, oculta en el bos-

I. Zupay. It is of interest to note in this connection that the gaucho of the pampa calls this spirit Mandinga, who, although evilly inclined toward men, does at times do them favors.

15. Salamanca. The University of Salamanca was famous in the Middle Ages as a great center of leaming. Its motto was Salamanca, maestra de todas las ciencias. In the thirteentl century Pope Alexander IV, by a bull, made it one of the four great academies of the world. In Argentina, the word Salamanca has become synonymous with learning used for evil purposes, and means both witcheraft and the school where witcheraft is taught. 
que, donde el neófito aprende su ciencia junto a las cátedras diabólicas. Zupay, maestro, da sus lecciones a la bruja, su discípula, en su escuela tenebrosa, la Salamanca.

Zupay, universal y ubicuo en su estado latente, 5 es multiforme en sus personificaciones y manifestaciones. Prefiere en sus metamorfosis figuras humanas. Ha encarnado alguna vez en cuerpo de hermoso mancebo, apareciéndose en un rancho a cierta mujer ingenua. Se ha mostrado otra ocasión como un gaucho rico y joven que visita la Selva en su caballo enjaezado de mágicos arreos. Otra sazón, un paisano, cantor de la comarca, atravesando el bosque, rumbo a la fiesta, vióse de pronto acompañado por alguien que le desafiaba $a_{15}$ "payar", guitarra en mano: era también Zupay, el Malo, como en la leyenda de Santos Vega. Los nativos hablan asimismo de un diminuto duende, que es como la encarnación humorística y bromista de Zupay. Es el travieso enano de la siesta, con 20

16. "payar". Music plays an important part in all the gatherings among Argentine countrymen. Two payadores, or bards, engage in a musical contest: each man sings in turn, accompanying himself on the guitar on any improvised subject, and at the end the audience expresses its approval of the winner by its applause.

20. enano de la siesta, the dwarf of the noonday nap. Tradition has it that ghosts walk about in the quiet hours of the noonday nap. This is not surprising if one bears in mind the deep stillness that pervades small Spanish-American towns, particularly those in the interior. 
su corta estatura, su rostro magro y barbirrucio, el ingenio maligno bullendo bajo el ancho sombrerote de copa en embudo. . . .

Los hijos de la Selva refieren otras revelaciones 5 de Zupay. Cierto día los montes saladinos oyeron el baladro de un fabuloso toro, bestia chúcara de olímpica frente sobre cuello crinado, y i era también Zupay! Otro día le vieron, entre las penumbras del ramaje, con rostro de sátiro, pelurodas piernas y hendidas patas de chivo. . .

He ahí cómo este dios o demonio numeroso parece mezclarse a la diaria existencia de esas campañas. Sus dominios se extienden a la espesura toda; y hasta un árbol de la flora local ${ }_{15}$ señala con nombre equívoco la presencia del mito. En la descriptiva nomenclatura de las plantas silvestres figura la malop'taco, " algarroba del diablo". ...

\section{El Kacuy}

Vive en la Selva un pájaro nocturno que, al zoromper el silencio de las sombras, estremece el alma con su lúgubre canto. Esa ave tiene su historia. Y es la tragedia de su origen lo que evoca con su grito lastimero, ayeando entre las arboledas tenebrosas : ¡Turay !... i Turay!... ${ }_{25}$ i'luray!...

5. montes saladinos, saline mountains. Cf. $4_{2}^{2}, 1_{4}$.

23. evoca. The subject is ave in the preceding sentence.

24. Turay, Quichua for brother. 
En la época muy remota, dicen las tradiciones indígenas, una pareja de hermanos (un hermano y una niña) habitaba un rancho en las selvas. Él era bueno; ella era cruel. Amábala él como pidiéndole ventura para sus horas huérfanas; pero 5 ella acibaraba sus días con recalcitrante perversidad. Desesperado, abandonaba él en ocasiones la choza, internándose en las marañas; y ella amainaba en el aislamiento sus iras, hilando alguna vedija en la rueca o tramando una colcha en o sus telares. Mientras vagaba por la Selva el buen hermano pensaba en la hermana, y, perdonándola siempre, llevábale al rancho las algarrobas más gordas, los místoles más dulces, las más sazonadas tunas. Vivían ambos de los frutos naturales en ${ }_{15}$ aquel siglo de Dios. Proveyendo a su subsistencia, él traía hoy para la casa un mikilo atrapado a garrote por el esterocercano; obien un sábalo pescado en fisga en el remanso del río; si no un quirquincho de la barranca próxima, o algún panal de lachi- 20 guana, manando rubio néctar por los simétricos alvéolos. Palmo a palmo conocía su monte, y, siendo cazador de tigres además, protegía la morada. Insigne buscador de mieles, nadie tenía más despiertos ojos para seguir a la abeja voladora 25

I. atrapado a garrote, clubbed to death.

18. pescado en fisga en el remanso del rio, harpooned in the still waters of the river.

I9. si no, if not; or else. 
que lo llevaba a su colmena: la de la ashpa-mishqui escondida en el suelo, en un cardón enjambrada; la del tiu-simi y la de cayanes o de queyas fabricada en el tronco de los más duros árboles. . . . Todo 5 esto le costaba trabajo y pequeños dolores; pero ella en cambio mostrábase indiferente, como gozándose en sus penas.

Volvió él una tarde sediento, fatigado, tras un día de infructuosa pesquisa; pues, como ro reinaba la sequía, estaban yermos y en escasez los campos. Sangrábale la mano, porque al pretender agarrar una perdiz boleada a lives y caída entre unas matas, pinchóle el uturuncu-huakachina, el cactus espinoso "que hace llorar al tigre". ${ }_{15}$ Pidió entonces a su hermana un poco de hidromiel para beberla y otro de agua para restañarse los arañazos. Trajo ella ambas cosas; mas, en lugar de servírselas, derramó en su presencia en el suelo la botijilla de agua y el tupo de miel. El hombre, zo una vez más, ahogó su desventura. Pero, como al día siguiente le volcara también la ollita donde se cocinaba el locro de su refrigerio habitual, desesperado, resolvió vengarse. Encubriendo en su in-

I-3. ashpa-mishqui, tiu-simi, cayanes, queyas, also moromoros $(83,3)$, Quichua names of different varieties of bees.

ro. en escasez, without game.

12. boleada a lives, brought down with light bolas. Cf. 64,5 .

r. tupo, Quichua name for a measure of any sort ; trans., jar.

22. el locro de su refrigerio habitual, his customary ration of locro. 
vitación sus deseos de venganza, invitóla para que le acompañase a un sitio no lejano, donde había descubierto miel abundante de moro-moros. No vistió su zamarra profesional, ni sus guanteletes, ni el sachasombrero, ni llevó la bocina de las melea- 5 das, porque juzgaba fácil la ventura. El árbol, un abuelo del bosque, era sin embargo de gigantesca talla. Cuando llegaron alli, el muchacho persuadió a su perversa hermana a que debían operar con cuidado, buscando beneficiarse del néctar sin ro destruir las abejas pequeñitas, pues se referían historias de cazadores meleros desaparecidos bruscamente a manos de un dios invisible que protege las colmenas.... Sobre la horqueta más alta hizo pasar un lazo; y lo preparó en un extremo, $a_{\text {I }_{5}}$ guisa de columpio, para que subiese su hermana, bien cubierta por el poncho, en defensa del enjambre, ya alborotado por la maniobra. Tirando al otro extremo, a manera de corrediza palanca, la solivió en el aire, hasta llegar a la copa ; y, cuando 23 ella se hubo instalado allí, sin descubrirse, él empezó a simular que ascendía por el tronco, desgajándolo a hachazos, mientras hajaba en realidad. Zafó después el lazo, y huyó sigilosamente. . . . Presa quedaba en lo alto la infeliz.

14-25. The brother has taken a position on some branch of the tree beneath la horqueta más alta, so that he could pull on his lasso in the manner of a pulley. From this point, when his sister had reached the horqueta más alta, he could pretend he was going up, although in reality he was going down. 
Transcurrieron instantes de silencio. Ellahabló. Nadie respondía... Como empezaba a temer, soliviantó la manta que la tapaba, dejando apenas una rendija para espiar. El zumbido ${ }_{5}$ de los insectos la aturdió, pues el armado enjambre revolaba furioso en derredor, vibrante de alas y trompas. Ese rumor confuso revelaba la profundidad del silencio. ¿Qué podría ser? No sospechaba la hora ni el lugar. Ciega de horror ro y de coraje se desembozó de súbito; al descubrir el espacio, el vacío del vértigo la dominó. . . . ¡Sola, sola para siempre!

Abandonada a semejante altura, sobre un tronco liso y largo, sin otras ramas que ésas a las cuales Is se aferraban sus prietas manos, espiaba para ver si el hermano reaparecía por ahí. La acometían deseos de arrojarse, pero la brusquedad del golpe amilanábala. No obstante, si perecía allá, quien sabe si los caranchos no vendrían a saciarse en ella, zo como en las osamentas de los animales que morían ignorados en el monte.

Mientras tanto la noche iba descendiendo en progresiva nitidez de sombra. Desde su atalaya, la pobre huérfana había podido, por primera vez, ${ }_{25}$ contemplar solore el panorama de la Selva la inmensidad de los horizontes, y la sucesión de las copas verdes que se unían formando obscuro océano

22. En progresiva nitidez de sombra, /tith gradual and ciear-cut shadows. 
encrespado de gigantescas olas. El col hundiéndose tras los árboles, la impresionó más soberbio que nunca, iluminado el enorme lomo del bosque con su claridad apacible y decorado el cielo de Occidente por cosmogónicos resplandores. Luego 5 vió aquella gran luz aguarse hasta disolverse toda en la noche, - noche sin astros para mayor desventura. . . . Nunca se le mostró más pavoroso el cielo, ni más callada la breña. Viniéronle ansias locas de perderse en lo ignoto, de hender esa in- ıo mensidad de árboles y tinieblas, o llenar el silencio de un solo grito. Mas, ahora, se le añusgaba la garganta muda y la lengua se le pegaba en la boca con sequedad de arcilla. Tiritaba como si el ábrego la azotase con su punzante frío y sentía el is $_{5}$ alma toda mordida por implacables remordimientos. Los pies, en esfuerzo anómalo con que ceñían su rama de apoyo, fueron desfigurándose en garras de buho; la nariz y las uñas se encorvaban; y los dos brazos, abiertos en agónica distensión, emplu- 20 mecían desde los hombros a las manos. Disnea asfixiante la estranguló, y, al verse de pronto convertida en ave nocturna, un ímpetu de volar arrancóla del árbol y la empujó a las sombras. . . .

Así nació el kacuy. La pena rompió en su gar- 25 ganta llamando a aquel hermano justiciero. Y el grito de contrición de esa mujer convertida en ave, resuena aún y resonará siempre sobre la noche de los bosques natales: ¡Turay!... iTuray!... ¡Turay!... 


\section{LA LEYENDA DE SAINTOS VEGA}

\section{O. Bunge}

Entre las leyendas pampeanas, y puede decirse que entre todas las leyendas argentinas, ninguna tan expresiva y popular como la de Santos Vega. Santos Vega es la más pura y elevada personifica5 ción del gaucho. Es el hijo, es el señor, es el dios de la Pampa. Su historia, que puede reducirse al episodio de su justa poética con el diablo, representa el destino de una raza y es la síntesis de su epopeya. Aunque fuera acaso alguna vez persona rode carne y hueso, transformóse Santos Vega en verdadero mito, hasta constituir un símbolo nacional.

En tiempos distantes y nebulosos, allí donde se pierde el recuerdo de los orígenes de la nacionali$15 \mathrm{dad}$ argentina, Santos Vega fué el más potente payador. Su numen era inagotable en la improvisación de endechas, ya tiemas, ya humorísticas; su voz de timbre cristalino y trágico inundaba el alma de sorpresa y arrobamiento; sus manos 20 arrancaban a la guitarra acordes que eran sollozos,

2. Note omission of es after ninguna.

16. payador. Cf. $79,16$. 


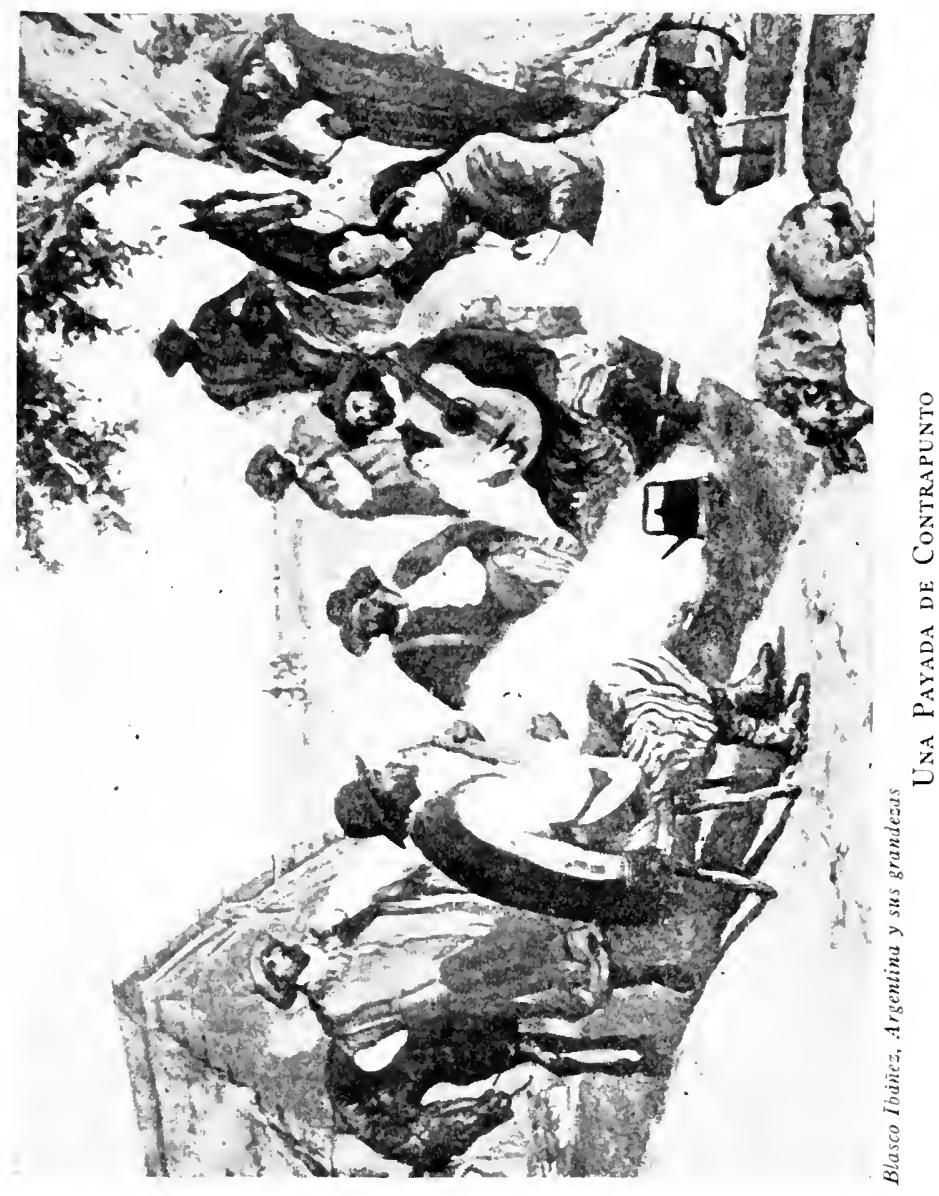


burlas, imprecaciones. Su fama llenaba el desierto. Ávida de escucharlo acudía la muchedumbre de los cuatro rumbos del horizonte. En las "payadas de contrapunto", esto es, en las justas o torneos ${ }_{5}$ de canto y verso, salía siemprè triunfante. No había en las pampas trovador que lo igualara, ni recuerdo de que alguna vez lo hubiese habido. Dondequiera que se presentase rendíale el homenaje de su poética soberanía aquella turba gauchesca ro tan amante de la libertad y rebelde a la imposición. Para el alma sencilla del paisano, dominada por el canto exquisito, Santos Vega era el rey de la Pampa.

A la sombra de un ombú, ante el entusiasta audi${ }_{15}$ torio que atraía siempre su arte, inspirado por el amor de su "prenda", una morocha de ojos negros y labios rojos, cantaba una tarde Santos Vega, el payador, sus mejores canciones. En religioso silencio escuchábanle hombres y mujeres, 20 conmovidos hasta dejar correr ingenuamente las lágrimas. . . En esto se presenta a galope tendido un forastero, tírase del caballo, interrumpe el canto y desafía al cantor. Es tan extrañ் su aspecto, que todos temen vaga y punzantemente s 5 una desgracia. Pálido de coraje, Santos Vega acepta el desafío, templa la guitarra y canta sus cielos y vidalitas. $\mathrm{Y}$ cuando termina, creyendo

3. "payadas de contrapunto". A contest such as the one described in the note to page 79 , line 16 , is called a payada de contrapunto. 
imposible que un ser humano le pueda vencer, los circunstantes lo aplauden en ruidosa ovación. Hácese otra vez silencio. Tócale su turno al forastero. . . Su canto divino es una música nunca oída, caliente de pasiones infernales, rebosante de 5 ritmos y armonías enloquecedoras. ... i Ha vencido a Santos Vega! Nadie puede negarlo, todos lo reconocen condolidos y espantados, y el mismo payador antes que todos. ... i Adiós fama, adiós gloria, adiós vida! Santos Vega no puede sobre- ı vivir a su derrota. . . Acaso el vencedor, en quien se reconoce ahora al propio diablo, al temido Juan sin Ropa, habiendo ganado, y como trofeo de su victoria, pretenda el alma del vencido. . . . Desde entonces, en efecto, desapareciendo delis mundo de los mortales, Santos Vega es una sombra doliente, que, al atardecer y en las noches de luna, cruza a lo lejos las pampas, la guitarra terciada en la espalda, en su caballo veloz como el viento.

Poetas populares y poetas cultos han cantado 20 hermosamente la leyenda de Santos Vega. La crítica le ha encontrado hoy un sentido épico. El diablo es la moderna civilización, que, con las máquinas y fábricas de su portentosa técnica, vence al gaucho y lo desaloja de sus vastos dominios. 25

3. Hácese . . silencio, Silence falls ağain.

13. Juan sin Ropa, picturesque name given to the devil by the gauchos.

22. le ha encontrado, i.e., a la leyenda; trans., has found in it. 
Como los primitivos cantores no podían prever este destino del gaucho, el símbolo viene a ser posterior, $y$, en realidad, no encuadra sino vagamente $y$ por coincidencia en los verdaderos términos de la ${ }_{5}$ leyenda. Su origen está más bien, a mi juicio, en la doctrina bíblica del Génesis. Como los metafísicos la adaptaron a la filosofía con su concepto de la " edad de oro", los gauchos la traducen en su leyenda de Santos Vega. Santos Vega en ro la Pampa fué Adán en el Paraíso Terrestre, antes de incurrir en el pecado original. Su "prenda" ocupa el mismo lugar secundario de Eva. El demonio tienta su orgullo de dueño y señor de la llanura. Él, estimulado por la presencia de ${ }_{15}$ la morocha, acepta el reto, y es vencido. El demonio lo desaloja de sus dominios. El ombú hace, aunque imperfectamente, el papel del árbol de la ciencia y del bien y del mal. Lo cierto es que la ciencia vencedora, el arte del de20 monio, se identifica al mal, contraponiéndola al bien, al arte espontáneo, a la inspiración del payador que viene de Dios. Así, aunque traidoramente vencido por sobrehumanas fuerzas, y quizá por su misma derrota tan trágicamente humana, Santos ${ }_{25}$ Vega queda triunfante en el alma del pueblo, y su sombra ha de verse pasar a la distancia mientras exista un palmo de tierra argentina.

6. la doctrina biblica del Génesis, i.e., the downfall of man.

13. su orgullo, i.e., the pride of Santos Vega. 


\section{LA TRADICIÓN DE LUCÍA MIRANDA \\ C. O. Bunge}

Apenas descubierto el estuario que se llamaría más tarde río de La Plata, sin dejarse intimidar por la trágica muerte de su glorioso descubridor, don Juan Díaz de Solís, remontó en I 526 sus majestuosas aguas don Sebastián Gaboto, marino vene- 5 ciano al servicio de España. Penetrando por primera vez en el río Paraná, fundó, en la desembocadura del río Carcarañá, sobre su margen izquierda, el fuerte del Espíritu Santo. Clavada allí la bandera de Castilla, dejó el fuerte a cargo ro de su guarnición, subió hasta las cataratas del Iguazú, y luego, por diversas circunstancias regresó a España.

4. Juan Díaz de Solís, a famous Spanish explorer of the sixteenth century who discovered the Río de la Plata, in 1516 , and called it Mar Dulce, thinking he had discovered a sea. Landing on the island of Martín Garcia, he was killed by the Charrúa Indians, a very warlike tribe that occupied the Plata basin.

5. Sebastian Gaboto. The name Cabot is usually connected with Newfoundland, but it has historical importance for Argentina also. Sebastian was the son of the wellknown North American explorer, John Cabot. He explored the Plata and Paraná rivers during the reign of Charles V. 


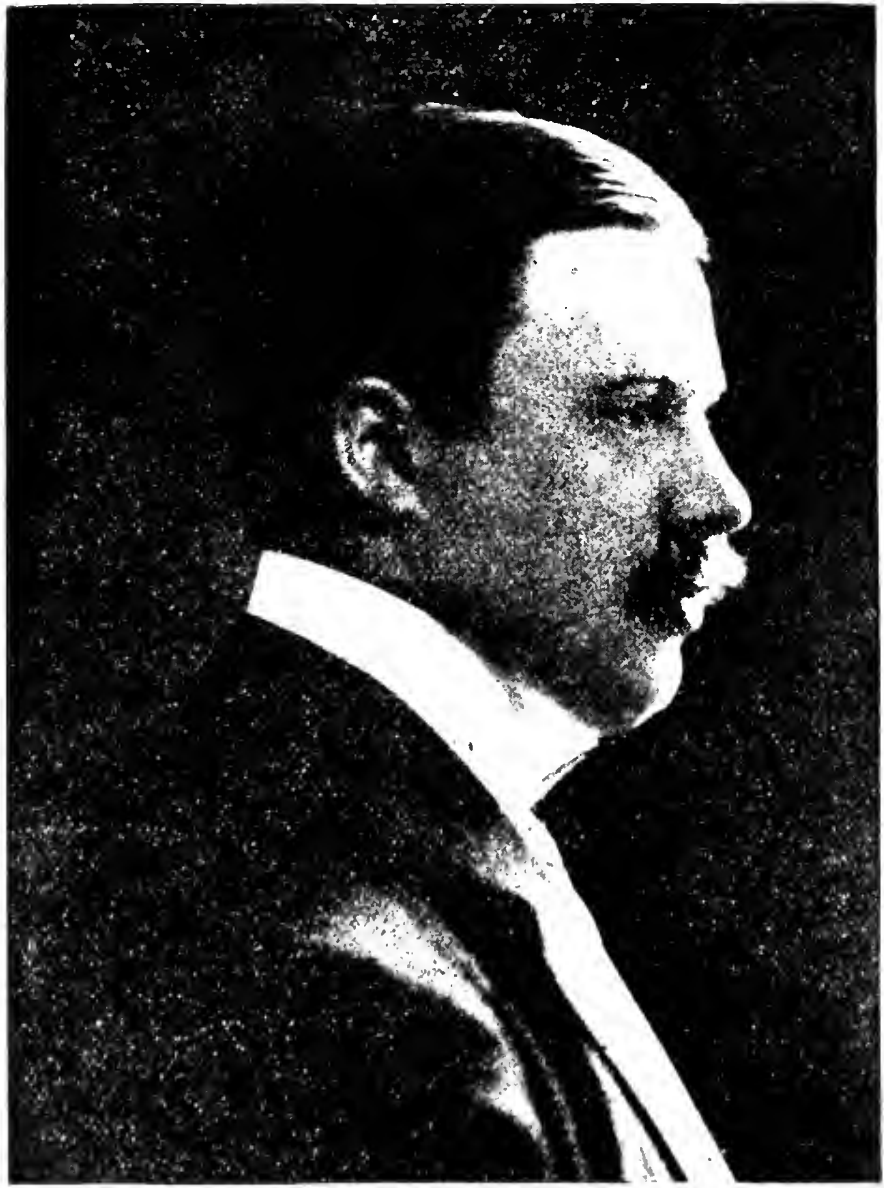

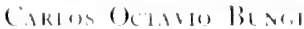


Dos años habían pasado desde la partida de Gaboto, y el fuerte del Espíritu Santo conservaba su paz inalterable. Gobernábalo un hombre de distinguido mérito, don Nuño de Lara, en quien delegó Gaboto el mando. Una severa disciplina, 5 sostenida por el ejemplo, quitaba a los suyos toda ocasión de desmandarse. Por su propia seguridad, los españoles mantenían pacífico trato con una vecina tribu de indios, los timbúes. La buena inteligencia y los oficios de la cordialidad más ro expresiva apretaban de día en día los nudos de esa útil alianza.

Había entre los españoles una dama, Lucía Miranda, mujer del soldado Sebastián Hurtado. El cacique de los timbúes, Mangoré, prendado de 15 su belleza, olvidó que era casada y resolvió hacerla su esposa. Decidido a robarla, preparó una horrible traición. Aprovechando una oportunidad en que salieron del fuerte, para procurarse víveres, buena parte de sus pobladores, al mando de uno 20 de los capitanes, presèntóse como amigo, seguido de treinta indios cargados de subsistencias. Esperaba afuera sus órdenes, escondido en la maleza y bien adoctrinado, su hermano Siripo, al mando de numerosa horda.

Sin sospechar los ocultos designios del cacique, recibió el donativo muy atento $y$ agradecido don Nuño de Lara. Con su castellana generosidad,

6. suyos, i.e., los hombres de don Nuño de Larą. 
acogió a Mangoré y a su séquito bajo su mismo techo. Obsequióles con un espléndido festín, brindando confundidos españoles e indios al dios de la amistad. Cuando terminó el festín recogié5 ronse a dormir unos y otros. El sueño rindió a los españoles. Y, entrada ya la noche, en el silencio y las sombras, Mangoré cambió sigilosamente sus señas y contraseñas con su hermano Siripo; hizo prender fuego a la sala de armas y abrió las puertas ro del fuerte. De común acuerdo, los indios de Mangoré y de Siripo cayeron sobre los españoles dormidos. Algunos de éstos lograron sus armas, trabándose en combate siniestro. Con increible valor, Lara repartía en cada golpe muchas muertes. ${ }_{15}$ En medio de la refriega buscó y encontró al fin a Mangoré. Aunque con una flecha en el costado, abrióse paso entre la confusa multitud hasta que pudo herir al traidor. La flecha, entretanto, con el movimiento y la lucha, habíale penetrado zo hondamente. Ambos, el cacique indio y el denodado capitán castellano, cayeron muertos. Sólo escaparon con vida del desastre algunos niños y mujeres, entre ellas Lucía Miranda, su inocente causa. Todos fueron llevados a presencia de ${ }_{25}$ Siripo, sucesor del detestable Mangoré, quien los guardó cautivos.

Al siguiente día volvió al fuerte Sebastián

3. brindando ... amistad, in which Spaniards and Indians, mingling freely, drank to the god of friendship.

6. entrada ya la noche, when night had already fallen. 
Hurtado. Su dolor fué igual a su sorpresa, cuando, después de encontrarse con ruinas en vez del baluarte, buscaba a su consorte y sólo hallaba despojos de la muerte. Luego que supo su cautividad, no dudó un punto entre los extremos de morir $\mathrm{O}_{5}$ rescatarla. Precipitadamente se escapó de los suyos y llegó hasta la presencia de Siripo. Pero este bárbaro, habiendo muerto Mangoré, cacique él ahora de los timbúes, olvidóse como su finado hermano que Lucía era casada, y aspiraba a su ro vez a tomarla por esposa. Ya que se le presentaba tan inopinadamente el legítimo marido, ardiendo en celos infernales, decidió matarlo. Comprendió la heroica mujer la suerte que esperaba a Hurtado, y, estimando más la vida de su marido que la pro- 15 pia, renunció al tono altivo con que antes contestaba los avances de Siripo, y tomó a sus pies el tono de la súplica y el llanto. De tal modo consiguió que el cacique revocara su sentencia de muerte y salvó la vida a Hurtado; mas con la 20 dura condición de que el soldado castellano se divorciase para siempre de Lucía y eligiera otra esposa entre las doncellas timbúes. Acaso por ganar partido en el corazón de la bella mujer blanca, que se mantenía firme en su resistencia a 25 aceptarlo por esposo, el cacique llegó a permitirles que se vieran de vez en cuando. No por eso

4. luego que supo su cautividad, as soon as he learned of her captivity.

26. llegó a permitirles, zuent so far as to permit them. 
consiguió el consentimiento de Lucía, que, como española y como cristiana, estaba resuelta a perder antes la existencia que la honra. Al contrario, en algunas de las breves entrevistas de los esposos, 5 pudo notar que ambos renovaban sus juramentos de conyugal fidelidad. Entonces su furia no tuvo límites. Hizo atar a Sebastián Hurtado a un árbol, donde se le mató a saetazos, y mandó arrojar a Lucía Miranda a una hoguera. Así, después de rolargo martirio y cautiverio, murieron ambos esposos, para eterno ejemplo de amor y de virtud.

Verdadera o fantástica, esta tradición ha perdurado en la mente de los habitantes del río de la Plata. Dos siglos y medio después de que ocurrió I5 o pudo ocurrir el épico y luctuoso suceso, servía él de argumento a una hermosa tragedia de corte clásico, en verso y tres actos, titulada Siripo. Su autor, el doctor Manuel José de Labardén, que nació en Buenos Aires en I754 y murió probable20 mente poco antes de la gloriosa revolución de i 8 Io, puede considerarse el más antiguo de los poetas cultos de la literatura argentina. Su obra, en sonoros hendecasílabos castellanos, representóse en el llamado Corral. Componíase este sitio, que ${ }_{25}$ hacía las veces de teatro, de un terreno rodeado

8. a saetazos, by arrow shots.

15. pudo. Translate as if it were hubiera podido.

24. Corral. As with the English stage the first theatrical performances in Argentina were produced in a courtyard, or open lot. 
de un cerco o muralla baja y algún rancho en el fondo, para guardar sus vituallas o adminículos. Una chispa de un cohete disparado en la iglesia de San Juan con motivo de celebrarse una fiesta religiosa, ocasionó un incendio que redujo a cenizas 5 el rancho. En el incendio se quemó el precioso manuscrito de la tragedia, conservándose sólo algunos largos fragmentos. Perdida la obra de Labardén, las sombras familiares y heroicas de Lucía Miranda, Sebastián Hurtado, Mangoré y 10 Siripo esperan, pues, el poeta que las cante en las nuevas generaciones de argentinos.

3. Una chispa ... rancho. Religious holidays in Catholic countries are often celebrated with display of fireworks, particularly St. John's day, June 24. 


\section{EL LUCERO DEL MANANTIAL}

Episodio de la Dictadura de don Juan Manuel Rosas

Manuela Gorriti

\section{María}

Era la hora en que calla el áspero relincho del potro salvaje; en que el " cucuyo" se adormece sobre el sinuoso tronco de los algarrobos, y en que el misterioso " pacui" comienza su lamentable ${ }_{5}$ canto. La luna alzaba su disco brillante tras los cardos de la inmensa llanura; y su argentado rayo, deslizándose entre el frondoso ramaje de los "ombús" y las góticas ojivas de la ventana, bañaba con ardor el dulce rostro de María.

ro ¡Viajeros del Plata! En vuestras lejanas excursiones en las campañas, ¿oísteis hablar de María? $\mathrm{Su}$ recuerdo vive todavía en las tradiciones del Sur. María era la flor más bella que acarició la brisa tibia de la Pampa. Alta y esbelta como el is junco azul de los arroyos, semejábale también en

4. "pacui". Quichua Indian name for owl, same as kacuy.

xx. ¿oísteis hablar de María? have you heard people speak of Mary? 
su elegante flexibilidad. Sombreaba su hermosa frente una espléndida cabellera que se extendía en negros espirales hasta la orla de su vestido. Sus ojos, en frecuente contemplación del cielo, habían robado a las estrellas su mágico fulgor; y 5 su voz dulce y melancólica como el postrer sonido del arpa, tenía inflecciones de entrañable ternura que conmovían el corazón como una caricia. Y cuando en el silencio de la noche se elevaba cantando las alabanzas del Señor, los pastores de los ro vecinos campos se prosternaban creyendo escuchar la voz de algún ángel extraviado en el espacio. El viajero que la divisaba a lo lejos pasar envuelta en su blanco velo de virgen a la luz del crepúsculo, bajo la sombra de los sauces, exclamaba: "iEs 15 una hada!" Pero los habitantes del " pago" respondían: "Es la hija del comandante, el Lucero del Manantial."

En los últimos confines de la frontera del Sur, cerca de la línea que separa a los salvajes de las 20 poblaciones cristianas, en el Pago del Manantial y entre los muros de un fuerte medio arruinado, habitaba María al lado de su padre, entre los soldados de la guarnición. El adusto veterano, antiguo compañero de Artigas, sólo desarrugaba el ceño 25 de su frente surcada de cicatrices para sonreír a su hija. Para aquellos hombres hostigados por frecuentes invasiones y cuyos rostros tostados por el sol de la Pampa expresaban las inquietudes de una perpetua alarma, era María una blanca es- 30 
trella que alegraba su vida derramando sobre ellos su luz consoladora.

Pero ella, que era la alegría de los otros, ¿̇por qué estaba triste? ¿Qué sombra había empañado el 5 cristal purísimo de su alma? La hora del dolor había sonado para ella, y María pensaba,... pensaba en su amor.

\section{Un Sueño}

Una noche vino a turbar una visión el plácido sueño de la virgen. Vió un vasto campo cubierto ro de tumbas medio abiertas y sembrado de cadáveres degollados. De todos aquellos cuellos divididos manaban arroyos de sangre que, uniéndose en un profundo cauce, formaban un río cuyas rojas ondas murmuraban lúgubres gemidos y se ensan${ }_{15}$ chaban y subían como una inmensa marea. Entre el vapor mefítico de sus orillas $y$ hollando con planta segura el sangriento rostro de los muertos, paseábase un hombre cuyo brazo desnudo blandía un puñal.

20 Aquel hombre era bello; pero con una belleza sombría como la del arcángel maldito; y en sus ojos azules como el cielo, brillaban relámpagos siniestros que helaban de miedo. Y, sin embargo, una atracción irresistible arrastró a María hacia 25 aquel hombre y la hizo caer en sus brazos. Y él, envolviéndola en su sombría mirada, albrasó sus labios con un beso de fuego, y sonriendo diabólicamente rasgóla el pecho y la arrancó el 
corazón, que arrojó palpitante en tierra para partirlo con su puñal. Pero ella, presa de un dolor sin nombre, se echó a sus pies y abrazó sus rodillas con angustia. En ese momento se oyó una detonación, y María, dando un grito se 5 despertó.

\section{El Encuentro}

- ¡ Era un sueño! - exclamó palpando su pecho virginal, agitado todavía por los tumultuosos latidos de su corazón. - i Era un sueño!

Y pasando la mano por su frente para alejar las 10 últimas sombras del terrible sueño, María saltó del lecho, vistió sus ropas de fiesta, trenzó con flores su larga cabellera, y sentada gallardamente sobre el lustroso lomo de un brioso alazán, dióse gozosa a correr por los frescos oasis, sembrados 15 como una vía láctea en las inmensas llanuras del Sur.

De repente el fogoso potro robado a las numerosas manadas de los salvajes, aspirando con rabioso deleite las magnéticas emanaciones que el viento 20 traía de su agreste patria, sacudió su larga crin, mordió el freno, y burlando la débil mano que lo regía, partió veloz como una flecha, saltando zanjas y bebiendo el espacio. María, pálida de espanto, vióse arrebatar lejos del límite cristiano 25 al través de las complicadas sendas que trillan los bárbaros con el afilado casco de sus corceles; y su terror crecía a la vista de un bosque negro que 
terminaba el horizonte, $y$ entre cuyo ramaje el miedo dibujaba sombras confusas que se agitaban.

De improviso vibró en el aire un silbido extraño, semejante al chillido de un águila, y el caballo ${ }_{5}$ embolado por una mano invisible se abatió sobre sí mismo a tiempo que la joven se deslizaba al suelo sin sentido. Al volver en sí, se encontró reclinada en los brazos de un hombre $\mathrm{y}^{\circ}$ con la mejilla apoyada en su pecho. Ese hombre era sin roduda quien la había salvado; y María, separándose de sus brazos, alzó hacia él una mirada de gratitud. El joven era bello; pero al verlo María dió un grito y volvió a caer exánime a los pies del incógnito.

${ }_{15}$ Aquel hermoso joven era el fantasma de su sangriento sueño.

\section{Amor y Agravio}

Ocho días más tarde María, velando inquieta, con el ó́do atento y la mirada fija, medio desnuda y oculta tras las vetustas ojivas, esperaba todas ${ }_{20}$ las noches a un hombre que, llegando cautelosamente al pie del ombú, asíase a sus ramas, escalaba la ventana y caía en sus brazos. Y la joven lo estrechaba en ellos con pasión; y apartándolo luego de sí, contemplábalo con delicia y votvía a ${ }_{25}$ arrojarse en sus brazos, exclamando: ¡ Manuel! ¡Manuel! por qué te amo tanto, a ti que no sé quién eres, a ti el terrible fantasma de mi sueño? $\mathrm{Y}$, sin embargo, quien quiera que seas, vengas del 
cielo o del abismo, y, aunque despedaces mi pecho y me arranques el corazón, i te amo! i te amo!

Y María deliraba de amor, hasta que la luz del alba le arrebataba a su amante que, deslizándose furtivamente entre el obscuro ramaje, se desvanecía 5 con las sombras.

Pero una vez María lo esperó en vano. Y desde entonces, cada noche, sola y con el corazón palpitante de dolorosa ansiedad, vió pasar sobre su cabeza y perderse en el horizonte todos los astros ro del cielo, sin que aquél que alumbraba su alma volviera a aparecer jamás.

Por ese tiempo, la antorcha de la guerra civil abrasó aquellas comarcas, y el fragor del cañón homicida ahogó las risas y los gemidos.

\section{Dieciséis Años Después}

En las últimas horas de un día de verano, una silla de posta atravesó rápidamente las calles de Buenos Aires, y entró en el patio de una hermosa casa en la calle de la Victoria. Un hombre de porte distinguido que, asomado al balcón, parecía 20 esperar con impaciencia, bajó presuroso, y adelantándose al cochero, corrió a abrir la portezuela del carruaje, tendiendo los brazos a una bellisima mujer que se arrojó a su cuello : ¡ Mi amada María! - ¡Amigo mío! - exclamaron ambos a la vez 25 estrechándose con ternura.

20. asomado, appearing or looking out. 
- ¿Y mi hijo?. . . ¿ Mi Enrique?-dijo de pronto la dama arrancándose de los brazos de su marido y tendiendo en torno una codiciosa mirada.

- Nuestro hijo, respondió él haciéndola entrar ${ }_{5}$ en un magnífico salón, - nuestro hijo, - amada mía, se halla en esta hora en el momento más solemne de su vida escolar: da un brillante examen. Acabo de dejarlo triplemente coronado; pero el premio más grato será el beso de su madre.

so -iQuerido niño! ¿Es tan bello como a los doce años? ¡Oh! . ¡ ¡Alberto! . . ¡ Perdón!

- ¿Perdón? ¿Y de qué ?, amada María. ¿De ser una buena madre como eres una buena esposa? ¡Al contrario!, gracias por el amor que guardas is para ese hijo cuya ternura ha alumbrado los tristes días de tu ausencia en los cinco años que me has dejado aquí sólo. ¡Ah! ¿Qué placer encontrabas en habitar Córdoba, lejos de tu hijo.. . lejos de tu esposo?

Alberto, noble y generoso corazón! exclamó ella doblando una rodilla ante su marido.

Alberto la alzó en sus brazos: ¡Todavía esa injusta timidez! ¡Todavía esos importunos recuerdos! Me habéis prometido desecharlos y 25 ser feliz.

24. me habéis prometido. The pronoun understood is vos, equivalent here to tú. This usage is very common in Argentina. From a very dignified form of address, employed as a rule in addressing kings, it has come to be used in Argentina as the most familiar and colloquial form of address. 
- Y soy dichosa, amigo mío. ¿Quién no lo sería cerca de ti? Pero, a medida que el tiempo pasa, la audaz confianza de la juventud desaparece, reemplazándola medrosos recelos. ¿ Será falta de fe? No, pues yo creo en ti como en el Dios del 5 cielo; pero mientras más grande, mientras más sublime me aparecías, menos digna me encontraba de acercarme a ti, y lo que tú llamas obstinación era un doloroso ostracismo.

-_Pobre María! ¿Que nunca te oiga hablar ı así! inunca! Te lo pido en nombre de tu hijo. Toca este corazón; es tu más firme apoyo. Reposa confiada sobre él, pues sólo alienta para ti.

— ¡Oh! ¡Dios núo!- dijo ella reclinándose en el seno de su marido, y elevando al cielo una mirada 15 de gratitud. - i Dios mío!, bendito seas porque has enviado al mundo degenerado que te reniega, estos seres de paz, de indulgencia y de amor para redimir su iniquidad y hacernos creer que en verdad formaste al hombre a tu divina imagen. 20 Dieciséis años han pasado, dieciséis años . . . y en cada uno de esos días, en cada una de esas horas ví brotar en ese corazón, elevarse y resplandecer, alguna nueva virtud. Dieciséis años hace encon-

4. Será, trans., Can it be? Note use of the future to denote probability or possibility.

6. pero mientras más grande, mientras más sublime . . ., menos digna . . ., but the greater, the more sublime . . ., the less worthy....

13. confiada, trusting or in confidence. 
tréme un día abandonada, sola entre mi dolor y un secreto terrible. La muerte era mi único recurso; pero yo no podía morir. Junto a mi corazón desgarrado palpitaba otro corazón que 5 me pedía la vida y me encadenaba a una existencia de oprobio. Tú me apareciste entonces, Alberto. - Te amo, me dijiste, y mi amor ha penetrado el secreto de tu dolor. ¿Quieres confiarte en mí? Yo seré tu esposo, tu amigo, ro y..., me dijiste al oído, el padre de tu hijo.

- ¡Y bien! ¡Y bien!- la interrumpió Alberto, con esa brusca genialidad de las almas generosas, para velar su grandeza. - ¡Vaya un gran mérito! ${ }_{5}$ i Cumplir con una misión que nos haga feliz! Desgraciadamente, amada mía, no siempre es tan fácil conciliar el deber con la felicidad. Hoy, por ejemplo, colocado entre el amor y la conciencia, voy a sacrificar al deber la dulce costumbre de una anti20 gua amistad. Yo que hasta ahora he sostenido a mi amigo con todos los recursos de mi influencia, voy a enarbolar contra él el estandarte de la oposición; y el cuerpo legislativo, que actualmente presido, me verá con asombro alzarme contra el 25 voto que pretende dar a Rosas la facultad de reunir todos los poderes del Estado.

A estas palabras de su esposo, María palideció.

14. I Vaya un gran mérito! Well, that is indeed a great virtue! 
- ¡Oh! ¡Alberto!- dijo, estrechando su mano con terror, - en nombre del cielo no toques la garra del tigre porque te despedazará!. . . Te despedazará y hará de tu cadáver una grada más para escalar la cima del poder.

- Y bien, amiga mía, moriría con la muerte de los buenos en el cumplimiento del deber. Pero tranquilízate, amada María; Rosas tiene un alma capaz de comprender mi sacrificio y me conservará su estimación, aunque me haya quitado su amistad. 1o

En ese momento un ujier anunció a Alberto que la cámara reunida esperaba a su presidente para discutir la importante cuestión del día. Alberto despidió al ujier y volvió hacia su mujer una mirada de ternura.

- ¿Lo veis, querida mía? - le dijo, - mi sacrificio comienza desde ahora. Apenas he tenido tiempo de posar mis ojos en tu semblante, la voz del deber me llama lejos de tí; y aunque sea por muy pocas horas, toda separación en este momento 20 me parece eterna.

Alberto se interrumpió. Habríase dicho que sus palabras encontraron algún eco misterioso en el fondo de su alma. Pero reponiéndose luego dijo a su esposa sonriendo:- Te dejo, amiga mía; 25 pero voy a enviarte a Enrique y él desvanecerá para siempre esos importunos recuerdos que turban todavía la paz de tu alma.

I2. cámara, i.e., de diputados, chamber of deputies. 
Y besando tiernamente la mano que ella le tendía, salió no sin volverse muchas veces para contemplarla.

\section{Madre e Hijo}

Cuando la dama quedó sola alzó los ojos al cielo 5 con dolorosa expresión. - ¡ Jamás!- exclamó, ¡Jamás!. . ¡Nunca se borrará esa imagen que encuentro siempre en el horizonte de mis recuerdos, en el semblante de mi hijo y en mi propio corazón! ¡He ahí esa frente altiva y meditabunda! ¡He ı ahí esos rasgados ojos azules de tan sombría y sin embargo tan hermosa mirada!... ¡Manuel! ¿ Manuel!

La puerta se abrió con estrépito, y un hermoso mancebo de dieciséis años, de porte arrogante y ${ }_{5}$ risueña expresión, se precipitó en la sala y corrió a arrojarse en los brazos de la dama que lo estrechó en ellos sollozando y besó mil veces sus mejillas y su frente.

- iQué hermosa eres, mamá! - decía el joven, 2o contemplando extasiado el radioso semblante de su madre. - Aunque tenía muy presentes las facciones de tu rostro, no creía que fueras tan bella. ¡Bendición del cielo! ¡Dejar la fría atmósfera del colegio para venir a contemplar los rayos de este ${ }_{25}$ bello sol que da vida a mi vida y calor a mi alma!

23. i Bendición del cielo! Thank héaren!

23. i Dejar la fría...! The infinitive is used elliptically with exclamatory force: trans., Ithat a joy to leate . . ! 
— ¡Poeta! ¡Poeta!--decía ella, sonriendo tiernamente a su hijo y meciéndolo como un niño en sus rodillas. - Me está recitando un madrigal.

- A propósito, - dijo el joven dejando su actitud de abandono y sentándose al lado de su madre. 5 - Manuela Rosas me envió su álbum pidiéndome un soneto. ¡Y lo había olvidado! iYa! la veo tan pocas veces. $Y$ no porque ella no sea una criatura amabilísima; pero me aleja de su lado el extraño sentimiento que me inspira su padre. so Llamaríalo odio si su amistad con la mía no hicieran el odio imposible.

- Todavía no conozco a ese hombre, y sin embargo me estremezco cuando oigo pronunciar su nombre; y no comprendo como el noble y bonda- 5 doso corazón de Alberto ha podido unirse a ese corazón feroz y sanguinario.

- Esta misma adhesión, madre mía, realza más la magnanimidad de ese corazón generoso, porque está exento de debilidad. Severa con el amigo, 20 jamás transigirá con el tirano.

— ¡Ay! sí, es verdad ... pero heme aquí estremecida de espanto a la idea de esa austera integridad que en este momento subleva quizá contra él en la cámara legislativa el bando entero del despotismo. 25

6. Manuela Rosas. The daughter of the Dictator Juan Manuel Rosas.

II. si su amistad con la mia, if her friendship toward me.

23. de esa austera integridad, i.e., de Alberto.

24. contra él, i.e., Alberto. 
- ¡Qué ! - exclamó el joven con los ojos centelleantes de entusiasmo, es hoy el día de su triunfo, y aun no estoy en la barra para aplaudirlo con la voz y con el alma.

5 Y besando rápidamente a su madre, desasióse de su convulsivo brazo y partió.

\section{En la Sala de Representantes}

En ese día la sala de representantes de Buenos Aires presenció una escena digna de los mejores tiempos de la Roma heroica. Rosas, armado con ro la clave del terror, habiendo impuesto silencio al pueblo, y hecho también callar al cuerpo legislativo, quiso dar el último golpe a la dignidad nacional, y aspiró a la dictadura. Aspirar en él era mandar; y un día oyóse la sacrílega proposición is en el santuario de las leyes. Ninguna voz se alzó para combatirla. Cada representante veía en el semblante de su vecino el triunfo del miedo sobre la conciencia, y si llevaba su mirada a lo alto de la sala encontraba bajo el dosel que la zodominaba al amigo, al confidente de Rosas ... y callaba.

El presidente invitó a sus colegas a dar sus votos, ordenando que los que estuvieran por la proposición, se pusieran en pie; y con rostro apacible dió 25 la señal. Dos hombres ínicamente votaron en contra. El uno era Escalada, el inmaculado obispo

18. a lo alto de la sala, i.e., the speaker's platform. 
de la metrópoli. El otro era . . el presidente de la sala, el amigo de Rosas.

Hubo un momento de asombro y silencio: pero cuando la barra arrebatada de entusiasmo prorrumpió en una tempestad de aplausos, cuatro 5 hombres enmascarados precipitáronse en la sala, y mientras tres de ellos rodearon la mesa del presidente, el cuarto hundió un puñal en el corazón de Alberto y huyó dejándolo clavado en el seno de su víctima.

Entonces en medio del silencio de horror que reinó en aquel recinto, oyóse la voz del anciano obispo, que, de pie aún, dijo alzando sobre el moribundo su mano venerable:- ¡Sube al cielo, mártir de la libertad argentina! Yo te absuelvo en nom- 5 bre de Dios y de la patria. - Y como si la noble alma de Alberto hubiera esperado aquella sublime bendición, exhalóse dulcemente en una triste sonrisa.

En aquel momento Enrique que entraba en el 20 peristilo de la sala de sesiones, fué atropellado por cuatro hombres que huían desolados entre las sombras. El intrépido niño, conociendo por sus máscaras que acababan de cometer un crimen, asió al que iba delante; pero éste por medio de un 25 violento esfuerzo logró escaparse, aunque dejando en las manos de su adversario la máscara que lo cubría. Al ver el rostro de aquel hombre el joven

22. desolados, panic-stricken. 
dió un gritó, y se precipitó en la sala. A la vista del cadáver de su padre, Enrique se detuvo un momento, inmóvil, mudo, con los puños cerrados y la mirada fija. Luego, cayendo de rodillas, arrancó ${ }_{5}$ de su pecho el puñal homicida, y besando la herida con siniestra serenidad, - i Adiós, padre mío!dijo estrechando la mano helada del muerto,muy luego me reuniré contigo; pero entonces te habré vengado.

1. Guardó en su seno el arma ensangrentada y se alejó con firmes pasos.

\section{E1 Terrible Drama}

La luz del siguiente día encontró en las calles de Buenos Aires numerosas huellas de escenas semejantes a la que turo lugar en la noche anterior en ${ }_{5}$ la sala de representantes. Un puñal había amenazado la vida de Rosas; aunque se había arrestado al delincuente, no habiendo podido arrancarle confesión alguna, había sacrificado indistintamente a todas personas sospechosas de complicidad en 20 aquel atentado.

A dos leguas de distancia, al frente del palacio dictatorial de Palermo, un destacamento de infantería acababa de hacer alto. Sonó el tambor Y aquella fuerza se formó en cuadro. Vióse en25 tonces en el centro del siniestro vacio un joven

22. Palermo, a suburb of Buenos lires. 
como Isaac, y maniatado como él, y en frente cuatro soldados que a la voz de un oficial preparaban sus armas.

Pero, cuando los fatales fusiles se inclinaron sobre él, cuando con la frente erguida y la mirada 5 serena el noble mancebo esperaba la muerte, oyóse un grito de suprema angustia y una mujer pálida, anhelante, desmelenada, rompiendo con esfuerzo febril la línea de bayonetas que le cerraba el paso, se arrojó de repente sobre el joven y estrechándolo ro en un abrazo desesperado lo cubrió con todo su cuerpo. Los soldados, vivamente conmovidos, volviéronse hacia el oficial que los mandaba. Pero éste que sentía pesar sobre sí una terrible responsabilidad, ahogando su profunda emoción, mandó ${ }_{15}$ apartar a la madre y conducirla fuera del cuadro. - i Ah!-_exclamó ella arrancándose de los brazos de su hijo y cayendo a los pies del oficial. Dadme al menos por lo que más améis en este mundo, dadme un cuarto de hora que necesito 20 para obtener la gracia de mi hijo, o morir.

El veterano sonrió tristemente:- Id, pobre madre, id - dijo siguiéndola con una mirada de compasión.

- En nombre de esta hora suprema, - gritó ${ }_{25}$ el niño, - yo os lo prohibo, madre mía. No pidáis gracia al asesino de vuestro esposo, o vuestro hijo os maldecirá desde la eternidad.

I. como Isaac. Reference to the sacrifice of Isaac. Cf. Genesis 22: 9 . 
Mas ella sin escucharlo corrió desolada hacia el palacio. Atravesó, sin que nadie pudiera detenerla, los patios, los vestíbulos, las galerías y los salones, preguntando a su paso por aquél de quien esperaba ${ }_{5}$ la muerte o la vida. Un edecán entreabrió un gabinete y la mostró un hombre que apoyado en una mesa ocultaba su rostro entre las manos. La desventurada, precipitándose en el cuarto, fué a caer a sus pies. Pero al mirar a aquel hombre ro el ruego se le heló en su labio pálido que se movió sin articular sonido alguno.

En ese momento sonó una detonación. La infeliz madre cayó sin sentido gritando:-i Manuel! ¡Manuel! ¿Qué has hecho de tu hijo?...

\section{Conclusión}

I5 Mucho tiempo hacía que el antiguo fuerte de la Pampa era ya sólo un montón de escombros ennegrecidos por el humo del incendio. Los indios en una salida lo habían quemado, asesinando al viejo comandante con toda la guarnición. Desde zo entonces el doble silencio de la muerte y del abandono reinó en torno de aquellos muros, y el terror supersticioso que inspiraban las ruinas apartó de allí los pasos del viajero.

Sin embargo, una noche, al alzarse la luna sobre 25 el horizonte, los habitantes del " pago" vieron una

I. desolada, grief-stricken.

6. la mostró. The commoner usage (so also I00, 28, rasgóla) is le. 
mujer pálida, enflaquecida y arrastrando negros cendales, que atrevesó gimiendo las avenidas de sauces y se perdió entre las desmoronadas murallas del fuerte.

Algunos la tuvieron por una aparición; pero 5 otros creyeron conocer en ella a María, la hija del viejo comandante, el bello Lucero del Manantial.

Lima, agosto de 1860 . 


\section{LOS 3000 PESOS DE DORREGO}

\section{O. Bunge}

Era en el año nefasto de I 820, el año de agudísima crisis, revolucionaria más bien que política. En la provincia de Buenos Aires cambiábase cada día, puede decirse, de gobernador. Siendo 5 gobernador el señor Ramos Mejía, partidario del directorio, el general Soler, enemigo del sistema, habíale depuesto, asumiendo el mando. Retiróse luego el nuevo gobernador al campamento de Luján, donde estableció su sede. Dejaba en Buenos ro Aires, como su lugarteniente, en el cargo de comandante general de armas, al coronel Dorrego. $Y$ para concluir con los unitarios, puso a precio las cabezas de los principales representantes del régimen directorial.

15 Entre ellos se contaba el doctor Tagle, cuya persona se tasó en 3000 pesos. Espíritu inquieto y combatiente, habiase arriesgado a venir de su voluntario ostracismo en el Uruguay a la misma ciudad de Buenos Aires. Ocultábase en la casa zode un amigo, el señor Marín. Su situación era

9. Luján. 'Y. måp. 
harto peligrosa, pudiendo ser reconocido $y$ denunciado en cualquier momento, hasta por la servidumbre. Además, agravábase esa situación por su personal y mortal enemistad con el coronel Dorrego, a quien había insultado con la virulencia 5 de las pasiones políticas de aquel tiempo semibárbaro.

Temiendo una sorpresa trágica y fatal para su huésped, el señor Marín resolvió salvarle dando un paso audaz y decisivo. Conocía a Dorrego y о confiaba en su caballerosidad. Sin comunicar su proyecto al doctor Tagle, fué a ver al comandante general en el piso bajo del Cabildo, donde se hallaba. Amigo también de Dorrego, díjole, medio en serio y medio en broma: "Sé que estás en 15 apurada situación financiera y vengo a ofrecerte la oportunidad de ganar 3000 pesos." Como en efecto, por las continuas revoluciones y violencias, escaseaba el dinero, Dorrego contestó agradecido por el ofrecimiento. No disponía en ese instante 20 de un peso, ni propio ni del Estado, para pagar a las tropas. El señor Marín anuncióle entonces que tenía al doctor Tagle en su casa. Dorrego se limitó a responder: "Muy bien. Esta noche iré a buscarlo.'

1. pudiendo .. momento, since he might be recognized and denounced at any moment.

14. Amigo tambien, Being also a friend.

I9. contestó .. . ofrecimiento, replied expressing his thanks for the offer. 
Sin' cambiar más razones, el señor Marín se retiró. Aunque tuviera plena confianza en la lealtad de Dorrego, una duda vaga se apoderó de su espíritu. ¿Y si el comandante general, llevado al 5 mismo tiempo por el antagonismo político y la necesidad de dinero, entregaba al general Soler la cabeza del doctor Tagle? Los hombres más rectos tienen momentos de ofuscación; y entonces todos parecían ofuscados por la sangrienta lucha ro política. . .

De vuelta en su casa, el señor Marín se sentó a conversar y tomar mate con el doctor Tagle. Estaba distraído y preocupado. Notándolo su huésped, le preguntó la causa de sus cavilaciones. ${ }_{1}$ No pudo callar por más tiémpo el señor Marín, y le enteró de su diligencia. Pálido como un muerto, el doctor Tagle exclamó : "Estoy perdido."

Quiso huir en ese momento ; pero como era su proyecto harto imprudente, el señor Marín le detuvo zo en su casa. Librado a la hidalguía de Dorrego, corría alguna probabilidad de salvarse; de otro modo, su pérdida era segura.

No tuvieron tiempo para deliberar largamente, porque apenas anocheciera presentóse el coronel ${ }_{25}$ Dorrego en la casa del señor Marín. “Aquí está el doctor "Tagle", dijo, y entró seguido de su ordenanza. Más muerto que vivo, presentóse el doctor' 'Tagle. Dorrego tomó un capote de manos

11. De vuelta en su casa, then he had returned home. 
de su ordenanza, y le dijo: "Póngaselo." El doctor se lo puso. En la puerta había dos caballos ensillados, el del coronel y el del ordenanza. Montando en el suyo, Dorrego dijo al doctor Tagle: "Monte a caballo y véngase conmigo." $\mathrm{Y}$ el 5 doctor Tagle montó en el caballo del ordenanza, convencido ya de que sólo le esperaban cuatro tiros.

A galope tendido cruzaron la ciudad de Sur a Norte. Llegaron, en la noche cerrada, al bajo de Palermo. En la orilla del río les esperaba una ıo embarcación a vela, aparejada para partir. "Embárquese y póngase en salvo en la Colonia”, ordenó Dorrego a su acompañante. Conmovido por su grandeza de alma, el doctor Tagle le observó: "Yo he sido y soy su enemigo, coronel." - "En 15 el campo de batalla", contestó Dorrego, " no hubiera vacilado en matarle; aquí, sólo un mal caballero podría aprovecharse de haberle hallado huído e indefenso." El doctor Tagle insistió: “Pierde usted, coronel, 3000 pesos que necesita." 20 Y el coronel Dorrego, montando de nuevo a caballo y despidiéndose, repuso con sencillez: "Todo el oro del mundo no bastaría para comprar la lealtad de un militar argentino."

12. póngase en salvo, take refuge.

12. Colonia, city in Uruguay. V. map. 


\section{CUMPLIR LA CONSIGNA}

\section{O. Bunge (Según Juan M. Espora)}

Inspeccionando una mañana el campamento de Mendoza, San Martín se detuvo ante una puerta cerrada y revestida de pieles de carnero con la lana para afuera. . . Custodiábala un censtinela. “ ‘Q Qué es esto?," preguntó a los sargentos que le acompañaban. - "El laboratorio de los mixtos", le respondieron. - " " Se trabaja ahora?" - "Sí, señor. Se están haciendo cartuchos, lanzafuegos, estopines, espoletas para rogranadas y otras municiones." - Sin averiguar más, dirigióse allí el general en actitud de entrar. “¡Alto ahí!", exclamó el centinela, poniéndosele delante. “No se puede entrar." A esta observación, San Martín le preguntó con vehemencia : ${ }_{15}$ "“Cómo es eso ? : No me conoces ?" — "Sí, señor, lo conozco; pero así no se puede entrar", repitió el soldado, refiriéndose al traje militar que vestía el general, con botas herradas y pesadas espuelas. Volvió a insinuar San Martín su ademán de abrir

2. Mendoza. San Marrin made ready his army in this renvince prior to the invasion of Chile. V. map.

7. ¿Se trabaja ahora? Are they storking now'? 
la puerta. El centinela caló entonces la bayoneta, y repitió de nuevo: "Ya he dicho, mi general, que así no se puede entrar." Y gritó con fuerza : "¡Cabo de guardia! ¡ El general en jefe quiere forzar el puesto!" Al ver esto, uno de los sar- 5 gentos corrió al cuerpo de guardia a llamar al cabo. Llegó el cabo, y dijo al general: "Señor, el centinela tiene la consigna de no dejar pasar a nadie al laboratorio vestido de uniforme, para no ocasionar un incendio. $\mathrm{Si} \mathrm{mi}$ general quiere ı visitarlo, para hacerlo en la forma permitida, sírvase pasar antes a ese otro cuarto y mudarse la ropa." Nada respondió el general, entró en el cuarto indicado, quitóse el uniforme, y se puso un par de alpargatas y saco y gorro de $\mathrm{I}_{5}$ brin. Luego visitó el laboratorio e inspeccionó sus trabajos. Cuando se retiraba, habiéndose vestido de nuevo el uniforme, pasó por el cuerpo de guardia y ordenó que, después de relevarse, se le mandara a su despacho al soldado que hacía de 20 centinela. Cumplió el soldado la orden y se presentó, temeroso de haber merecido una admonición. Pero al verle entrar, el general en jefe se puso de pie y le tendió la mano para felicitarle calurosamente. Al obedecer a su consigna había cum- ${ }_{2.5}$ plido su deber.

18. cuerpo de guardia, headquarters of the guard. 


\section{LA LEALTAD DE SAN MARTÍN -}

C. O. Bungf (Según Juan M. Espora)

Hallábase el general San Martín en el campamento de Mendoza. El edecán de servicio en la antesala de su tienda de campaña, entró un día en su escritorio, anunciándole:- "Un oficial pre5 gunta por el ciudadano don José de San Martín.” — "Hágale usted entrar." - Entró el oficial, ratificándose en que venía a ver al ciudadano, y no al general en jefe. - " Puede usted hablar", le dijo San Martín. - "Vengo a confiarme a usted rocomo un hijo a su padre", balbuceó el oficial. "Soy habilitado de mi cuerpo. Ayer recibí de la comisaría de guerra, para socorro de los oficiales y soldados, una suma de dinero. Llevábala a su destino, cuando entré por mi desgracia I5 a saludar a un oficial amigo mío que se halla enfermo. Varios compañeros estaban jugando a los naipes en su aposento. Me invitaron a acompañarles. Al principio rehusé. I, uego quise tentar la suerte. Resolví jugar la pequeña suma

2. de servicio, on duty.

7. ratificándose en que, reiterating that. 
que me correspondía como oficial de la cantidad total que me fuera entregada. Como debo al sastre, a la lavandera y a varios proveedores, no pudiendo pagar mis deudas con esa pequeña suma, ocurrióseme que, si lograba duplicarla $o_{5}$ triplicarla, saldría de apuros. El caso es que la perdí. Ofuscado por el golpe, quiero reponer la pérdida, juego de nuevo, y vuelvo a perder. . . . En fin, arriesgué todo lo que llevaba, y i lo perdí todo!... He pasado la noche vagando por los alrededores del campamento como un loco. Estoy deshonrado. i Ruégole, señor, que se apiade de mi situación y salve mi honor! Yo le pagaré después como pueda, aunque sea sirviéndole de criado. ¡ Lo que no quiero es que no se me ajusticie 15 como ladrón, y llegue luego la noticia a mi pobre madre!..." El general San Martín le contestó, después de una pausa: "Como general estaría obligado a hacerle enjuiciar ante el consejo de guerra. . . Pero usted se ha confiado a mi 20 lealtad y me promete enmendarse. . . ." Y tiró una gaveta de su escritorio, sacó en onzas de oro de su propio peculio la suma que el oficial le pedía, y, al entregársela, le dijo: "Vaya usted y en el acto entregue ese dinero en la caja de su $_{23}$ cuerpo. iQue en su vida se vuelva a repetir un

15. es que no. The no is redundant; omit it in translating.

26. i Que ... semejante! Never let such an occurrence happen again in your life! 
pasaje semejante!.. Y , sobre todo, guarde usted en el más profundo secreto el asunto de esta entrevista, porque si alguna vez el general San Martín llega a saber que usted ha revelado 5 algo de lo ocurrido, en el acto le manda fusilar." 


\section{LAVALLE EN RÍO BAMBA \\ Pedro Lacasa}

El combate de Río Bamba es el choque de caballería más lucido que haya tenido lugar en la guerra de nuestra emancipación, y el que ha revelado también a más alto grado el renombre de bravo que llevaba el ejército de los Andes, en los 5 gloriosos tiempos que dejamos a la espalda. En él se vió al intrépido Lavalle con 96 granaderos arrollar cuatro escuadrones, fuertes cada uno de I 20 hombres, de las mejores tropas del Rey, hasta meterlos a sablazos bajo los fuegos de la ro infantería, habiendo pasado antes por la villa de Río Bamba, que estaba interpuesta entre los dos ejércitos, para desafiar a la caballería enemiga. Esta con la intención de alejarlo de toda protección, no salía de la pequeña planicie que está al 15 pie de las alturas que coronan aquel pueblo, y a

I. Río Bamba, city in Ecuador. V. map.

7. Lavalle (Juan, $1794^{-1841}$ ), one of the heroes of the war of independence.

ro. bajo los fuegos de la infanteria, under the protection of the (Spanish) infantry fire.

II. habiendo pasado. The subject is Lavalle. 
las cuales quería atraer al general Sucre el jefe español, para batirlo con ventaja.

La posición de Lavalle, en ese día, era tanto más conspicua, cuanto que estaba peleando por primera

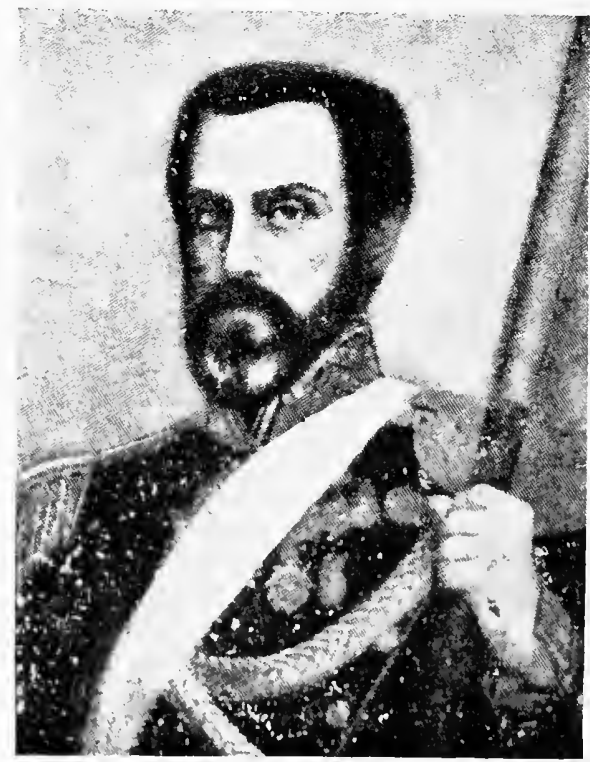

Navirro y Lamarca, IIistoria general de América

$$
\text { JUAN Lavalie }
$$

5 vez con una fuerza cuatro veces mayor que la suya, en presencia de los orgullosos soldados de Colombia, y contra la voluntad del general en

I. Sucre. V. 239,14 . 
jefe, que en esos momentos lo acusaba de imprudente, por haber comprometido un choque en que tenía que combatir uno contra cinco, y del cual, según él, no podía salir victorioso. En prueba de lo que dejamos dicho, citaremos las 5 palabras que el coronel Ibarra, sobrino del libertador Bolívar, dirigió al general Sucre en aquellos momentos supremos, y sus contestaciones, sacadas de los apuntes del coronel del ejército de los Andes, don Juan Espinosa, publicadas en el Correo ıo Peruano del 23 de mayo de i 846 . Después de la primera carga que Lavalle dió a los españoles, y en la cual llegó hasta tiro y medio de fusil, los granaderos se retiraron al tranco. Entonces el general enemigo organizó los cuatro escuadrones que is habían sido acuchillados momentos antes, y los hizo cargar poniéndose él mismo a la cabeza. Lavalle, cuando estaban a cien pasos a su retaguardia, volvió caras por pelotones, y cargó al centro de los cuatro escuadrones. En este 20 momento el general Sucre creyó perdidos a los granaderos por la imprudencia de su jefe, “y no quiso protegerlos", dice Espinosa, "por no comprometer una acción general para la cual no estaba preparado, y por ser mu avañada la hora”. $\mathrm{A}_{25}$ las repetidas instancias que le hicieron de proteger

5. dejamos dicho, we have said.

25. por ser. Note the difference in the use of por here and in line 23 where it means in order to; translate here, because the hour was. 
al escuadrón con alguna infantería, contestó: "El comandante Lavalle ha querido perderse, que se pierda solo." El coronel Ibarra, sobrino del Libertador $y$ un valiente de primera clase, sle dijo: "Mi general, déjeme V. S. ir con mis guías en protección de los granaderos, y yo le respondo del triunfo" ; y saltándosele las lágrimas, añadió: "¡Cómo se pierde un escuadrón tan valiente! mi general, permítamelo V. S." $\mathrm{El}$ rogeneral Sucre, con una calma inalterable, le contestó: "Coronel Ibarra, aquí el único responsable soy yo; pero vaya V. y haga su deber."

Poníanse recién al galope los denodados guías de Colombia, cuando los bizarros granaderos ${ }_{15}$ decidían la victoria, sin que les cupiese más que a cincuenta de esos bravos ayudar a recoger los laureles, que los inmortales granaderos habían alcanzado, segando cabezas españolas con el corvo de los Andes, en aquel anfiteatro de la Edad Media.

7. saltándosele las lágrimas, with tears in his eyes.

8. ¡ Cómo se pierde un escuadrón tan valiente! To think that such a braet squadron is being destroyed!.

9. permítamelo. 'The pronoun lo refers to ir con mis guias.

13. Ponianse recién. Argentinism for acababan de ponerse.

15. sin que . . laureles, lit, without its falling to the lot of more than fifty to gather the laurels.

19. anfiteatro de la Edad Media. That is, the condition and civilization of Ecuador were then medieval; trans., mediesal amphitheater. 


\title{
EL OMBÚ
}

\author{
Marcos Sastre
}

El ombú es el único objeto que se eleva sobre la dilatada pampa, destruyendo la monotonía de

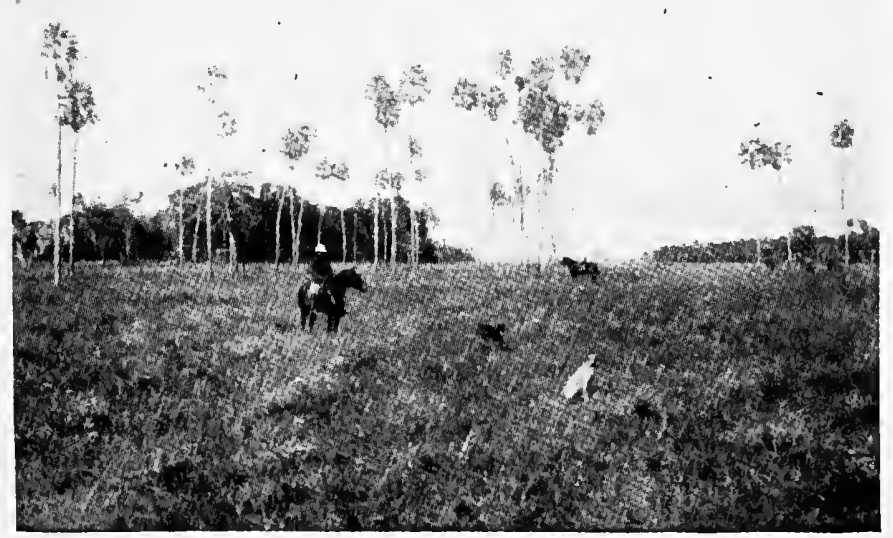

Fraser, The Amazing Argentine

Una Vista de la Pampa

ese océano de verdura. Sus abultadas raíces que se levantan en una enorme masa cónica, base de 
un tronco, imitan las rocas, simulando en los huecos de su seno sombrías cavernas que pueden servir de cómoda habitación en el desierto. Casi siempre su presencia indica desde muy lejos la

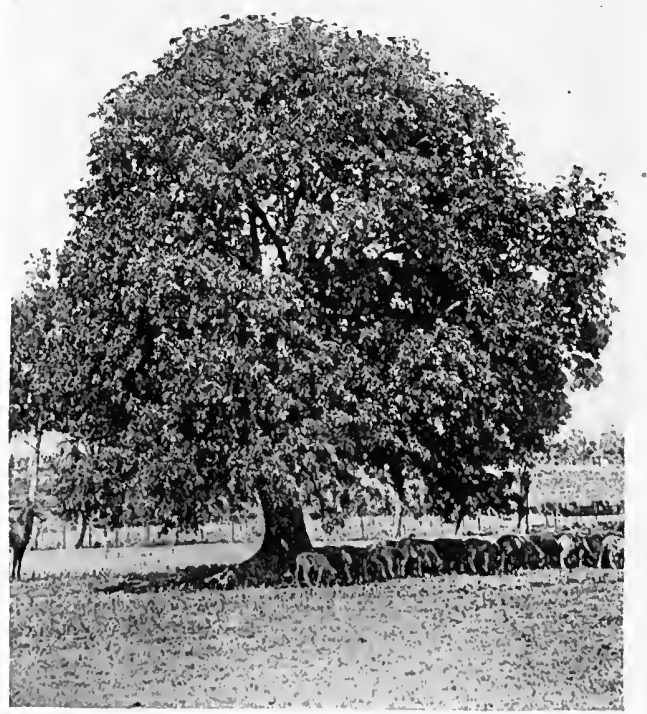

Karsten und Sehenek, legetationsbilder

UN OMBú

5 morada humana al caminante extraviado, que apresura hacia él sus pasos para gozar el seguro reposo del rancho hospitalario de nuestros campos. En las dilatadas llanuras sin camino, el ombú es el norte del viajero, y levantándose sobre la 
planicie de las costas del Plata, en forma de colinas invariables como las montañas, es el guía seguro del navegante para tomar el puerto, evitando los bajíos peligrosos.

Uno de los caracteres distintivos del ombú es 5 su longevidad dilatada, condición requerida en un ser que con dificultad se reproduce. No se conoce el término de su vida, nadie ha visto hasta ahora un ombú seco de vejez, no hay tradición que recuerde la edad juvenil de algunos. Por las ro enormes dimensiones de muchos de ellos con treinta varas de circunferencia en su monstruosa raíz, y diez en su tronco, puede juzgarse que tienen miles de años de existencia.

Además de su extraordinaria longevidad, tiene 5 el ombú tal fortaleza, que no hay huracán que lo derribe, y es su vitalidad tan prodigiosa que ni la sequedad ni el fuego tienen poder para destruirlo. Si por acaso algún violento torbellino llega a destrozar su copa, muy pronto se rehace con asom- 20 broso vigor y lozanía. . .

Él ha resistido las sequías destructoras que, de tiempo en tiempo, han asolado las campiñas.

El ombú prospera en los lugares más áridos y 25 en toda clase de terrenos, con tal que no tenga una humedad excesiva. Sólo se multiplica por la semilla, y es preciso, mientras es pequeño, ponerlo

ro. algunos, i.e., ombús. 
a cubierto de las heladas. Trasplantándolo joven, no requiere ya ningún otro cuidado, ni el de riego, y a los cuatro o cinco años es un árbol frondoso.

5 No hay árbol como el ombú para formar umbrosas alamedas $y$ avenidas arboladas. La naturaleza de nuestro clima, madrastra de los árboles exóticos, parece que les niega el sustento; exigen la solicitud y constante atención del homsobre. El ombú, su hijo predilecto, prospera admirablemente sin necesidad de sus cuidados. Y, ¿ cuál es el árbol de otros climas, que aventaja a nuestro ombú en frondosidad, majestad, hermosura? Bien puede herir su copa un sol is abrasador, bien puede faltarle el refrigerio de los rocíos y el alimento de las lluvias, no por eso dará paso a un solo rayo del astro, ni soltará a una sola de sus hojas: mientras que los demás árboles languidecen, se agosta su follaje y ralea su sombra 20 en la estación de los calores.

7. madrastra, lit., stepmother, hence unkindly, harmful.

r9. su follaje, i.e., de los demás árboles. 


\section{EN LA CORDILLERA}

Juan María Gutiérrez

En mi calidad inalienable de porteño, ayuno de granito y de basalto, huérfano de mesetas, de morros y promontorios, sin conocer otros montes que los de durazno, i cuánto no ansiaba por acercarme a ese lindero del occidente argentinos divinizado en los cantos guerreros con que me había arrullado en la cama! iQué ansia tenía por poner pie donde lo estamparon los valientes de San Martín y los leones de Necochea!

Un día 6 de mayo, de un año que no quiero rc

3. montes. Note the pun on the word monte, which may mean a wood or a mountain.

4. no ansiaba. The negative is redundant.

8. lo estamparon. Lo refers to pie.

9. los leones de Necochea. Reference to mounted troops of this famous leader during the war of independence. Necochea was in command of the Argentine forces at the battle of Junin (1824), where he and his mounted grenadiers covered themselves with glory at a moment when the success of the battle seemed to be in danger.

10. The apparent contradiction in dates, 6 de mayo and 3 I de marzo ( 134,10$)$, is due to the fact that a part of the author's letter, at the end of the second paragraph, has been omitted, and that the third paragraph refers to events which took place the year following the first date. 
acordarme, esos Andes tan deseados se presentaron a mi vista. Sus cumbres, celestes como nuestra bandera, en la mañana, y rosadas como la inocencia y la juventud al ponerse el sol, fueron s para mí verdaderos iris de bonanza después de cuarenta días de capa y tempestades en ese cabo, acabador de toda paciencia, que se llama de Hornos. . . .

En todo esto cavilaba, mi querido amigo, en rotanto que la luna del 3 I de marzo brillaba sobre mi cabeza peregrinando por el cielo transparente de la provincia de Aconcagua.

Una mula con el equipaje y provisiones, dos de remuda, el guía tras de ellas, y yo cabalgando en is silla inglesa a retaguardia, íbamos en procesión por una senda angosta a las cuatro de la mañana siguiente. La luna no alumbraba; las estrellas, tímidas todavía ante la reina eclipsada, no alumbraban tampoco; y yo sólo contaba para mi 2o salvación con el instinto de mi cuadrúpedo y - del bípedo delantero. No sabía si caminaba

2. nuestra bandera, i.e., the Argentine flag, the colors of which are sky-blue and white.

6. dias de capa, lit.. days of cloak, i.e., of clouds; trans., bad weather.

6. cabo, acabador. Notice pun on cabo, end or cape, and acabador, that which puts an end to anything.

12. Aconcagua, province of Chile opposite the Argentine province of Mendoza.

21. del bipedo delantero, i.e., del arriero. 
para adelante o para atrás ; y por salir de una ofuscación muy frecuente en semejantes situaciones, llevaba la mano a la cabeza del caballo porque me parecía que el animal estaba al revés. "Las tinieblas estaban sobre la haz del abismo", como en el 5 primer capítulo del Génesis. Poco a poco comenzó a fosforescer la columna del vapor tibio de la respiración de las bestias; el aire tomó el oriente de las perlas; la inevitable compañera de todo cuerpo comenzó a marcarse en el suelo; hasta que ro al fin, el dedo de Dios "separó la luz de las tinieblas " que huyeron. ¿Qué sitios tan bellos había robado la noche a mi contemplación! La montaña estaba a mi derecha; el torrente a mi izquierda. Unas tunas del género cirio, más cor-15 pulentas y cilíndricas que las que conocemos aquí, reunidas en familia de cinco y seis individuos de todas edades y estaturas, se levantaban verdes $y$ airosas, con envidia del aficionado a jardines. Con este instinto del mal que distingue al hombre, so las hacía emigrar con la imaginación, y las colocaba dentro del círculo artificial de un parque a la inglesa. No sólo por sus formas y color que eran bellos, la naturaleza les había dado aduladores para realzar sus méritos: una planta parásita 25

1. para adelante o para atrás, forward or backward.

3. me parecia... revés, for it seemed to me that the animal was headed in a direction opposite to mine.

19. con envidia del aficionado a jardines, an object of enoy to the lover of gardens. 
llamada quiltre, que a merced de sus tenaces púas se injerta en los árboles hasta connaturalizarse con ellos, formaba de rojo y amarillo guirnaldas preciosas sobre la cabeza de los cactus; 5 en otros, ceñidos más abajo por las mismas flores, remedaban sartas de corales en la garganta de una mujer de Arauco. Piedras enormes, árboles pequeños, obligaban al sendero a arrastrarse por aquellas faldas como una serpiente; que tal so parece en realidad, cuando la vista puede descubrir la serie sin interrupción de sus anillos blanquizcos.

Voy a hacer una advertencia. Cuando le diga a Vd. : "Me paré, almorcé aquí, comí allá, dormí en ${ }_{5}$ tal parte", no era yo el que tenía cansancio, hambre ni sueño, sino las mulas o el conductor, porque mi voluntad no entraba para nada en la formación de las leyes de aquella república ambulante. Por otra parte, las jormadas están señaladas por zola naturaleza, por decirlo así, combinada por la necesidad del transeunte en las Cordilleras. Es preciso parar a comer donde haya agua y sombra:

3. de rojo y amarillo guirnaldas preciosas. The commoner word order is guirnaldas preciosas de rojo y amarillo.

5. en otros, i.e., en otros cactus.

6. remedaban. The subject is guirnaldas.

7. Arauco, province of Chile, scene of the struggles between the Spaniards and the Araucanian Indians in Ercilla's epic, La Araucana.

9. que tal parece, for such it appears. 
dormir en paraje abrigado y en la cercanía de algunas hierbas para que pasten las bestias.

A las once y media de la mañana mi caballo no quiso obedecer a las espuelas; lo atribuí a la mala calidad del pingüelo o a la peor colocación 5 de estos instrumentos pedestres que se me habían subido a las pantorrillas. Pero esto era un mal juicio en toda la extensión de la palabra. El pobre cedía a una costumbre inveterada: habíamos llegado al lugar de almorzar, y a fe que el ro sitio era a propósito para el efecto. Un hilo de nieve derretida caía transparente de la montaña por entre sombra de árboles, y un peñón plano y extenso prestaba mesa para una orgía de 25 cubiertos. Esta piedra rodeada en círculo de ${ }_{5}$ otras en forma de pirámides, altas y truncadas, realizaba con perfección la idea que tengo de las aras druídicas de los antiguos galos; y por un rapto vagabundo de la imaginación, me transporté al teatro de Carlos Alberto, en donde había 20 oído por primera vez aquella sublime elegía que inspiró a Bellini el presentimiento de una muerte

6. estos instrumentos pedestres, i.e., las espuelas in line 4. The use of pedestre in the sense of the feet is not accurate.

8. El pobre, i.e., animal.

20. teatro de Carlos Alberto, theater in Buenos Aires.

22. Bellini (Vincenzo), Italian composer, born in Catania, Sicily, in I80I. His most famous operas are I Puritani, La Sonnambula, and Norma. His music is characterized by sweetness and melancholy. 
prematura. El poco respeto que me infundía el criterio músico del muletero, me dió ánimo para echar al aire algunas notas, y entoné la famosa cavatina de la sacerdotisa sacrílega: i Casta ${ }_{5}$ Diva!

Un pollo fiambre y un trago de jerez bien rubio. me habían infundido tan buen humor, que me puse a reír a vista de un espectáculo artísticamente interesante y patético también, que aquel momento ro se ofreció a los ojos de Norma. - Un anciano, vestido pobremente, descendía, en sentido opuesto al nuestro, la ladera del camino, colgadas dos arganitas de cuero a los ijares de su mula cuyana, ética y tropezadora. La fruta que traía en ellas ${ }_{5}$ no la producen ni los árboles ni las plantas. Eran dos chiquillos de 5 a 6 años que, hincaditos, parecían esas ánimas de bulto que con las manos juntas al pecho, coloca la piedad pedigüeña sobre las alcancías de las iglesias católicas. - Murillo, que zo ha llenado los conventos de España con esos lienzos inmortales que representan la huída a Egipto de la Santa Familia, habría tomado

4. ;Casta Diva! one of the best known arias of the opera Norma, sung by the priestess Norma after whom the opera is named.

I0. se ofreció a los ojos de Norma, i.e., as the author sings the famous aria be identifies himself with the priestess who is supposed to sing it in the opera.

19. Murillo (Bartolomé Estehan, 1617-1682), famous Spanish painter, born in Seville. His Asunción de la Virgén is one of the great masterpieces of ant. 
de aquí asunto para un cuadro original como pocos.

Siguiendo nuestro camino, nos encontramos hasta tener literalmente a nuestros pies el torrente, compañero fiel del sendero. - El Salto se 5 presentaba en el fondo de la cima dando salida por un corte gigantesco de la montaña al agua anhelante por esparcirse en un lecho menos limitado que el que la trae emparedada por un trecho considerable. El cauce por donde corre allí, ro está sembrado de piedras de colores variados y de formas redondas dadas contra la voluntad del granito por esa pertinacia del agua, que eternamente se desliza y que se ha presentado como imagen del triunfo de la constancia: "la gota ${ }_{15}$ horada la piedra, non oi sed saepe cadendo." Fuera imposible contemplar aquel espectáculo sin atribuir inteligencia a la lucha que levantaba

r. original como pocos, lit., original as few; trans., unique in its originality. had.

3. nos encontramos hasta tener, we went along till we

5. El Salto. Reference to the falls of the river Mapocho, in the province of Santiago, Chile.

12. formas redondas dadas contra la voluntad del granito, round shapes assumed despite the resistance of the granite.

I5. " la gota horada la piedra, non vi sed saepe cadendo." The whole Latin expression is " non vi sed saepe cadendo gutta cavat lapidem". Trans., " not through violence but by constant dripping a drop of water hollows stone." Ovid's Epistolae ex Ponto, IV, 6o, 5. 
espumas de plata y de jazmines en torno de los guijarros desnudos. Allí había sin duda Náyades que lavaban sus encajes y sus túnicas de Cambray con pasta perfumada de almendras de la fábrica 5 de Monpelas; Ninfas de la fuente que contaban sus amores desconocidos y desgraciados a los escasos viajeros; y de ella (no puede por menos) es esa cadencia monótona que llena el oído y convida a "soñar e imaginar con desaliño", frases castizas ro que guardo en la memoria porque me parece la traducción más genuina del verbo francés rêver, que tanto da qué hacer a los traductores noveles.

3. Cambray, city in northern France, also spelled Cambrai; famous for its manufactories of cloth, from which we get the English word cambric.

4. fábrica de Monpelas, a firm in France, famous for its perfumes and soaps.

7. y de ella, i.e., de la lucha, in $139,18$.

7. (no puede por menos), trans., (without a doubt).

9. " soñar e imaginar con desaliño", "to dream and give free rein to the imagination". 


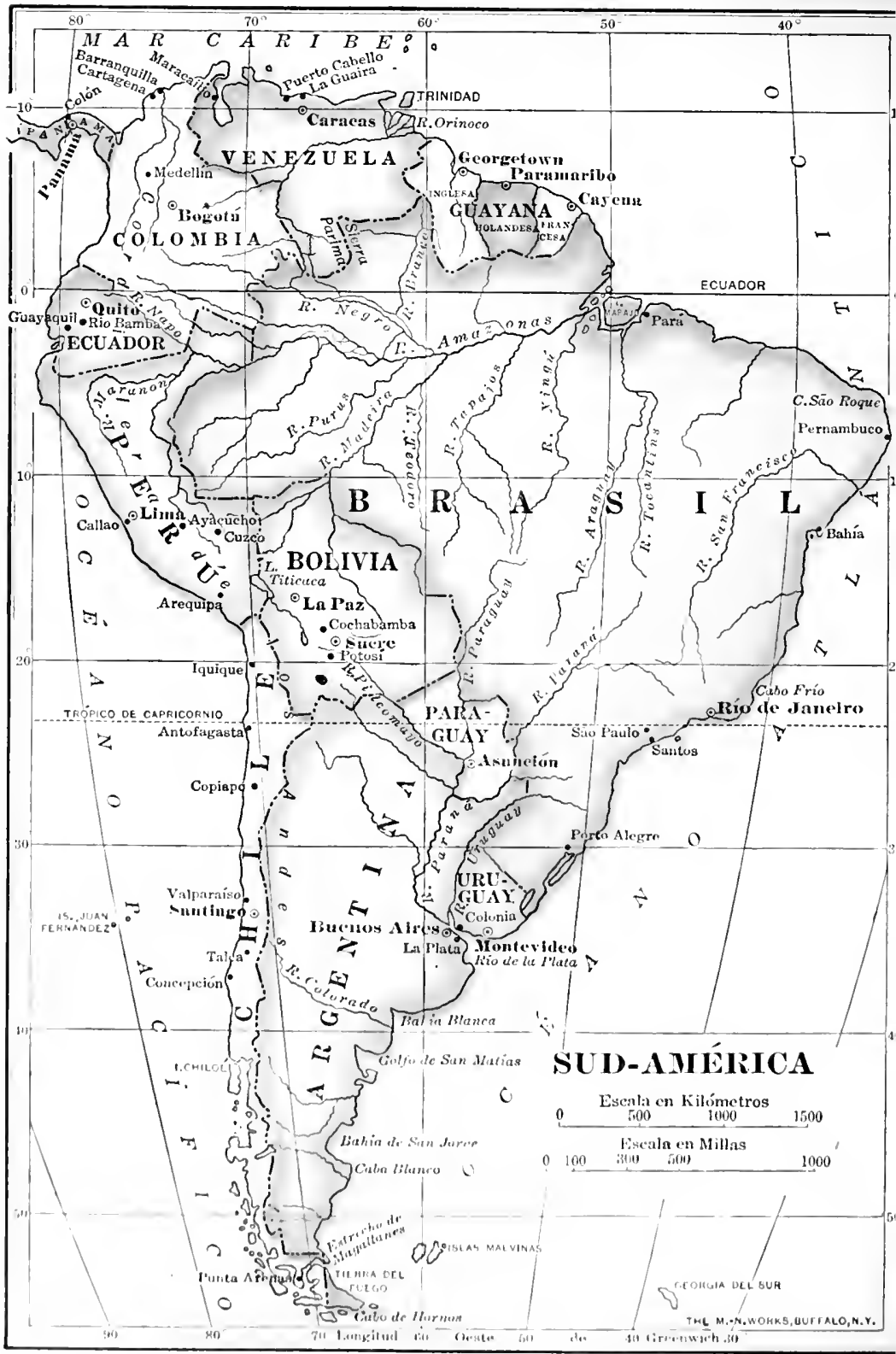




\section{LA NATURALEZA SUDAMERICANA}

De Valparaíso a Buenos Aires

Juan María Gutiérrez

El camino a vapor es el Valdivia, el Hernán Cortés, el Pizarro, de nuestros días, para completar la conquista de América en servicio de la civilización y la paz. La espada comenzó esa conquista : la ayudó y continuó la cruz, en manos de los 5 misioneros; la ciencia de la mecánica que da la dirección asombrosa a la fuerza expansiva de uno de los elementos antiguos encerrado en una caldera

I. El camino a vapor, The railroad.

I. el Valdivia, el Hernán Cortés, el Pizarro, names of Spanish conquistadores; the first conquered Chile and died in combat against the Araucanian Indians; the second conquered Mexico, despite the opposition of his own countrymen under Narváez, who had been sent to capture Cortés for disobeying orders; Pizarro conquered Peru. Cf. 2, 6.

5. en manos de los misioneros. Reference to the missionaries who always accompanied Spanish expeditions. One of the hard things in history is to reconcile the cruelty of the conquistadores and the gentle, patient endeavor of the missionaries to convert the Indians to Christianity.

8. elementos antiguos, allusion to belief in the elements, air, fire, earth, water, by the ancient philosophers of Greece. 
de hierro, acortando en tiempo las distancias, dando al andar del hombre la rapidez del vuelo de las aves, satisfaciendo una necesidad apenas sentida, acercando los pueblos apartados para 5 que conversen, por decirlo así, mano a mano, está llamada en este siglo a completar la obra comenzada en América por el guerrero y el sacerdote. El silbo de la locomotiva es hoy la voz del verdadero apóstol, el sonido de la lira de los Anfiones ro modernos, eço de los taumaturgos del siglo, que predica la unión y la paz entre los hombres, hablándoles de sus intereses, que levanta centros sociales por encanto y aconseja el amor al prójimo y el respeto a Dios, tiñendo con dulces colores de ${ }_{15}$ rosa los horizontes de esta existencia de un día para las criaturas y eterna para las sociedades.

¿ No piensa Vd., mi amigo, como yo? ¿ Cree $\mathrm{Vd}$. que una ley escrita y nada más sea tan poderosa como el fiat de Dios para dar condiciones de nación $20 \mathrm{y}$ formas regulares de cuerpo social a una familia de desiertos como son los miembros de todas las repúblicas sudamericanas? El aislamiento natural ahoga la eficacia del pacto, como agosta la maleza robusta e indómita a la planta delicada

5. está llamada. The subject is la ciencia de la mecánica, $14 \mathrm{I}, 6$.

9. Anfiones. Amphion, a Theban prince, was reputed to have built Thebes by charming the stones into their places with his lyre.

19. el fiat, the will. 
acostumbrada a sentir cerca de si la mano inteligente del hombre. La América es el campo de aplicación de todos los descubrimientos de la ciencia europea, no porque yo lo digo, sino porque así lo dispuso el Artífice que fraguó una vez para 5 siempre los destinos de la cadena del mundo. El poder de la dilatación de esa ciencia es como el de la mente de Colón - no puede reconocer por meta las columnas de ningún Hércules. La América es el jardín del mundo para la aclimatación de todo 10 lo grande y de todo lo bueno. Si alguien lo duda, que ponga la vista en el mapa de su geografía, y diga después si el hombre podrá encontrar en ninguna otra parte del mundo mejor cielo que admirar, mejores sombras a que asilarse, mejores frutas ${ }_{15}$ para su paladar, aguas más frescas y salubres para su sed, ríos más capaces de ser surcados, montañas más preñadas de plata y de oro, tierras más fértiles que en América. En poco tiempo el habla y la religión cristiana se aclimataron en nuestro con- 20

2. La América. The definite article may be used in Spanish before the name of a continent or country for personification.

9. 1as columnas de ningun Hércules. The pillars of Hercules is the name applied to the Strait of Gibraltar in Greek mythology. Hercules, among his other feats, separated the mountains Calpe, the promontory of Gibraltar in Spain, and Ábila, ancient name of a mountain in Morocco. Calpe and Ábila are the pillars of Hercules. Previous to Columbus' time, it was thought that these pillars were the end of the world and the barrier to exploration. 
tinente desde la tierra magallánica hasta la alta California; el hijo del conquistador $y$ de las Indias cautivas fué superior en fuerza muscular y en inteligencia a sus padres. El inca Garcilaso, 5 criado al seno de una Palla cuzqueña, escribió con veracidad y talento las proezas de Pizarro, que no sabía escribir su nombre. Esta facultad absortiva de asimilación y de mejora que distingue al nuevo mundo, se manifiesta desde luego en el ro hombre americano por su facilidad para imitar, por su notable aptitud para las artes y los idiomas; en segundo lugar, se manifiesta en las condiciones del suelo, algunas de las cuales podemos señalar sin salir de casa. Los españoles, por ejemplo, istraen al Río de la Plata unos cuantos potros andaluces, y esos céfiros del Betis, como los llama Góngora, encuentran su verdadera patria en las llanuras argentinas: se reproducen al infinito; la libertad los mejora, y açuí en su centro, es

I. la tierra . . California, i.e., from Tierra del Fuego (land about the Straits of Magellan) to upper California.

4. El inca Garcilaso. He wass the son of one of the conquistadores of Peru and a princess of Inca descent. He wrote Comentarios Reales del Peria and La Florida del Inca.

14. sin salir de casa, i.e., de la Argentina.

16. Betis, ancient name of the Guadalquivir, a river in Andalusia, southern Spain.

17. Gongora. Ile was the chaplain of Philip III of Spain; his writings have given rise to the term Gongorism, which is applied to a metaphorical and far-fetched style. Cf. enphrism in linglish. 
donde aconseja Bufón que se contemple y se estudie ese bruto generoso, "la mejor conquista entre cuantas hizo el hombre". El pico de un ave o el movimiento de una ola depone a las orillas del Paraná la simiente de un durazno, y de 5 ahí el origen de esa abundancia de "fruta del monte", que nos deleita entre los meses de febrero y marzo. Dos carozos de damasco traídos por casualidad de Italia, poco más ha de medio siglo, bastaron para reproducirse en Buenos Aires ro en los términos que conocemos. El morueco de las colonias españolas tan mimado en Sajonia, crece $y$ se reproduce sin desmejorar en nuestros campos, sin más techo ni cobertizo que la benignidad del temperamento. Para estos animales, pues, 15 y para aquellas semillas, estaba preparada ab initio la tierra que tanta $y$ tan agradecida hospitalidad les brinda.

1. Bufón, Buffon, French naturalist ( I $707-1788$ ).

3. un ave. With feminine words beginning with an initial stressed $\mathbf{a}$ it is common to use an old apocopated form of the feminine article, which looks like the modern masculine form of the article.

6. "fruta del monte". Peaches are so common in the province of Buenos Aires that they are called "fruit of the woods". In this connection Darwin says: "Among the introduced kinds may be enumerated poplars, olives, peach, and other fruit trees; the peaches succeed so well that they afford the main supply of firewood to the city of Buenos Aires." - The Voyage of the Beagle.

I6. $a b$ initio, from the beginning; a stock Latin quotation. 
Y ahora, dígame Vd., mi amigo, ¿ para qué puede haber nivelado la mano de la naturaleza el espacio que media entre el Plata y el Paraná ("caminos que caminan") y las faldas de las ${ }_{5}$ Cordilleras, límites de nuestro país con Chile y Bolivia? ¿Será para que se arrastre sobre esa superficie plana la tarda rueda de la carreta al paso lerdo del robusto buey tucumano, cuya piel y cuya carne se pagan a peso de oro al occidente rode los Andes? ¿Será para que se espacie en ella el avestruz "privado por Dios de inteligencia”, como quiere la Escritura, y para que, "cuando llegue la ocasión, levante las alas y se burle del caballo y del cabalgador"? ¿ Será para que ${ }_{5}$ pueble sus soledades el alarido de los ranqueles y el relincho de los potros orejanos; o para que se convierta, en fin, en Calvario, demostrando a cada paso con sus cruces que la vida del hombre no es alli de Dios, ni de la ley humana, sino de la zobarbarie codiciosa?

¡No! El ingeniero invisible sujetó a regla ese mar de verdura, como sujetó la superficie del océano a un nivel permanente, y con iguales de-

4. "caminos que caminan", descriptive of the Plata and the Paraná, rivers which move continuously and are highway's of travel and commerce.

12. la Escritura: i.e. Job 39: 17.

16. se convierta. The subject is el espacio, line 3 .

17. Calvario, mountain on which Christ was crucified; here synonymous with suffering. 
signios. Divorció con el agua salobre los continentes, porque había puesto en la mente humana el germen de la navegación y en la atmósfera los vientos constantes. Tendió el desierto, que es en apariencia el sudario de la vida social, porque en 5 el siglo XIX el hombre había de inventar un monstruo corpulento como los megaterios, veloz más que el gamo, sobre cuya espalda había de erguirse en realidad como Rey de la Creación, mostrándose invencible en las luchas con las io resistencias de la naturaleza y del espacio. 


\title{
LINIERS Y LA RECONQUISTA DE BUENOS AIRES
}

\author{
C. O. Bunge (Según P. Groussac)
}

I. Los Preparativos y la Marcha hacia Buenos Aires

Conquistada por los ingleses en i 806 la ciudad de Buenos Aires, Santiago de Liniers tomó su partido: se dirigió a Las Conchas y se embarcó en una lancha para la Colonia. Se dice que había s pasado parte de la noche anterior en oración en el santuario de la Recoleta: sería la vela de las armas de los antiguos caballeros, y a fe que no sentaba mal en quien descendía de Guy de Liniers, muerto en la batalla de Poitiers. Desde la Co-

3. las Conchas. V.map.

6. la Recoleta. V. mip.

6. seria. Note use of the conditional to express probability in past time.

6. la vela de las armas. In the days of chivalry the squire kept watch over his arms the night before being knighted.

7. y a fe ... quien, and indeed it did not ill befit one who.

9. Poitiers. The English under the Black Prince in 1356 defeated the firench here. As a descendant of the defeated French, Santiago de liniers had an opportunity to avenge the defeat of his forefithers. 
lonia escribió a Ruiz Huidobro, gobernador de Montevideo, reseñando el estado de la capital y proponiéndole reconquistarla " con 500 hombres de tropas escogidas que se le confiasen". I a Junta de Guerra allí establecida para preparar la resis- 5 tencia a la anunciada invasión de Popham, opinó que se debía oír a Liniers. Y se le confió el mando que solicitaba.

El 22 de julio la división salió de Montevideo entre las aclamaciones del vecindario. Al frente ro iba Liniers, vistiendo el brillante uniforme azul y rojo, flordelisado de oro, de capitán de navío, y, en el pecho, la cruz de Caballero de Malta. Era de alta estatura, de robusta presencia, y poseía una belleza risueña y varonil que formó parte ${ }_{5}$ de su prestigio entre la muchedumbre. Galante por raza y temperamento, saludaba a las mujeres apiñadas en los balcones y azoteas, anunciando la victoria que le tenía prometida aquella voz secreta, misterioso confidente de todo conquistador. 20

6. invasión de Popham. In I806 Popham, a famous British admiral, proposed the seizure of Buenos Aires to the English government. For this purpose he was sent in command of a fleet to attack Buenos Aires.

7. se debía oír a Liniers, heed should be given to Liniers.

13. Caballero de Malta. In the eleventh century the Knights Hospitalers were established in Jerusalem to furnish shelter to the pilgrims. The order became successively the Knights of St. John, the Knights of Rhodes, and, in 1530, the Knights of Malta, when Charles V ceded that island to them. Now it exists as an honorary order only. 


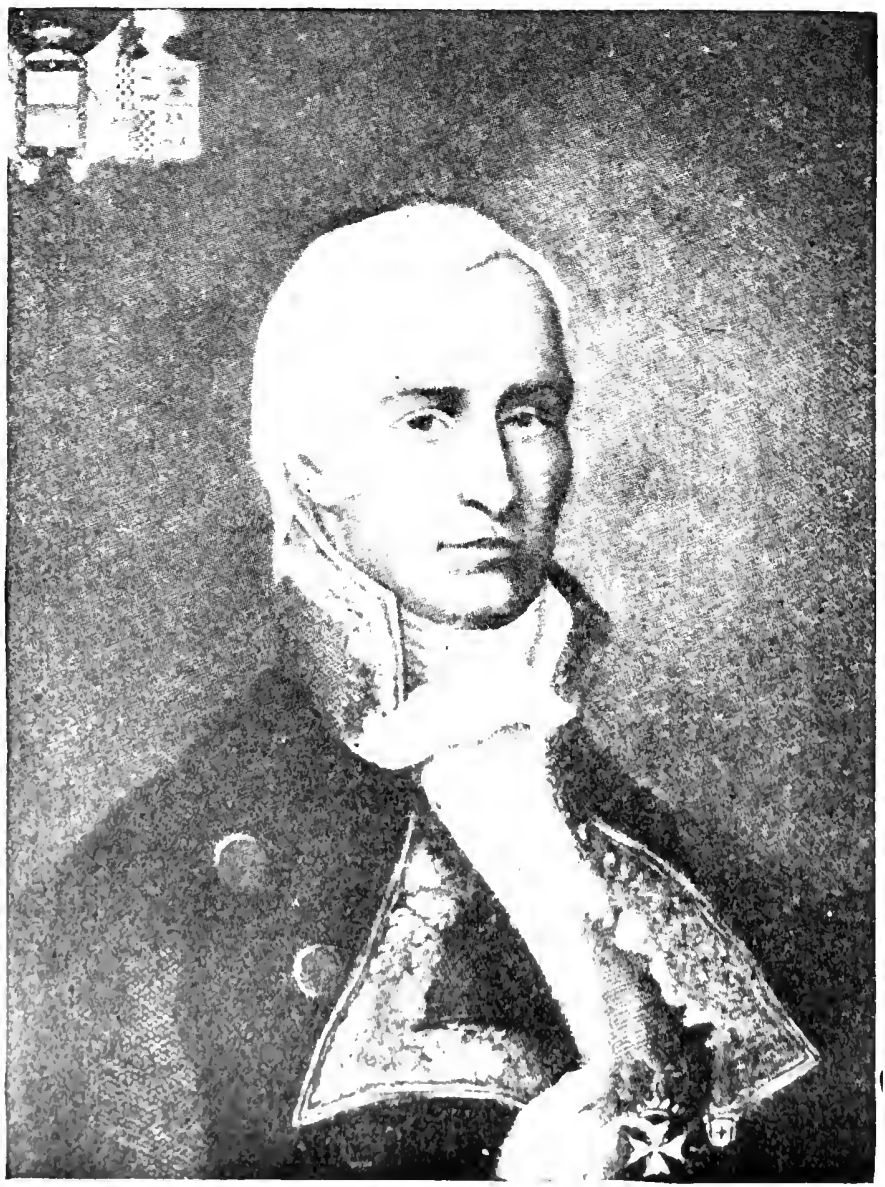

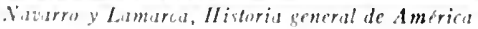

Savilago Antonio de linilers 
¡Al fin tenía su hora histórica! Y, radiante de entusiasmo, blandía al claro sol de invierno, dulce como una caricia, la espada tanto tiempo herrumbrada, que había flameado en Gibraltar y Menorca contra esos mismos ingleses que ahora iba a vencer. 5

Embarcadas las tropas el día 3 de agosto, la travesía de la Colonia a la otra costa se efectuó sin inconveniente grave, aunque con bastante labor por la suestada y los chubascos. Parte de la flotilla extravió el rumbo en la obscuridad, teniendo ro que fondear, sin saberlo, a inmediaciones de una fragata enemiga. Al salir la luna, zarparon las naves y rectificaron su rumbo, amaneciendo a la vista de Buenos Aires y de la escuadra inglesa. Arreciando la suestada, Liniers resolvió desem- 5 barcar en Las Conchas, y no ya en Olivos, como se había determinado. Allí fondeó el 4 por la mañana, realizándose inmediatamente el desembarco de las tropas y artillería e incorporándose además los marineros disponibles de la.flotilla. 20 El día 5 las fuerzas entraron en San Isidro, donde encontraron provisiones frescas y abrigo; el tem-

4. Gibraltar y Menorca. During the War of American Independence France and Spain attempted to wrest these two places from England, but succeeded only in recovering Minorca. Liniers took an active part in both these campaigns.

13. amaneciendo ... Buenos Aires, finding themselves at dawn in view of Buenos Aires.

16. Olivos. V. map.

21. San Isidro. V. map. 
poral se había desencadenado, dispersando a las naves enemigas $y$ echando a pique cinco lanchas: cañoneras. Las tropas emplearon el día en limpiar el armamento y apercibirse para el combate.

5 Al día siguiente, domingo, el capellán celebró misa al aire libre, en el centro de las tropas formadas. Concluído el oficio, se dió orden de marcha para los Corrales de Miserere, donde se llegó a las diez de la mañana. Desde este punto, ro el jefe de la división española dirigió a las once, con su primer ayudante Quintana, una enérgica intimación al general inglés. No habiendo sido admitido por Beresford en los quince minutos fijados, el enviado se retiró sin entregar la misiva ; is pero Liniers no aprobó este exceso de celo y despachó nuevamente a su ayudante, que fué recibido en el acto. La respuesta de Beresford fué muy significativa, viniendo de un jefe tan circunspecto como valiente. Al contestar que se defendería 20 "hasta el caso que la prudencia le indicara", confesaba implicitamente lo que dejaban entrever sus pedidos de conferencias con las autoridades bonaerenses y, un poco más tarde, con Pueyrredón. la situación del invasor se presentaba cada día

8. Corrales de Miserere. I'. map.

ı. el jefe, i.e., Liniers.

13. Beresford. He was in command of the British infantry forces landed by Popliam.

2I. dejaban entrever, hered. The subject is pedidos.

23. Pueyrredón. Later chosen Director of Argentina. 
más difícil e insostenible en la atmósfera hostil de la ciudad; $y$, si bien estaba resuelto a cumplir con su deber, no se le ocultaba la desigualdad de condiciones con que se empeñaba el combate. Vencedor, su victoria sería estéril; vencido, su 5 pérdida era irreparable. Puede decirse, pues, que la acción se inició, en esa misma tarde, contra un adversario moralmente derrotado. A las cinco, la división rompió marcha hacia el Retiro, yendo de vanguardia el cuerpo de voluntarios catalanes so con dos obuses.

\section{La Reconquista}

El grueso de la división no salvó sin gran trabajo, y sólo merced al auxilio del vecindario y gauchos a caballo, las dos millas de malísimo camino, sembrado de baches y pantanos, que mediaba I $_{5}$ entre el Miserere (hoy Once de Septiembre), y el Retiro. Entretanto, los miñones o migueletes, apoyados por la compañía de infantería de Buenos Aires, llegaban a dicha plaza del Retiro "a paso de carrera" y atacaban el Parque, defendido 20 por 200 soldados ingleses, a quienes desalojaron con una carga a la bayoneta. La fuerza enemiga se replegaba hacia la Fortaleza, dejando varios

5. Vencedor, if victorious; vencido, if sanquished.

6. era. The imperfect is used here, instead of the conditional, for emphasis.

9. el Retiro. V. map.

I2. salvo. The object is las dos millas. 


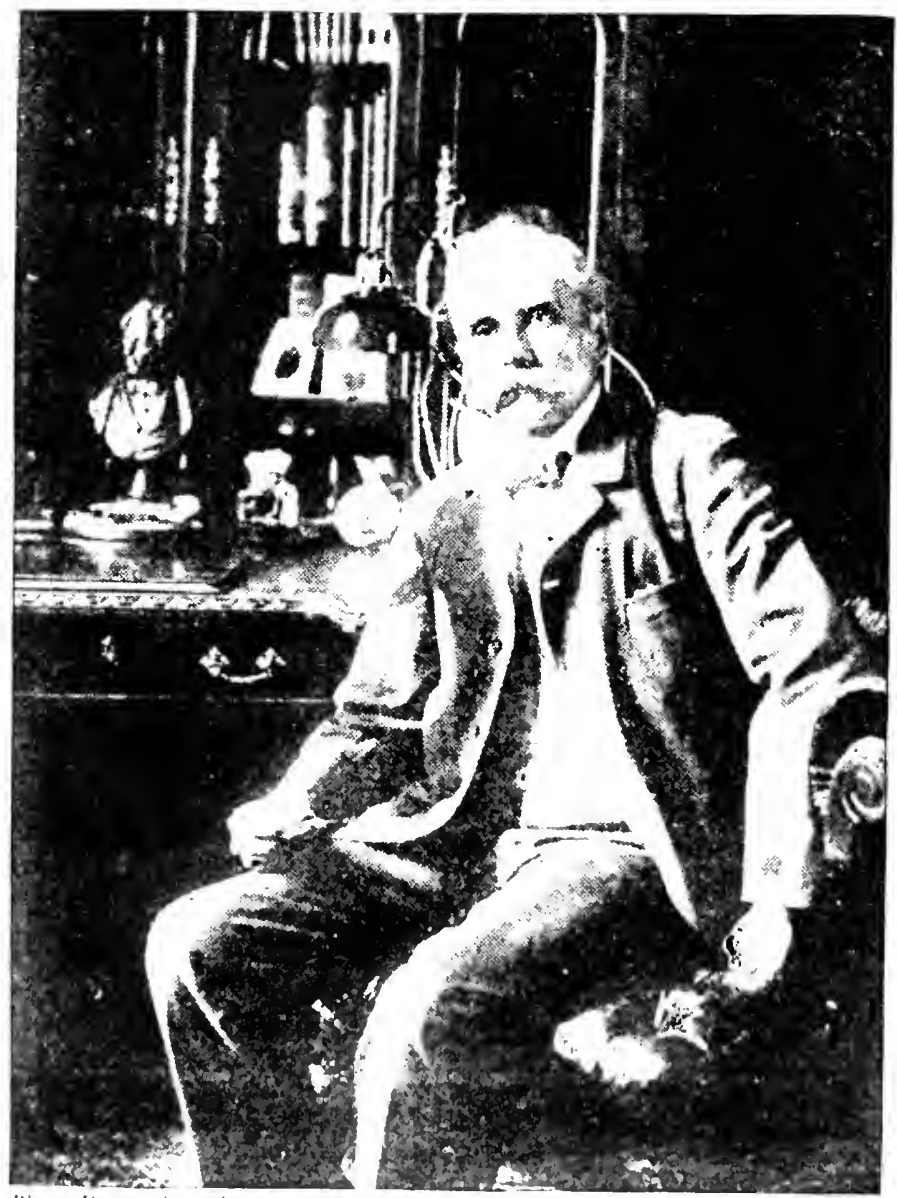

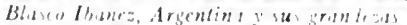

l'il (ikntsic 
muertos y prisioneros en el sitio, cuando encontró a Beresford, que acudía en su auxilio por la calle del Correo (Florida), con una columna de 400 a 500 hombres. En este mismo momento, desembocaban en la plaza a marcha redoblada, 5 vivamente estimulados por Liniers en persona, los voluntarios de Montevideo con una parte de la artillería de Agustini. Tan decisivo fué, al enfilar la calle, el fuego del obús cargado de metralla, que el enemigo se detuvo bruscamente $\mathrm{y}_{\text {so }}$ emprendió retirada hacia la Plaza Mayor, dejando unos 30 muertos o heridos $y$ abandonando un cañon.

Era muy tarde para seguir las operaciones, y, además, las tropas estaban rendidas de can-15 sancio. Liniers se contentó con ocupar fuertemente el Retiro y sus bocacalles, tomando todas las precauciones del caso contra cualquier sorpresa. Las tropas pasaron la noche sobre las armas $y$ sin comer. El día i r fué ocupado en 20 montar los cañones de is desembarcados de la goleta Dolores, y otros de igual calibre que se encontraron en el Parque: había que prevenirse contra un posible bombardeo de la escuadra, y también separarse para batir en brecha a Beres- 25 ford, que parecía dispuesto a encerrar su defensa

3. calle del Correo. 'Today known as calle Florida, the Fifth Avenue of Buenos Aires.

I I. Plaza Mayor. 'Today Plaza de Mayo.

23. habia que prevenirse, preparation had to be made. 




en la Plaza Mayor. El efecto moral de este primer triunfo se hizo visible el mismo día; acudieron a engrosar las fuerzas regulares o tomar órdenes muchos jóvenes patricios y hombres del 5 pueblo, algumos de los cuales se preparaban antes a ma lucha de enerrilleros. A mediodía, para probar los cañones recientemente montados, 
Liniers en persona apuntó sucesivamente a una lancha cañonera y a una fragata enemigas, con tan raro acierto que, después de dar en el casco de la primera, cortó con el segundo tiro la pena de su mesana, donde tremolaba la bandera 5 británica, que cayó al agua. Túvose el hecho por un pronóstico feliz.

Al amanecer frío y brumoso del día it se tocó generala, y, después de revistar las tropas, Liniers tomó sus últimas disposiciones para el ataque ıо de la plaza. Dividió en tres columnas su ejército, reducido en número, pero exuberante de entusiasmo $y$ de confianza en la victoria. La columna de la izquierda, al mando de Liniers, entraría por la calle de la Merced; la del centro is enfilaría por la calle de la Catedral, en tanto que la de la derecha seguiría la calle del Correo hasta el centro, para allí dividirse y ocupar las cuadras del Oeste y del Sur inmediatas a la Plaza Mayor. Ia artillería debía preparar el avance, 20 barriendo el camino y haciendo replegar al enemigo. El ataque general se había fijado para las doce del día; pero un incidente lo precipitó. Destacados en avanzada, un cuerpo de marineros y otro de miñones se habían deslizado por las 25 aceras, rasando las casas a favor de la neblina, hasta llegar a dos cuadras de la plaza y encantonarse en algunos edificios, desde donde rompieron el fuego sobre las partidas enemigas. Habiendo salido a contenerlos y desalojarlos una columna 30 
inglesa, nuestros impetuosos exploradores se replegaron en guerrilla y avanzaron resueltamente. Eran las nueve de la mañana; los imprudentes voluntarios pedían refuerzos y municiones, no 5 resolviéndose a abandonar el terreno conquistado. Las tropas enardecidas por la fusilería, querían marchar al fuego. . . . Entonces Liniers modificó

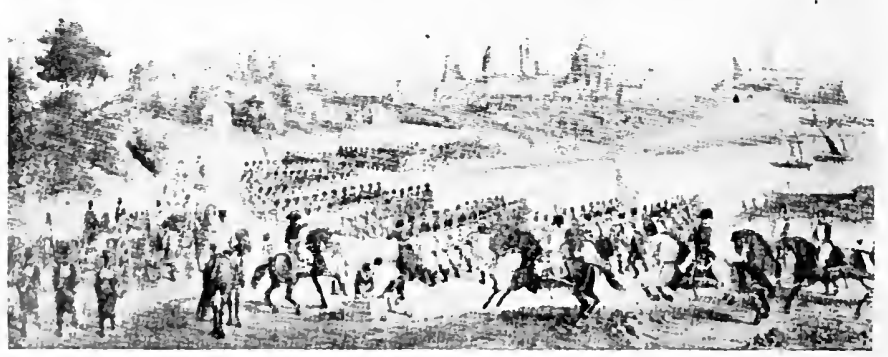

Navarro y Lamarca, Historia gencral de A mérica

Avance de los Ingleses sobre Buenos Aires

rápidamente su plan anterior: lanzó la caballería de milicias de la Colonia y los dragones de Buenos ro Aires con artillería volante por la calle del Santo Cristo, en tanto que se movía penosamente la reserva con sus cañones de batir, y él mismo se adelantaba por la de la Merced, situándose en la plazoleta de la iglesia. La refriega se hizo general.

4. no resolviéndose a abandonar, being unable to bring themseles to abandon. 
El brío de las tropas suplió la desbaratada estrategia; el vecindario arrastró los cañones sin caballos: todo el plan se reducía ahora, para cada jefe de cuerpo, compañía o pelotón, a desalojar al enemigo que tuviera al frente, hasta desembocar en la 5 Plaza Mayor.

Los ingleses, acantonados en los altos del Cabildo, la azotea de la Recova, el pórtico de la Catedral, tenían que hacer frente a los combinados ataques de seis columnas convergentes. Cedieron ro primero los de la Catedral; los del Cabildo, acometidos por el Sur y por el Norte, se replegaron sobre la Recova, ya batida por la metralla de Liniers, y desde cuyo arco Beresford dirigía la defensa. Aquí se concentró el combate y comenzó is a diseñarse el triunfo.

Atacada por todos lados, la posición inglesa hacíase insostenible. Casi al mismo tiempo los dos generales enemigos, Beresford y Liniers, vieron caer a su lado sus respectivos ayudantes. 20 Liniers, atravesado el uniforme por tres balazos, se dirigía hacia la plaza. En el momento en que Beresford, convencido de que era imposible la resistencia, daba la señal de retirada cruzando su espada sobre el brazo izquierdo, la diezmada divi- 25 sión inglesa se replegó hacia la Fortaleza, siendo su general el último que ocupó el puente levadizo. El pueblo, victorioso, hizo irrupción en la plazoleta del Fuerte, dominando con sus clamores el ruido de la fusilería y batiendo sus murallones zo 
con sus oleadas enfurecidas. Trajéronse escalas para emprender el asalto como si fuera un abor- daje; pero entonces apareció Beresford, espada en mano, por el ángulo Nordeste del parapeto, 5 y se izó bandera parlamentaria. Con todo, el humo y la distancia impedían divisarla y no cesó el fuego de los asaltantes. Al pie de la muralla, el comandante Mordeille, que contenía difícilmente a sus hombres, cruzaba un diálogo en francés con ro Beresford. Preguntando éste "si su vida corría peligro", el otro contestó que estaba salvada con rendirse a discreción. El general arrojó su espada al pie de la muralla, pero Mordeille se la devolvió por medio de pañuelos atados; al mismo tiempo is se izó en el bastión una bandera española suministrada por un marinero; y de repente cesó el fuego, alzando el pueblo una inmensa aclamación.

II. con rendirse a discrecion, prosided he surrendered unconditionally. 


\section{EL NEGRO FALUCHO}

\section{Bartolomé Mitre}

En la noche del 3 de febrero, subsiguiente a la sublevación, hallábase de centinela en el torreón del Real Felipe un soldado negro del regimiento del Río de la Plata, conocido con el nombre de guerra de Falucho.

Era Falucho un soldado valiente, muy conocido por la exaltación de su patriotismo y, sobre todo, por su entusiasmo por cuanto pertenecía a Buenos Aires. Como uno de tantos que se hallaban en igual caso, había sido envuelto en la sublevación, ı que hasta aquel momento no tenía más carácter que el de un motín de cuartel.

Mientras que aquel oscuro centinela velaba en el alto torreón del castillo, donde se elevaba el asta en que hacía pocas horas flameaba el pabellón ${ }_{15}$ argentino, Casariego decidía a los sublevados a enarbolar el estandarte español en la oscuridad de la noche, antes que se arrepintiesen de su resolución.

Sacada la bandera española de la sala de armas zo donde se hallaba rendida y prisionera, fué llevada en triunfo hasta el baluarte de Casas-Matas, donde 
debía ser enarbolada primeramente, afirmándola con una salva general de todos los castillos.

Faltaba poco para amanecer, y los primeros resplandores de la aurora iluminaban el horizonte. 5 En aquel momento se presentaron ante el negro Falucho los que debían enarbolar el estandarte, contra el que combatían desde catorce años.

A su vista, el noble soldado, comprendiendo su humillación, se arrojó al suelo y se puso a llorar ro amargamente, prorrumpiendo en sollozos.

Los encargados de cumplir lo ordenado por Moyano, admirados de aquella manifestación de dolor, que acaso interpretaron como un movimiento de entusiasmo, ordenaron a Falucho que presentase is el arma al pabellón del rey que se iba a enarbolar. - Yo no puedo hacer honores a la bandera contra la que he peleado siempre, - contestó Falucho con melancólica energía, apoderándose nuevamente del fusil que había dejado caer.

20 - i Revolucionario! i Revolucionario! - gritaron varios a un mismo tiempo.

- i Malo es ser revolucionario, pero peor es ser traidor! - exclamó Falucho con el laconismo de un héroe de la antigüedad; y tomando su fusil 25 por el cañón, lo hizo pedazos contra el asta, entregándose nuevamente al más acerbo dolor.

Los ejecutores de la traición, apoderándose inmediatamente de Falucho, le intimaron que iba a

I. afirmándola con una salva, asserting its posver with a salio. 


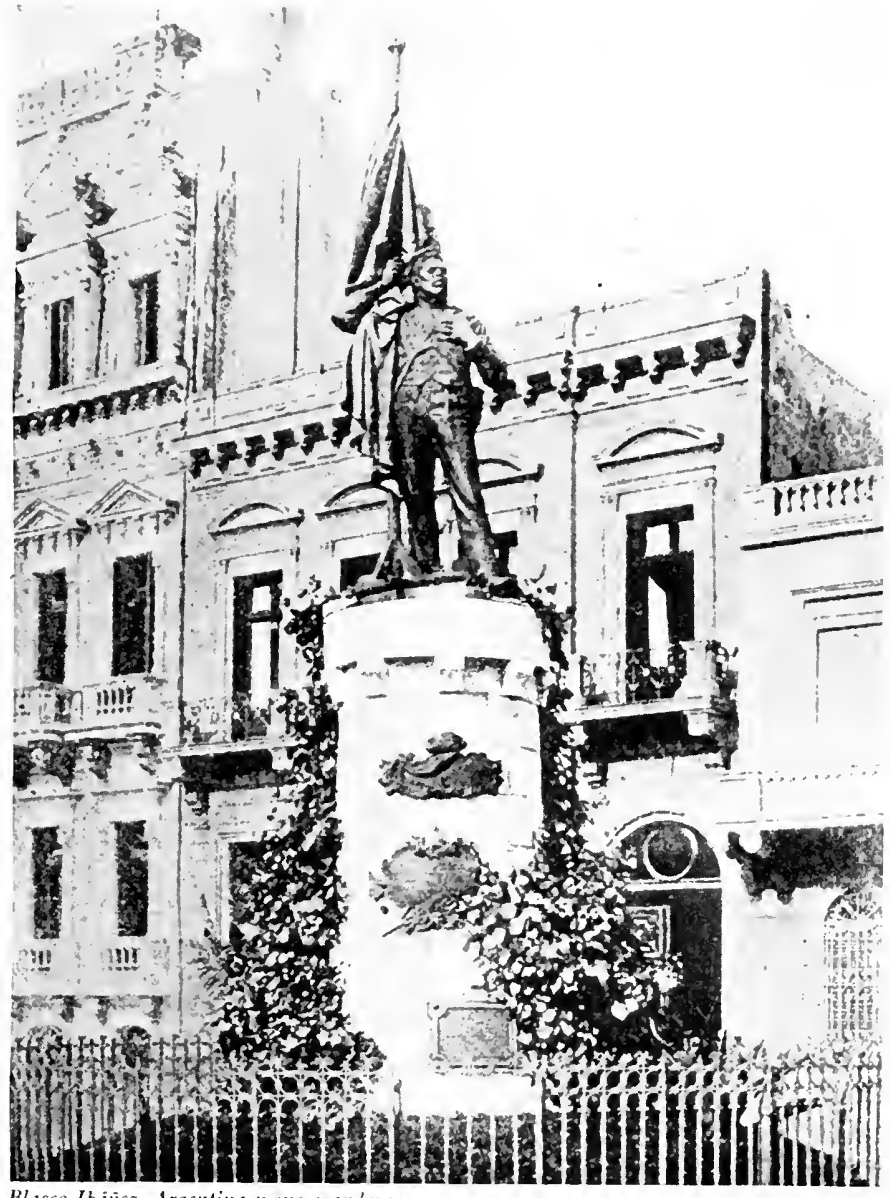

Blasco Ibiñez, Argentina y' sus grandezas

Estatua al Negro Falucho en Buenos Aires 
morir, y haciéndole arrodillar en la muralla que daba frente al mar, cuatro tiradores le abocaron sus armas al pecho y a la cabeza. Todo era silencio, y las sombras flotantes de la noche aun 5 no se habían disipado. En aquel momento brilló el fuego de cuatro fusiles; se oyó una sorda detonación; resonó un grito de iViva Buenos Aires! y luego, entre una nube de humo, se sintió el ruido sordo de un cuerpo que caía al suelo. Era el ro cuerpo ensangrentado de Falucho, que caía gritando ;Viva Buenos Aires! i Feliz el pueblo que tales sentimientos puede inspirar al corazón de un soldado tosco y oscuro!

Así murió Falucho, como un guerrero digno de is la República de Esparta, enseñando cómo se muere por sus principios y cómo se protesta bajo el imperio de la fuerza. Para enarbolar la bandera española en los muros del Callao, fué necesario pasar por encima de su cadáver; se enarboló al 20 fin, pero salpicada con su sangre generosa; y aun tremolando orgullosamente en lo alto del baluarte, el valiente grito de i riva Buenos Aires! fué la noble protesta del mártir contra la traición de sus compañeros. Esa protesta fué sofocada por el 25 estruendo de la artillería en todos los baluartes del Callao.

Falucho era nacido en Buenos Aires, y su nombre verdadero era Antonio Ruiz. ; l'ocos generales

18. Callao, city and port of Peru.

27. era nacido. The more common usage is habia nacido. 
han hecho tanto por la gloria como ese humilde y oscuro soldado, que no tuvo sepulcro, que no ha tenido una corona de laurel, y que recién hoy tiene un recuerdo en la historia de su patria!

El martirio de Falucho no fué estéril. Pocos 5 días después se sublevaron en la Tablada de Lurín dos escuadrones del regimiento de granaderos a caballo, y deponiendo a sus jefes y oficiales, marcharon a incorporarse a los sublevados del Callao. A la distancia vieron flotar el pabellón rc español en las murallas. A su vista, una parte de los granaderos, que ignoraban que los sublevados hubiesen proclamado al Rey, volvieron avergonzados sobre sus pasos, como si la terrible sombra de Falucho les enseñase el camino del honor. Sólo is los más comprometidos persistieron en su primera resolución, y volvieron sus armas contra sus antiguos compañeros, quedando así disuelto por t] motín y la traición el memorable ejército de los Andes, libertador del Chile y del Perú.

4. recueraio. Reference to the statue of Falucho in Buenos Aires.

6. Tablada de Lurín, tollhouse of Lurín; in the suburbs of Lima. 


\section{LA ABDICACIÓN DE SAN MARTÍN}

\section{Bartolomé Mitre}

Se ha dicho con verdad que sólo dos grandes figuras de los tiempos modernos bajaron tranquilas de la cima dé la grandeza, Wáshington y San Martín, porque ellos no fueron ni poder, ni ambi5 ción, ni partidos, ni odios, ni gloria egoísta, sino una misión que debía concluir en un día irrevocable, en medio de la propia existencia.

Wáshington no abdicó. Al colgar su espada después del triunfo, y entregar el poder público ro en manos de un pueblo libre, afirmó la corona cívica sobre sus sienes, siguió sin violencia el ancho camino que le estaba trazado, y alumbrado por astros propicios, se extinguió en el reposo con la angélica serenidad de los ángeles tutelares.

is San Martín abdicó en medio de la lucha, antes de completar su obra, no por su voluntad, como él lo dijo en su despedida y como se ha créido por mucho tiempo, sino forzado por la lógica de su destino y obedeciendo a las inspiraciones del bien; 20 y' en haberlo reconocido en tiempo bajo los auspicios de la razón serena, consiste la grande moral 
I.I IBDIC.MION DE S.I.N M.ARTINA I67

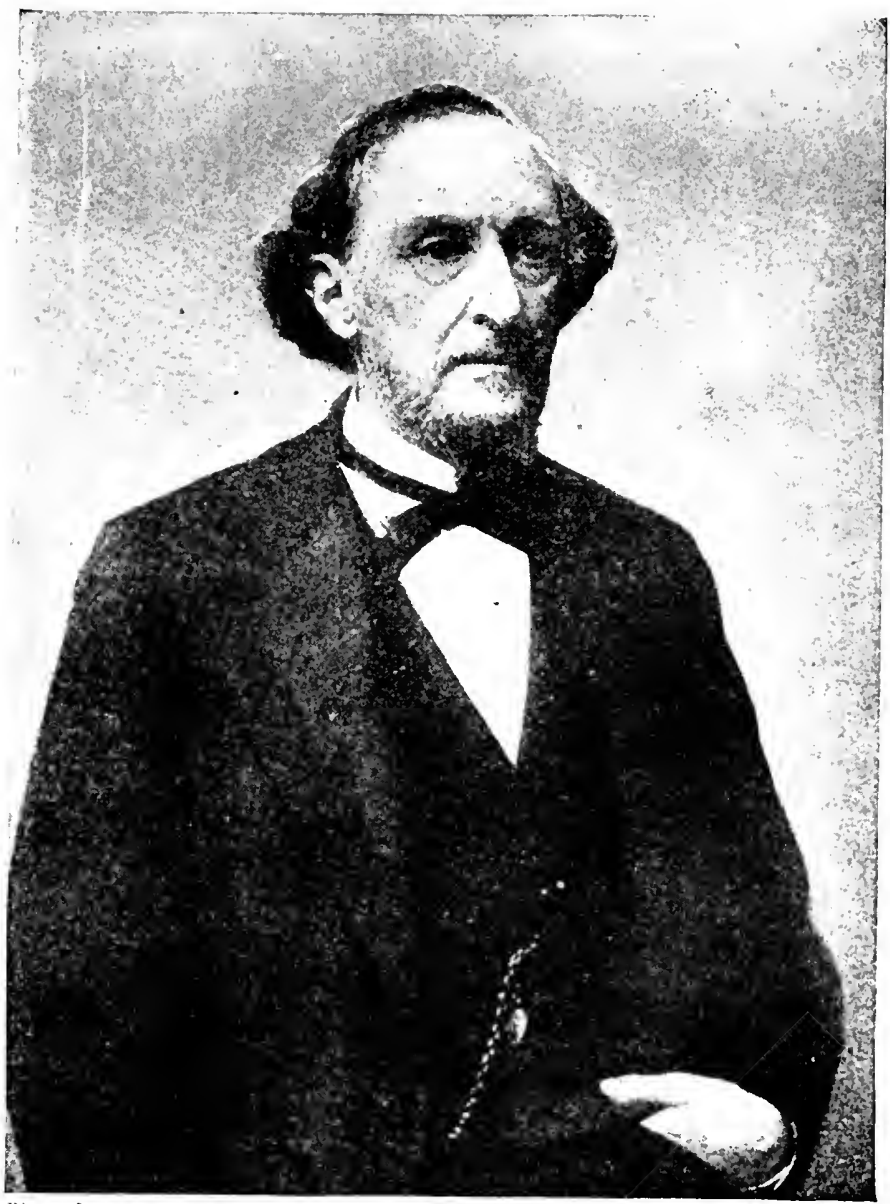

Blusco lbuñez, Argentina y sus grandeats

Bartolomé Mirre 
de su sacrificio. Buscó su camino en medio de la tempestad en que su alma se agitaba, y lo encontró; y tuvo previsión, abnegación, y fortaleza para seguirla, y por eso el sacrificio no fué estéril.

5 El Perú había sido libertado por un puñado de cuatro mil hombres (dos mil argentinos y dos mil chilenos) contra veintitrés mil soldados, que mantenían en alto los pendones del rey de España en toda la extensión del continente americano. 1o San Martín, sosteniendo en sus brazos robustos, como muy bien se ha dicho, el cadáver de su pequeño ejércitó diezmado por la peste y los combates, había declarado la independencia del Perú.

r5 Esta grande empresa, realizada con tan pobres medios, con tanta economía de fuerzas y de sangre, y tan fecundos resultados, se caracteriza como profunda combinación política y militar, en que circunscribió la lucha de la independencia amerizocana a un punto estratégico; en que forzó el último baluarte de la dominación española en SudAmérica; en que hirió el poder colonial en el corazón, con la espada de Chacabuco y Maipo; en que

13. la independencia del Perú. San Martín declared the independence of Peru in 1821 .

17. se caracteriza como... militar, can be characterized as a profound polivical and military plan.

23. con la espada de Chacabuco y Maipo, i.e., the two most decisive battles fought by San Martin in Chile, in 1817 and 1818 . These victories gave Chile its independence. 


\section{LA ABDICACION DE SAN MARTINN. I69}

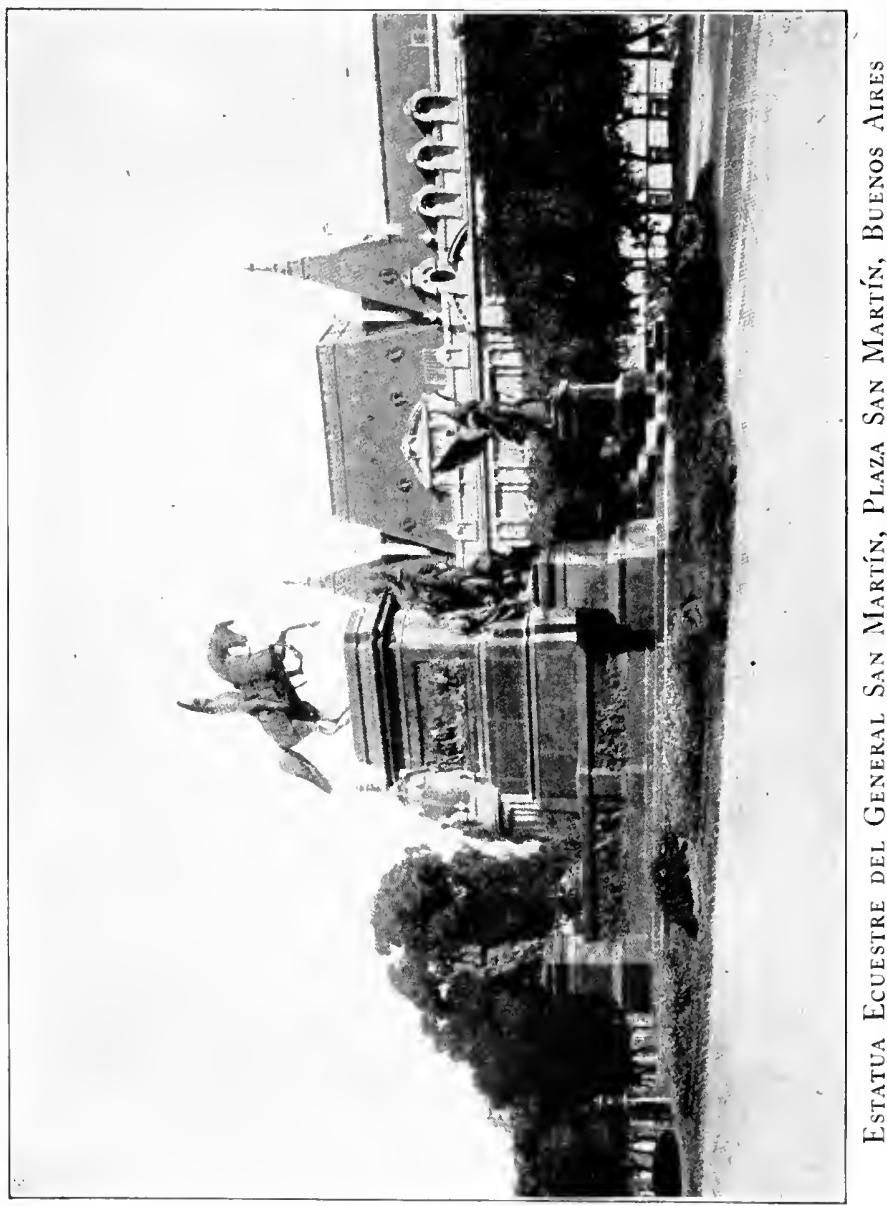


encerró en un palenque sin salida a los últimos ejércitos españoles y realistas, dentro del cual debía decidirse por un supremo y definitivo combate a muerte, la causa de la emancipación de un 5 mundo.

Desde ese momento, el triunfo de la causa de la independencia americana dejó de ser un problema militar y político: fué simplemente cuestión de más esfuerzos y de más tiempo.

ro Desde ese día, el sol al levantarse sobre el hemisferio de Colón, no alumbró más esclavos que los que aún continuaban aherrojados bajo las plantas de los últimos ejércitos realistas, atrincherados en las montañas del Perú.

is Pero, para alcanzar la victoria definitiva, era necesario que el mismo Perú, hondamente revolucionado, pusiese sobre las armas diez mil soldados más, y el Perú no podía ponerlos. Chile no podía repetir el supremo esfuerzo que había hecho, para zo remontar sus tropas expedicionarias. La República Argentina, política y socialmente disuelta, al mismo tiempo que sus hijos ausentes emancipaban lejanos pueblos, no podía enviar nuevos contingentes a su ejército libertador de los Andes.

25 Mientras tanto, las legiones triunfantes de Bolivar, que desde las bocas del Orinoco habían cruzado

4. emancipación de un mundo, i.e., South America.

25. Bolivar (Simón). Together with San Martin he brought about South American independence. He had been triumpliant in the North and founded the republic of 
de mar a mar el continente, se encontraban con las de San Martín, que desde el Plata habian cruzado al Pacífico, dominándolo; y bajo la línea ardiente del ecuador y al pie del Chimborazo, se saludaban las banderas independientes de las 5 Provincias Unidas del Río de la Plata, de Chile, del Perú, y de Colombia, sellando la alianza continental con una nueva victoria alumbrada por los fuegos volcánicos del Pichincha.

En tal situación, Colombia era el árbitro de los ıо destinos del Nuevo Mundo, y en manos del Libertador Bolívar estaba la masa hercúlea que debía dar el golpe final, en el supremo y definitivo combate que iba a librarse en el Perú.

Para concentrar este supremo esfuerzo, los dos 15 grandes libertadores se encontraron en aquel punto céntrico del mundo en que sus soldados habían fraternizado. Sus miradas se cruzaron como dos relámpagos en la región tempestuosa de las nubes, sus brazos se unieron, pero sus almas no se con- 20 fundieron, porque comprendieron, que aunque

Gran Colombia, now Colombia, Venezuela, and Ecuador. He was born in Caracas, Venezuela, in 1783 , and died in 1830. The hopes and ambitions for which he had fought (a great republic by the name of Gran Colombia) had been set at naught in his own times by the revolt of the constituent members.

4. Chimborazo, lofty mountain and volcano in Ecuador.

9. Pichincha, volcano in Ecuador; the allied troops of Bolivar and San Martin won a decisive victory over the Spaniards in this vicinity in 1822 . Cf. 126,1 . 
profesaban una misma religión, no pertenecían a la misma raza moral.

Bolívar era el genio de la ambición delirante, con el temple férreo de los varones fuertes, con el 5 corazón lleno de pasiones sin freno, con la cabeza poblada de flotantes sueños políticos, sediento de gloria, de poder, de esplendor, de estrépito, que acaudillando heroicamente una gran causa, todo lo refería a su personalidad invasora y absorvente. ro $\mathrm{El} \mathrm{mismo} \mathrm{se} \mathrm{ha} \mathrm{retratado} \mathrm{así,} \mathrm{prorrumpiendo} \mathrm{en}$ uno de sus teatrales simulacros de renuncia del mando supremo: "Salvadme de mí mismo, porque la espada que libertó a Colombia no es la balanza de Astrea.

15 San Martín era el vaso opaco de la Escritura, que escondía la luz en el interior del alma : el héroe impersonal que temía la ambición honrada del bien común, por todos los medios, por todos los caminos, y con todos los hombres de buena volunso tad, según él mismo se ha definido con estas sencillas palabras: "Un americano, republicano por principios, que sacrifica sus propias inclinaciones por el bien de su suelo."

7. que. The antecedent is genio, referring to Bolivar in line 3 .

8. todo lo referia a, considered eserything in relation to.

14. Astrea, the goddess of Justice in (ircek mythology.

15. vaso opaco de la Escritura, "nassuming chosen vessel of the Scriptures. 
Por eso los dos murieron en el ostracismo. El uno en su edad viril, precipitado de lo alto, con las entrañas devoradas por el buitre de su inextinguible ambición personal, llorando hasta sus últimos momentos el poder perdido. El otro descendió 5 sereno y resignado la pendiente del valle de la vida, con la estoica satisfacción del deber cumplido, guardando en su ancianidad el secreto roedor de sus tristezas, como en los heroicos días de su épica carrera había guardado el sigilo pavoroso de sus io concepciones militares.

Estas dos naturalezas opuestas y compactas, fuerte la una por sus defectos en el choque, y la otra por sus calidades en la resistencia, se midieron como dos gigantes al abrazarse, y se penetraron 15 mutuamente. San Martín fué vencido por el egoísmo de Bolívar; pero San Martín venció a su rival en gloria, mostrándose moralmente más grande que él.

El Libertador de Colombia alcanzará más triun- 20 fos, cosechará más laureles y merecerá más la admiración de la historia por su gloriosa epopeya terminada.

El Libertador argentino, venciendo las más arduas dificultades, preparando el camino y ven- 25 ciéndose a sí mismo, merecerá en los tiempos la simpatía etérea de las almas bien equilibradas.

I-5. This sentence has no principal verb. Supply murió-

13. la una, i.e., de Bolívar.

13. la otra, i.e., de San Martín. 
San Martín, con su alto buen sentido, dándose cuenta clara de la situación y de sus deberes para con ella, se inmoló en aras de una ambición implacable, que era una fuerza eficiente, y cuya

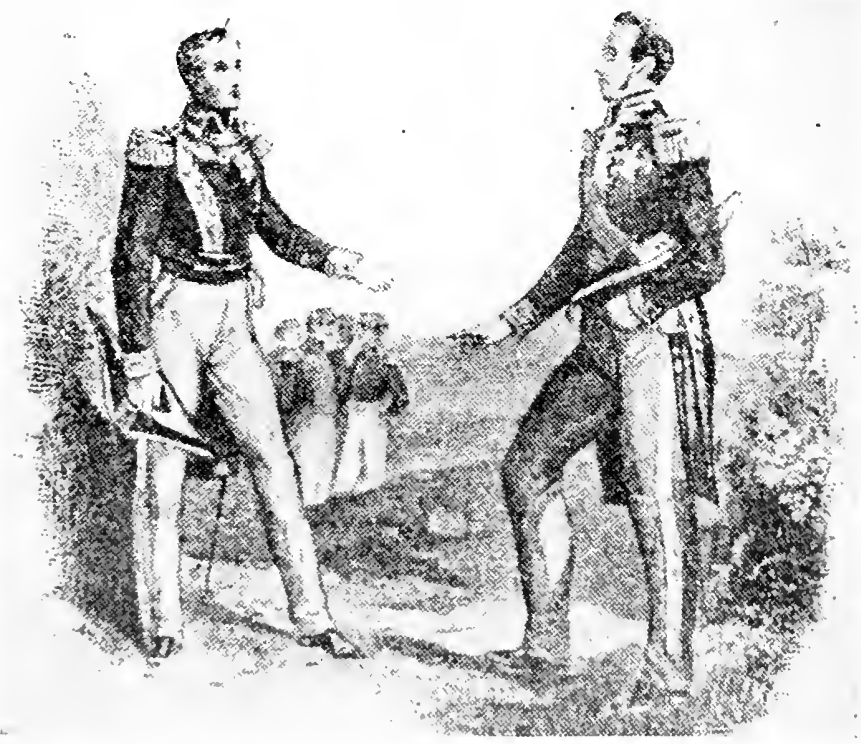

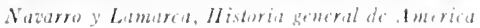

San Martin y Bolímar in (igayaguh.

5 dilatación fatal era indispensable al triunfo de su causa.

Los realistas conservaban aún diez y nueve mil hombres en las montañas del l'eru. San Martín apenas contaba con ocho mil quinientos, y necesi- 
taba forjar nuevos rayos para continuar la lucha. Bolivar, al frente del victorioso ejército de Colombia, tenía en sus manos el rayo, que a uno de sus gestos podía fulminar las últimas reliquias del poder español en América; pero a 5 condición de compartir con nadie su gloria olímpica.

Ante esta solemne espectativa, San Martín reconoció el temple de sus armas de combate, y vió: que el Perú flaqueaba, que su opinión so pública estaba sublevada, que su ejército no tenía ya el acerado temple de Chacabuco y Maipo, y que no podría dominar estos elementos rebeldes sino haciéndose tirano. - Interrogó al porvenir, y previendo que en un término fatal su gran per-is sonalidad se chocaría con la de Bolívar, dando quizás un escándalo al mundo, y retardando de todos modos el triunfo de la América con mayores sacrificios para ella, prefirió eliminarse como obstáculo. - Sondeó su conciencia, comprendió que no zo era como Macabeo el caudillo de su propia patria, y reconociéndose sin voluntad para ser tirano y sin poder moral y material para continuar la lucha con fuerzas eficientes, abdicó a Bolivar la

ro. su, i.e., del Perú.

Ir. su, i.e., de San Martín.

21. Macabeo. Judas Maccabeus, of the Maccabees, led the Jews against the tyrant Antiochus IV, assuming the leadership of the revolt in B.c. I64, upon the death of his father Matathias. 
espada de Chacabuco y Maipo, después que se convenció de que su ofrecimiento de servir no sería aceptado.

Tal es el significado histórico y el sentido moral 5 de la abdicación de San Martín. 


\section{EL GENERAL BELGRANO}

\section{Bartoloné Mitre}

Belgrano es una de las más simpáticas ilustraciones argentinas, y una de las glorias más puras de la América, no sólo por sus memorables servicios a la causa de la independencia y de la libertad, sino también, y muy principalmente, 5 por la elevación moral de su carácter y por la austeridad de sus principios democráticos.

Su gloria es un patrimonio nacional, y pretender arrancar a su corona cívica una sola de sus hojas, sin justificar el derecho con que tal despojo se haga, ro sería defraudar al pueblo de su propiedad legítima.

Belgrano no ha sido un genio político del vuelo de Moreno, ni un genio militar de la altura de San Martín, con quienes comparte la gloria de haber sido, a la par del primero, uno de los fundadores is de la democracia argentina, y con el segundo, el héroe y el fundador de la independencia.

Fué un gran ciudadano y un verdadero héroe republicano, y ésa es su gloria.

13. Moreno (Mariano), Argentine patriot and statesman. Cf. 195 . 
El general Belgrano ha ejercido dos clases de autoridad en el mundo: exigía de sus subordinados una obediencia religiosa al cumplimiento del deber, y una exactitud casi igual a la que se exige a una 5 orden monástica, siendo inflexible en el castigo de los delincuentes.

Estas cualidades de mando han formado escuela. El general La Paz, que lo criticó por ellas, mandaba sin embargo sus ejércitos a la manera de Belgrano, ro y no por eso ha sido calificado de déspota.

El mando militar tiene en sí mismo algo de despótico, porque es personal, sólo tiene por límite la responsabilidad moral del que lo ejerce y el sentimiento de la justicia y de la dignidad humana. ${ }_{15} \mathrm{Si}$ el carácter de Belgrano hubiera sido despótico, se habría manifestado en el ejercicio de ese mando casi absoluto, que las exigencias de la revolución y el peligro común hacían que fuese más tirante que en las condiciones de la vida ordinaria; $y$ sin zo embargo, es sabido que Belgrano fué siempre justo a la vez que severo en el ejercicio tranquilo de su autoridad; que jamás abusó de ella, ni fué cruel ni voluntarioso, y todos cuantos militaron bajo sus órdenes, le guardaron por toda la vida, 25 estimación, respeto y amor.

Como autoridad política en los territorios donde hizo la guerra, responde en su favor el amor, el respeto, la confianza que supo inspirar a los pueblos,

23. todos cuantos, all who. 




Blasco Ibinea, Argentina y sus granteals

Manule Belgrano 
y que se conserva hasta hoy aún en los hijos de los indios a quienes trató justiciera y paternalmente en Misiones y en las montañas del Alto Perú.

Belgrano no era un demócrata a la manera de ${ }_{5}$ Artigas y de Güemes, expresiones exageradas de la democracia en una época de revolución: era un demócrata de la escuela de Wáshington y de Franklin, cuyos principios profesó toda su vida.

Lo prueba su anhelo por la instrucción de las romasas, atestiguado por los establecimientos de educación que fundó antes y después de la revolución; su respeto a la igualdad humana, manifestado hasta en su conducta con los indios de Misiones y del Alto Perú; su amor a la libertad ${ }_{5}$ del pueblo a que consagró su vida y sus afanes; su empeño constante por que la revolución se constituyera sobre la base de un poder deliberante

3. Misiones. V. map.

3. Alto Perú, old name of the present republic of Bolivia. It became an independent state in 1825 , with Bolivar as its first president.

5. Artigas (José, $17+6-1826$ ). Although Mitre speaks thus of Artigas, present-day Uruguayans regard him as their national hero. Works published lately on his life show that he was misunderstood. The federal system of government for which he stond obtains today in Argentina, though not in Uruguay.

5. Güemes (Martin), Gaucho leader in northern Argentina, whose deeds are commemorated in many tales. He may be compared with Marion, the American guerrilla fighter in the Carolinas during the American War of Independenece. 
emanado directamente del pueblo, como lo demuestra su correspondencia con Rivadavia; su respeto a la ley y a las autoridades constituídas, y más que todo, su abnegación, su desinterés y su modestia en presencia de los altos intereses públicos. 5

Por eso el general Belgrano es el ideal del demócrata. Ningún argentino ha merecido mejor que él este nombre, y negárselo, sería querer privar a su patria de uno de los más hermosos y acabados modelos que en tal sentido se pueden presentar so como ejemplo digno de admirarse y de imitarse.

Belgrano y San Martín, los dos verdaderos grandes hombres de la historia revolucionaria argentina, pueden llamarse padres y autores de la independencia de su país, teniendo de común, que is los dos fueron hombres de orden, ajenos a los partidos secundarios de la revolución, que nunca pertenecieron sino al gran partido de la patria, ni tuvieron más pasión que la de la independencia, la de la libertad americana, cuyo sentimiento 20 inocularon profundamente en el corazón de los pueblos y ejércitos que dirigieron.

2. Rivadavia (Bernardino), first president of Argentina and supporter of the unitarian or centralized form of republican government. During his presidency he established primary education and encouraged the Iniversity of Buenos Aires, which had come into being under his tutclage. He was far in advance of his time.

ro. en tal sentido, of this type.

20. cuyo sentimiento, the sentiment for which. 
San Martín en las provincias de Cuyo, y Belgrano en las del Norte, levantando el espíritu público en ellas, conquistando el amor y la confianza de las poblaciones, consiguiendo que los ${ }_{5}$ ciudadanos acudiesen voluntariamente y con entusiasmo a sus banderas, dispuestos a la lucha y al sacrificio, haciendo concurrir hasta las mujeres a la defensa de la causa común, prueban que tanto el uno como el otro eran verdaderos hombres de ro revolución, que si bien no se cuidaban de encabezar partidos, sabían como se mueve a las democracias encabezando una causa popular.

El general Belgrano, recibiendo el mando del ejército desorganizado de dos derrotas, haciendo ${ }_{15}$ la guerra en medio de pueblos decaídos o descontentos en parte como lo hemos probado ya, obteniendo una victoria en una retirada desigual, haciendo por último pie firme en Tucumán, lle-

r. Cuyo. P'revious to his invasion of Chile, San Martin was ostensibly (iovernor of Cuyo, a region including the present provinces of Mendoza, San Juan, and San Luis. It was in this capacity that he made realy his Ejército de los Andes to attack the Spaniards in Chile.

2. las del Norte. This includes the provinces of Salta, Tucumán, Jujuy, and what was known as Alto Perú, or Bolivia.

10. encabezar partidos, i.e., secundarios. Cf. 181, 17.

14. dos derrotas. The Argentinc army of the North had been defeated twice: at Huafuí in June, 1811 , and in the battle of Nazareno in January, 1812.

18. haciendo por último pie firme, making at last a resolule stand. 
vando a su población al campo de batalla, y predisponiendo a la provincia de Salta a hacer los sacrificios más sublimes de que es capaz el patriotismo, nos enseña cómo los verdaderos demócratas encabezan, no los partidos, sino los grandes movi- 5 mientos de la opinión que deciden del destino de los pueblos. 


\section{EL GENERAL LAS HERAS}

\section{Bartoloné Mitre}

Hay héroes de circunstancias que ocupan y abandonan bulliciosamente la escena de la historia ; héroes que a veces aparecen grandes a los ojos de sus contemporáneos más bien por el medio en que 5 viven $\mathrm{y}$ los accesorios que los rodean, que por sus propias cualidades y por sus propias acciones.

Estos son los héroes teatrales de la historia.

Ellos necesitan para brillar de las luces artificiales de la popularidad pasajera. Sólo se estiro mulan con los aplausos de la calle y de la plaza pública. Para ellos no hay elocuencia posible sino en lo alto de la tribuna $y$ en medio de una pomposa decoración, ni heroísmo sino en presencia de millares de testigos. Esclavos de ajenas pars siones y de su propia vanidad, sólo conciben la gloria de un carro triunfal arrastrado por adoradores, y prefieren una corona de cartón dorado con

Titul:. Las Heras (Juan Gregorio de, 1780-1866), Argentine patriot and general who distinguished himself in the Chilean campaign under San Martín. At Cancha Rayada (1818) where the troops of San Martin suffered a reverse, it was Las Heras who saved the day by his masterly retreat and coolness in the general confutsion. 
tal que todos la tomen por oro de buena ley, a la inmortal corona de laurel sagrado que sólo resplandece en la obscuridad de la tumba. Hambrientos de vanagloria, ebrios de aplausos, enfermos de celos y de vanidad pueril, el aplauso de 5 la propia conciencia no llega a sus oídos; la verdadera gloria no les satisface, el silencio los anonada, la soledad los hace creerse muertos, y el retiro es para ellos como el vacío de la máquina neumática que apaga los oídos.

Sobre la tumba de éstos no se escribió nunca el sublime epitafio de Esparta: "Murieron en la creencia de que la felicidad no consiste ni en vivir ni en morir, sino en saber hacer gloriosamente lo uno y lo otro."

Los hombres grandes por sí mismos, que no trafican con la gloria, para quienes el mando es un deber, la lucha una noble tarea, y el sacrificio una verdadera religión; los que al abandonar el teatro de la vida pública no tienen que despojarse a su 20 puerta de las alas prestadas de un día, y queman aceite de su propia vida en la lámpara de sus vigilias, ésos viven en paz y conversan familiarmente con el genio de la soledad, el silencio serena su alma agitada por las tempestades populares. A esos 25 hombres sienta bien el modesto retiro en que pueden ser estudiados y estimados por lo que en

9. como el vacío de la máquina neumática que apaga los oídos, like the vacuum of the pneumatic pump which deadens the hearing. 
sí valen, despertando la admiración o la simpatía por cualidades superiores a los ingeniosos prestigios de la prosperidad.

Tales o semejantes reflexiones a éstas hacía en 5 una hermosa y apacible tarde de verano del año I 848, atravesando la magnífica alameda de Santiago de Chile, y dirigiéndome a uno de los barrios más apartados de la ciudad, donde vivía y vive aún el general D. Juan Gregorio de Las Heras, rocapitán ilustre y libertador de tres Repúblicas, republicano sencillo y desinteresado, que siendo uno de los héroes más notables de la epopeya de la independencia americana, vivía tranquilo en el retiro, sin espada, sin poder y sin fortuna.

Is Iba a pagarle la visita que infaliblemente hace este soldado lleno de cortesía a todo argentino que llega a aquel país: y al hacerlo era arrastrado por algo más que un deber social, pues admirador de sus servicios y virtudes, había encontrado en él zo un héroe según mi ideal, y un hombre según mi evangelio.

Al dirigirme a su casa, podía contemplar a la distancia las nevadas cordilleras de los Andes, a cuyo pie está el memorable campo de Chacabuco; 25 y mi vista se perdía en la vasta llanura del valle de Maipú y los caminos que desde él conducen al Sur de Chile, donde Las Heras, siguiendo has huellas

ro. tres Repúblicas. Argentine by birth, Las Heras fought for the independence of Peru and Chile besides that of his own country. 


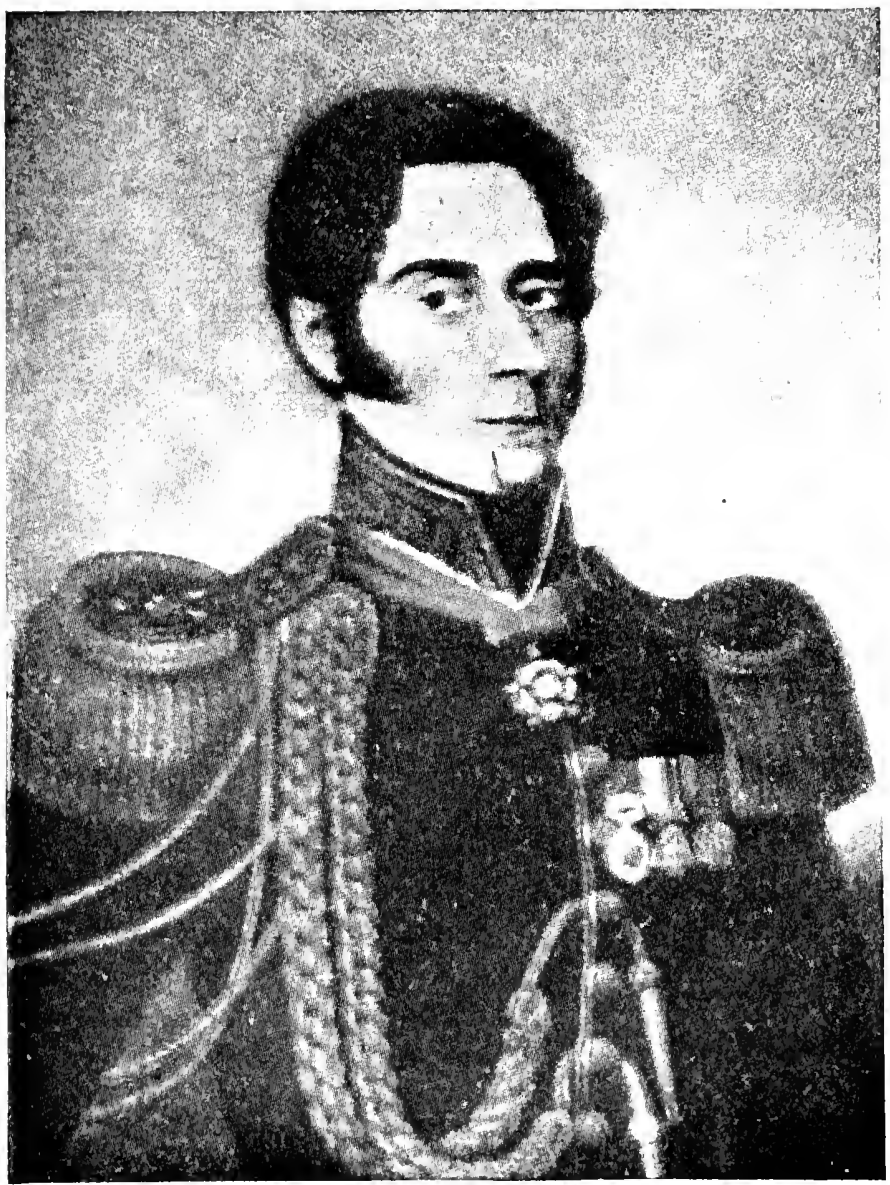

Sararro y Lamarca, Hi warin senerill de America

Juan Girkgorio de Las lferas 
de San Martín, se había ilustrado en grandes batallas y combates.

Lleno de estas ideas, de esos recuerdos y de este espectáculo grandioso, llegué a su antigua casa de ${ }_{5}$ familia, cuya arquitectura pertenece a la época colonial. Era singular que quien más había contribuído a destruir aquel régimen con su espada, hubiese encontrado en medio de tantas ruinas como hizo en ella, un viejo techo con el sello de la rodominación española, donde abrigar su cabeza en el invierno de la vida.

Es el Bayardo de la República Argentina, el militar $\sin$ miedo $y \sin$ reproche, decano del ejército argentino por su edad, por sus servicios $15 \mathrm{y}$ por sus elevadas cualidades morales.

En su avanzada edad y a pesar de las dolencias que le aquejaban, conservaba aún cuando le vi por la última vez en Chile, en i 850, toda la arrogancia del soldado, y el reflejo de la belleza varonil de sus 20 heroicos años. Su talla es alta y erguida, su ojo negro, profundo y chispeante, respira la firmeza y la bondad, y en sus maneras se nota algo de la habitud del mando, unido a la exquisita cortesanía de los hombres de su tiempo. En aquella época ${ }_{25}$ le vi una vez de grande uniforme en medio del Estado Mayor de Chile, y su imponente figura

9. en ella, i.f., en la época colonial.

12. Bayardo, famous French knight of the fifteenth century who was called "le cheodier sans peur of sans reproche", "the fearless and faulless knight". 
militar eclipsaba a todos, llamando sobre él la atención del pueblo, que veía en él al representante de sus más queridas glorias.

El general Las Heras no necesita apelar a la posteridad para esperar justicia y afirmar la 5 corona sobre sus sienes. El juicio que el pueblo sólo pronuncia en los funerales de sus héroes, ha sido pronunciado ya, para honor y gloria de él $y$ de su patria, por los hijos de la heroica generación a que perteneció, que es la posteridad a que ro apelaba San Martín, su ilustre maestro y compañero de gloria. 


\section{DON JUAN MARTÍN DE PUEYRREDÓN}

\section{F. López}

Pueyrredón era hombre de dotes distinguidísimas y sólidas; tenía dignidad personal y un imperio particular sobre sí mismo que no se desmintió en el resto de su vida ni aun en medio de los desca${ }_{5}$ labros que le esperaban. Sabía guardar con una firmeza imponente el decoro de su persona y de su poder. No mostraba ambición codiciosa ni urgente de mando. No se le vió nunca entrar en intrigas ni en tentativas, encubiertas o manifesro tadas, para apoderarse de la autoridad. Pero cuando era llamado a tomar parte en la dirección de los negocios, ocurría sin vacilar; mostraba una paciencia pertinaz en perseguir los propósitos que lo movían; y su energía, pero sin ninguna osten${ }_{15}$ tación, se hacía sentir en la netedad de sus ideas y en la firmeza de sus actos, no sólo para servir sin descanso a la causa de la independencia, sino para castigar también con una severidad extrema $y$ extraña a los hombres que se atrevían a ponerle

8. No se le vió nunca, He cens never seen. 
estorbos en su camino. Sus pasiones eran tranquilas en la superficie, y no se dejaban sentir sino

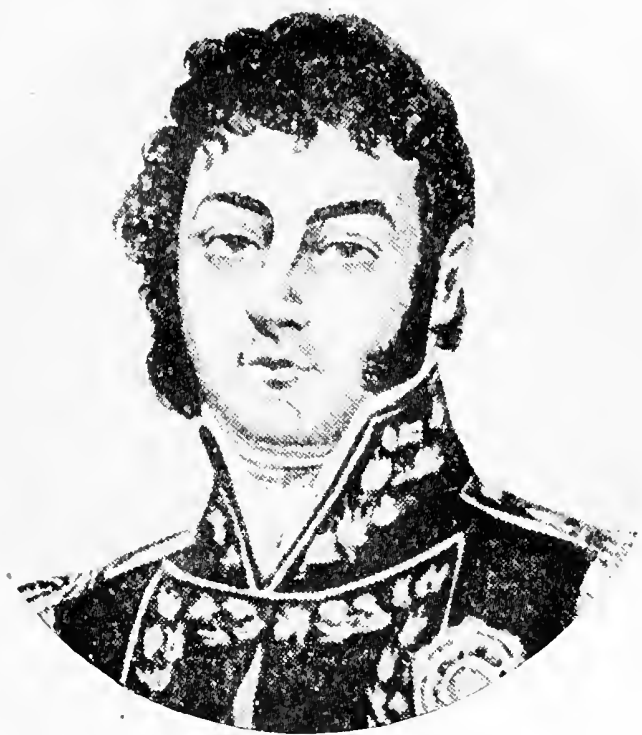

Navarro y Lamarca, Historia general de América

Juan Martín de Pueyrredón

por la fuerza latente y bien seguida de sus frías manifestaciones.

Siempre que las circunstancias lo habían exigido, 5 Pueyrredón se había presentado al peligro con

2. y no . . manifestaciones, and were felt only through the hidden and persevering force of their cold manifestations. 
decisión. Sin blasonar de ser guerrero había adquirido grados militares con una justicia que nadie podía negarle, sin que él reclamase jamás su competencia. Había figurado con honor y con 5 notoria fama de arrojado en la primera tentativa que los ingleses hicieron para apoderarse de Buenos Aires. Después de la revolución de Mayo había desempeñado una parte principal en las provincias limítrofes del Perú como Gobernador Intendente ro de Chuquisaca; y cuando el desgraciado encuentro de Huaquí obligó nuestras fuerzas a evacuar la línea del Desaguadero, Pueyrredón mostró un tino consumado para atravesar un país enteramente insurreccionado en contra nuestra; y con una is serenidad ejemplar, salvó del contraste recursos importantísimos en dinero, materiales y tropa, privando al enemigo de todas esas ventajas que habrían sido precisas para él en aquellos momentos.

En todas las cuestiones graves de guerra o de zo política, Pueyrredón pensaba con madurez; pesaba el valor de los hechos y las probabilidades de todas las consecuencias, poniendo al servicio de sus combinaciones una razón fría para meditar y para resolver, con una vigorosa precisión para ejecutar. ${ }_{25}$ Escribía sin brillo, pero con una corrección en la

3. sin que êl reclamase jamás su competencia, without his ever putting forcuard his finess.

I1. Huaqui. The Argentine forces under the command of Batcarce suffered here a severe defeat, after which Pueyredion took command of the retreating forces. 
frase, con tal trabazón en la lógica de sus ideas, con tal claridad clásica y consumada, que hoy mismo podría ser envidiado por el más hábil literato; y la proligidad con que sabía dividir su tiempo para encontrar el momento oportuno que correspondía 5 al despacho de cada asunto de interés público, rivalizaba con la atención esmerada que daba a sus negocios particulares, con la moderación y con la equidad con que arreglaba los negocios que estaban ligados con los suyos; de ello tenemos 10 pruebas numerosísimas y ejemplos bien testificados en los papeles que ha dejado.

La reserva de su carácter, la prudente parquedad de sus palabras, algo de interno y de poderoso que se percibía en él, sin poder decir cómo ni dónde, le I $_{5}$ hacían impenetrable y le daban un influjo eficaz aunque latente. Su astucia era tanto más fina y previsora cuanto que todo parecía en él natural y elevado, modesto e imparcial. Con la misma naturalidad con que tomaba el poder, lo manejaba 20 hasta en los extremos de la firmeza y de la severi$\mathrm{dad}$, apareciendo casi indiferente a sus encantos, $\mathrm{y}$ dispuesto siempre a abandonarlo: y como sus modales eran cumplidos y atentos, sin ser abiertos ni obsequiosos, imponía a los demás aquella dis- 25 tancia respetuosa que hace tan peligrosos a los

14. algo de interno y de poderoso, something profound and poiverful.

20. lo manejaba... severidad, he wielded it even in the extremes of firmuess and severity. 
hombres serios cuando juegan en el terreno falaz de la política o de la diplomacia, y que les da ese poder mágico a que jamás llegan los charlatanes de atraer $y$ de alejar al mismo tiempo a los que los stratan. Puestos en el poder imponen un cierto temor misterioso al vulgo, que no lo puede definir, y una sumisión religiosa a los agentes que los tienen que obedecer. Esto es lo que distingue el buen género del género falsificado.

ro Estas cualidades que Pueyrredón tenía en alto grado, eran las que hacían de él un hombre de gabinete consumado, y un compañero de Logia incomparable para San Martín, con quien tenía rasgos comunes de fisonomía política y de carácter Is personal.

I2. compañero de Logia. Francisco Miranda, a Venezuelan patriot, had been the prime mover in establishing a vast secret society with branches in Europe and America. The purpose of this socicty was to bring about a republican form of government in all South America. San Martin established a chapter of it in Buenos Aires under the name of Logia de Lautaro, and with its support carried through his invasion of Chile and Peru, despite party opposition. Lautaro was synonymous with patriotism because it was the name of an Araucanian chief famous for his fierce resistance against Valdivia, the conqueror of Chile.

13. con quien ... personal, with whom he held political riews in common and shom he resembled in his personal character. 


\section{MARIANO MORENO}

\section{Juan María Gutiérrez}

El nombre de don Mariano Moreno estará para siempre ligado a los orígenes de nuestra independencia, como lo está en las concepciones humanas, la idea a la forma, el hecho a las intenciones. Y cuando en las solemnidades patrias miramos brillar 5 la imagen del sol en una de las faces de nuestra bandera, colocamos con el pensamiento en la opuesta, la imagen de aquel ciudadano, porque él fué la luz de la revolución.

Él concentró los instintos del pueblo en su ro cabeza y depurándolos en tan vasto crisol, presentólos ante el mismo pueblo y ante el mundo, como su propósito grande y generoso.

Title. Mariano Moreno was born in Buenos Aires in 1778. He was a man whose early death was a sad loss to the cause of the Revolution. He was a lawyer renowned for his integrity and love of country. As secretary of the Junta Gobernativa in $18 \mathrm{ro}$, he championed the republican form of government. La Gaceta de Buenos Aires, of which he was editor, marks the beginning of the Argentine press. He died on the high seas in 1811 , bound for England as the delegate of the newly established Argentine government.

5. solemnidades patrias, national holidays.

6. sol. The Argentine flag has two horizontal blue stripes and in the middle a white one with the image of the sun in it. 
Nuestra revolución nació serena como la aurora de un día hermoso, y dió sus primeros pasos conducida por la razón y el desprendimiento. Nuestros padres discutieron antes de obrar, y no 5 admitieron el sacrificio de la sangre en el altar de la libertad que fundaban. En mayo de i8io, el resentimiento y la venganza se transformaron en heroísmo, en acción vigorosa la apatía colonial, en patriotismo la antigua fidelidad, los vasallos roen señores de su destino, y brotaron como por encanto, ejércitos, instituciones liberales, sentimientos de nacionalidad y todos los elementos que constituyen la Patria.

Si un pueblo sacude su yugo antiguo con tanta ${ }_{15}$ dignidad, es porque se siente fuerte en la justicia de su resolución, porque la virtud que es la fuerza por excelencia, le preside en sus actos.

Esa fuerza y esa virtud tuvieron por fortuna su representante en don Mariano Moreno, miembro so del primer gobierno revolucionario.

Comenzó a desempeñar sus delicadas funciones a la edad de treinta años con toda la precoz madurez de sus aventajadas facultades. Brioso de carácter, elocuente, avezado a las luchas de ${ }_{25}$ la lógica y del derecho en las discusiones forenses, reunía en su persona otras cualidades que le ha-

6. mayo de 18 ro. A reference to the 25th of May, 18 ro. The first cry of independence was heard in Buenos Aires, and Cisneros, then Viceroy, was put out of power. V. Introduction. 


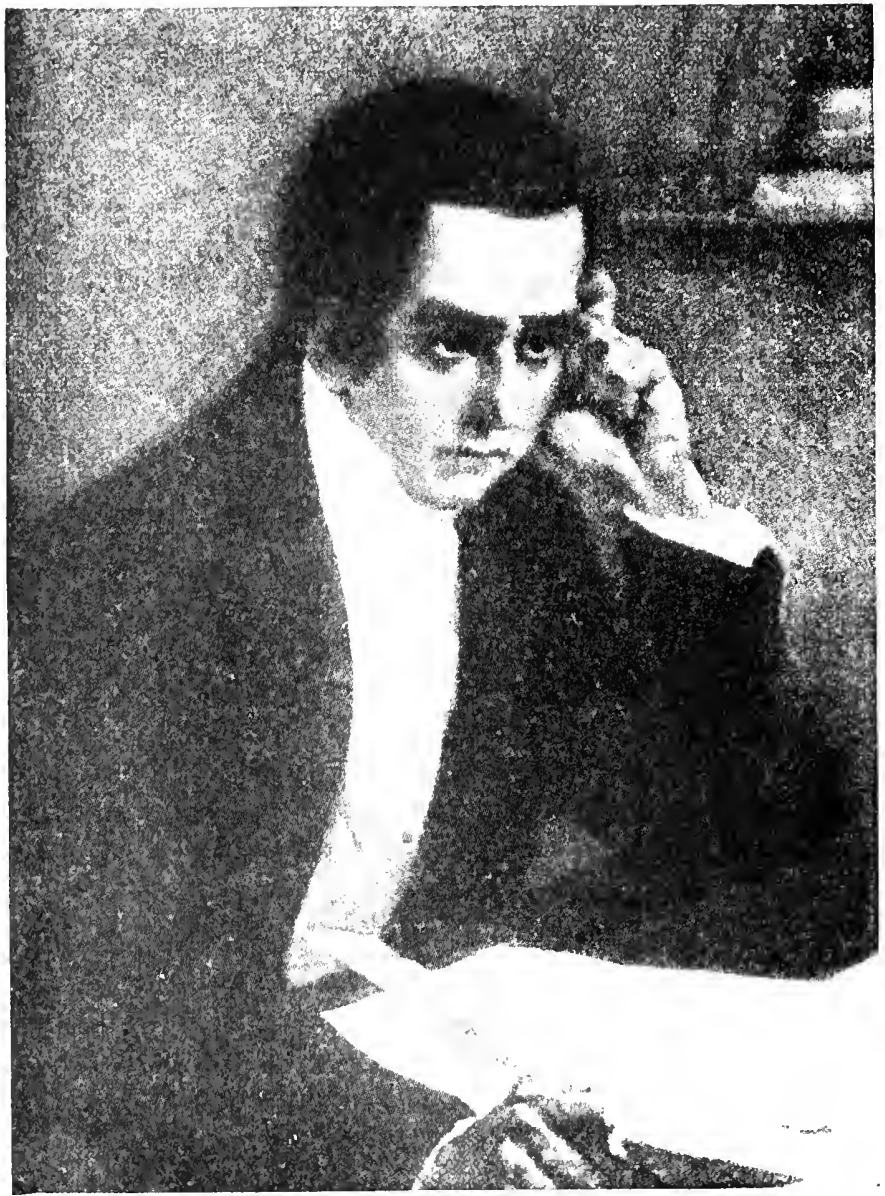

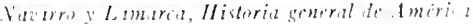

$$
\text { Marane Moreno }
$$


cían simpático y popular. Brillaba en su abierta fisonomía la iluminación del genio, y la rica sangre de la juventud circulaba en su rostro, bajo una tez blanca y transparente, como la savia de una 5 planta lozana.

Este atleta bajó a la arena en toda la plenitud de sus fuerzas, acendradas en la austeridad del hogar y de los estudios serios. Hijo excelente, padre afectuoso, agradecido discípulo, unía a una ro virginidad de sentimientos a la antigua, el atrevimiento y la audacia que inspiran las ideas que son la gloria de los tiempos modernos.

Su personalidad se eclipsa dentro de su idea, como el núcleo de un cometa en su atmósfera ${ }_{5} 5$ luminosa. La posteridad y la historia, no él, le colocan entre los primeros hombres de la independencia, y le conceden su papel principal de revelación y de iniciativa en el drama de la revolución. No aspira a mandar sino a dirigir. Piensa 2o recta y generosamente para que el pueblo pueda gobernarse a sí propio con acierto. Quiere como borrar hasta los nombres propios de los mandatarios, para que la autoridad que preside los nuevos destinos de la patria, se sienta como influencia ${ }_{25}$ benéfica, y no se palpe como cosa natural, aspirando a dotarla, en su noble exaltación democrática, con los atributos de una entidad sobrehumana.

15. no él, i.e., he made no efforts at self-glorification.

21. Quiere... propios, Ile wishes as it were to do away with the very names. 
Moreno no tenía confianza sino en las fuerzas morales y quiso traerlas al gobierno y darlas al pueblo como palanca para remover los obstáculos que la marcha de la Revolución iba a encontrar en su camino.

Y como entre aquellas fuerzas, la más poderosa es la prensa, - instrumento hasta entonces vedado a los hijos de la Colonia para ventilar las cuestiones políticas y los intereses sociales, - el secretario de la Junta se constituyó voluntariamente en ro redactor de La Gaceta, colocando al frente de sus escritos uno de aquellos magníficos arranques de amor a la libertad que son tan frecuentes en las inmortales páginas de Tácito. Este periódico nació con el nuevo régimẹn, proclamando los is tiempos "en que era dado pensar y manifestar sin trabas el pensamiento".

La prensa se hizo desde entonces militante y popular. Los anteriores ensayos periodísticos se arrastraban tímidos por la senda de la erudición, y 20 apenas si una que otra chispa se derramaba a favor de los intereses públicos. Los talentos y el patriotismo de Vieytes y de Belgrano no habían conseguido interesar al pueblo en la contemplación de su propio destino, y los tipos de nuestra única ${ }_{25}$

8. Colonia, i.e., Argentina, prior to its independence.

14. Tácito, Tacitus, famous Roman historian (55-I 20 A.D.).

20. y . . chispa, hardly any light.

23. Vieytes (Hipólito), one of the leaders of the Argentine revolution and member of the Junta Gobernativa. 
imprenta aparecian yertos sobre cl papel como el metal de que estaban fundidos.

La Gaceta demolía y creaba al mismo tiempo. Fué el ariete asestado contra las murallas de la ${ }_{5}$ tiranía retrógrada del Virreinato, y la fuerza que levanta sobre el cimiento de la libertad al pueblo que surgía del seno de los Cabildos abiertos. ¡ Qué hermosa era la patria que pintaba la pluma del ilustre redactor! ¡Cuán orgulloso se sentía rotodo argentino al reconocerse hijo de esa Patria y árbitro de fraguarse su propia felicidad, ejerciendo derechos que antes no había comprendido! La ciencia de la política amaneció entre nosotros y se popularizaron sus aplicaciones. Súpose er-${ }_{15}$ tonces lo que era una sociedad entregada a sí misma y libre del freno pesado $y$ de las riendas mezquinas manejadas por un elegido de la casualidad desde las remotas orillas del Manzanares. Discutiéronse las diversas formas de gobierno a zoque pueden someterse los hombres en sociedad; y las Provincias, convocadas por primera vez a un Congreso, vieron con sorpresa que los habi-

5. Virreinato, i.e., Spanish rule in Argentina.

I . árbitro de, frèt to.

II. ejerciendo, by exercising.

18. Manzanares, river in Spain, on the banks of which Madrid is located; here synonymous with Spain.

22. Congreso, reference to the Congress of Tucumin, in 1816 , which dectared the independence of Argentina. Cf. 
tantes podían dignificarse hasta el punto de dar fuerza de ley a aquellas aspiraciones más en consonancia con sus intereses y bienestar.

Bajo el influjo de tan hábil piloto, la Revolución no podía naufragar. El rumbo estaba dado a la 5 mejor estrella, y por muchos desvíos que hubiera de experimentar la nave de la República, tenía forzosamente que llegar a la democracia.

Ésta fué la obra de don Mariano Moreno. El pueblo había conseguido su independencia; pero го aquel gran patriota le preparó el porvenir americano que es hoy su modo de ser definitivo.

5. El rumbo ... estrella, The course was pointed toward the best star, i.e., democracy.

I2. su modo de ser definitivo, its established form of government. 


\section{GÜEMES}

\section{Bartolomé Mitre}

Güemes, perteneciente a una notable familia de Salta, se presenta él mismo en sus actos, en sus documentos políticos, en su correspondencia confidencial, como lo que es, como un caudillo 5 político y militar. Éste es el rasgo prominente y verdaderamente original de su fisonomía: y es el único digno de llamar la atención, sea que se le admire, sea que se le condene, porque como caudillo, fué grande, combatiendo por la causa ro común, y como caudillo fué funesto, contribuyendo a la desorganización política y social.

Quítese a Güemes el carácter de caudillo, y Güemes no es nada, o es cuando más una pálida fisonomía militar, que nada de extraordinario is tendría en sí misma, si los hechos que ejecuta o promueve no fuesen la consecuencia de la táctica, del prestigio, de los medios de acción de caudillo representante de las masas populares, fanatizadas

2. Salta, province of Argentina, and its capital. Gïemes used to refer to Sialta as mi provincia.

7. sea que ..., sea que, whether... or. 
por la doble pasión de la independencia y de la ciega adhesión a su persona, dispuestas igualmente, a un gesto suyo, a esgrimir sus armas ya contra el enemigo común, ya contra la sociedad.

Bórrese del retrato histórico de Güemes el 5 nombre de caudillo, y Güemes, o no será nada como militar, o será cuando más, el activo jefe de una vanguardia, hostilizando a un enemigo que, invadiendo un país accidentado y cuya opinión le es contraria, viendo cortados los recursos io por la resistencia de la población en masa, se ve al fin obligado a retirarse después de una serie de guerrillas y combates, lo que si bien es meritorio, no sería por sí solo una cosa extraordinaria, cuando a la retirada de ese enemigo concurrieron poderosas ${ }_{5}$ causas más o menos inmediatas.

Quitarle ese título como el de gaucho que él hizo glorioso y que fué su nombre de guerra, es despojarle de la agreste corona que sus heroicos compañeros, aquellos hijos de la naturaleza a 20 quienes él llamaba mis gauchos, colocaron sobre sus sienes en los bosques y valles de Salta, cuando le apellidaron el Padre de los Pobres; sería borrar

9. país accidentado. Salta and Jujuy, as can be seen from the map, are in a mountainous region.

Ir. la resistencia de la población en masa. While San Martín was conquering Chile in 1817 and invading Peru in 1821 , the Spaniards were trying to fight their way down from Peru into Argentina. Güemes' efforts were most important in holding the Spanish forces back until San Martin struck at the heart of their power, Lima. 
uno de los rasgos característicos y propios de la resistencia popular que hizo el caudillo desde $\mathbf{I} 8 \mathbf{I} 7$ a $\mathrm{I} 82 \mathrm{I}$.

Güemes era, pues, un verdadero caudillo, bajo ${ }_{5}$ cualquiera faz que se le considere; así lo califican

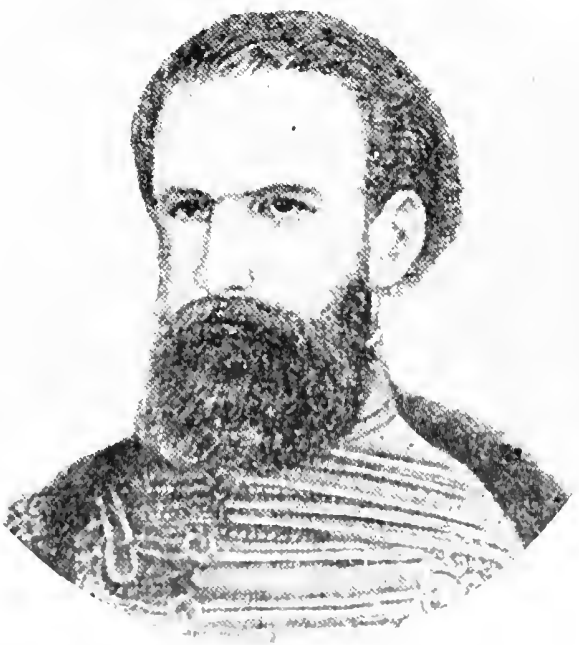

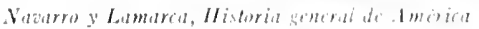

Martín (iugahs

los contemporáneos que lo conocieron, así lo pintan sus admiradores: aś lo aclamaron sus partidarios y así se retrata él mismo.

Gïemes emcontró el campo preparado. No 
inició la revolución ni libertó pueblos, ni imprimió dirección a los acontecimientos, ni fundó nada.

La fuerza de Güemes no residía tanto en su propia individualidad, cuanto en la fuerza de 5 las multitudes que acaudillaba y representaba, y cuya substancia, diremos así, se asimilaba: y aun cuando sin injusticia no pueden negarse cualidades superiores al que así dominaba y dirigía esas masas fanatizadas por su palabra, condu- ro ciéndolas a la lucha y al sacrificio, no era de cierto un genio superior ni en política, ni en milicia; ni sus hechos fueron precisamente los que decidieron de los destinos de la revolución, que se decidían de otros campos, con medios más poderosos de 15 acción, y bajo una dirección más inteligente, más metódica y con miras más trascendentales.

Su gloria no es ésa. Su gloria consiste en que, como caudillo, si bien cooperó, directamente algunas veces e indirectamente otras, a la desor- 20 ganización general que ha prolongado una revolución social, fué siempre fiel a la idea de la unidad nacional, y salvo un corto paréntesis, reconoció siempre la autoridad general, aunque a condición de hacer lo que mejor le convenía, pues era dueño 25 $y$ señor absoluto dentro de las fronteras de $s u$ provincia, como él la llamaba.

Su gloria consiste en que jamás desesperó de la

16. dirección más inteligente, i.e., de San Martín. 
suerte de la revolución; que en los más tristes días, cuando ella era vencida en el exterior y se veía desgarrada en sus propias entrañas por las furias de la guerra intestina, él combatió solo al frente de 5 sus valientes gauchos en las fronteras, paralizando las operaciones de ejércitos poderosos y dando tiempo para que se desenvolviesen otras combinaciones positivas que fueron en definitiva las que salvaron la revolución. A esas operaciones ro concurrieron eficazmente los extraordinarios esfuerzos de Güemes, dignos sin duda de ocupar un lugar distinguido en la historia argentina, porque así comola primera conmoción revolucionaria, en i 8 Io, determinó las actuales fronteras de la República, I 5 así tambien, en esa época aciaga, la espada de Güemes trazó con una línea imborrable la frontera definitiva de la Nación Argentina por el norte.

Cuando Güemes se puso al frente de la provincia de su nacimiento, ya robustecida por la fuerza zo moral de sus triunfos en 'Tucumán y Salta, por el desarrollo de las fuerzas populares que ocho años de revolución habian puesto en acción, contó además en las cuatro primeras campañas con el apoyo de un ejército que cubría su retaguardia 25 Y su flanco; Y en la de $1 \$ 17$ con el de otro que iba a atravesar los Andes para dar libertad a la

2. se veía. . entrañas, sat its sery sitals torn.

24. un ejército, i.t., el ejército del Norte under Belgrano's (c)mmand.

25. de otro, i.e., San Martin's army. 
América, que ya para los argentinos era un hecho irrevocable.

De ahí la energía de la resistencia de Güemes, de ahí su buen éxito. i Honor a las Provincias del Norte, que en la época más calamitosa de la 5 revolución, cuando el congreso de Tucumán, producto del cansancio más bien que de la fe, trazaba con colores sombríos el cuadro de una situación desesperada, apoyaron la declaratoria de la independencia que inspiraron San Martín ı y Belgrano! A ellas que desde entonces fueron el baluarte de la Nación, cuando ardía ésta en guerra civil y cuando esa guerra devoraba hambrienta sus ejércitos regulares. ¡ Honor a Güemes que dirigió esa heroica resistencia, en la cual rindió noble-15 mente su vida! Pero i honor también a aquél que fué el primero que les reveló su fuerza, que les dió dos días de gloria inmortal, y encendió en sus corazones el fuego sagrado de la revolución, que no había prendido en todos o se había amorti- 20 guado en algunos, cuando los llamó a empuñar las armas, y a defender a la vez su credo y sus hogares en los campos de Tucumán y Salta!

Dice de él el general La Paz en sus Memorias

12. guerra civil. From the very beginning there was, as in the United States, a "Tory" party in Argentina that stood against independence.

16. aquêl, i.e., Belgrano, who defeated the Spaniards in the battles of Salta and Tucumán.

24. el general La Paz (José María), Argentine states- 
Póstumas, que, según el Dr. Vélez Sársfield, deben ser un texto bíblico para el historiador: "Si Güemes mandaba con un despotismo sostenido de la plebe que acuadillaba, se veía constituído en circuns5 tancias especiales, $y$ por grandes que fuesen sus defectos, era el único dique que se oponía al retorno de la tiranía peninsular. Si cometió grandes errores, sus enemigos domésticos nos fuerzan a correr un velo sobre ellos, para no ver en él sino roal campeón de nuestra libertad política, al fiel soldado de la independencia y al mártir de la patria."

man and general who, in defense of the unitarian cause, fought against Rosas and made himself famous during the eight-year siege of Montevideo (1835-18+3).

I. el Dr. Vélez Sársfield, fanous Argentine statesman and jurist; author of the Argentine Civil Code.

4. constituído, placed. 


\title{
FACUNDO QUIROGA
}

\author{
Domingo F. Sarmiento
}

Le llamaron Tigre de los Llanos, y no le sentaba mal esta denominación. La frenología y la anatomía comparada han demostrado, en efecto, las relaciones que existen entre las formas exteriores y las disposiciones morales, entre la fisonomía 5 del hombre y la de algunos animales a quienes se asemeja en su carácter. Facundo, porque así lo llamaron largo tiempo los pueblos del interior - el general D. Facundo Quiroga, el Exmo. brigadier general D. Juan Facundo Quiroga, todo Is esto vino después, cuando la sociedad lo recibió en su seno y la victoria lo hubo coronado de laureles, - Facundo, pues, era de estatura baja y fornida; sus anchas espaldas sostenían sobre un cuello corto una cabeza bien formada, cubierta 15 de pelo espesísimo, negro y ensortijado. Su cara un poco ovalada estaba hundida en medio de un bosque de pelo, a que correspondía una barba igualmente espesa, igualmente crespa y negra, que subía hasta los juanetes, bastante pronum-2o ciados para descubrir una voluntad firme y tenaz. Sus ojos negros, llenos de fuego y sombreados por 
pobladas cejas, causaban una sensación involuntaria de terror en aquellos en quienes alguna vez llegaban a fijarse; porque Facundo no miraba casi nunca de frente; por hábito, por arte, por deseo ${ }_{5}$ de hacerse siempre temible, tenía de ordinario la cabeza inclinada, y miraba por entre las cejas, como el Alí-Bajá de Monvoisin. El Caín que representaba la famosa compañía Ravel me despierta la imagen de Quiroga, quitando las posiro ciones artísticas de la estatuaria que no le convienen. Por lo demás, su fisonomía es regular, y el pálido moreno de su tez sentaba bien a las sombras espesas en que quedaba encerrada.

La estrechura de su cabeza revelaba, sin emis bargo, bajo esta cubierta selvática, la organización privilegiada de los hombres nacidos para mandar. Quiroga poseía esas cualidades necesarias que hicieron del estudiante de Brienne el genio de la Francia, y del Mameluco oscuro que se batía zo con los franceses en las pirámides, el virrey de Egipto. La sociedad en que nacen da a estos

7. Ali-Bajá de Monvoisin, reference to the painting by the French artist Monvoisin of Ali Pasha, who was known for his cruelty in Albania and put to death in 1822 .

8. Ravel (Pierre-Alfred), French actor of the nineteenth century.

18. estudiante de Brienne, i.e., Napoleon, who studied at the military school of that name.

19. Mameluco oscuro, i.... Mehemet-Ali, who, though not a Mameluke himself, fought with the Mamelukes against Napoleon in 1798, and later became Viceroy of Egypt. Cf. 70, 3 . 


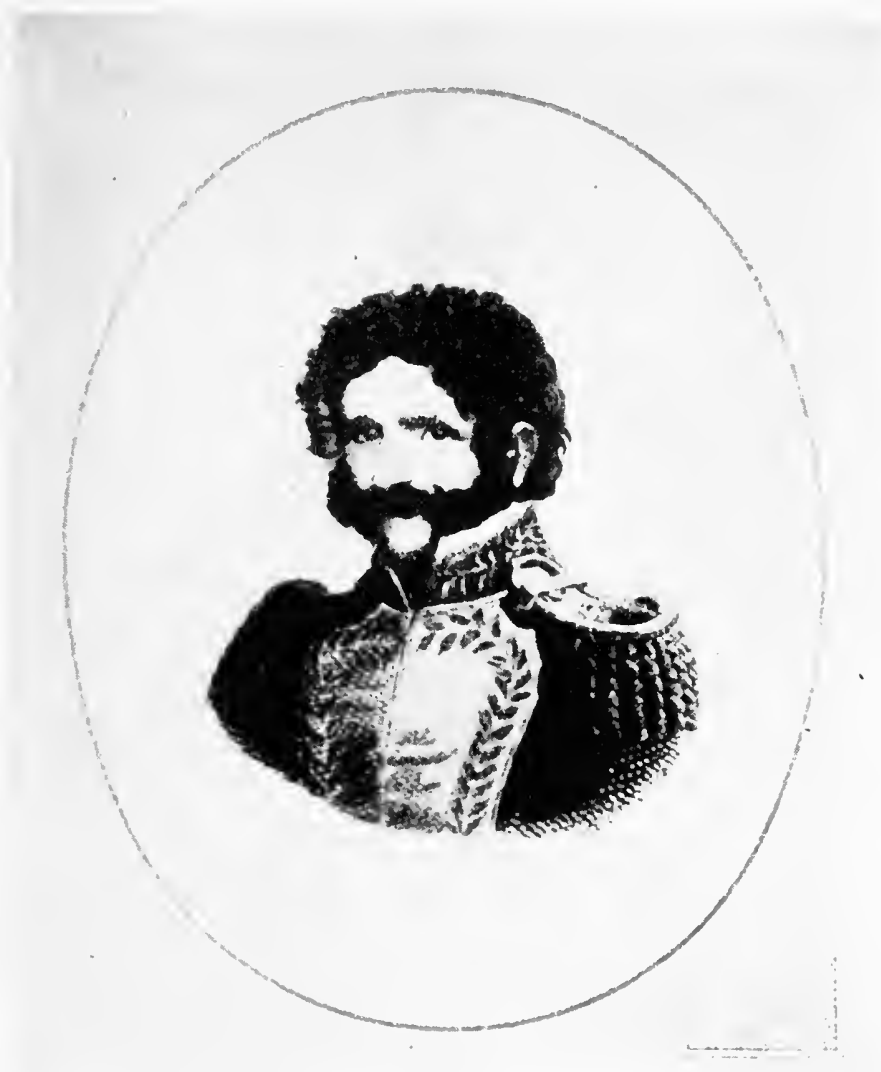

Iuan Facundo Quiroga 
caracteres la manera especial de manifestarse: sublimes, clásicos, por decirlo así, van al frente de la humanidad civilizada en algunas partes; terribles, sanguinarios y malvados, son en otras su 5 mancha, su oprobio.

Quiroga es el hombre de la naturaleza que no ha aprendido aún a contener o a disfrazar sus pasiones, que las muestra en toda su energía, entregándose a toda su impetuosidad. Éste es el carácter ıo original del género humano; y así se muestra en las campañas pastoras de la República Argentina.

Facundo es un tipo de la barbarie primitiva; no conoció sujeción de ningún género; su cólera era de las fieras; la melena de renegridos y is ensortijados cabellos caía sobre su frente y sus ojos en guedejas como las serpientes de la cabeza de Medusa; su roz se enronquecía, sus miradas se convertían en puñaladas : dominado por la cólera, mataba a patadas estrellándole los sesos a $\mathrm{N}$. por zo una disputa de juego; arrancaba ambas orejas a una querida porque le pedía 30 pesos para celebrar un matrimonio consentido por él; y abría a su hijo Juan la cabeza de un hachazo, porque no había cómo hacerlo callar; daba de bofetadas

17. Medusa, one of three sisters in Greek mythology, whose hair was rurned into a tangle of serpents because she incurred the wrath of Minerva. Any one who looked at her was turned to stone.

23. no habia cómo hacerlo callar, there atas no way of making him keep quit. 
a una linda señorita en Tucumán a quien ni seducir, ni forzar podía; en todos sus actos mostrábase el hombre bestia aún, sin ser estúpido, y sin carecer de elevación de miras. Incapaz de hacerse admirar o estimar, gustaba de ser temido : 5 pero este gusto era exclusivo, dominante hasta el punto de arreglar todas las acciones de su vida a producir el terror como expediente para suplir al patriotismo y a la abnegación; ignorante, rodeábase de misterios y se hacía impenetrable; valiéndose de ro su sagacidad natural, de una capacidad de observación no común, y de la credulidad del vulgo, fingía una presciencia de los acontecimientos, que le daba prestigio y reputación entre las gentes vulgares.

Es inagotable el repertorio de anécdotas de que ${ }_{15}$ está llena la memoria de los pueblos con respecto a Quiroga; sus dichos, sus expedientes, tienen un sello de originalidad que le daban ciertos visos orientales, cierta tintura de sabiduría salomónica en el concepto de la plebe. ¿Qué diferencia hay, zo en efecto, entre aquel famoso expediente de mandar partir en dos el niño disputado, a fin de descubrir la verdadera madre, y este otro para encontrar un ladrón?

2I. famoso expediente. When two women came before Solomon, each claiming a newly born child as hers, he ordered that the child be cut into two parts so that each claimant might have a half. The true mother was found to be the one who, for the love of her son, abandoned her claim rather than cause his death. 
Entre los individuos que formaban su compañía, habíase robado un objeto, y todas las diligencias practicadas para descubrir el ladrón habían sido infructuosas. Quiroga forma la tropa, hace cortar 5 tantas varitas de igual tamaño cuantos soldados había; hace en seguida que se distribuyan a cada uno; y luego con voz segura, dice: "Aquél cuya varita amanezca mañana más grande que las demás, ése es el ladrón." Al día siguiente formóse ro de nuevo la tropa, y Quiroga procede a la verificación y comparación de varitas; un soldado hay, empero, cuya vara aparece más corta que las otras. " iMiserable!” le grita Facundo con voz aterrante, "i tú eres . . . " y en efecto él era; is su turbación lo dejaba conocer demasiado. El expediente es sencillo; el crédulo gaucho, temiendo que efectivamente creciese su varita, le había cortado un pedazo. Pero se necesita superioridad y cierto conocimiento de la naturaleza zo humana, para valerse de estos medios.

Habíanse robado algunas prendas de la montura de un soldado, y todas las pesquisas habían sido inútiles para descubrir al ladrón. Facundo hace formar la tropa y que desfile por delante de 25 él, que está con los brazos cruzados, la mirada fija, escudrinadora, terrible. Antes ha dicho: "Yo

8. amanezca mañana, appears at daicn tomorrow.

14. i tú eres. . . ! you are the culprit!

25. que está.. The antecedent is él, referring to Facundo. 
sé quien es", con una seguridad que nada desmiente. Empiezan a desfilar; desfilan muchos, y Quiroga permanece inmóvil: es la estatua de Júpiter Tonante, es la imagen del Dios del juicio final. De repente se avanza sobre uno, le agarra 5 del brazo y le dice con voz breve y seca : “ ¿ Dónde está la montura?.. .” "Allí, señor”, contesta señalando un bosquecillo. - "Cuatro tiradores", grita entonces Quiroga.

¿Qué revelación era esta? La del terror y la so del crimen hecha ante un hombre sagaz. Estaba otra vez un gaucho respondiendo a los cargos que se le hacían por un robo. Facundo le interrumpe diciendo: "Ya este pícaro está mintiendo; ja ver! cien azotes. .." Cuando el reo hubo salido, 5 Quiroga dijo a alguno que se hallaba presente: "Vea, patrón, cuando un gaucho al hablar está haciendo marcas con el pie, es señal que está mintiendo." Con los azotes el gaucho contó la historia como debía de ser, esto es, que había 20 robado una yunta de bueyes.

Necesitaba otra vez y había pedido un hombre resuelto, audaz para confiarle una misión peligrosa. Escribía Quiroga cuando le trajeron el hombre: levanta la cara después de habérselo anunciado 25

I. que nada desmiente, that nothing can belie.

4. Júpiter Tonante. Jupiter was represented as the Thunderer in Cireek mythology.

25. después de habérselo anunciado. The more correct usage is, después que se lo han anunciado. 
varias veces, lo mira, $\mathrm{y}$ dice continuando de escribir: “¡Eh !!! . . ¡ Ése, es un miserable! ¡Pido un hombre valiente y arrojado!" Averiguóse en efecto que era un patán.

5 De estos hechos hay a centenares en la vida de Facundo, y que al paso que descubren un hombre superior, han servido eficazmente para labrarle una reputación misteriosa entre los hombres groseros, que llegaban a atribuirle poderes sobreso naturales.

I. continuando de, unusual for continuando a. 


\section{ESTEBAN ECHEVERRÍA}

\section{Pedro Goyena}

Echeverría es uno de nuestros literatos más afamados. Sus composiciones líricas, sus poemas, sus escritos en prosa fueron leídos con avidez en los tiempos ya lejanos en que inició lo que puede llamarse el movimiento revolucionario de 5 nuestra literatura. Conviene que la joven generación se familiarice con aquel noble y vigoroso espíritu que condensaba, por decirlo así, todas las nociones de la ciencia social en la época en que vivió, y que supo abrir al arte anchos y nuevos to caminos, por los cuales hallaron nuestros peetas un mundo entero de bellezas desconocidas. Echeverría era un hombre reflexivo, estudioso, inspirado, y amante de su patria. Podría presentársele como el tipo del ingenio sud-americano, 5 sagaz, delicado, flexible, apto para comprender las verdades que obtiene como premio la paciente

5. el movimiento revolucionario de nuestra literatura. The publication of Echeverria's La Cautiva in 1837 inaugurated a movement towards the Americanization of literature in Argentina. Cf. 24, 13 .

14. Podría presentársele, He might be presented. 
investigación, y para sentir con viveza las emociones que los bellos espectáculos de la naturaleza despiertan en las almas noblemente apasionadas.

Los jóvenes que cultivan la literatura hallarán 5 sin duda en la lectura de las obras de Echeverría, placeres delicados y puros, enseñanzas fecundas y severas. Cuando se trata de evitar que los hombres de letras se puerilicen en busca de una popularidad fácil y pervertidora, cuando se trata ro de hacerles adquirir esos hábitos meditativos indispensables para el progreso intelectual, Esteban Echeverría, desdeñoso como Horacio de la insipiencia del vulgo, investigador concienzudo en las cuestiones de la ciencia y del arte, es todavía, I5 después de la muerte, el bienvenido para los pueblos del Plata.

Sus escritos políticos no son, no pueden ser ya, por la marcha natural e incesante de las ideas, una revelación sorprendente para sus conciuda-

5. las obras de Echeverría. His most important works are Elaira o la novia del Plata, los Consuelos, Lara o la Partida, Las Rimas (which contain among other shorter poems La Cautica), El Dogma Socialista, and Cantos a Mayo.

7. Cuando se trata de evitar que los hombres de letras se puerilicen, When it is a question of keeping men of letters from becoming childish.

12. desdeñoso como Horacio. The latin poet Horace has expressed his distaste for the rabble in his often-cuoted verse: Odi profanum oul"us, "I hate the ignorant rabble."

${ }^{1} 5$. el bienvenido, i.c., el escritor bienvenido, the faitorite ieriter. 
danos, como lo fueron tal vez cuando el malogrado argentino volvió al seno de su patria, después de beber a largos sorbos la ilustración europea; pero son y serán siempre un alto ejemplo para enseñarnos a disciplinar y dirigir las fuerzas intelectuales 5 en orden a hallar la solución de los problemas que se refieren al bien de la sociedad.

Nada tan eficaz para inspirar aversión hacia el hueco charlatanismo de los que hablan y escriben sin reflexionar, como la lectura de las obras de ro Echeverría. Él conocía los serios deberes del literato y sabía practicarlos con escrupulosa austeridad. No escribía para halagar las preocupaciones vulgares y alcanzar las victorias estruendosas, pero efímeras, obtenidas por $\operatorname{los}_{15}$ que dicen a gritos las necedades que el vulgo ama como a sus hijos; y sacrificaba siempre el efecto inmediato a las reglas del criterio artístico, inaccesible para la gran mayoría de personas que no tienen un gusto refinado. Escribió La Cautiva 20 en humildes octosílabos como para hacer contraste con los ampulosos alejandrinos a cuya sonoridad deben algunos versificadores su fama poco envidiable, probando que la poesía reside en las ideas $y$ en el sentimiento, que las modestas formas de 25

I. el malogrado argentino. Besides his voyage to Europe in 1825 , Echeverria had to exile himself from his country twice owing to the persecution of the Dictator Rosas.

7. que se refieren al bien de la sociedad, which deal with the welfare of society. 
un metro sencillo pueden albergar dignamente la sublime inspiración del poeta.

Supo reconcentrarse en los senos de la conciencia y sondar pacientemente las profundidades del 5 mundo interior, así como había estudiado las maravillas de la naturaleza. Esperó los favores de la musa en las horas silenciosas de austeras vigilias, y la invisible confidente bajó a su alma con una frecuencia y una amabilidad de que pocos ro pueden jactarse a pesar de haberla invocado muchas veces. Rompió la tradición clásica a que habían estado sujetas las generaciones poéticas de la República Argentina, quitó a nuestra literatura el carácter de " cosmopolitismo incoloro" rs que había tenido hasta entonces, inspirándose en las peculiaridades de nuestra naturaleza y de nuestra sociedad, e introdujo en la poesía las audaces franquezas de la expresión, que muestran con verdaderos matices $y$ en todo su vigor los zofenómenos del alma humana. Sus cuerdas favoritas eran las que se armonizan con la solemne majestad de la meditación y con los tiemos suspiros de la elegía.

En su alma se albergaba ese indefinible senti25 miento en que se condensan, perdiendo mucho de su amargura, los males de la sida, sin llegar a confundirse jamás con la horrible desesperación o la

8. la invisible confidente, i.t, la musa.

I I. Rompió la tradición clásica. ('f. $24,13$.

25. perdiendo, with concessive force, though losing. 
sarcástica indiferencia de los que han dado a la esperanza un eterno adiós. Su espíritu se oscurecía con las nubes de la tristeza como el mundo con las sombras del crepúsculo, pero brillaba también con los fulgores de halagüieñas visiones. 5 Echeverría ha contemplado el ideal, ha sentido los dolores y los placeres de esa contemplación, y ha reflejado en bellas estrofas las variadas escenas de su drama interior. 


\section{EL CONGRESO DE TUCUMÁN $1816-1916$}

\section{Ernesto Nelson}

Desde una humilde casa de adobe de la ciudad de Tucumán, las Provincias Unidas de la Plata lanzaron al mundo, el 9 de julio de 1816 , la declaración solemre de su independencia. Fué ése 5 un acto que, aunque más modesto que el celebrado cuarenta años antes por las trece colonias inglesas, tuvo igual si no mayor significación relativa en los destinos del pueblo que la realizaba. Esa declaración audaz que se hacía seis años después rode iniciada la guerra separatista, en momentos en que las armas patriotas eran dominadas desde Méjico hasta Chile, tuvo la virtud de retemplar los espíritus abatidos, salvando acaso la suerte de

2. Tucumán. V. map.

2. las Provincias Unidas de la Plata. Until 1853, the date of the adoption of the lederal Constitution, the republic of Argentina was known by the above name.

8. del pueblo que la realizaba. The pronoun la refers to declaracion, in the previous sentence; trans., of the people that proclaimed it.

9. seis años después, ete. The first revolutionary uprising took place the 25 th of May, I8 o. The great victories of Chacabuco and Maipo did not come until 1817 and 1818 . 
las armas. Proclamada esa declaración en medio de una horrorosa anarquía, "que habría de retardar por otro medio siglo la unidad nacional, logró sin embargo polarizar los espíritus en el sentido de la democracia. Clausurado ese Congreso $\sin q u{ }_{5}$ sus tareas se viesen cumplidas, su papel en la historia fué el de un monumento inconcluso que recordará a los pueblos el deber sagrado de completar sus grandes líneas.

Los lineamentos de las dos grandes revoluciones ro de la independencia en el norte y en el sur del continente son demasiado diversos para que se los pueda superponer. No debe olvidarse que el grito revolucionario resonó en la América del Sur en I 8Io, cuando ya la Europa había olvidado la 15 aventura a que se lanzara Francia en i789; cuando las acciones de la democracia habían sido despreciadas en el mercado político europeo, dominado como estaba por un escepticismo contra el cual tenía escasa acción el éxito relativo con que la 20

I. las armas, the armies - by metonymy.

I. Proclamada, with concessive force, Though proclaimed.

2. que habría de retardar por otro medio siglo, which was to retard for another half century. It was not till 1853 that the Constitution was adopted. Even then it took some ten years more before the old feud between federalists and unitarians was settled.

Io. las dos grandes revoluciones, i.e., in North and in South America.

16. a que se lanzara Francia, upon which France had embarked. 


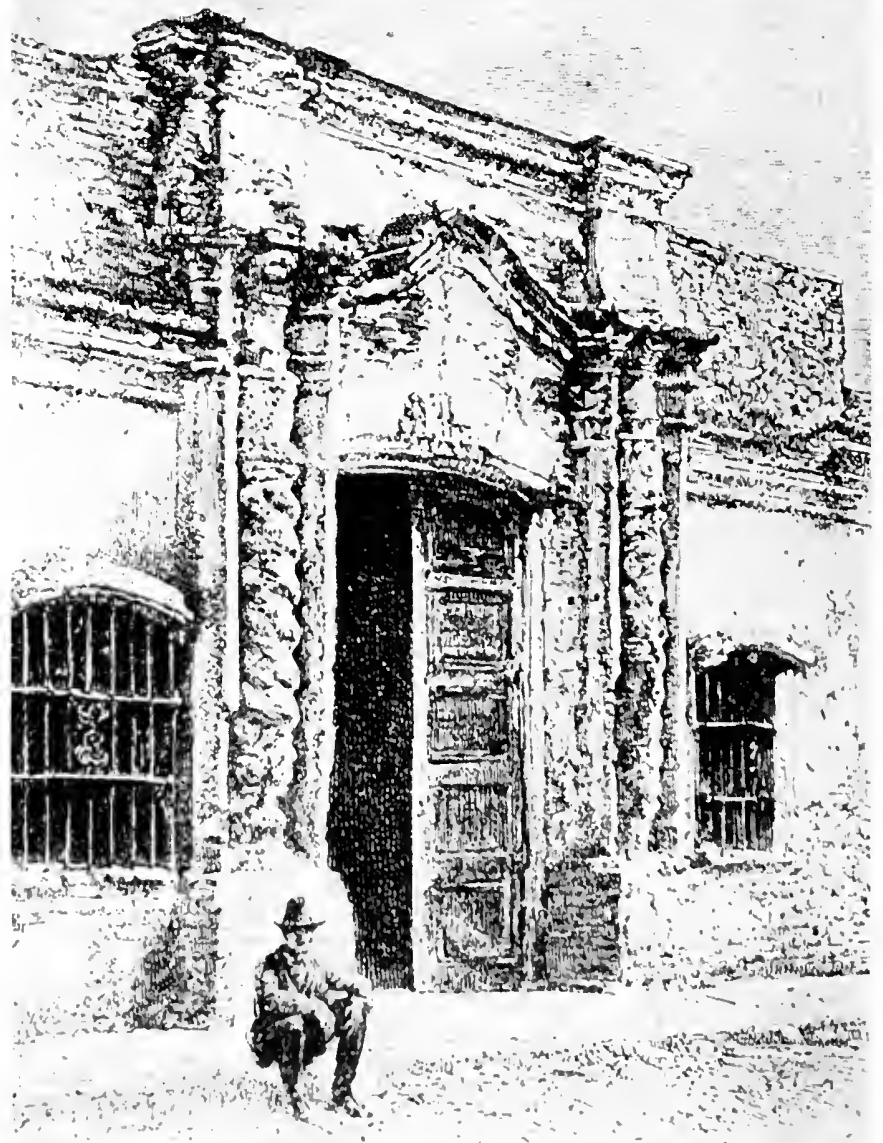

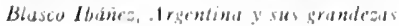

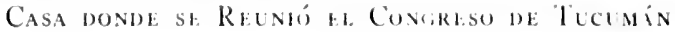


América sajona había comenzado a poner en práctica sus instituciones democráticas. En el norte el deseo de instituir un gobierno propio primaba sobre el anhelo de independencia, según lo comprueba el of recimiento de obediencia $y \mathrm{de}_{5}$ voluntaria contribución que hicieron las colonias inglesas al soberano; en el sur el deseo de independencia era lo primero y la forma de gobierno lo segundo. Fracasada la libertad de Francia en el imperio militar y desacreditada la república то por los crímenes del Año Terrible, la democracia no tenía atractivos especiales para los promotores de la revolución, por lo menos para los espíritus más prácticos; antes bien esa forma de gobierno concitaba peligros, entre los cuales el más grave ${ }_{15}$ era sin duda el de no alcanzar de la Europa el anhelado reconocimiento de la independencia.

Si éstas son razones históricas y por lo tanto ocasionales, otras más profundas y de un orden social hicieron el proceso diferente en ambos 20 extremos de América; y por lo que toca a la del Sur, más dramático y doloroso que en el Norte.

3. un gobierno propio, a government of their own.

ro. imperio militar, i.e., of Napoleon Bonaparte.

I1. Año Terrible. The period in French history from May 3I, I793, (that is, from the fall of the Girondins), to July 27, 1794. (date of the fall of Robespierre), is known as the "Reign of Terror".

14. antes bien, emphatic form of antes, rather.

21. a la del Sur, i.e., por lo que toca a la América del Sur, as regards South America. 
El gobierno español había establecido un régimen colonial fundado en la opresión y el egoísmo, dentro de cuyo programa absoluto no cabía el ejercicio de la más débil iniciativa local. Tan 5 profundo fué el sello impreso por el ejercicio de este paternalismo estrecho, que sus resabios son visibles todavía en la vida política de casi todas las naciones que estuvieron un tiempo sometidas. a España. En muchas de ellas la evolución ro político-democrática ha sido entendida, a lo sumo, como el paso de la autocracia despótica al paternalismo benévolo. Aun hoy día el estudioso podría descubrir en la legislación de algunos países de la América española, una como pre15 sunción de que el pueblo es el sujeto pasivo de la actividad social ejercida por el Estado, de quien se aguardan todas las iniciativas. El Estado, por su parte, no hace mucho por modificar este concepto, antes bien se apresura a confirmarlo tozo mando así toda carga que conduzca al progreso social. Hay la tendencia a mirar este progreso, este resultado, como el fin mismo de la actividad del Estado y de aquí que esas sociedades casi carezcan de legislación y de órganos para instaurar procesos 25 sociales que tengan en vista aquellos resultados, pero en los que intervenga la actividad general,

14. una como presunción, a certaill superior assumption.

I 7. se aguardan. I. 2, o.

19. se apresura, is anximus.

23. y de aqui, and hence it is, The verb es is understood. 
con cuyo ejercicio se perfecciona la verdadera educación democrática.

Si esto ocurre en la hora presente, no es extraño que en los obscuros días de $\mathbf{8} 8 \mathbf{0}$, cuando la institución de la república había caído en descrédito, 5 los fundadores de las nacionalidades hispanoamericanas no tuvieran una idea clara de la función social del gobierno democrático. Así se explica la creencia de que la perfección del estado político dependiera más de cierta virtud intrínseca de las ro leyes que de la virtud de los hombres. ¿No deseaban esos próceres "leyes tan perfectas que fuera imposible al pueblo contravenirlas"? Se admitirá pues, que en la América española la fórmula lincolniana del gobierno del pueblo, para $\mathbf{I}_{5}$ el pueblo y por el pueblo, habría pecado por exceso, al juicio de los legisladores que a lo sumo deseaban fundar un gobierno para el pueblo, pero no veían la posibilidad, ni acaso tampoco la ventaja, de instituir gobiernos del pueblo y por el pueblo, 20 excepto en cuanto reconocían la necesidad de que los gobernantes estuvieran identificados con el pueblo por razón de su origen. Como lo hace notar

12. esos próceres, i.e., the leaders of the Revolution.

16. habría pecado por exceso, would hate gone too far.

21. excepto en cuanto reconocian, except in so far as they recognined.

23. por razón de su origen, i.e., by reason of their common nationality.

23. hace notar, brings out. 
nuestro Sarmiento: “el cabildo abierto sólo admitía los notables de la ciudad, apartando al pueblo del lugar de la reunión, como lo repiten las actas de la época. En el pueblo vendrían 5 indios, negros, mestizos, mulatos, y no querían abandonar a números tan heterogéneos la elección de magistrados, si estos habían de ser blancos, y de la clase burguesa y municipal."

En definitiva, todos los caracteres de nuestra ı revolución proceden de una modalidad social de las colonias hispanoamericanas, modalidad sobre cuyas consecuencias históricas nunca se insistirá demasiado, pues proporcionan la clave para comprender la evolución política y el estado actual ${ }_{15}$ de esos pueblos. Durante el coloniaje existían alli la más brillante cultura y la ignorancia más densa. Por una parte esos países habían instituído la educación superior en sus universidades muchos años antes de que los primeros peregrinos arribasen 2o a Plymouth; por otra, las clases inferiores de la sociedad unian a su falta de luces, la barbarie transmitida en las luchas con los elementos indigenas.

Estratificada asíla sociedad, el historiador puede 25 seguir una línea correspondiente de separación durante todo el proceso histórico. Dos factores,

I. el cabildo abierto, the town meting.

12. nunca se insistirá demasiado, one can neter insist too much. Notice that insistira is future of probability or possibility. 
diferentes cuando no antagónicos, se desarrollaron en esas sociedades al sonar la hora de la revolución. El uno el factor idealista, que pudiéramos decir, se inspiraba en un pensamiento aristocrático, siquiera sea dicho en su estricto sentido etimoló- 5 gico, puesto que respondía a la convicción de que las clases superiores y cultas tienen la responsabilidad de tutela social. Para estas clases el problema político era un problema filosófico, dependiente en gran parte de una legislación ıo apropiada. Aunque para los prohombres el gobierno más perfecto era el que garantizaba el mayor bien al mayor número, ése era el límite extremo de sus teorías democráticas. Dado el medio en que actuaban, ninguno de ellos hubiera ${ }_{15}$ ido tan lejos como para proclamar el derecho de todos y de cada uno a contribuir con su expresión individual a formar el ideal colectivo; a constituir, en suma, una nación que fuera expresión fiel de la cultura moral y social existente entonces 20 en el pueblo. Ninguno se habría resignado a dejar en manos de las ciegas mayorías el futuro de la nación. Nadie habría llevado tan lejos su fe en los instintos de la colectividad. Creían, pues, en el gobierno de los mejores, es decir, de los que 25 ellos créan tales, pues para medir los méritos de los hombres aplicaban el cartabón de la cultura y de la sabiduría y no el simple magnetismo

I. cuando no, if not.

6. puesto que, since. 
personal ni otras cualidades elementales y primitivas, que en los estratos inferiores de la sociedad despiertan admiración y deciden la superioridad.

De acuerdo con este criterio, las naciones sud5 americanas han dado a sus instituciones políticas un sello a veces diferente del que imprimieron a las suyas las colonias anglo-sajonas, diferencia, por otra parte, que nadie sería osado a condenar pues son variantes del problema que con su existencia ro plantea desde hace siglo y medio la democracia. Para no detenernos sino en uno de esos contrastes, véase el diferente alcance que las naciones de la América hispánica han dado al concepto "representativo", respecto del sentido que ese término s 5 recibe en las prácticas políticas de la América inglesa. Según éstas, el gobierno representativo debe reflejar fielmente la fisonomía de la sociedad que representa; y para asegurar ese carácter, los representantes son emanación directa de las cirsocunscripciones locales. El gobierno, pues, no puede nunca ser superior al pueblo, ni acaso para el espiritu de esas sociedades es deseable que lo fuese. Los países latinoamericanos han dado a la representación un significado menos 25 estricto, haciendo que los representantes lo sean

1o. plantea. The subject is democracia.

25. haciendo que los representantes lo sean en común de las grandes divisiones politicas, lit, bringing it about that the representatives be so in common from the great political divisions; trans., electing their representaties at large from 
en comín de las grandes divisiones políticas, con lo cual se cumple el propósito de que la representación recaiga sobre las personas de mayor prestigio y sabiduría, residentes por lo general en las capitales y centros importantes.

El otro componente de la revolución argentina lo suministra el pueblo ignorante e ineducado, aunque celoso como pocos de su independencia personal. A despecho del papel pasivo que con la mejor intención se pretendía hacerle desempeñar ıo en el drama, ese pueblo fué el verdadero protagonista. Adivinó que llegaba el momento histórico de actuar y actuó, obrando según sus fieros y primitivos impulsos, exteriorizando los cuales comenzaba en realidad su larga auto-educación is política. La repugnante arena de las luchas fratricidas en que se debaten sus crudos intereses, ha sido en realidad la escuela de la democracia en Sud-América. Los caudillos locales que las turbas exaltaron, son el exponente y la expresión de las 20 sordas voluntades colectivas. Aunque figuras menores de la historia, siniestras a veces, no por eso son indignas del estudio del sociólogo.

the great political divisions, i.e., the representatives represent a province and not a district.

Io. se pretendía hacerle desempeñar, they (la gente culta de las ciudades) intended to have it (the people) play.

14. exteriorizando los cuales, upon manifesting which.

2I. Aunque figuras menores. The verb son is understood. 

232
ARGIETINI

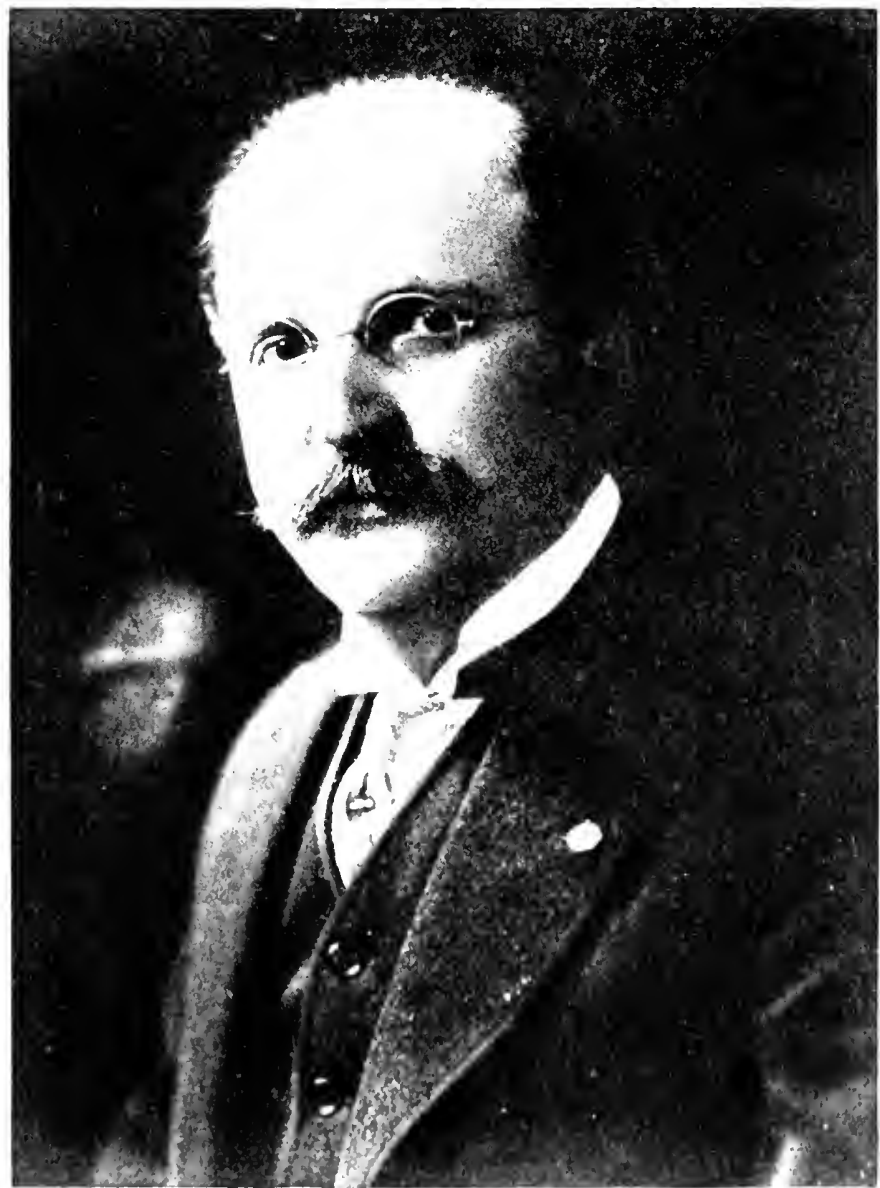

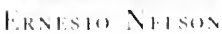


El factor idealista de la revolución y de la organización nacional tiene su campo privativo de acción en la obra legislativa y de pensamiento; el otro en la acción concreta y visible de la negra anarquía y la sangrienta dictadura. Del choque 5 de ambas corrientes, de su compenetración gradual, resulta la fisonomía política actual de la República Argentina, país donde el conflicto entre ambas formas de acción ha durado menos que en los otros, muchos de los cuales son todavía ro mundos políticos en formación, habiendo algunos en los que el orden $y$ el equilibrio aun no han aparecido. No sólo ha salvado la Argentina la época ígnea de las revoluciones, sino que su ambiente social permite ya que prospere en él la is forma más delicada de la democracia, o sea el voto secreto, cuyo advenimiento en las prácticas políticas de la gran república del sur tiene un significativo valor filosófico, como prenda de concordia y de colaboración entre las luces de la 20 cultura y los instintos populares a cuyas inspiraciones esa ley entregó con plena confianza sus destinos futuros. En la fisonomía actual del país los dos elementos de la evolución social han dejado

II. habiendo algunos, there being some.

I6. o sea el voto secreto, that is, the secret ballot. Mr. Hipólito Irigoyen, the present incumbent of the presidency, is the first Argentine president to have been elected by the secret or Australian ballot.

22. esa ley, i.e., of the Australian ballot. 
impresa su huella. El espíritu democrático, ya madurado, coexiste con un pronunciado idealismo, un respeto casi religioso por la cultura, que ha llevado a las legislaturas y a las mansiones 5 presidenciales hombres de pensamiento más bien que obreros de acción práctica, con decidida ventaja a veces para la exaltación del ideal político, si bien con alguna desventaja para la acción concreta inmediata. La constante calificación de rocultura que ha servido de principal requisito al ejercicio del poder, ha impedido que éste caiga en manos mercenarias o bajo el dominio de inteligencias sin cultura que degradasen su función social. Por eso ha sido motivo de sorpresa para ${ }_{15}$ los observadores inadvertidos el encontrar en las repúblicas latinas gobiernos no tan representativos como pudiera esperarse de la general falta de cultura de las masas. Los prestigios del mando, con su escuela de méritos y de honores para los servizodores del país, las prácticas apenas atemperadas del paternalismo ancestral, han creado el anhelo del bien público llevado con extrema frecuencia hasta el sacrificio personal. $Y$ si esta excesiva actividad central acaso obra, según se ha dicho $25 \mathrm{ya}$, inhibiendo las actividades locales, no hay duda que ha contribuído a revestir la función política de mayor dignidad $y$ a darle el carácter de una defensa contra los avances del

13. su refers to poder.

25. inhibiendo, trans., to prevent. 
capitalismo. Un tipo tal de democracia traerá tal vez cierto exceso de intervención oficial que no se advierte en las democracias más homogéneas, en las que el estado recibe toda la savia de los estratos inferiores de la sociedad; pero sin duda 5 evita la maléfica influencia de los poderosos intereses privados, de cuya presión son a veces resultado legislaciones que disimuladamente los sirven.

Si la legislación constructiva y la demagogia destructiva constituyen respectivamente el anverso ro y el reverso de la vida nacional, en pocos momentos de la historia argentina se exhiben con mayor evidencia ni en forma más irreconciliable que en el acto de celebrarse el Congreso de Tucumán. Se iniciaba esta asamblea después de seis años 15 de rotas las hostilidades con la madre Patria y sucedía a una serie de esfuerzos por dar forma política definitiva a la nueva nación. El Congreso era un incidente en el proceso idealista y llevaba involucrados todos los caracteres de este último. 20 Así, no fué, ni podía ser, una emanación normal

7. de cuya presión ... los sirven, the results of whose pressure oftentimes are laws favorable to them, though ostensibly not meant to be such.

13. que en el acto de celebrarse el Congreso de Tucumán, than on the occasion when the Congress of Tucuman was held.

I5. despuês de seis años de rotas las hostilidades, six years after the breaking out of hostilities.

I9. llevaba involucrados, carried within itself.

20. de este último, i.e., el proceso idealista. 
de las voluntades populares. Sus organizadores " poco se cuidaron de dar a la asamblea un origen democrático " y apenas representaba ésta una parte de las " provincias unidas" en cuyo nombre ${ }_{5}$ hablaba. Los caudillos habían aparecido. Uno de ellos atraía hacia sí a Córdoba, Uruguay, Entre Ríos, Corrientes, y poco después a Santa Fé, mientras el Paraguay se mantenía en su aislamiento. El Congreso procuró pacificar a los so rebeldes decretando indultos generales, envió delegados para calmar desavenencias entre aquellos y hasta empleó la fuerza para sofocar sediciones que estallaban a su alrededor. Las actividades del Congreso eran, pues, denegatorias de todo is carácter representativo y significaban el ejercicio de una actividad que se invocaba en nombre de los principios absolutos más bien que en los de la representación, por mucho que se estirara el significado de ese concepto. Dada la descomposición 20 a que en los seis años de guerra habían conducido los excesos del individualismo desenfrenado, el Congreso se abrogó la misión tutelar a que se sentía llamado, ejerciendo una acción realmente ejecutiva que lo distrajo de los propósitos car${ }_{25}$ dinales para que había sido convocado, es decir, la declaración de la independencia y para redactar la constitución que habría de regir la nueva nación.

5. Uno de ellos, i.e., unc of the caudillos. V. Introduction.

I3. a su alrededor, around it.

27. que habria de regir, which was to mile. 
El anverso y el reverso de ese momento histórico están representados, respectivamente, en la composición del Congreso por una parte, y la composición de los partidos en lucha, por la otra. El Congreso era la expresión más acabada de la 5 cultura del virreinato; sus miembros, productos de las universidades de Córdoba, de Charcas, de Santiago de Chile, del Colegio de San Carlos, todos ellos competentes, poseidos del patriotismo más acendrado. Como sombrío contraste, véase el ro estado general del país, según lo pintó uno de los más ilustres miembros del Congreso: "Divididas las provincias, desunidos los pueblos y aun los mismos ciudadanos, rotos los lazos de la Unión social, inutilizados los resortes todos para mover ${ }_{15}$ la máquina, erigidos los gobiernos sobre bases

7. Córdoba. V. map. Its university, having been founded in 1613 , is the third oldest in South America, that of San Marcos in Lima (which was founded in 1551) and that of Bogotá (founded in 1572) having preceded it.

7. Charcas, capital of Bolivia, today called Sucre. It used to be known also under the names of Chuquisaca and La Plata. Its famous university was founded in 1623 . It has a school of law, theology, and medicine.

8. Santiago de Chile, capital of Chile. V. map. The university was founded in 1738 .

8. Colegio de San Carlos, in Lima, Pern.

Io. véase el estado general del país, see the general condition of the country.

II. uno de los más ilustres miembros del Congreso, i.e., Fray Cayetano Rodrígue\%. Cf. $24^{\circ}, 3$. 
débiles y viciosas, chocados entre sí los intereses comunes y particulares de los pueblos, negándose algunos al reconocimiento de una autoridad común, enervadas las fuerzas del estado, agotadas las ${ }_{5}$ fuentes de la pública prosperidad, paralizados los arbitrios para darles un curso conveniente, pujante en gran parte el vicio y extinguidas las virtudes sociales (o por no conocidas o por inconciliables con el sistema de una libertad mal entendida), roconducidos, en fin, los pueblos por senderos extraños - pero análogos a tan funestos principios - a una espantosa anarquía (mal el más digno de temerse en el curso de una revolución iniciada por meditados planes, sin cálculo en sus progresos y sin is una prudente previsión en sus fines), ¿qqué dique más poderoso podía oponerse a este torrente de males políticos que amenazaban absorber la patria y sepultarla en sus ríos que la instalación de un gobierno que salvase la unidad de las provincias, zoconciliase su voluntad y reuniera los votos, concentrando en sí el poder?"

A la anterior pintura habria que agregar que la revolución estaba en una situación desesperada, cercadas como se hallahan las provincias por fuer${ }_{25}$ zas españolas en Chile y en el Alto Perú. El

I. chocados, clashing.

2. negándose algunos, some licing opposed.

22. habria que agregar, there ought to be added.

25. Alto Perú, name applied to the present republic of Bolivia during the colonial and revolutionary period. 
Congreso mismo debió trasladarse a Buenos Aires ante la aproximación del enemigo, que bajaba del Norte.

En tales condiciones la valiente declaración de la Independencia, el 9 de julio de 1816 , salvó la 5 suerte de las armas galvanizando los entusiasmos del ejército y convirtiendo la revolución en invasora: pocos meses después, en efecto, San Martín cruzará los Andes para batir a España en Chile, desde donde, unidos los argentinos y los io chilenos, iniciarían la expedición libertadora que heriría al enemigo en su corazón, Lima, para luego engrosar el ejército de Bolívar a quien tocaría dar el golpe definitivo al poder español en América.

2. la aproximación del enemigo. The last secret session of the Congress of Tucumán was held January 17, I817, when the Spanish forces were advancing from the north, after invading the province of Jujuy.

12. Lima, capital of Peru, was founded in 1535 by Pizarro. It was by far the most important South American city during the colonial period.

13. a quien tocaría, whose lot it would be.

14. el golpe definitivo. The battle of Ayacucho (1824), fought between the Spaniards and the combined Colombian and Argentine forces under the command of Sucre, Bolivar's lieutenant, put an end to Spanish domination in South America. As a feat of arms it stands among the most brilliant of those recorded in the annals of South American history. Sucre, though his forces numbered but half those of the Spaniards, completely routed them, capturing about one-third of their army, in cluding La Serna, the commanderin-chief, as well as all their baggage and anmunition. 
Dados los caracteres sociológicos de la revolución; dadas, además, las circunstancias en que se hallaba el país, según las describiera Fray Cayetano Rodríguez, no es de extrañar que el Con5 greso de I8I 6 fuese monarquista. En su seno, en efecto, se deslizaron los más extraños proyectos para alzar en el país un trono. . . : un trono cuya fuerza fuera capaz de asegurar el orden interior y cuyo prestigio diera al país las garantías morales y ro materiales que sin duda reclamaría Europa antes de reconocer la independencia de la nueva nación y de prestarle su poderosa alianza. Se pensó en traer algún miembro de una casa real europea, y hasta se propuso restaurar con tal objeto la antigua 5 monarquía incásica.

Nos parecen absurdos tales proyectos hoy que vemos lozano el árbol de la democracia que a todos los pueblos de América nos cobija; pero no se olvide que para entonces el Congreso de Viena zohabía arrancado esa planta del suelo de Europa como cizaña peligrosa, sin que el débil retoño sajón hubiera dado todavía los ricos frutos que los tiempos le reservaban. Para los americanos

3. describiera. Cf. 66,$16 ; 223,16$.

3. Fray Cayetano Rodriguez (1761-1823), historian of the proceedings at the Congress of Tucuman. As a poet he wrote a sonnet Al 25 de Mayo, and versified on other events of his time.

4. no es de extrañar, it is not to be wondered at.

12. Se pensó en traer, Some thought of bringing. 
de hoy, a uno y otro lado del ecuador, el patriotismo del suelo está reforzado por un patriotismo de principios, un noble orgullo de haber nacido bajo la estrella de la igualdad de ventajas; pero entonces la libertad no tenía el sentido noble que le 5 han dado después los triunfos del individualismo. Felizmente, aun cuando el bando monarquista contaba con opiniones de tanto peso como las de San Martín y de Belgrano - al segundo de los cuales el Congreso hizo el honor de oír en sesión ro secreta especial - y aun cuando la causa de la democracia tuvo una pobre defensa de parte de uno de los detractores de la monarquía, la buena doctrina triunfó en esa hora crítica para la república y para la América toda. Como se ve, 15 aquel instante de la historia es un punto de empalme en el cual los destinos del continente estuvieron en peligro de tomar otro carril que hubiera llevado las ideas y los hombres por otros campos de la acción política y social, transfor-20 mando la vida de medio hemisferio y afectando tal vez seriamente la suerte de las instituciones democráticas en los Estados Unidos. Afortunadamente, en ese minuto supremo, una mano firme

9. San Martín, Belgrano. Cf. I 8, I7, and Introduction.

13. uno de los detractores de la monarquía. One of the few voices raised against the monarchical idea was that of the deputy Anchorena, but his arguments were so specious that they rather strengthened the supporters of the monarchy.

24. una mano firme. Argentina owes in large measure her 
se apoderó de la palanca que podía haber cambiado la marcha $y$ antes de que los demás actores se percataran, un gran convoy de pueblos había entrado en la vía que conduce a los destinos s superiores de la humanidad.

Aunque el Congreso no dió al país la constitución que de aquél se esperaba, salvó, como se ha visto, la suerte de la democracia. Por este solo hecho la posteridad le ha perdonado su ofuscación, sus ro vacilaciones entre el régimen republicano federal por el cual se pronunció primero y el centralista que luego adoptó, y hasta las veleidades monárquicas en que más tarde reincidió. En cambio, la luz que encendió en aquella hora vespertina is señaló constantemente el puerto seguro a los pueblos que estuvieron a punto de extraviarse para siempre cuando cerró la larga noche de la anarquía.

present republican form of government to Fray Justo de Santa Maria de Oro, who at the Congress of Tucumán stood out firmly and energetically in behalf of a republic.

4. la vía, i.e., of democracy.

7. de aquél, i.e., del Congreso.

17. la larga noche de la anarquia. The period of internecine struggles, from the expulsion of the Spaniards till the downfall of Rosas and the subsequent adoption of the Federal Constitution. 


\section{BUENOS AIRES EN 1815}

\section{Vicente Fidel López}

Se necesita hacer un esfuerzo de imaginación para comprender hoy lo que era Buenos Aires ahora setenta años. La porción urbana que servía de asiento a la iniciativa política y gubernamental de la comuna, ocupaba un radio bastante 5 modesto. Tomando por texto el plano de la ciudad, que, por orden del virrey Avilés, levantó en el año de 1800 el señor don Pedro Cerviño, agrimensor $y$ piloto muy competente, se ve que los suburbios, es decir, la parte en que no había ıo paredes sino cercos de tunales, comenzaban, por el sur, en las manzanas limitadas hoy por las calles de Méjico y de Chile. A ese lado, la ciudad quedaba separada de sus orillas por esa avenida caudalosa de las lluvias que llaman el tercero del ${ }_{15}$ sur, cuyo nombre antiguo era el Puente de los Granados, porque atravesaba terrenos de la pro-

Title. Buenos Aires. The name Buenos Aires goes back to two legends. The one says that on landing the settlers exclaimed, "i Qué buenos aires!", whence the name. The other, and more likely one, says that the sailors, hard pressed by bad weather, made vows to "la Virgen de Buenos Aires", their patron saint, and upon landing safely named the place Buenos Aires, in gratitude to her.

15. el tercero del sur. On rainy days the streets of 243 
piedad de la familia de este nombre, a la que pertenecía la virtuosísima madre de nuestro amigo y co-redactor D. Juan María Gutiérrez. Alli comenzaban ya los cercos que encerraban una 5 infinidad de huecos o eriales atravesados por sendas, y en cuya extensión vivían, en casas muy modestas, no sólo las familias pobres, sino también un extenso número de las de mediana condición, sin necesidad y sin idea ninguna de la ro riqueza. El amueblado de una familia común podía calcularse, cuando más, entre cien y ciento cincuenta pesos de plata. Duraba de una generación a la otra, y no se renovaba jamás sino por piezas insignificantes. La mesa $y$ el manteni${ }_{15}$ miento se reducía, en general, al gasto de dos a cuatro reales por día, sin dejar de ser abundante y suculenta, porque todos tenían aves y verduras en sus corrales, y lo único que se compraba era la carne y el pan.

20 Estos suburbios, muy bien caracterizados por Cerviño con el nombre de tunales, se corrían desde el Puente de los Granados (en la calle del Perí), siguiendo una línea oblicua hacia el noroeste,

Buenos Aires were turned into veritable brooks, which were named numerically, first, second, third, etc.

\section{p. liii.}

3. D. Juan Maria Gutiérrez. Cf. Biographical Notes,

15. se reducia. The verb is in the singular because the subjects, la mesa y el mantenimiento, are taken to be one and the same thing. 
hasta la plaza de Monserrat, que quedaba lindera, diremos así, con el despoblado; y que era por lo mismo un suburbio popular de los más poblados, y muy turbulento por cierto. La iglesia y la parroquia de la Concepción quedaban natural- 5 mente entre las quintas y entre los cercos agrestes de las orillas. Entre Monserrat y la Plaza Nueva (hoy Mercado del Plata) había unas cuantas manzanas de población algo compacta aunque de pura clase pobre; y lo que es hoy calle de Salta г quedaba entonces entre los eriales y los huecos, que eran verdaderos matorrales de hinojos y de cardos, erizados de arbustos de sauco, y de montes de durazneros que servían para abastecer de leña a la población. En toda la línea del norte, que es 15 hoy la calle de Corrientes, comenzaban de nuevo los tunales, los huertos, los cercos agrestes, los eriales con sendas, hasta el Retiro, donde estaba la Plaza de Toros, y cuyas cercanías estaban rústicas y muy pobladas de orilleros. Había 20 también por allí algunas quintas, que eran verdaderas soledades bastante difíciles de cuidar : campo de la justicia de los prebostes de la Hermandad.

15. En toda la línea del norte, All along the northern boundary.

23. prebostes de la Hermandad. The Santa Hermandad was a police institution founded in the fifteenth century in Spain, and carried over into her colonies. Its purpose was to keep the highways and the country clear of robbers. A preboste was an officer of the Hermandad; he exercised both judicial and police powers. 
En un país tan pluvioso como el nuestro, formado por terrenos de aluvión, es evidente que entonces no podía haber caminos públicos en un estado de mediano servicio. Los pantanos ro${ }_{5}$ deaban la ciudad haciendo un verdadero laberinto de sendas y de portillos, que requerían una especial vaquía de parte de los que tenían que practicarlos. Más atrás de la zona solitaria de las quintas, había algunas chacras extensas erizadas de montes, de ro espinillos $y$ de durazneros, entre los cuales eran célebres, como abrigos de bandidos, el monte de campana cerca de lo que es hoy la Floresta, el monte de Castro, entre Flores y Morón, el callejón de Ibáñez; a los que no les iban en zaga otros is lugares, que aunque más cercanos, tenían también malísima fama; como el hueco de los Sauces, los cercos de los Ejercicios, la quinta de Riradaria, el paso de Burgos, el hueco de Cabecitas y el de doña Ingracia; y sobre todo, los wanjones del tercero zodel norte, que eran hasta i 830 uno de los puntos más selváticos y agrestes que puliera tener a su costado una ciudad civilizada y revolucionaria como era la de Buenos Aires en is 5 .

Era natural que el centro más urbano y más 25 noble de la Comuna participase en algo de las malas condiciones de sus suburbios. La carestía de la piedra, la dificultad de sacarla de la Banda Oriental,

22. revolucionaria. The term revolutionary, after the French Revolution, was synonymous with progressive. 
por falta de brazos aptos y por falta de buques en que conducirla, hacían que apenas hubiese una que otra calle, malísimamente empedrada. Se conocía por calle del Empedrado la que hoy es de la Florida; y no es poca lástima que se le haya ${ }_{5}$ quitado este título original de nobleza, que le corresponde en la tradición de la cultura de nuestra ciudad. Las lluvias copiosísimas de aquellos tiempos han dejado fama en el recuerdo de nuestros padres. Al correr como torrentes, para salir al río, o para empozarse en los pantanos, se llevaban gran parte del piso, abriendo curvas de zanjas profundas y de precipicios entre una y otra acera, y hacían imposible atravesar las calles (fuera de ocho o diez cuadras en el centro) por otra parte 15 que por las esquinas, donde había apoyos de grandes piedras puestas a distancia para afirmar el pie. Era tal este estado, que en la parte que es hoy calle de Cangallo (entre Florida y Maipú) había lagunas donde se ahogaron algunos lecheros 20 en tiempos del virrey Vértiz, como consta de documentos oficiales.

Por la noche, esta espléndida ciudad de Buenos Aires, que hoy enrojece su atmósfera con los reflejos del gas, presentaba un aspecto desolado, 25

I. brazos aptos, men suited for the task.

2. hacían que apenas hubiese una que otra calle, malísimamente empedrada, were the cause of there being only a few paved streets, and very poorly pased at that.

4. calle del Empedrado, Pared Street. 
si es que las tinieblas pueden tener aspecto. A lo largo de la calle del Correo (hoy Perú) se divisaban de un extremo a otro, cuatro linternillas diminutas que señalaban las cuatro mesitas en que los ${ }_{5}$ loteros privilegiados por el Cabildo expedían cedulillas, arrimados a la pared y con un pequeño farol que era la única luz de esa calle central. Las veredas eran de mal ladrillo, húmedas, estrechas, desiguales, y temblorosas encima del barrial ro en que tenían su asiento; y en muy pocas calles las había.

Buenos Aires era una ciudad baja, aplastada y cubierta con las capuchas de los tejados de feísimo aspecto; que tenía, sin embargo, la reputación de ${ }_{15}$ la belleza entre las otras ciudades españolas. Pero esa fama le venía de sus habitantes, más bien que de su suelo. En ambos sexos, ellos eran de espíritu alegre y suelto; de alma impresionable y simpática; admiradores entusiastas y copistas 20 ardientes de las grandes novedades de la civilización. Naturalmente inclinados a lo liberal; con algo de aturdido $y$ de liviano, pero siempre bien inspirados, inclinados a la pompa y halagados por la vanagloria que viene de hacer el bien y de ${ }_{25}$ realizar hazañas. La sociedad era por esto expansiva y hospitalaria. Su arrogancia era abierta. porque consistía siempre en el anhelo de que

II. Las habia, were there any.

14. la reputación de la belleza, a reputation for beauty. 
su revolución y sus progresos sirviesen a todos, e hiciesen de nuestro suelo y de nuestras leyes, el abrigo de todas las razas del mundo que no estuvieran bien avenidas en el suyo.

Tal era entonces la capital, en cuya frente el 5 poeta de la revolución había escrito estos versos tan arrogantes como adecuados, entonces, al genio de la Comuna:

Calle Esparta su virtud:

Su virtud calle Roma;

iSilencio! que al mundo asoma

La gran capital del Sud.

Pero, ésta era la ciudad que había hecho la Revolución de Mayo, que la había defendido y salvado contra todo el poder de la España, pro-15 clamando los principios más elevados, más generosos y más humanitarios de la civilización moderna. Ésta misma era la ciudad que había vencido y rendido dos ejércitos ingleses; que había deshecho y apresado tres escuadras españolas; que 20 había plantado la bandera argentina en las murallas de Montevideo; que iba con un paso seguro a reconquistar a Chile, a libertar al Perí, y a llevarle

I. su revolución. The revolution for independence in 1810 was mainly the work of the population of Buenos Aires, whereas the civil revolution that followed later was started by the provinces.

5. el poeta de la revolución, i.e., Vicente López y Planes, the author of the Himno Nacional. 
soldados a Bolivar para ganar la batalla famosa de Junín y libertar a Quito. Para motejar, entonces, la arrogancia de la cuarteta, sería preciso ver cómo podrían borrarse de la historia, o como 5 podrían motejarse los hechos gloriosos que la inspiraron. 


\title{
BUENOS AIRES
}

\section{Las Tiendas Antiguas}

\author{
Lucio V. López
}

No era entonces Buenos Aires lo que es ahora. La fisonomía de la calle del Perú y de la Victoria ha cambiado en los veintidós años transcurridos: el centro comenzaba en la calle de la Piedad y terminaba en la de Potosí, donde la vanguardia de 5 las tiendas estaba representada por el establecimiento del señor Bolar, local de esquina, mostrador democrático al alba, cuando cocineras y patronas madrugadoras acudían al mercado, y burgués, si no aristocrático, entre las siete de la ro noche y el toque de las ánimas. El barrio de las tiendas de tono se prolongaba por la calle de la Victoria hasta la de Esmeralda, y aquellas cinco cuadras constituían en esa época el boulevard de la fashion de la gran capital.

Las tiendas europeas de hoy, híbridas y raquíticas, sin carácter local, han desterrado la

4. el centro, the "down-town" section.

7. mostrador democrático, a people's store. 
tienda porteña de aquella época, de mostrador corrido y gato blanco formal sentado sobre él a guisa de esfinge.

¡Oh, qué tiendas aquéllas! Me parece que veo 5 sus puertas sin vidrieras, tapizadas con los últimos percales recibidos, cuyas piezas avanzaban dos o tres metros al exterior sobre la pared de la calle; y entre las piezas de percal, la pieza de pekín lustroso de medio ancho, clavada también ro en el muro, inflándose con el viento y lista para que la mano de la marchanta conocedora apreciase la calidad del género entre el índice y el pulgar, sin obligación de penetrar a la tienda.

Aquélla era buena fé comercial y no la de hoy, ${ }_{15}$ en que la enorme vidriera engolosina sin satisfacer las exigencias del tacto que reclamaban nuestras madres con un derecho indiscutible. i Y qué mozos! iQué vendedores los de las tiendas de entonces! ¡Cuán lejos están los tenderos francezo ses y españoles de hoy de tener la alcurnia y los méritos sociales de aquella juventud dorada, hija de la tierra, último vástago del aristocrático comercio al menudeo de la colonia! No pasaba una señora ni una niña sin tributar los más afectuo${ }_{25} \operatorname{sos}$ saludos a la rueda de contertulianos sentados comodamente en sillas colocadas en la calle y presididos por el dueño del establecimiento. Ý cuando las lindas transeuntes penetraban a la

I. de mostrador corrido, with its long counter.

13. penetrar a, unusual for penetrar en. 
tienda, el dueño dejaba a sus amigos, saludaba a sus clientas con un efusivo apretón de manos, preguntaba a la mamá por "ese caballero", echaba algunos requiebros de buen tono a las señoritas, tomaba el mate de manos del cadete y 5 lo ofrecía a las señoras con la más exquisita amabilidad; y sólo después de haber cumplido con todas las reglas de este prefacio de la galantería, entraban clientas y tenderos a tratar de la ardua cuestión de los negocios.

Había siempre en las tiendas de antaño un olor inextinguible a tripe, porque nunca faltaban cuatro o seis grandes cilindros de tripe inglés formados a la entrada de la casa, que, a su calidad de mercadería de fondo, reunían la ventaja accesoria ${ }_{5}$ de servir de poyos para sentarse los tertulianos habituales del establecimiento. Y después los mostradores estaban alfombrados con tripes representando todo un jardín zoológico de fieras estampadas, tigres, panteras, gatos monteses y leones zo rubicundos, reposados majestuosamente sobre pai-

3. "ese caballero", i.e., her husband.

$4^{-10}$. Something similar in the way of courtesy used to be the habit among shopkeepers in this country. Nowadays we find it only with the older generation. Although the author here complains that these pleasant customs have already disappeared in Argentina, it is nevertheless true that Spaniards and Spanish-Americans prefer to do business in a way that still savors of social relationship.

I6. para sentarse los tertulianos habituales del establecimiento, where the habitués of the establishment could sit. 
sajes historiados de selvas de lana, con que las fábricas de Manchester reemplazaban en nuestras mansiones aristocráticas de entonces la carencia de Aubusson y de Gobelinos.

5 i Qué agilidad aquélla con la que el patrón, apoyándose sobre la mano izquierda, saltaba el mostrador! iQué gracia con la que desplegaba ante los ojos de las clientas, de un golpe, y como un prestidigitador, la pieza de percal, de muselina o ro de barège envuelta alrededor de la tablilla, que quedaba, desnuda de su preciosa mercancía, abandonada indiferentemente sobre el mostrador! ¡Qué elasticidad de movimientos, qué vertiginosa rapidez, la que el tendero de aquel tiempo desplegaba para ${ }_{15}$ medir sobre la vara el lote vendido, dejándolo amontonarse ampulosamente sobre el mostrador con elegante negligencia, acariciando el género con los dedos, llevándolo a los ojos de la compradora, poniéndoselo en la mano, restregándolo para 20 justificar la falta absoluta de goma y otras añagazas de fábrica, y hasta trayendo el úmico vaso de la trastienda lleno de agua, para ensopar en él el extremo de la pieza de muselina y justificar la tinta indeleble de la tela!

4. de Aubusson y de Gobelinos. Aubusson, city in France, famous for tapestries; Gobelinos, the Cobelins, in the fifternth century, established a tapestry factory in Paris which is now famous throughout the world.

15. dejándolo amontonarse ampulosamente sobre el mostrador, permitting it (el lote vendido) to heap up in folds on the counter. 


\section{CON RUMBO A LA ESPERANZA}

\section{Vicente Blasco โbáÑeZ ${ }^{1}$}

Europa pierde anualmente una parte de su población, insignificante por el número si se la compara con la gran masa humana que habita su suelo, valiosa por las iniciativas enérgicas y el coraje que demuestra al abandonar la tierra patria con 5 rumbo a lo desconocido.

Todas las semanas apártanse de sus costas enormes buques, que vomitando humo se lanzan a través de las infinitas y azules soledades, replets el cóncavo vientre de carne humana, que sufre, se ro agita, sueña o se estremece con los internos espejismos de la esperanza. Salen de los muelles escarchados y brumosos del Báltico; de los puertos ingleses, negros de polvo de hulla, en cuyo ambiente grasoso parece esparcirse un vago perfume 15 de té y tabaco con opio; de las costas de la Francia oceánica, que opone sus bancos vivos de mariscos y los obscuros pinares de sus landas a los

${ }^{1}$ La Argentina y sus grandesas.

I7. vivos de, alive with. 
rabiosos asaltos del fiero golfo de Gascuña; de las bahías españolas, inmensas copas de tranquilo azul, sobre las cuales trenzan $y$ destrenzan las gaviotas el blanco aleteo, como asustadas por el 5 intempestivo chirrido de una grúa o el mugido de una sirena; de las escalas del Mediterráneo, sonrientes y adormecidas bajo la ardiente lluvia del sol; ciudades blancas, con la alba crudeza de la cal o la suave y aristocrática del mármol; ro ciudades en cuyos embarcaderos flota un ambiente de hortalizas marchitas $y$ frutos sazonados, $y$ en las que el viento de tierra lleva hasta los buques, junto con el nupcial aliento del naranjo $y$ el varonil incienso del almendro, briosos rasgueos r 5 de la guitarra ibera, los repiqueteos del tamboril provenzal y lánguidos arpegios de las mandolinas italianas.

Los gigantes marinos mueven las invisibles uñas de sus hélices y se despegan de la tierra. Su proa, 2ocomo $11 n$ hocico inteligente, parece husmear el horizonte para adivinar la senda a través del infinito, $y$ en torno de su grupa rebullen convertidas en jabonosa espmma las aguas grises o negruscas de los mares septentrionales, las azules 25 ondulaciones atánticas o las verdes linfas mediterráncas, pobladas de chisporroteos de sol y

15. la guitarra ibera. 'The guitar is the national musical instrument of Spain.

22. grupa, here, poes, carrying out the figure implied in los gigantes marinos. 
escamas de oro, que pasan y se renuevan como estrellas fugaces en las glaucas profundidades.

Desapareció la tierra: agua por todas partes. El azul blanquecino del cielo sobre el azul negrusco de las olas. La proa que se alza hasta ocultar 5 la faja del horizonte o se hunde elevando sobre su ángulo la lejana línea del mar, como una muralla oscura; la popa, que parece desplomarse en el abismo a cada ondulación, o al remontarse acaricia algunas veces el espacio con infructuosas pa- ro letadas de sus hélices; el mugir lejano de las máquinas en lo más profundo de las entrañas del leviatán de acero, revelan únicamente el movimiento, la marcha. Sin esto el buque parecería inmóvil encantado en medio de la inmensidad ${ }_{5}$ circular y monótona. Avanza y avanza, y siempre parece estar en el mismo sitio, en el centro exacto del circo infinito.

¿Adónde va el buque a través del misterio azul? ¿A qué lejana tierra de ensueño conduce 20 su cargamento de miseria y esperanza? . . .

4. El azul blanquecino del cielo. The verb is yace. understood.

13. revelan únicamente, alone reveal.

15. inmóvil, encantado en medio de la inmensidad. Cf. Ancient Mariner, Part II, 8 :

"As idle as a painted ship

Upon a painted ocean." 
Hace años, estos férreos transportadores de hombres seguían todos el mismo rumbo, con la tenacidad rutinaria del rebaño que, una vez aprendido un camino, no sabe salirse de él.

5 Al abandonar las costas europeas ponían la proa al Oeste, siguiendo los mares septentrionales agitados o brumosos. Todos se daban cita en las costas de una inmensa nación, tragaderos insaciables de hombres, olla hirviente de todas las ı razas, tierra de prodigios monstruosos, de iniciativas desconcertantes en fuerza de ser grandiosas; país rodeado de una leyenda de maravillas, con minas de oro más opulentas que las del tiempo de Salomón, edificios de mayor altura que la torre rs de Babel o los pensiles de Semíramis, e invenciones como no las soñaron los antiguos magos.

Ahora ya no navegan todos los gigantes del mar con rumbo a los Estados Unidos de la América del Norte. El camino se ha bifurcado. El zocolosal rebaño de humo $y$ acero se reparte, y mientras unos marchan todavía hacia el Oeste para llevar las últimas provisiones de energía

4. no sabe salirse de él, cannot lease it.

8. tragaderos insaciables, i.e.. las costas de una inmensa naciôn.

I4. Salomón, king of the Israelites, famous for his wealth as well as for his wisdom.

14. la torre de Babel. According to biblical tradition Noali's sons attempted to build a tower reaching unto heaven.

15. Semiramis, legendary (juecen of Assyria, said to have foumded babylon and built its storied hanging gardens. 
humana al pueblo más progresivo de los tiempos modernos, otros ponen la proa al Sur en busca de un nuevo país abierto a la ilusión y al noble espíritu aventurero de los que desean cambiar de medio.

En todas las épocas de la Historia han existido ciudades de renombre mundial, ciudades-esperanza hacia las cuales se han vuel to con anhelante deseo los ojos de los hombres. Lo que la gloriosa Atenas fué para los artistas de remotos siglos, lo ro que representó Roma para los varones del mundo antiguo, que veían en ella un escenario sonoro de su actividad intelectual, lo han sido otras poblaciones para los hombres ansiosos de conquistar rápidamente una posición económica sin trope- I5 zarse con las trabas y obstáculos que oponen las sociedades viejas y exuberantes de población.

El nombre de estas ciudades de prodigios evoca imágenes de suntuosidad y amontonamiento de riquezas; sugiere la visión de fortunas amasadas 20 vertiginosamente; suena en los oídos con el

7. ciudades-esperanza, cities of hope. A noun is seldom used in Spanish as an adjective to modify another noun, but when that occurs the modifying noun is placed after the noun modified, not before, as in English.

12. que veían en ella un escenario sonoro de su actividad intelectual, who saw in her an attractive field for their intellectual activity.

I3. 10. Note the use of the neuter article to sum up a preceding idea. In this case the clauses beginning with 10 que in lines 9 and Io are recapitulated. 
sugestivo retintín del oro, $y$ todos los valerosos en el eterno combate de la vida corrieron a ellas con la desesperación heroica del que ansía morir o abrirse paso.

5 Bagdad, la mágica Bagdad de Las mil y una noches, ha hecho soñar durante mil años a los pueblos orientales, que veían en la lejana metrópoli del Tigris inmensos tesoros guardados por los genios y las peris para premios de los buenos. ro La medioeval Toledo, patria de mágicos prodigiosos, brujos omnipotentes y alquimistas fabricantes de oro, ocupó la imaginación de los europeos siglos y siglos, evocando en su sencilla fantasía montones inmensos de monedas rutilantes, is cuevas rellenas de barras del precioso metal, palacios carcomidos, próximos a hundirse bajo el peso de inauditas riquezas. i Ser brujo de Toledo! i Poseer la receta misteriosa para la fabricación del oro!... Esta ilusión estaba tan arraigada zo en el alma medioeval, que ha perdurado a través de los siglos, y aun hoy las viejas judías de Salónica

5. Bagdad, city on the banks of the Tigris, in Arabia. It was the capital of an important caliphate, from the thirteenth to the fifteenth centuries, and its name was synonymous with riches and wonders in the Moslem world.

10. Toledo, city in Span, famous for its Gothic cathedral, which contains many historical and artistic treasures. The metal industries of Toledo were justly renowned in the Middle Ages.

16. próximos a, ready to.

21. Salónica, city and port in northern Greece, captured 
y Constantinopla que guardan las tradiciones de España, patria de sus mayores, cantan viejos romances a la gloria de la ciudad del Tajo y sus fantásticas riquezas.

Durante la colonización hispanoamericana, el 5 renombre de una ciudad casi desconocida ahora, conmovió el mundo. ¡Potosí !. . Al pronunciar este nombre veíase con la imaginación un monte inmenso de engañosa corteza terrena, en la que bastaba arañar un poco para que que-so dasen al descubierto las entrañas de metal deslumbrador. Semejantes al rey Midas de la leyenda, que convertía en oro todo cuanto tocaba, los hombres de este país de maravillas vivían rodeados de una abrumadora y forzosa suntuo- is sidad. La plata valía menos que el hierro y la loza grosera. De plata eran las herramientas del trabajo, los objetos de usos más viles, las vajillas from the Turks during the recent Balkan War (I9I2). When the Jews were expelled from Spain during the reign of Philip II, they took refuge in Turkish lands, particularly in Salonica, which to this day is largely populated by them. Their language, a form of Spanish corrupted by years of separation from Spanish-speaking peoples, is called ladino and can be easily understood by one speaking Spanish. In New York there is published to-day a ladino newspaper in Hebrew characters.

7. Potosí, city in Bolivia famous for its silver mines.

12. Midas, king of Phrygia about whom mythology has woven various legends. Besides the one referred to here, he is said to have irritated Apollo, who inflicted the ears of a donkey upon him. 
ordinarias, y hasta los guijarros con que se apedreaban los muchachos.

¡Potosí! ¡ Mágico nombre!... En Europa los labriegos se hacían soldados para poder llegar ${ }_{5}$ en son de conquista al famoso país: los estudiantes y los clérigos cambiaban las negras bayetas escolásticas por el coleto de ante y la espada del aventurero: hasta los nobles abandonabán el regalo y las intrigas de la corte y partían a la so conquista del Vellocino, despreciando la renta vulgarísima y reposada de sus cortijos, toradas y tierras de pan llevar, ante la esperanza de una fortuna inmensa, rápida, fulminante, en un país donde acababa de realizarse el secular ensueño de ${ }_{15}$ El Dorado.

Luego, durante una mitad del siglo XIX, otro nombre de América hizo palidecer el de la famosa ciudad del Alto Perú. ¡California! ¡Los placeres de oro inmediatos al Pacífico!... Y los soñazodores de Europa que habían dedicado de antemano su vida a la aventura y al peligro, corrieron al encuentro de esta nueva resurrección de la

ro. Vellocino, the Golden Fleece. Jason and the Argonauts, Greek mythological characters, went to Colchis and brought back the Golden lifeece, after slaying the dragon which kept guard over the fabled treasure.

I2. tierras de pan llevar, grain-producing lands.

15. El Dorado. The early conquistadores imagined there existed a country marvelously rich somewhere in America, which they called El Dorado, i.e., The Golden.

17. la famosa ciudad del Alto Perúvi.e., P'otosí. 
Quimera que agitaba sus escamas de oro al otro lado de los mares: y las gentes de simple entendimiento y férrea voluntad les siguieron en esta peregrinación hacia la riqueza, descuajándose de la existencia sedentaria, arracándose de las raíces que les unían 5 a la aldea natal, al campo alimentador de su estirpe, para afrontar los peligros de una correría errante e incierta.

Hoy todos estos nombres no son más que recuerdos históricos, rótulos sonoros de ilusiones ıo muertas, de esperanzas hechas polvo. El metal precioso, que era su alma, desapareció arrastrado por la circulación mundial, y sólo queda la mísera máscara que lo contuvo, ruinas que hablan con su triste aspecto de una esplendidez desaparecida rs $_{5}$ para siempre.

Pero la humanidad necesita una ilusión, una esperanza de riqueza que la acaricie en sus horas de desengaño y penuria, y otro nombre ha venido a sustituir a los mágicos nombres antiguos: . . . 20 ¡Buenos Aires!

Es necesario ser europeo para comprender lo que estas palabras significan en el Viejo Mundo. ¡Buenos Aires!... Al pronunciar este nombre,

I. Quimera, Chimera, monster in Greek mythology slain by Bellerophon, the Corinthian hero. The meaning of illusion has come as a result of the fantastical shape ascribed to the monster.

13. la misera máscara, i.t., the exhausted mines of Peru and California. 
la imaginación no ve minas de oro, tesoros resplandecientes que se ofrecen a la codicia del recién llegado sin más trabajo que agacharse para poseerlos. Hoy hasta los más ilusos saben que la 5 conquista de la riqueza supone esfuerzo, y Buenos Aires, a través de las más optimistas fantasías, aparece siempre como un El Dorado del trabajo. Lo que este nombre evoca en la mente de los peregrinos mundiales que marchan hacia la tierra ro argentina no es una visión de oro, sino de rebaños infinitos, al lado de los cuales parecen míseras tropillas los ganados bíblicos de los profetas y la fortuna pastoril de los pueblos nómadas de la antigüedad; campos inmensos como un océano is terrestre sobre los cuales tiene el cielo los mismos espejismos y rutilantes atardeceres que sobre el mar; suelos de maravillosa fecundidad, que sólo hay que abrirlos con el surco para que surja al momento, en forma de espléndidas cosechas, una zo energía fecundante, resto sin duda de las primeras fuerzas que presidieron la formación planetaria y que han estado dormidas durante miles de siglos en las entrañas del globo.

Buenos Aires, cuyo nombre se confunde con el ${ }_{25}$ de todo el país argentino en la simple imaginación de muchas gentes, significa la fortuna por el trabajo. Pero hasta este trabajo tiene algo de maravilloso, de inaudito, de nunca visto. El trabajo (uropeo es para el cmigrante una escla3o vitud penosa, ingrata, degradadora, de la que 


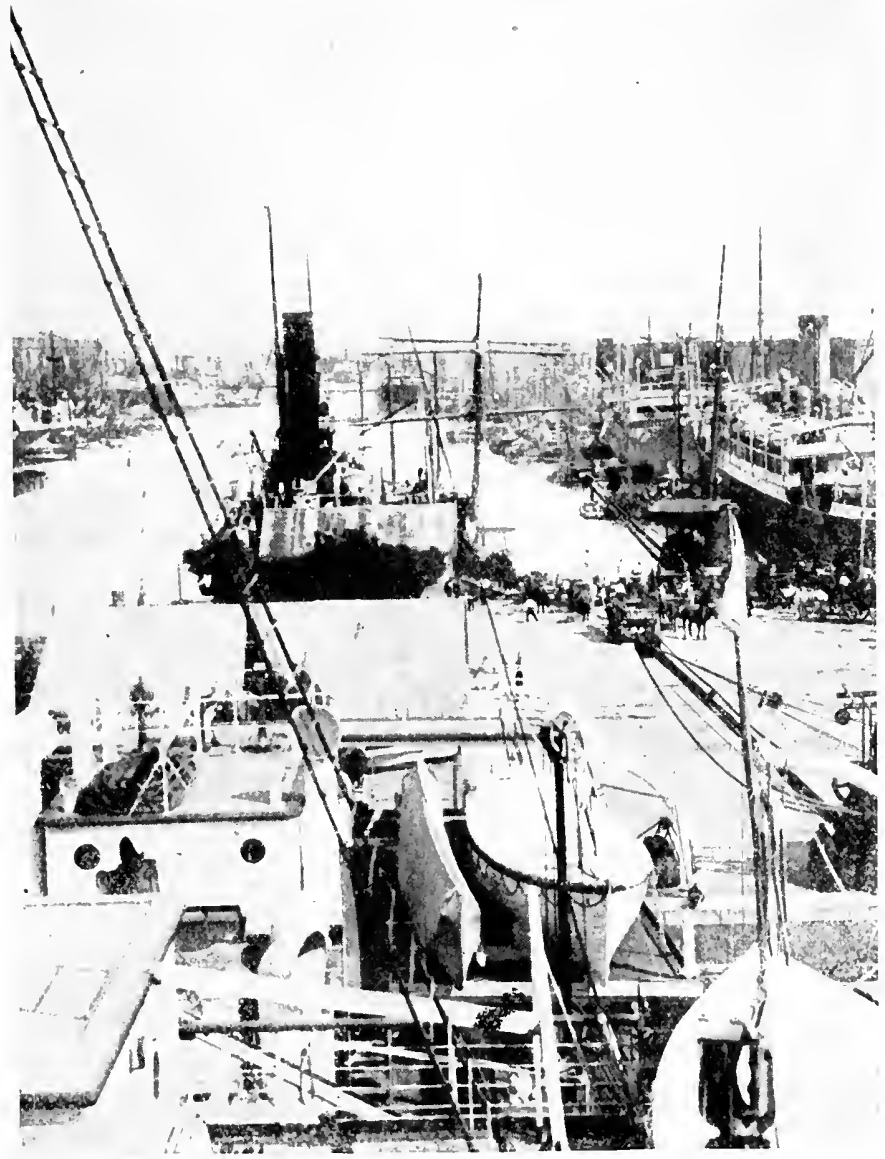

Copyright by Underwo.t in Unterwot, . . .

Vista del Puerto de Buenos Aires 
quiere librarse para siempre: escasos jornales, que apenas si bastan para la satisfacción de las necesidades más primarias; imposibilidad del ahorro como medio de cambiar algún día de s posición; falta absoluta de esperanza de mejoramiento; largas temporadas de famélico descanso por abundancia excesiva de brazos, y por encima de todo esto el fatalismo social del mundo viejo, que marca al pobre desde que nace, condenándolo so a permanecer eternamente abajo, sin una ilusión, sin un resquicio en su mísera obscuridad, por donde pase la mano de la Fortuna $y$ le busque a tientas tirando de él hacia lo alto.

¡ Buenos Aires!. . Este nombre hace soñar is al desesperado. Al repetirlo mentalmente se siente fortalecido, con energías centuplicadas para la lucha. i Trabajará! el trabajo no le da miedo. Desarrollará una actividad triple o cuádruple que en Europa sin sentir cansancio, porque zo verá inmediatamente en sus manos el resultado de sus esfuerzos y conocerá la remuneración amplia y generosa. Sus brazos van a ser algo solicitado y respetado, con un valor positivo, sin el desprecio de la infinita concurrencia. Al fin va a entrar en 25 relación con el dinero, antes invisible, y el trabajo le buscará, en vez de marchar tras él implorándolo como una limosna.

Hay además en todo emigrante algo de esperanza novelesca; la quimera que acompaña siempre a 2. que apenas si bastan, which barely suffice. 
los hombres, aun a los de pensamiento más rudimentario, en todas las empresas de su vida. ¡Buenos Aires!. . . Al conjuro de este nombre surgen en la memoria historias maravillosas de rápidas y enormes fortunas; cuentos reales de lo 5 que pudieran llamarse Las mil y una noches de la riqueza moderna: historias de españoles que llegaron al suelo argentino sin otro haber que un hato de ropa al hombro, para juntar en los años de su existencia veinte millones de pesos y extensiones ro de tierras grandes como provincias: historias de italianos que emprendieron el viaje para ser músicos en cualquier teatrillo de extramuros y acabaron poseyendo centenares de leguas en la fecunda Pampa. ¿Por qué han de ser ellos los únicos? Lo 15 que ocurre a un hombre, ¿ no puede ocurrirle a otro?

- ¡Quién sabe!... ¡Quién sabe!...

$Y$ murmurando mentalmente palabras de esperanza, se duermen sobre las cubiertas en la noches templadas de la travesía, unos contra otros, con- 20 fundiendo miserias e ilusiones, como dormían en sus campamentos, muchas veces sin comer y transidos de frío, los soldados de Napoleón, pensando en el majestuoso Murat, antiguo mozo de mulas; en el rey Bernadotte, nacido en una ${ }_{25}$

24. Murat (Joaquín). He was the son of a humble innkeeper, and rose to be one of Napoleon's most trusted marshals, and was king of Naples from I 808 to 1814.

25. Bernadotte (Carlos), another marshal of Napoleon, risen from the ranks. In 1818 he became king of Sweden. 
panadería; en todos los príncipes, mariscales y monarcas venidos de abajo, lo mismo que el último granadero; recuerdos que inflamaban su entusiasmo, borrando con el cálido esponjazo de la 5 ilusión penalidades y desalientos.

¡Buenos Aires!... ¿Qué misterioso poder hace circular este nombre por toda Europa? ¿A impulsos de qué ley surge siempre con caracteres de fuego en la negra pesadilla del desesperado que ro recuerda con terror los compromisos y miserias del día siguiente? ¿Quién lo murmura, como un tenue susurro de esperanza, al oído de todos los que desean cambiar de suelo y de existencia?

Años atrás el Gobierno argentino fomentaba ${ }_{15}$ directamente la inmigración, tenía agentes reclutadores en todas las naciones, pagaba los pasajes; pero ahora hace mucho tiempo que ha abandonado este sistema. Ya no se cuida de atraer gente, pues tiene confianza en las excelentes 20 condiciones del país y sabe que aquélla no ha de faltarle. Deja que el emigrante llegue a impulsos de su propia voluntad, costeándose el viaje (con lo que evita en parte el contingente de mendigos profesionales), y sólo se encarga de auxiliarle y ${ }_{25}$ dirigirle desde que pisa el suelo argentino. Quién, pues, aconseja al emigrante europeo este viaje? ¿ Quién ha lanzado el nombre mágico, evocador de esperanzas, en el escondido valle del centro de Europa, en la casa de madera perdida zo bajo las nieves de la estepa rusa o los fiords 
noruegos, en la exigua aldea de pescadores a orillas del Atlántico y del Mediterráneo, o en los barrios policromos de las tortuosas y dormidas ciudades de Oriente?. . .

Se dirá que los más de los que emigran tienen 5 parientes o amigos establecidos desde muchos años antes en la tierra argentina. Cerca de dos millones de extranjeros viven en ella, y éstos, satisfechos de su nueva existencia y gozando de una prosperidad - por escasa que sea-siempre su- то perior a la que disfrutaban en el viejo continente, ejercen una atracción poderosa sobre su lejana patria.

Muchos de los que se embarcan sienten acallada su zozobra por la seguridad de que alguien les is espera en la orilla americana. El muchachuelo español de boina azul que entona canciones en los bailoteos de a bordo, lleva oculta en el pecho una carta para el paisano y pariente que salió hace años de la aldea asturiana o la casería vasca 20 para no volver más, sobreviviendo en la memoria de la familia y el vecindario con el prestigio de lejanas y fabulosas riquezas. El personaje omnipotente es almacenero en el campo, tiene un boliche en las inmensidades de la Pampa o Río Negro, y 25 el muchachuelo, apenas desembarque, pasará por Buenos Aires velozmente, yendo a caer en línea recta tras un mostrador, centenares de leguas

5. los más, the majority.

25. Río Negro, river in the Argentine pampas. V. map. 
tierra adentro, donde con una adaptación sonriente, como si hubiera salido de la casa paterna un día antes, comenzará a servir copas a los parroquianos de poncho, chiripá, bota de potro y sonoras ${ }_{5}$ espuelas, que tal vez saluden a un futuro millonario en el listo galleguito. Los hebreos del lejano Oriente llevan recomendaciones fraternales para sus correligionarios de Buenos Aires dedicados a industrias urbanas, o para los que cultivan ro las colonias de Entre Ríos. Los italianos cuentan siempre en Argentina los parientes a centenares. Algunos de los que van en el buque han hecho el viaje varias veces. Son golondrinas que llegan en la época de la recolección de las cosechas, cuando ${ }_{5}$ se pagan los jormales a precios exorbitantes, y luego, con los ahorros bajo el ala, emprenden el viaje de retorno; tomando el transatlántico como quien toma el tranvía. Muchos que llegan por primera vez serán colonos, peones del campo, al 2olado de los amigos que les precedieron, o se dedicarán bajo su dirección y consejo a todas las faenas urbanas.

Es cierto que una parte de emigración actual

4. chiripá, gaucho trousers - composed of a piece of cloth wound around the loins and the lower end brought between the legs and fastened in front.

Io. las colonias de Entre Ríos. The province of Entre Rios has many colonies of fewish farmers.

13. golondrinas, name given in Argentina to the immigrants who go back to their native land each year after the harvest. 
va a la Argentina atraída por los compatriotas que hicieron antes el viaje, o recomendada a éstos. Pero, ¿quién atrajo y aconsejó a los que llegaron primeramente por su propia iniciativa? ¿Quén impulsa ahora a los que se presentan solos, $\sin _{5}$ apoyos ni conocimientos, fiados al buen gesto del destino? ¿Quién ha hecho que el recuerdo de Buenos Aires surja como una suprema solución en el ánimo de todo europeo que atraviesa uno de esos conflictos que cambian una vida?

Cada grupo cosmopolita que llega a los muelles de Buenos Aires es una nueva prueba de la fama mundial de la ciudad-esperanza, moderna Sión para todos los que ansían paz, trabajo y bienestar.

Su nombre circula por el mundo viejo como una ${ }_{5}$ brisa dulce que despierta las almas adormecidas. Las razas sin patria y los pueblos que empiezan a dudar de la que tienen por no encontrar en su seno más que pobrezas y opresiones, sienten como un rejuvenecimiento al pensar en este país ma-zo ravilloso donde se realizan los más asombrosos avatares. Es la tierra donde el holgazán se siente activo, el apático se mueve con los entusiasmos del optimismo, y el que era en el viejo continente torpe e inútil, deformado por la estrechez del ambiente 25 natal, surge del duro quiste rutinario con originales iniciativas, como si le inspirase el nuevo medio.

"¿Buenos Aires!", murmura el viento en las noches invernales, al colarse por el cañon de la chimenea en la cocina campestre, española $0_{30}$ 
italiana, donde la familia pasa las horas triste y silenciosa, rumiando cómo podrá evitar al día siguiente el embargo de los cuatro terrones que constituyen su fortuna, o cómo adquirirá el pan s necesario: “i Buenos Aires!", muge el vendaval cargado de copos de nieve al filtrarse por entre los maderos de la isba rusa: "¡Buenos Aires!”, parece escribir el sol en arabescos temblones de luces y sombras en los muros calizos de la callero juela oriental, ante los ojos del pobre otomano, encorvado por la servidumbre y el miedo: “ ¿ Buenos Aires!", repiten las alas de oro de la Ilusión cuando vuela de reverbero en reverbero, a altas horas de la noche, por los desiertos buleI 5 vares de las grandes metrópolis europeas, precediendo los pasos del pobre desesperado, sin hogar, sin pan, que estudió para morirse de hambre, que ha visto fracasadas por falta de ambiente todas sus iniciativas, y tal vez piensa en el sui20 cidio.

Y todos, sin distinción de razas y clases, ignorantes e intelectuales, fuertes o humildes, al conjuro de este nombre ven alzarse en el último término del paisaje de su fantasía, bañada por la

3. los cuatro terrones, the niggarlly palch.

8. parece escribir el sol .. la callejuela oriental, the sun seems to write in arabesque characters trembling with lights and shadows upon the whitewashed walls of the narrow criental streets.

14. a altas horas de la noche, in the late hours of the night. 


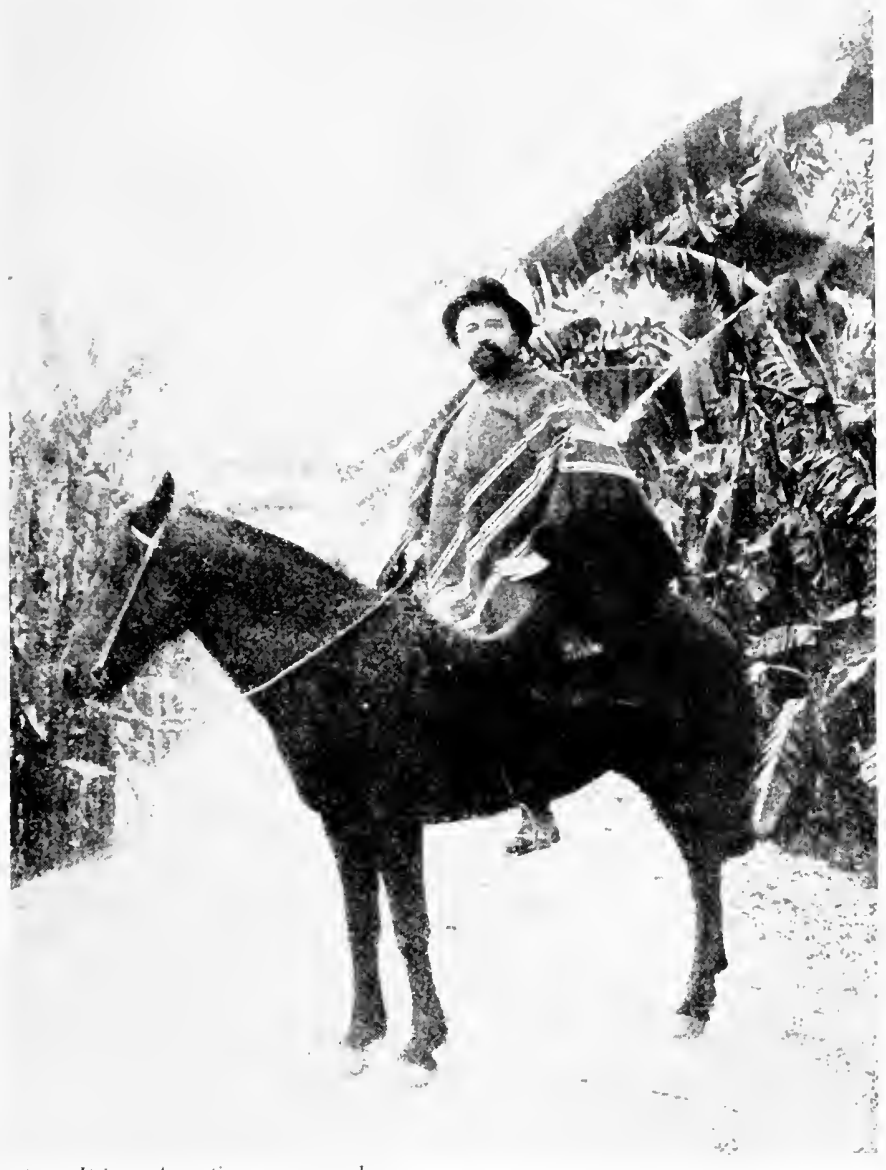

wisto Ibines, Argentina y sus grantersts

Vicente Blasco Ibáñez 
luz verde de la esperanza, una mujer majestuosa, pero de esbeltez juvenil, sin la pesadez imponente de la matrona; una mujer blanca y azul como las vírgenes soñadas por Murillo, con el purpúreo 5 tocado, signo de libertad, sobre la suelta cabellera; una mujer que sonríe abriendo en cruz los brazos amorosos y deja caer desde su altura de montaña palabras que revolotean como pétalos de rosa y mariposas de oro.

ro - Venid a mí, los que tenéis hambre de pan y sed de libertad. Venid a mí, los que llegasteis tarde a un mundo demasiado repleto. Mi hogar es grande; mi casa no la construyó el egoísmo. Está abierta a todas las razas de la tierra, a todos ${ }_{5} 5$ los hombres de buena voluntad. -

El buque sigue avanzando. Cambia el cielo y cambia el mar. Hay días en que el férreo vaso cabecea con mayor violencia sobre las olas y la muchedumbre aparece menos espesa, con grandes zoclaros. Los que se sienten heridos por el mareo, ocúltanse en las profundidades del buque. Otros permanecen tendidos al aire libre, pálidos, inmóviles como cadáveres después de una catástrofe. Ya no suenan músicas: una tristeza gris 25 parece gravitar sobre la cubierta, rociada de vez

3. una mujer blanca y azul, a cermun clad in blue and schite, i.e, the colors of the Areentine flag.

4. Murillo, Spanish painter. Cf. 138,19 . 
en cuando por el polvo acuoso de las olas, que chocan contra los flancos de la nave, levantando una cortina de espumas. Los habituados al viaje, que llevan a prevención como supremo lujo un asiento de tijera o una silla de lona, permanecen $s$ sentados, fuman y miran al mar con aire de conocedores, insensibles a la general molestia que parece enseñorearse del buque.

Cuando las muchedumbres europeas de la primera Cruzada, armadas al azar, y sin otra so disciplina que el entusiasmo religioso, caminaban hacia Oriente, su fe y su ignorancia les hacían sufrir tremendas decepciones.

Siempre que en el horizonte aparecían las torres y cúpulas de una ciudad, la piadosa e inocente $5_{5}$ turba estremecíase de gozo.

- ¿ No es Jerusalén? . . Sí: es Jerusalén; la ciudad santa. ¡Hosanna! ¡ Hosanna!

Los viejos gemían enternecidos; los monjes lanzaban su inflamada predicación; los hombres 20 requerían las armas, creyendo llegado el momento de pelear contra los infieles; los niños entonaban cánticos y las hembras gritaban de entusiasmo, incorporándose en los carretones, a la cola del inmenso éxodo.

Estos infelices cruzados, cuando imaginaban hallarse próximos a Jerusalén, estaban aún en las llanuras de la Baja Alemania o de Austria, y el 4. a prevención, in their foresight. 
espejismo del entusiasmo repetíase todos los días al avanzar por el centro de Europa, creyendo haber llegado al término de la jornada cada vez que columbraban a lo lejos una ciudad o un castillo. 5 La misma ilusión del deseo acompaña a los pobres emigrantes, entusiastas cruzados de los tiempos modernos. La ansiada Jerusalén surge ante sus ojos en toda ribera que costea el buque, en todo puerto donde echa el ancla.

ı ¡Buenos Aires! ¿ Dónde está Buenos Aires? .. Un estremecimiento de esperanza corre por la muchedumbre cuando aparece frente a la proa una faja de tierra. Hasta los más ignorantes conocen la cantidad de días que debe durar la is navegación; pero la ansiedad les hace creer en un milagro, en una marcha extraordinaria del buque, y al ver la tierra, se gritan unos a otros:

\section{Aires?}

- iBuenos Aires!... ¿ Será esto Buenos 20 No: no es la ciudad-ilusión. Es Pernambuco, es Bahía, es Río Janeiro; y cuando el transatlántico queda fondeado a la vista de la tierra, los peregrinos se agolpan en la borda, mirando la ciudad lejana, pero sin deseos de bajar a ella, ${ }_{25}$ faltos decuriosidad. Para ellos no hay nada que les interese en este país: su esperanza viela más lejos. Los que hacen el viaje por primera vez, admiran cl color negro y la crespa y lanuda pelambrera de los lancheros; compran las frutas raras amontozo nadas con las barcas que circulan como insectos en 
torno del gigante marino; admiran su sabor exótico, y al fin acaban por volver la espalda a la costa, tendiéndose en sus mantas y colchonetas, aburridos de esta inercia, deseando reanudar antes el viaje. Buenos Aires es lo que les importa. 5 ¿Cuándo llegarán a Buenos Aires? . . .

En la espléndida bahía de Río Janeiro, la hermosura del panorama los conmueve unos instantes. Luego reaparece la indiferencia. Ellos no han de vivir en esta tierra; ¿ para qué intere-ro sarse por sus montañas rosadas de bizarras formas, y sus calles blancas, con dobles filas de altos cocoteros?

Cuando el transatlántico emprende otra vez la marcha, la gente canta y ríe, creyéndose próxima 15 al término del viaje. Ya no aguardarán más: casi se hallan a la vista de la ciudad de la esperanza: la próxima escala es Buenos Aires. Y transcurren varios días sin ver otra cosa que cielo y mar. Algunas veces se marcan en la línea del 20 horizonte manchas obscuras que parecen nubes bajas y son montañas.

El aislamiento de la navegación, la vida común con gentes tan diversas en medio de la soledad de los elementos, la marcha hacia otro mundo mis- 25 terioso, parece haber transformado la moral de los emigrantes, creando en ellos una nueva personalidad. ¡ Adiós, timideces del terruño, humildades de familia, miedos rutinarios a todo lo que se sale de la estrecha norma de lo vulgar! 
El pobre campesino, acostumbrado en su país al expolio y la miseria resignada, se siente ahora altivo, con nuevas fuerzas para hacer frente a todos los obstáculos. El viento del océano, al ensanchar 5 sus pulmones, parece echarle atrás los hombros, dando a la cabeza una erguida altivez. Oyendo a los aventureros, a todas estas gentes de extraños países, empieza a considerar con cierto orgullo su condición de emigrante y de pobre. La soledad ro atlántica, las largas horas de recogimiento, lejos de toda organización social, le hacen apreciar la pequeñez de los hombres y de sus leyes, y se contempla a sí mismo más grande, más poderoso. Las preocupaciones que en tierra firme fueron 15 muchas veces su tormento, las desprecia ahora por insignificantes, viéndose lejos de ellas.

El hombre del viejo mundo desaparece. Cada singladura se lleva algo de su antiguo sér. Van desapareciéndose de su ánimo las timideces y 2o resignaciones de la educación tradicional. Son a modo de escamas del primitivo organismo que se despegan de la piel y caen al agua. Cada día pierde una. Cuando llegue al término de su viaje será otro.

Siéntese capaz de las grandes iniciativas. El 25 pobre de Europa, sometido, y a la huelga, sin esperanzas, sin afanes de actividad, que al fin turo que embarcarse y emigrar, le parece ahora un bombre distinto. ¡Lo que trabajará él en el

18. Van desapareciéndose, Cradually there disappear.

28. i Lo que trabajará... ! How he will suork! 
Nuevo Mundo! Hará fortuna a las buenas o las malas. Siente en su ánimo la fría audacia, el egoísmo homicida de los aventureros que todo lo justifican con las necesidades imperiosas de la lucha por la existencia. Su alma es la de los héroes 5 de Balzac que contemplaban París desde una altura, con ojos de invasor implacable y desdeñoso, murmurando: "iTú serás mío!"

¡Buenos Aires!... Él conquistará la gran ciudad; se batirá con ella a brazo partido para ro poseerla, para dominarla. Aislado en el mar, lejos de la realidad, en plena fantasmagoría de la ilusión, se considera capaz de los más estupendos esfuerzos. En sus conquistas imaginativas entra por mucho el desconocimiento del país adonde se 15 dirige, esa ignorancia de América que es en el viejo mundo algo secular e inconmovible. Sabe que Buenos Aires es una gran ciudad, se la imagina semejante a una buena capital de provincia pero al mismo tiempo, con bizarra confusión imagina- 20 tiva, ve tigres que saltan y juguetean como gatos en los alrededores de la urbe; serpientes colosales que ondulan o se arrollan a los árboles de los paseos; negros indolentes a los que hay que dar con el látigo para que trabajen; indios pintarra- 25

6. Balzac (Honore de), French novelist of the nineteenth century.

8. “i Tú serás mío!" Cf. Les Illusions Perdues, by Balzac, chapter entitled, Un Grand 110 mme de Province à Paris.

I4. entra por mucho, plays an important part. 
jeados y emplumados que asaltan los tranvías de los arrabales y se llevan cautivas a las señoras; una mezcla de civilización avanzadísima y de tremenda barbarie. ¡ Desdichado país si no 5 vinieran de afuera los hombres blancos para salvarlo!.. El alma de un paladín de romances de caballería late en él, quitando todo valor a la palabra "imposible". Matará, si es preciso, tigres y pitones; hará prisiones a los feroces ro indios y, pasándoles una anilla por la nariz, los llevará a trabajar ricas tierras, escogidas a su gusto. ¡Él lo hará todo!...

Las olas violentas que chocan contra el buque han cambiado de color. Ahora son rojizas, como is una melena leonada, y sucias por el barro que llevan en suspensión. Se ve el lejano perfil de una costa por estribor, y los emigrantes abren los ojos asombrados al oír que ya no están en el mar, que este espacio infinito de agua, con su oleaje zo tempestuoso, es un río, el famoso río de la Plata.

Empieza a anochecer, y en la costa, cada vez más cercana, se marcan centenares de luces. $\mathrm{Al}$ principio, forman lineas, como si indicasen la horizontalidad de caminos y bulevares exteriores; 25 luego se hacen más densas, se agrupan, se remontan por invisibles cuestas, se diferencian en rojas y blancas, destacándose las eléctricas como gotas caídas de la luna, entre las temblonas pinceladas del gas.

28. entre las temblonas pinceladas del gas, among the quivering gleams of gas lights. 


\section{- ¡ Buenos Aires! ¡ Viva Buenos Aires! -} gritan a proa, con entusiasmo de peregrinos.

No, tampoco es Buenos Aires. Es Montevideo.

El buque tras una detención de algunas horas, sigue su rumbo. Ahora parece que navega so- 5 bre algodones. Los pasajeros, acostumbrados al movimiento de todo cuanto les rodea, a sentir ondular el piso bajo sus plantas, a la oscilación general de los objetos, experimentan una extrañeza casi molesta, al ver que el buque avanza, $y, \sin$ ro embargo, parece inmóvil. El río, obscuro, toma blancuras de leche bajo la luz de las farolas de los buques. Una línea de boyas encendidas marca el paso a las embarcaciones en esta inmensidad.

La placidez de la navegación, el momentáneo is silencio, el descansar de maderas y hierros que han venido frotándose y cantando un monótono ric-ric durante medio mes, todo invita al sueño; $\mathrm{y}$ sin embargo, pocos duermen.

La gente, tendida en la cubierta y en los sollados, 20 sueña con los ojos abiertos. Percibe la proximidad de algo extraordinario, algo que la estremece con la emoción de lo desconocido. Cree oír la respiración de un organismo enorme. Buenos Aires está cerca. Y los que ansiaban tanto llegar a 25 ella, vacilan ahora y tiemblan. i Adiós, fantasías de la soledad! Ya se hallan vecinos a la gran Esfinge. ¿Cómo irá a recibirles? . . :

Los bravos exterminadores de serpientes y de

II. toma blancuras de leche, becomes milk-white. 
indios empiezan a dudar de sus fuerzas. Hay algo en el ambiente que repele estas fantasmagorías, que ríe de ellas, como los buenos vecinos de la Mancha reían de los heroicos e irreales propósitos ${ }_{5}$ del esforzado hidalgo. El emigrante empieza a sentirse igual a como era antes de poner el pie en el transatlántico. ; Acabaron los ensueños del mar! Reaparecen sus indecisiones, sus timideces, su falta de confianza en la suerte.

ı El animal humano está próximo, la sociedad sale a su encuentro, y esto basta para que se desvanezca el superhombre de vida fugaz engendrado en las soledades de la navegación; el héroe de todos los arrojos, que no reconocía obstáculos.

${ }_{5}$ Apenas apunta el día, la cubierta se llena de gente. Las boyas luminosas destacan sus luces cabeceantes en la penumbra del crepúsculo. Todos se agolpan en la proa deseosos de ser los primeros en contemplar la esperada visión.

$20-$ - B Buenos Aires!. . . ¿ Dónde está Buenos Aires?

Una cortina de niebla oculta el horizonte. Ia sirena del buque ruge a ciegas en este ambiente blanco y denso, semejante al de los mares septen25 trionales. El agua, de un color lácteo, a impulsos

3. La Mancha, region in New Castile, Spain, birthplace of 1)on Quijote, hero of Cervantes' novel, The Ingenious cienteman Don Onijote of lo Mancha. The esforzado hidalgo mentioned is line 5 is Don Quijote.

I I. a su enouentro, to me't him. 
de la marea ascendente, choca con manso susurro contra los costados de la nave. A través de los espesos telones de la atmósfera pasan otras sombras, lentas, enormes y negras: vapores que avanzan con la grave calma del peligro; veleros de arbola- 5 dura escueta que se deslizan siguiendo sumisos el tirón del remolcador.

De pronto, el transatántico modera su leve marcha; apenas se mueve ya. Al mismo tiempo desgárranse los velos del horizonte y la luz pálida ro de la mañana saca de la bruma todo un mundo. Aparece a ambos lados del buque el río inmenso, sin orillas, como un mar de dilatados horizontes, y frente a la proa una ciudad, más bien dicho, una extensión cubierta de edificios, ilimitada, sin 15 términos visibles, infinita como la superficie acuática.

- ¡ Buenos Aires! ¡Al fin!... Esto es Buenos Aires.

La retina no puede abarcar los muelles, que se 20 pierden de vista; las dársenas llenas de buques, que se esfuman en el horizonte; los almacenes y elevadores de trigo, altos $y$ majestuosos como catedrales; las arboledas que siguen la ribera; las calzadas polvorientas por donde pasan trenes $y_{25}$ rosarios interminables de carretas. Detrás, altos edificios y suaves rampas marcan una altura, una cuchilla de tierra, el perfil de una meseta de contornos pulidos por al secular arrastre 20. se pierden de vista, are lost to view. 
del río; y sobre esta meseta se extiende la urbe, uniforme, baja, monótona, pero de una grandiosidad inabarcable; una ondulación de tejados grises, que se pierde en el horizonte, que 5 avanza tierra adentro, borrando toda idea de limites, desorientando a las imaginaciones, que en vano pugnan por abrazarla; un caparazón gigantesco, en el cual cada escama es la cubierta de una vivienda; un escudo inmenso e igual, del que rosobresalen torres y cúpulas como un adorno de clavos, $y$ borlones de seda verde, que son frondosos jardines.

Los que llegan se sienten intimidados por esta enormidad. La capital gigantesca parece caer ${ }_{15}$ sobre ellos con mortal gravitación.

— ¡Qué grande!... i Qué grande!..

¡ Adiós arrogantes propósitos de conquista, gallardías audaces de dominación y rápido encumbramiento! Es la ciudad la que conquista a los zorecién venidos, la que los hace sus esclavos, tímidos y sumisos, con sólo mostrarse un momento, fría y casi dormida entre las brumas del amanecer.

Muchos de los que llegan nacieron en una aldea 250 en el campo; no han visto otras ciudades que las de los puertos de embarque, y quedan espantados, enmudecidos por el respeto y el pavor a la vista de esta gran metrópoli de rápidas transformaciones, que todo lo encuentra estrecho, que rompe cada zo cinco años el traje de albañilería que le fabrican los 


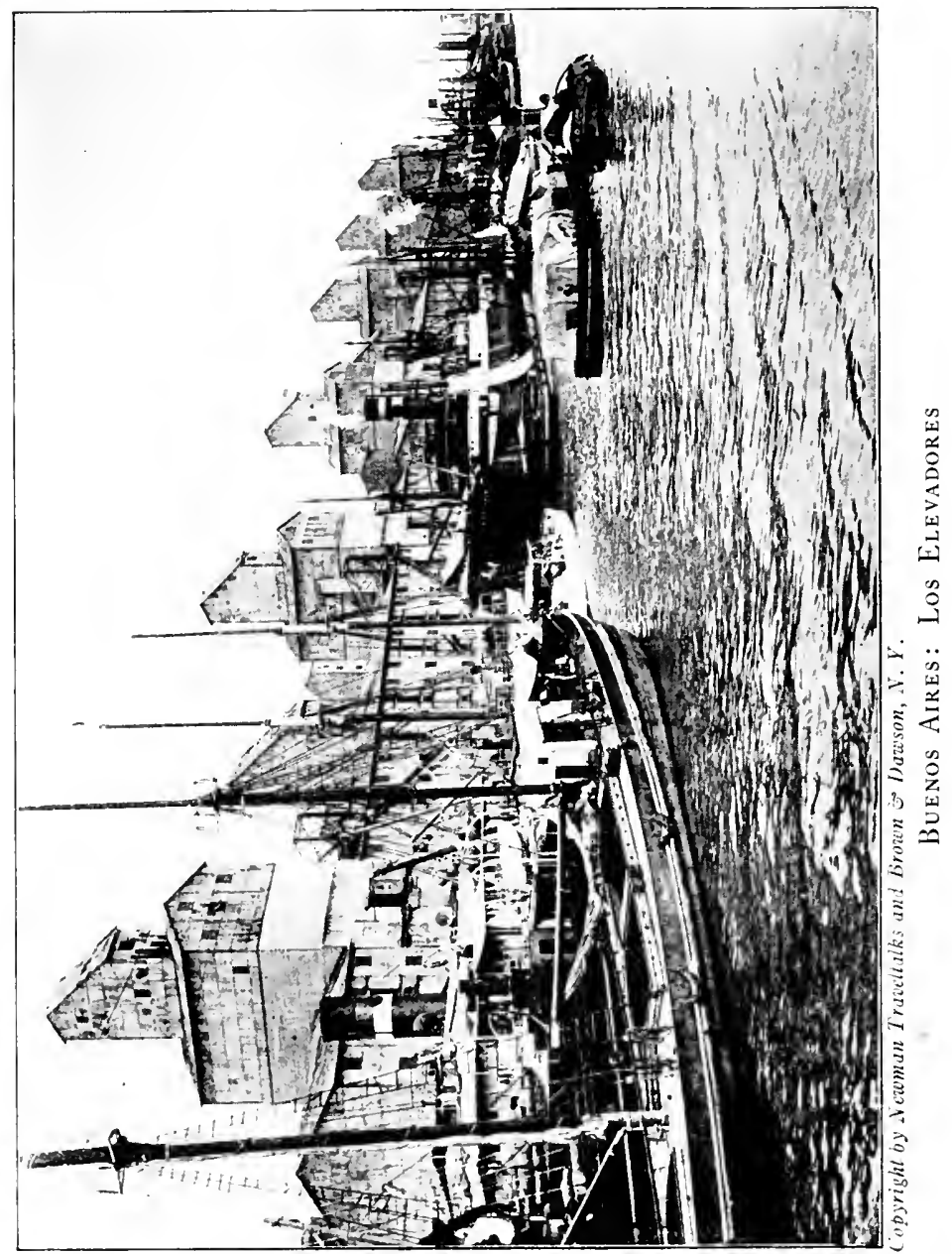


hombres, $\mathrm{y}$ crece $\mathrm{y}$ crece, no reconociendo fronteras en su desarrollo.

Lisboa es más escenográfica, con su caserío en cuesta que permite apreciar las grandezas de s la edificación: Río Janeiro realza su belleza arquitectónica dentro de un estuche de verdura, entre montañas que forman un marco rosado a la copa de su bahía; pero los emigrantes experimentan una impresión más profunda, de asombro y anonarodamiento, a la vista de Buenos Aires. Sus frentes se contraen; sus ojos miran con incertidumbre.

- i Qué grande!. . . i Qué grande!...

$\mathrm{Y}$ todos piensan con una emoción parecida al miedo, en lo que les aguarda dentro de este caserío is achatado, monótono, infinito, igual a la concha protectora de una gran bestia prehistórica.

Avanza lentamente el transatlántico, con ligeras pausas de inmovilidad, como si fuese tanteando el camino para evitarse un encontrón. Navega entre zodiques, y va a atracar dulcemente en un amplio muelle defendido por una cubierta de acero y cristales, como una estación de ferrocarril.

En el desembarcadero se reúnen grupos de curiosos. Los marineros de la vigilancia marítima, 25 con el machete al cinto, forman fila para contener al gentío que pretende avanzar y llama a gritos a los amigos que llegan en el buque. la policía huroncal y mira con ojos inquietos, temiendo el desembarco de gentes peligrosas, de elementos de 4. en cuesta, on a slope. 
desorden barridos por las aventuras del viejo mundo.

¡Cuán pequeño es ahora el transatlántico! Pegado a tierra puede apreciarse mejor su grandeza, y, sin embargo, parece más mezquino, más 5 insignificante que en medio de los amplios puertos donde echó sus anclas antes de llegar aquí. La comparación con centenares y centenares de otros buques, que alineados en las tranquilas aguas del río, entre muelles, diques y puentes se ro esfuman en el horizonte, borra la apreciación de su tamaño. La cantidad desvanece el valor de la dimensión. ¡Son tantos y están tan agrupados los gigantes marinos!. . . Cada uno de estos buques, destacándose aislado en medio del azul ${ }_{15}$ de una bahía, puede admirar por la grandeza $y$ arrogancia de sus proporciones. Aquí no es nada; se pierde entre sus compañeros en uıa extensión acuática de catorce kilómetros: es una chimenea más entre centenares de chimeneas; dos mástiles 20 que vienen a confundirse en la inmensa selva de palos y cordajes sobre la que revolotean las banderas como mariposas de colores.

Las dársenas, enormes plazas de agua, no son dársenas: son corrales de buques donde se aglo- 25 meran los monstruos flotantes como doméstico rebaño.

Los mercenarios de Salambó, al marchar de Car-

28. Salambo, novel by Flaubert, the great French novelist of the nineteenth century. It depicts life in Carthage. 
tago, veían con cierta inquietud, clavadas a los árboles por los cuatro remos, bestias moribundas que agitaban su roja melena entre estertores agónicos.

5 - ¿ Qué nación es ésta que crucifica a los leones ?. . . - murmuraban asombrados los personajes de Flaubert.

Algo semejante piensa el viajero al llegar al puerto de Buenos Aires, en una mañana fría y robrumosa.

- ¿ Qué pueblo es éste que trata a los gigantes del mar como si fueran reses? . .

Todos los días se presentan en sus muelles enormes transatlánticos, mansos, lentos, como is vacas rojas o negras que vinieran a pastar en las praderas azules del océano. Detiénense junto a sus almacenes para ser ordeñados por la poderosa ciudad, a la que dan generoso alimento; y cuando sus entrañas están exhaustas, cuando han soltado 20 el chorro de hombres y hasta la última gota sólida del cargamento, Buenos Aires les da con un pie en la amplia grupa, enviándolos a descansar en sus inmensos corrales de agua. Entran en una dársena, y si en ella no hay lugar, se trasladan a otra, 25 y luego a otra, pasando entre murallas, apartando puentes, seguidos de remolcadores que silban, corren y rodean el pesado rebaño de leviatanes

21. les da con un pie en la amplia grupa, shoves them (1) 17 .

25. apartando puentes, causing bridges to be drasun. 
como si fuesen sus zagales. $\mathrm{Y}$ en los inmensos apriscos acuáticos descansan los monstruos varios días, recibiendo la alimentación de tierra adentro, que les sirven grúas y elevadores, hasta que repletas sus entrañas de vigorosas riquezas y con nueva 5 sangre negra en las carboneras, vuelven a emprender la marcha, río abajo, hacia los azules campos.

Ya atracó la nave. Se arrancan los emigrantes de la contemplación de la ciudad, para arrollar y ro enfardar sus ropas. El puente ha quedado tendido desde el muelle a un costado del buque. ¡ Gente a tierra!... Las mujeres toman de la mano sus ristras de pequeñuelos y se colocan sobre la cabeza, como enorme turbante, el atado de ropas. Is Los hombres se concorvan bajo los fardos de mantas y colchones. Algunos, pobremente vestidos de señoritos, desembarcan con las. manos en los bolsillos, silbando para distraer su emoción. Otros llevan por todo equipaje una guitarra y saludan 20 con gritos y risotadas a los amigos que les esperan en el muelle.

El rebaño de miseria y esperanza desfila y desfila hacia lo desconocido. ¿Qué les aguardará en el interior de este monstruo gris y achatado que todos 25 los días devora su ración humana?. . .

Los peregrinos pasan y pasan por el puente de madera, bajo la mirada escrutadora de la policía. ¡ Ni una palabra! El ambiente es de libertad.

7. río abajo, downstream. 
El Hotel de Emigrantes ofrece asilo a los que se presentan sin amigos $y$ recomendaciones. Las oficinas están abiertas para los que llegan desvalidos, sin un propósito determinado. La nueva 5 tierra les ofrece cama, alimento y el ferrocarril o los vapores fluviales necesarios para que se trasladen al interior, donde hay demanda de brazos.

Los que llegan no encuentran obstáculos, y, sin embargo, parecen cohibidos, atemorizados.

ıо “ Ay, Buenos Aires! . . ¡ Tan grande!... ¡Tan grande!..."

La inmensa metrópoli sudamericana pesa sobre ellos con toda su enormidad.

Nadie echa ya la cabeza atrás con arrogancia is belicosa, ni saca el pecho fanfarronamente. Las frentes se bajan a impulsos de la inquietud; las espaldas parecen encorvarse como si sintieran por adelantado el peso de una vida de laboriosidad que va a empezar.

20 Y los soñadores del océano, que fantasearon las más absurdas grandezas como final de su viaje, entran a la nueva vida por un camino fácil, encontrando inmediatamente el trabajo y el pan; pero entran cabizbajos . . como animales domados 25 . . como ilusos que despiertan para caer en la realidad. 


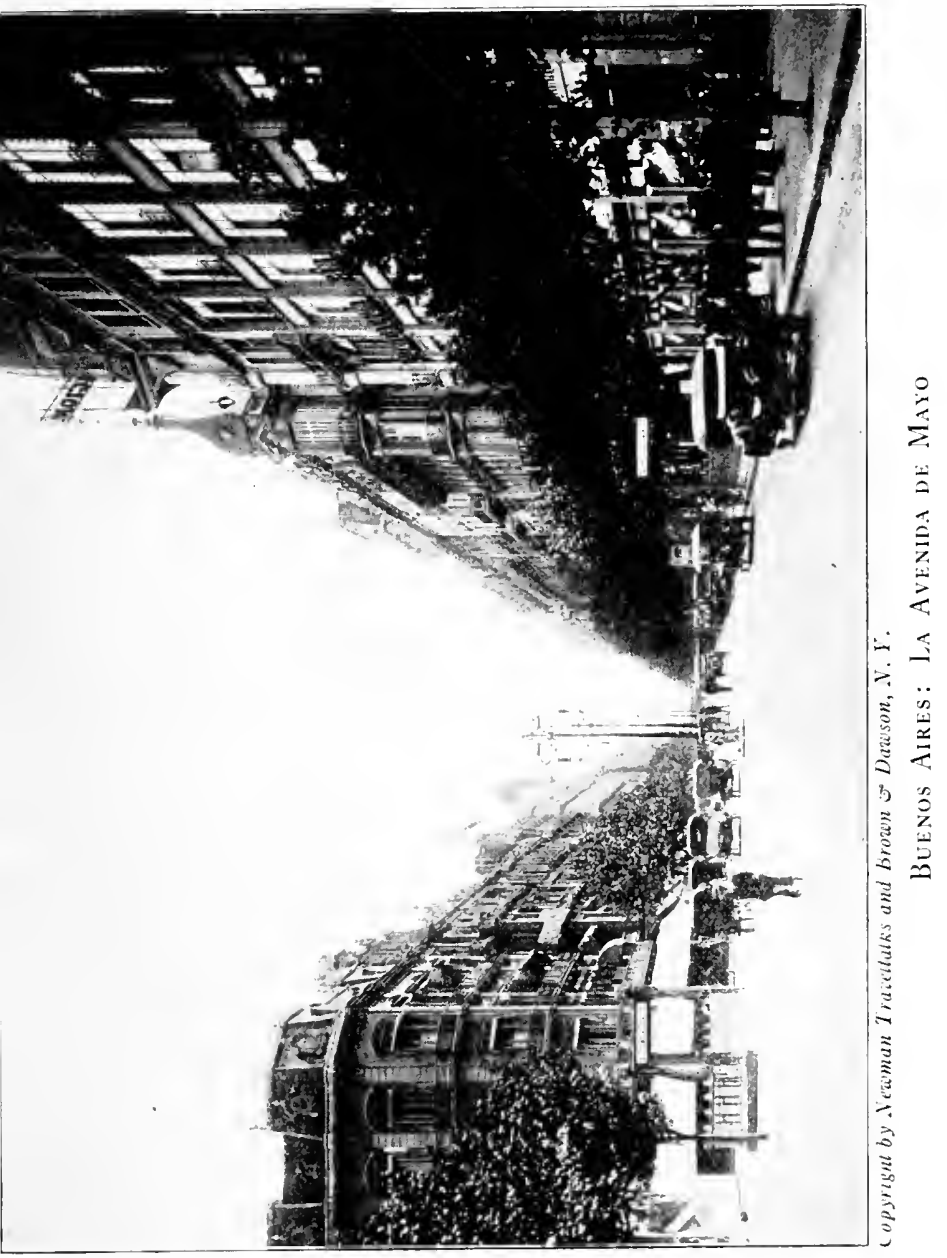




\title{
EL MINISTRO DRAGO AL MINISTRO GARCÍA MÉROU
}

\author{
Buenos Aires, 29 de Diciembre de $\mathbf{1 9 0 2}$
}

Señor ministro :

He recibido telegrama de $V$. E., fecha 20 del corriente, relativo a los sucesos últimamente 5 ocurridos entre el gobierno de la República de Venezuela y los de la Gran Bretaña y la Alemania. Según los informes de V. E., el origen

Title. Drago. Towards the end of the year 1902 the internal dissensions of the republic of Venezuela and the mismanagement of Dictator Castro's administration caused the destruction of much forcign capital, and finally led to the repudiation of loans contracted by Venezuela in Europe. The situation became acute when in 1903 England, Germany, and Italy scont a combined fleet to blockade the ports of Venezuela. Castro appealed to the L'nited States, claiming that the Monroe Doctrine was being violated. The matter, at the instance of the Lnited States, was finally settled by the Hague Court of Arbitration, which decidcd that Veneznela should meet the British. German, and Italian claims. Previous to the blockade Argentinal, through her secretary of state, Drago, sent the following note to the United States, protesting against the use of force on the part of any foreign nation to collect indemnities due to their subjects, or installments on loans. This further extension of the Monroe Doctrinc is called by the Argentineans the Drago Doctrine. 
del conflicto debe atribuirse en parte a perjuicios sufridos por súbditos de las naciones reclamantes, durante las revoluciones y guerras que recientemente han tenido lugar en el territorio de aquella república y en parte también a que ciertos servicios 5 de la deuda externa del Estado no han sido satisfechos en la oportunidad debida.

Prescindiendo del primer género de reclamaciones, para cuya adecuada apreciación habría que atender siempre las leyes de los respectivos io países, este gobierno ha estimado de oportunidad transmitir a V. E. algunas consideraciones relativas al cobro compulsivo de la deuda pública, tales como las han sugerido los hechos ocurridos.

Desde luego se advierte, a este respecto, que is el capitalista que suministra su dinero a un Estado extranjero, tiene siempre en cuenta cuales son los recursos del país en que va a actuar, y la mayor o menor probabilidad de que los compromisos contraídos se cumplan sin tropiezo.

Todos los gobiernos gozan por ello de diferente crédito, según su grado de civilización y cultura y su conducta en los negocios, y estas circunstancias se miden y se pesan antes de contraer ningún empréstito, haciendo más o menos onerosas 25 sus condiciones, con arreglo a los datos precisos

7. en la oportunidad debida, at the proper time.

9. habría que, one should.

15. se advierte, it is clear.

20. se cumplan, will be met. 
que en este sentido tienen perfectamente registrados los banqueros.

Luego, el acreedor sabe que contrata con una entidad soberana y es condición inherente de toda 5 soberanía que no pueda iniciarse ni cumplirse procedimientos ejecutivos contra ella, y que ese modo de cobro comprometería su existencia misma, haciendo desaparecer la independencia y la acción del respectivo gobierno.

10 Entre los principios fundamentales del derecho público internacional que la humanidad ha consagrado, es uno de los más preciosos el que determina que todos los Estados, cualquiera que sea la fuerza de que dispongan, son entidades de derecho, per${ }_{15}$ fectamente iguales entre sí y recíprocamente acreedoras por ello a las mismas consideraciones y respeto.

El reconocimiento de la deuda, la liquidación de su importe, puede y debe ser hecha por la 20 nación, sin menoscabo de sus derechos primordiales como entidad soberana; pero el cobro compulsivo e inmediato en un momento dado, por medio de la fuerza, no traería otra cosa que la ruina de las naciones más débiles y la absorción de su gobierno ${ }_{25}$ con todas las facultades que le son inherentes por los fuertes de la tierra. Otros son los principios proclamados en este continente de América. "Los

I. en este sentido, to this effect.

8. la independencia y la acción, freedom of action. 26. Otros, Different. 


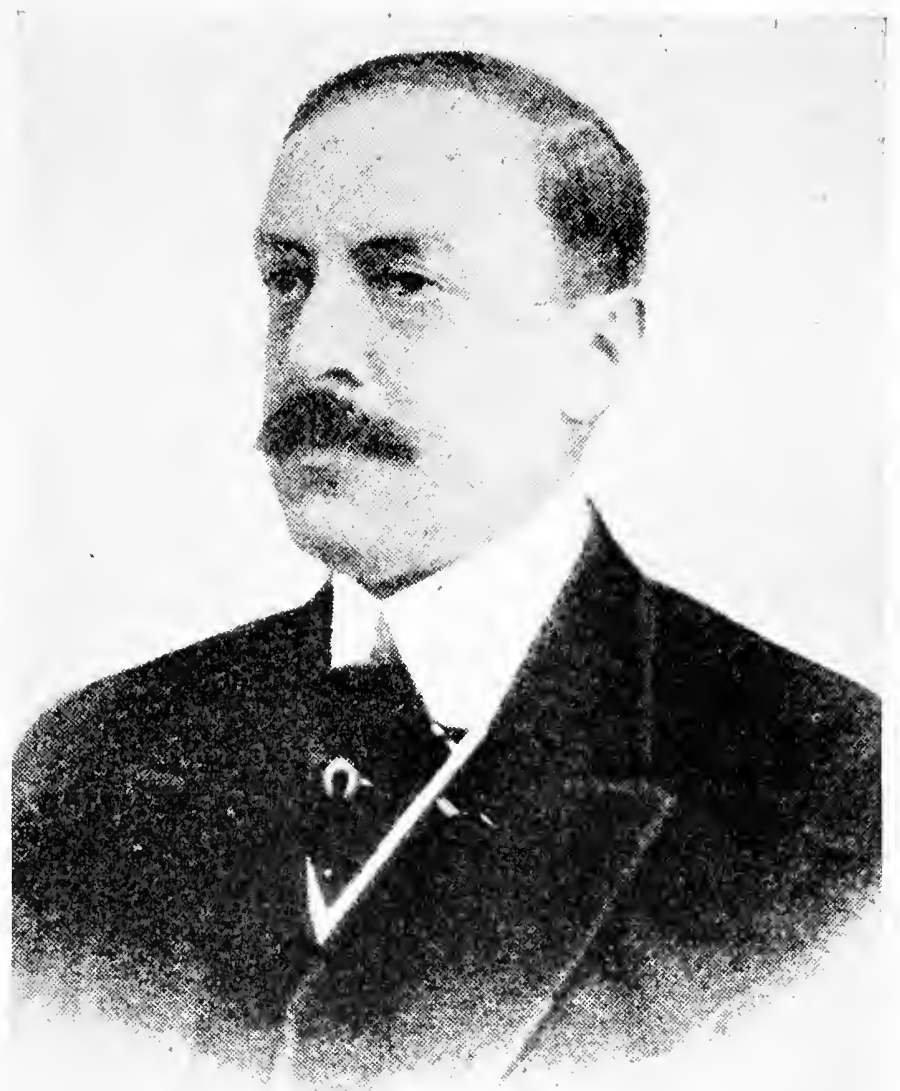

Bluseo Loance, Argentina y sus grandesas

Luis M. Drago 
contratos entre una nación y los individuos particulares son obligatorios según la conciencia del soberano, y no pueden ser objeto de fuerza compulsiva", decía el ilustre Hamilton. "No confieren de5 recho alguno de acción fuera de la voluntad soberana.'

Los Estados Unidos han ido muy lejos en ese sentido. La enmienda undécima de su constitución estableció, en efecto, con el asentimiento ro unánime del pueblo, que el poder judicial de la nación no se extiende a ningún pleito de ley o de equidad seguido contra uno de los Estados Unidos por ciudadanos de otro Estado, o por ciudadanos o súbditos de un Estado extranjero. La República ${ }_{15}$ Argentina ha hecho demandables a sus provincias y aun ha consagrado el principio de que la nación misma pueda ser llevada a juicio ante la Suprema Corte por los contratos que celebra con los particulares.

2o Lo que no ha establecido, lo que no podría de ninguna manera admitir, es que, una vez determinado por sentencia el monto de lo que pudiera adeudar, se le prive de la de elegir el modo y la oportunidad del pago, en el que tiene tanto o más

4. Hamilton (Alexander), American statesman and economist (1754-I 804 ).

17. pueda ser llevada a juicio, can be indicted.

23. se le prive, i.e., a la nación mentioned in line 16.

23. de la de elegir, i.t., de la sentencia de elegir. 'Trans., of the pocuer to select. 
interés que el acreedor mismo, porque en ello están comprometidos el crédito y el honor colectivos.

No es ésta de ninguna manera la defensa de la mala fe, del desorden y de la insolvencia deliberada 5 $y$ voluntaria. Es simplemente amparar el decoro de la entidad pública internacional que no puede ser arrastrada así a la guerra, con perjuicio de los altos fines que determinan la existencia y la libertad de las naciones.

El reconocimiento de la deuda pública, la obligación definida de pagarla no es, por otra parte, una declaración sin valor porque el cobro no pueda llevarse a la práctica por el medio de la violencia.

El Estado persiste en su capacidad de tal, y más tarde o más temprano las situaciones obscuras se resuelven, crecen los recursos, las aspiraciones comunes de equidad y de justicia prevalecen y se satisfacen los más retardados 20 compromisos.

El fallo, entonces, que declara la obligación de pagar la deuda, ya sea dictado por los tribunales del país o por los de arbitraje internacional, los cuales expresan el anhelo permanente de la ${ }_{25}$ justicia como fundamento de las relaciones políticas de los pueblos, constituye un título indiscutible

13. porque el cobro ... violencia, for preventing the collection of it from being carried out by means of siolence.

16. de tal, as such. 
que no puede compararse al derecho incierto de aquél cuyos créditos no son reconocidos y se ve impulsado a apelar a la acción para que ellos le sean satisfechos.

5 Siendo estos sentimientos de justicia, de lealtad y de honor, los que animan al pueblo argentino, y han inspirado en todo tiempo su política, V. E. comprenderá que se haya sentido alarmado al saber que la falta de pago de los servicios de la ro deuda pública de Venezuela se indica como una de las causas determinantes del apresamiento de su flota, del bombardeo de uno de sus puertos y del bloqueo de guerra rigurosamente establecido para sus costas. $\mathrm{Si}$ estos procedimientos fueran ${ }_{15}$ definitivamente adoptados, establecerían un precedente peligroso para la seguridad y la paz de las naciones de esta parte de América.

El cobro militar de los empréstitos supone ocupación territorial para hacerlo efectivo, y la zo ocupación territorial significa la supresión o subordinación de los gobiernos locales en los países a que se extiende.

Tal situación aparece contrariando visiblemente los principios muchas veces proclamados por las 25 naciones de América y muy particularmente la doctrina Monroe, con tanto celo sostenida y defendida en todo tiempo por los Estados Unidos,

I. de aquél, i.e., el capitalista.

23. aparece contrariando visiblemente, seems to contradict outright. 
doctrina a que la República Argentina ha adherido antes de ahora. ${ }^{1}$

Dentro de los principios que enuncia el memorable mensaje de 2 de diciembre de 1823 , se contienen dos grandes declaraciones que particu- 5 larmente se refieren a estas repúblicas, a saber: "Los continentes americanos no podrán en adelante servir de campo para la colonización futura de las naciones europeas, y reconocida como lo ha sido la independencia de los gobiernos de ro América, no podrá mirarse la interposición de parte de ningún poder europeo, con el propósito de oprimirlos o controlarlos de cualquier manera, sino como la manifestación de sentimientos poco amigables para los Estados Unidos."

La abstención de nuevos dominios coloniales en los territorios de este continente, ha sido muchas veces aceptado por los hombres políticos de Inglaterra. A su simpatía puede decirse que se debió el gran éxito que la doctrina de Monroe 20 alcanzó apenas promulgada. Pero en los últimos tiempos se ha observado una tendencia marcada en los publicistas y en las manifestaciones diversas de la opinión europea, que señalan estos países como campo adecuado para las futuras expansiones 25

${ }^{1}$ Véase el discurso pronunciado por el Ministro argentino en los Estados Unidos, don Domingo F. Sarmiento, en la fiesta oficial de la Sociedad Histórica de Rhode Island, en presencia del Gobernador del Estado.

3. el memorable mensaje, i.e., the Monroe Doctrine. 
territoriales. Pensadores de la más alta jerarquía han indicado la conveniencia de orientar en esta dirección los grandes esfuerzos que las principales potencias de Europa han aplicado a la ${ }_{5}$ conquista de regiones estériles, con un clima inclemente, en las más apartadas latitudes del mundo. Son muchos ya los escritores europeos que designan los territorios de Sud América con sus grandes riquezas, con su cielo feliz y su clima ro propicio para todas las producciones, como el teatro obligado donde las grandes potencias, que tienen ya preparadas las armas y los instrumentos de la conquista, han de disputarse el predominio en el curso de este siglo.

15 La tendencia humana expansiva, caldeada así por las sugestiones de la opinión y de la prensa, puede, en cualquier momento, tomar una dirección agresiva, aun contra la voluntad de las actuales clases gobernantes. Y no se negará que el camino 2o más sencillo para las apropiaciones y la fácil suplantación de las autoridades locales por los gobiernos europeos, es precisamente el de las intervenciones financieras, como con muchos ejemplos pudiera demostrarse. No pretendemos de ${ }_{25}$ ninguna manera que las naciones sudamericanas queden, por ningún concepto, exentas de las responsabilidades de todo orden que las violaciones del derecho internacional comportan para los puchlos civilizados. No pretendemos, zo nii podemos pretender que estos páses ocupen 
una situación excepcional en sus relaciones con las potencias europeas, que tienen el derecho indudable de proteger a sus súbditos tan ampliamente como en cualquier otra parte del globo, contra las persecuciones o las injusticias de que 5 pudieran ser víctimas. Lo único que la República Argentina sostiene. y lo que vería con gran satisfacción consagrado con motivo de los sucesos de Venezuela, por una nación que, como los Estados Unidos, goza de tan grande autoridad y poderío, ro es el principio ya aceptado de que no puede haber expansión territorial europea en América, ni opresión de los pueblos de este continente, porque una desgraciada condición financiera pudiese llevar a alguno de ellos a diferir el cumpli- 15 miento de sus compromisos. En una palabra, el principio que quisiera ver reconocido, es el de que la deuda pública no puede dar lugar a la intervención armada, ni menos a la ocupación material del suelo de las naciones americanas por 20 una potencia europea.

El prestigio y el descrédito de los Estados que dejan de satisfacer los derechos de sus legítimos acreedores, trae consigo dificultades de tal magnitud que no hay necesidad de que la intervención 25 extranjera agrave con la opresión las calamidades transitorias de la insolvencia.

La República Argentina podría citar su propio ejemplo, para demostrar lo innecesario de las intervenciones armadas en estos casos. 
El servicio de la deuda inglesa de I824 fué reasumido espontáneamente por ella, después de una interrupción de treinta años, ocasionada por la anarquía $y$ las convulsiones que conmovieron 5 profundamente el país en ese período de tiempo, $y$ se pagaron escrupulosamente todos los atrasos y todos los intereses, sin que los acreedores hicieran gestión alguna para ello.

Más tarde una serie de acontecimientos y conrotrastes financieros, completamente fuera de todo control de sus hombres gobernantes, la pusieron, por un momento, en situación de suspender de nuevo temporalmente el servicio de la deuda externa. Tuvo, empero, el propósito firme y Is decidido de reasumir los pagos inmediatamente que las circunstancias se lo permitieran y así lo hizo, en efecto, algún tiempo después, a costa de grandes sacrificios, por su propia y espontánea voluntad y sin intervención ni conminaciones de 2o ninguna potencia extranjera. $\mathrm{Y}$ ha sido por sus procedimientos perfectamente escrupulosos, regulares $y$ honestos, por su alto sentimiento de

4. la anarquía y las convulsiones. Reference to period of civil strife in Argentina from 1818 to 1851 . V. Introduction.

9-14. The period from 1880 to 1890 was one of great financial stress in Argentina. The country became bankrupt during the administration of Juárez Celman (1886-1890). Confidence in Argentina was restored during the administration of Uriburu (1894-1898) by the nation's decision to acknowledge the external indebtedness of the individual provinces. 
equidad y de justicia plenamente evidenciado, que las dificultades sufridas en vez de disminuir han acrecentado su crédito en los mercados europeos. Puede afirmarse con entera certidumbre que tan halagador resultado no se habría 5 obtenido, si los acreedores hubieran creído conveniente intervenir de un modo violento en el período de crisis de las finanzas, que así se ha repuesto por su sola virtud.

No tememos ni podemos temer que se repitan 10 circunstancias semejantes.

En el momento presente no nos mueve, pues, ningún sentimiento egoísta ni buscamos el propio provecho al manifestar nuestro deseo de que la deuda de los Estados no sirva de motivo para 5 una agresión militar de estos países.

No abrigamos, tampoco, respecto de las naciones europeas ningún sentimiento de hostilidad. Antes por el contrario, mantenemos con todas ellas las más cordiales relaciones desde nuestra emanci- 20 pación, muy particularmente con Inglaterra, a la cual hemos dado recientemente la mayor prueba de la confianza que nos inspiran su justicia y su ecuanimidad, entregando a su fallo la más importante de nuestras cuestiones internacionales 25 que ella acaba de resolver fijando nuestros límites

24. entregando a su fallo. Reference to boundary dispute with Chile regarding southern Patagonia and the region of Atacama in the northwest. The British crown settled the dispute during the summer of 1902 . 
con Chile después de una controversia de más de sesenta años.

Sabemos que donde la Inglaterra va, la acompaña la civilización y se extienden los beneficios 5 de la libertad política y civil. Por eso la estimamos, lo que no quiere decir que adhiriéramos con igual simpatía a su política en el caso improbable de que ella tendiera a oprimir las nacionalidades de este continente, que luchan por su progreso, roque ya han vencido las dificultades mayores $y$ triunfarán en definitiva para honor de las instituciones democráticas.

Largo es, quizás, el camino que todavía deberán recorrer las naciones sudamericanas. Pero tienen ${ }_{15}$ fe bastante $y$ la suficiente energía y virtud para llegar a su desenvolvimiento pleno, apoyándose las unas en las otras.

$Y$ es por ese sentimiento de confratemidad continental y por la fuerza que siempre deriva del 20 apoyo moral de todo un pueblo, que me dirijo al señor ministro, cumpliendo instrucciones del excelentísimo señor presidente de la República, para que transmita al gobieno de los Estados Unidos nuestra manera de considerar los sucesos 25 en cuyo desenvolvimiento ulterior va a tomar una

21. del excelentísimo señor presidente de la República. Julio Roca, who had been president from 1880 to 1886 , was president at this time.

23. transmita. The subject of this verb is el señor ministro in line 21 . 
parte tan importante, a fin de que se sirva tenerla como la expresión sincera de los sentimientos de una nación que tiene fe en su destino y la tiene en los de todo este continente, a cuya cabeza marchan los Estados Unidos, actualizando ideales 5 y suministrando ejemplos.

Quiera el señor ministro aceptar las seguridades de mi consideración distinguida.

\section{Luis M. Drago}

I. a fin de que se sirva tenerla, so that it (el gobierno de los Estados Unidos) may be pleased to consider it (nuestra manera de considerar los sucesos).

7. Quiera el señor ministro aceptar, May it please the minister to accept. 


\section{ABBREVIATIONS}

a. and s. adjective and $f$. or $f e m$. feminine substantive i.e. id est, that is

abbr. abbreviation impers. impersonal

adj. adjective infin. infinitive

adi. adverb $m$. masculine

Arg. Argentinisin p. page

cf. confer, compare $p \cdot p$. past participle

collect. collective pl. plural

comp. comparative prep. preposition,

dim. diminutive $\quad r$ vide, see

prepositional

Note. - Gender indications are omitted as follows :

$m$. omitted: names of males

masculine nouns in -o

agent nouns in -or, -nte

$f$. omitted: names of females

feminine nouns in -a, -ión, -dad, -tud, -ez 


\section{VOCABULARY}

A

a, to, in, at

abajo, below

abandonar, to abandon, forsake

abandono, abandon, abandonment, playfulness

abarcar, to embrace, include abatir, to flatten, overwhelm, deject

abdicación, abdication

abdicar, to abdicate, give

up

abeja, bee

abertura, opening

abierto, -a, open

abismo, abyss

abnegaciôn, self-denial

abocar, to aim a gun, enter mouth of a channel

abonar, to pay in advance,

to subscribe

abordaje, $m$., a boarding at-

tack

abrasador, -ora, burning, hot abrasar, to burn, parch, in-

flame

abrazar, to embrace

ábrego, southwest wind abrigar, to shelter, protect, entertain

abrigo, shelter, protection

abrir, to open

abrogar, to repeal, annul

abrumador, -ora, crushing,

overwhelming

abrupto, $-a$, abrupt

absoluto, $-a$, absolute, total, alone

absolver, to absolve; p. $p$. absuelto

absorción, absorption

absortivo, $-a$, absorptive, absorbing

absorvente, absorbing

absorver, to absorb

abstención, abstention

absurdo, -a, absurd

abuelo, grandfather

abultado, -a, thick, bulging,

large

abundancia, abundance

abundante, abundant, plentiful

abundantemente, sufficiently aburrido, -a, bored, weary

abusar, to abuse, misuse

abuso, abuse 
acabador, -ora, destructive acabar, to end; - de, to have just academia, academy acallar, to hush; to mitigate acantonar, to quarter acariciar, to caress, stroke, fondle

acarrear, to carry; to cause acaso, perhaps

acaso, event, chance

acaudillar, to head, espouse accesorio, -a, a. and s., additional; accessory accidentado, - a, rough accidental, accidental accidente, m., accident, characteristic

acciôn, action, effect; share aceite, $m$., oil, incense acendrado, - a, purified, refined

acento, accent

aceptar, to accept acequia, canal, drain acera, sidewalk, path acerado, - a, steel-like acerbo, -a, sharp, kcen acercarse, to draw near acero, steel

acertar, to succeed, hit the mark:

aciago, a, sad, disastrous acibarar, to embitter acierto, ability to do the right thing ; chance, aim aclamación, acclamation aclamar, to acclaim

aclimatación, acclimatization, adaptation

aclimatarse, to acclimate, adapt

acoger, to receive, welcome acometer, to attack

acompañante, companion, escort

acompañar, to accompany aconsejar, to advise acontecimiento, event acordarse, to remember acorde, m., harmony, chord acortar, to shorten, cut down acosar, to harass acostumbrar, to accustom acrecentar, to increase acreedor,-ora, a. and s., creditor: - a, entitled to acribillar, to riddle, pierce acta, act, record of proceedings, minutes actitud, attitude actividad, activity, liveliness activo, - a, active

acto, act, action; en el-, at once

actual, present, modern actualizar, to make actual, carry out

actualmente, at present actuar, to act, have dealings; to live acuático, -a, watery, aquatic 
acuchillar, to knife, saber acudir, to flock, hasten; to have recourse (to)

acuerdo, accordance, agreement; de - in accordance with

acuoso, -a, watery

acusación, accusation

acusar, to accuse, point out achatado, -a, flattened out Adán, Adam

adaptación, adaptation, adaptability adaptar, to adapt adecuado, $-a$, adequate, fit adelantado, -a, advanced; por - in advance adelantarse, to advance, get ahead adelante, ahead, forward; en -, from now on

ademán, $m$., gesture, manner, attitude

además, moreover

adentro, within; tierra inland

adeudar, to owe; - -se, to indebt oneself

adherir, to adhere adhesión, allegiance, adhesion adicto, $-\mathbf{a}, a$. and s., addicted;

follower

adiôs, $m$., farewell

adivinar, to guess

adminículo, need, necessity administrar, to administer admirable, admirable, surprising admirablemente, admirably admiración, admiration admirado, -a, surprised admirador, admirer admirar, to admire; - -se de, to marvel at; to cause wonder, surprise admitir, to admit admonición, admonition, reprimand

adobe, m., mud, adobe adoctrinado, $-\mathbf{a}$, instructed adonde, whither adoptar, to adopt adorador, adorer, worshiper adormecer, to put to sleep adormecido, $-\mathbf{a}$, asleep

adorno, ornament adquirir, to acquire aduar, $m$., Bedouin hamlet adulador, adulator, flatterer adusto, -a, gloomy, austere advenimiento, coming, advent adversario, adversary adversidad, adversity adverso, - $\mathbf{a}$, adverse, unfortunate; lo -, misfortune advertencia, notice, warning, advice

advertir, to notice, warn afamado, - a, famous afán, $m$, anxiety, effort, eagerness afección, affection 
afectar, to affect

af ectuoso, -a, affectionate, kindly

af errar, to grasp, seize; - se a, to cling to

afición, affection

aficionado, $-\mathbf{a}, a$. and s., fond; amateur

afilar, to sharpen

afinidad, affinity, anatogy

afirmar, to secure, make firm;

- el pie, to make one's

footing sure

afligir, to afflict

afluente, $m$., tributary

afortunadamente, fortunately

afrontar, to face

afuera, outside

agacharse, to bend down

agarrar, to seize, clutch ; $A$ rg.,

to catch

agasajar, to receive kindly, regale

agente, m., agent

ágil, agile, light, fast

agilidad, agility, dexterity

agitarse, to be agitated, stirred

aglomerar, to heap up, assemble

agobiar, to oppress, weigh down

agolparse, to crowd

agonía, agrony

agónico, $-\mathbf{a}$, agonizing

agostar, to wither, wilt

agosto, August

agotar, to exhaust, drain

agradecer, to be thankful

for

agradecido, -a, grateful

agravar, to aggravate

agravio, offense, insult

agregar, to add

agresión, aggression

agresivo, $-a$, aggressive

agreste, rustic, wild

agrícola, agricultural

agricultura, agriculture

agrimensor, surveyor

agrio, -a, sour, bitter

agrupado, -a, grouped, gathered together

agrupar, to group; - se, to

gather, come together

agua, water

aguada, $A r g$., watering place

aguar, to dilute; - $-\mathrm{se}$, to be

diluted, disappear

aguardar, to await, expect

agudisimo, -a, very sharp,

acute

águila, eagle

aherrojar, to oppress, put in irons

ahi, there; he -, there you

have it, behold

ahogar, to stifle; - -se, to be

stifled; to drown

ahora, now; - setenta años,

seventy years ago

ahorcar, to hang

ahorro, saving 
aire, air; appearance; al -

libre, in the open air airoso, $-a$, elegant, proud aislado, $-\mathbf{a}$, isolated, alone aislamiento, isolation ajeno, $-a$, alien, strange, $a b$ horrent; belonging to another

ajusticiar, to put to death ala, wing alabanza, praise alameda, row of trees alarde, m., display; hacer to boast alarido, mournful cry alarma, alarm alarmar, to alarm alazán, m., sorrel horse alba, dawn albañilería, masonry albergar, to shelter, contain, house albergue, $m$, dwelling place albo, -a, white alborada, dawn alborotar, to arouse, excite álbum, $m$., album alcance, $m$. , reach, breadth; meaning; dar - to overtake

alcancía, chest, money chest alcanzar, to reach, obtain, attain

alcurnia, standing, family, race aldea, village

alegrar, to gladden alegre, cheerful, gay alegria, joy, happiness alejandrino, a twelve-syllable verse ale jandrino, -a, alexandrine alejar, to set at a distance, put off; - -se, to withdraw Alemania, Germany alentar, to encourage, cheer alerta, watchword aleteo, winging, flight alfombrar, to cover with carpets

algarroba, carob bean algarrobo, carob tree algo, something algo, somewhat algodón, m., cotton alguien, some one . alguno, -a, some aliado, ally alianza, alliance aliento, breath, courage, spirit alimentación, nourishment alimentador, -ora, $a$. and s., feeding, nourishing; feeder, supplier

alimentar, to nourish alimento, nourishment alineado, $-a$, lined up, in line alistar, to enlist alma, soul, character, spirit almacén, $m$., warehouse, store, shop almacenero, shopkeeper 
almendra, almond

almendro, almond tree

almorzar, to breakfast, lunch alpargata, hemp slipper alquimista, alchemist alrededor, around, about alrededores, $m$. pl., environs altivez, pride, arrogance altivo, -a, proud, haughty, lofty

alto, halt

alto, upper floor

alto, $-a$, high, deep

altura, height, summit, level alumbrar, to light, enlighten aluvión, $m$., alluvion, inundation, alluvial deposit

alvéolo, alveolus, cell

alzar, to raise; - - se, to rise, stand

allá, there; mâs - bevond alli, there

amabilidad, amiability

amabilisimo, $-\mathbf{a}$, most amiable amainar, to haul down, relax,

appease

amalgamar, to amalgamate, fuse

amanecer, to dawn

amante, a. and s., loving:

lover

amar, to love

amargamente, hitterly

amargo, - a, bitcer, painful

amargura, hitterness

amarillo, -a, yellow amasar, to amass

ambición, ambition

ambicioso, -a, ambitious, scheming

ambiente, m., air, environment, atmosphere

ambiguo, $-\mathbf{a}$, ambiguous

ambos, -as, both

ambulante, ambulant, roving amenazante, threatening, dangerous

amenazar, to threaten americano, -a, American, i.e. pertaining to either or both Americas

amigable, friendly

amigo, friend

amilanar, to frighten

amistad, friendship

amo, master

amontonamiento, accumulation

amontonar, to heap up

amor, love: - propio, selflove, self-respect

amoroso, -a, loving

amortiguar, to deaten, soften, extinguish, put out amparar, to shelter amparo, shelter

ampliamente, amply amplio, -a, ample, full

ampuloso, - a, intlated, pompous

amueblado, furnishings, furniture 
análogo, -a, analogous, similar anarquía, anarchy anatomía, anatomy anca, croup, haunch ancestral, ancestral ancianidad, old age anciano, -a, old, ancient ancla, anchor ancho, -a, wide, broad, extensive

ancho, width; de medio of half width

anchuroso, $-\mathrm{a}$, broad, wide Andalucía, Andalusia, region in the south of Spain, watered by the Guadalquivir andar, to go

andar, $m$., gait

andrajoso, $-a$, ragged

anécdota, anecdote

anfiteatro, amplitheater

ángel, angel

angélico, $-\mathbf{a}$, angelical

anglo-sajón, -ona, Anglo-

Saxon

angosto, $-\mathrm{a}$, narrow

ángulo, angle, corner

angustia, anguish, suffering anhelante, breathless, anxious,

\section{eager}

anhelo, desire, anxiety anidar, to nestle, dwell anilla, ring, circle, hoop anillo, ring, spiral ánima, soul; - de bulto, sculptured figure animado, - a, animated, lively animal, $m$., animal animar, to encourage ánimo, mind, courage; no es $\mathrm{mi}-$, it is not my intention animoso, $-\mathrm{a}$, courageous anochecer, to become night, grow dark

anómalo, -a, anomalous, unwonted

anonadamiento, annihilation anonadar, to annihilate, overwhelm

ansia, anxiety, eagerness

ansiar, to crave, be anxious to

ansiedad, anxiety

ansioso, $-\mathrm{a}$, anxious

antagonismo, antagonism

antaño, former times; always used with the prep. de preceding it

ante, before

ante, $m_{\text {., buckskin, buff }}$ antecedente, antecedent antemano, before; de beforehand anterior, former, previous antes, before, formerly; rather: - de, before antesala, antechamber anticipar, to pay in advance, anticipate

antigiedad, antiquity antiguo, $-a$, old, former, ancient 
antojo, whim, caprice

Antonio, Anthony

antorcha, torch

anualmente, annually

anublar, to cloud, darken

anunciar, to announce

anuncio, announcement

anverso, obverse

añadir, to add

añagaza, deception, artificiality

año, year

añusgar, to choke

apacible, peaceful

apagar, to put out, extinguish aparato, preparation, osten-

tation

aparcero, partner, associate

aparecer, to appear

aparejar, to prepare

aparejo, harness, tools in general

aparición, apparition

apariencia, appearance

apartar, to set off, aside; push

off, separate

aparte, apart, aside

apasionado, -a, inspired, im-

passioned

apatia, apathy

apático, -a, apathetic, indif-

ferent

apedrear, to stone

apelar, to appeal, have re-

collrse to, summon

apellidar, to name, proclaim apenas, hardly, with difficulty; as soon as

apercibir, to perceive, make ready, prepare

apero, implements; - de

labranza, farm tools

apetecer, to long for, desire

apiadarse, to have pity; -

de, to have pity for

ápice, $m$., trifle, apex

apiñado, -a, close, gathered

together

apiñarse, to crowd

aplastado, -a, flattened

aplaudir, to applaud

aplauso, applause

aplazar, to postpone

aplicable, applicable

aplicación, application

aplicar, to apply

apoderarse, to take posses-

sion; - de, to take posses-

sion of

aporcionar, to apportion

aportar, to contribute

aposento, room

apóstol, apostle

apoyar, to support, help;

- se, to lean

apoyo, prop, help

apreciación, appreciation,

understanding apreciar, to appreciate

aprender, to learn

apresamiento, seizure

apresar, to seize, impress 
apresuramiento, hurry apresurar, to hurry apretar, to squeeze, bind apretón, $m$., squeeze; - de manos, handshake aprisco, sheepfold, pen aprobación, approval aprobar, to approve aprontar, to make ready, hasten

apropiación, appropriation apropiar, to appropriate aprovechar, to take advantage of aproximación, approach, approximation aproximadamente, approximately aproximar, to approach aptitud, aptitude apto, - a, suitable, apt apuntar, to aim, make note of ; to dawn, break forth apunte, jotting, note, memoir apurado, -a, straitened apurar, to obtain, drain; - - se, to hurry apuro, hurry, distress; salir de - , to get out of a difficulty aquejar, to afflict, grieve aquel, that aquél, that one aquí, here; de -, hence ara, altar árabe, $a$. and s., Arab, Arabian arabesco, $-a$, arabesque arañar, to scratch

arañazo, scratching, scratch arbitraje, arbitration arbitrario, -a, arbitrary arbitrio, free will, opinion; pl., revenues, means árbitro, arbiter, judge árbol, tree, mast as bolado, -a, arbored arboladura, rigging arboleda, grove arbusto, shrub arcabuz, m., arquebuse, blunderbuss arcángel, archangel arcilla, white earth, argil arco, bow, arch arder, to burn ardiente, eager, burning ardor, $m$., warmth, eagerness, yearning arduo, -a, arduous, hard arena, sand, arena arganita, basket; (mostly used in the pl.), - $\mathrm{s}$, baskets slung like saddle-bags and used for carrying fruit

Argel, Algiers

argentado, $-a$, silvery

argentino, - a, Argentine, silvery argumento, argument, story árido, -a, arid, dry ariete, $m$., battering ram arisco, -a, shy, rough, intractable 
aristocrático, -a, aristocratic arma, weapon; poner sobre las $-s$, to put under arms

armamento, armament, arms armar, to arm, equip, provide armonia, harmony armonioso, -a, harmonious armonizar, to harmonize aroma, aroma, flower of the aromo, acacia tree arpa, harp arpegio, arpeggio, strain arquitectónico, - a, architectural

arquitectura, architecture arrabal, m., suburb, environs arraigado, -a, rooted arrancar, to pluck, tear out

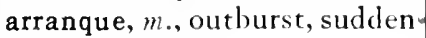
fit, impulse

arrastrar, to drag arrastre, m., flow; dragging arrebatar, to snatch, carry away arreciar, to increase in violence arreglar, to arrange, fix, settle arreglo, arrangement; con -

a, according to

arreo, trappings

arrepentirse, to repent arrestar, to arrest, stop arria, drove of beasts, beast train

arriba, above arribar, to arrive, put into harbor in distress

arribo, arrival arriero, muleteer, driver arriesgar, to risk arrimado, $-\mathbf{a}$, close arrobamiento, ecstasy, ravishment arrodillarse, to kneel down arrogancia, arrogance, pride arrogante, arrogant, proud arrojado, $-\mathbf{a}$, bold, reckless arrojar, to throw arrojo, boldness, recklessness arrollar, to rout, fold back; - se, twist, roll arroyo, brook arruinar, to ruin, destroy arrullar, to lull arte, $m$. , art, power, skill, cunning artesa, trough articular, to articulate artífice, m., artificer, maker artificial, artificial artillería, artillery artista, $m$., artist artísticamente, artistically artístico, a, artistic asaltante, assailant asaltar, to assiult, assail asalto, assautt asamblea, assembly asar, 10 roast ascendente, arising, rising ascender, to ascend 
ascenso, promotion, rise asegurar, to assure asemejarse, to resemble asentimiento, assent, consent asesinar, to murder asesinato, assassination asesino, assassin asestar, to strike, direct, aim aseveración, statement, affirmation

asfixiante, asphyxiating así, thus; - es que, and so asiático, -a, Asiatic asiento, seat; - de tijera, collapsible chair, campchair asilar, to shelter asilo, asylum asimilación, assimilation asimilar, to assimilate asimismo, likewise asir, to seize; - se de, to catch hold of asistir, to assist; - a, to be present

asociación, association, group, social spirit asolar, to destroy, raze asomar, to show, loom; - - se,

to appear asombrado, -a, amazed asombro, amazement, dread, admiration asombroso, - a, amazing aspecto, aspect, appearance áspero, -a. rough aspiración, aspiration aspirar, to aspire, breathe asta, flag-pole astro, star, any heavenly body astucia, astuteness asturiano, -a, Asturian, from region of Asturias in northwestern Spain asumir, to assume, put on asunto, topic, matter asustar, to frighten atacante, attacker atacar, to attack atado, bundle atalaya, watchtower, observation point ataque, $m$,, attack atar, to tie, bind atardecer, to become night; to grow late atardecer, m., sunset; al -, at nightfall atemorizado, -a, frightened atemperado, -a, tempered, softened

Atenas, Athens atención, attention, care atender, to attend, bear in mind

atentar, to attempt atento, $-\mathbf{a}$, attentive, polite aterrante, terrifying aterrar, to terrify atestiguar, to testify, attest atizar, to stir Atlántico, Atlantic Ocean 
atlantico, $-\mathbf{a}$, pertaining to the Atlantic

atleta, $m$., athlete

atlético, -a, athletic

atmósfera, atmosphere, en-

vironment

atracar, to moor, approach

atracción, attraction

atractivo, attraction

atraer, to draw, attract

atrapar, to catch, overtake

atrás, behind; back

atraso, arrear, delay, backwardness

atravesar, to run across,

pierce, cross

atreverse, to dare, venture

atrevimiento, daring

atribuir, to attribute, assign

atrincherar, to intrench

atropellar, to trample, push,

be hurried

aturdido, - a, giddy, wild aturdir, to daze, confuse

audacia, boldness, audacity

audaz, bold, audacious

auditorio, audience

aun, still, yet, even

aunque, although

aura, gentle breeze

aurora, dawn

ausencia, absence

ausente, absent

auspicio, auspice; (used moslly"

in the plo), s, aluspices austeridad, austerity

austero, -a, severe, austere

autocracia, autocracy

auto-educación, self-education

autor, author

autoridad, authority

auxiliar, to help

auxiliar, m., helper

auxilio, help

avance, $m$., advance

avanzada, advance

avanzadísimo, -a, very advanced

avanzado, - a, advanced, early, inopportune

avanzar, to advance, reach out

avaro, $-a$, miserly

avatar, m., avatar, transformation

ave, $f$, bird, fowl

avenida, avenue, row ; freshet, flood

avenido, $-\mathbf{a}$, reconciled, satisfied

aventajado, -a, gifted, excellent

aventajar, to have the advan-

tage over, surpass

aventura, adventure

aventurero, $-\mathbf{a}, a$. and s., ad-

venturous; adventurer

avergonzar, to shame

averiguar, to find out, investigate

aversión, aversion

avestruz, m., ostrich 
avezado, - a, accustomed avidez, avidity

ávido, -a, eager, greedy avisar, to warn, give notice i ay! alas!

ayear, to cry out iay!, moan ayer, yesterday ayudante, helper, aide-de-

camp

ayudar, to help ayuno,-a, fasting; lacking; ignorant, unacquainted azar, chance, hazard; al -. at haphazard azorar, to excite, stir azotar, to strike, beat azote, m., blow, lash azotea, roof azul, blue

\section{B}

bache, $m$., hole, rut

Bahia, seaport of Brazil to the north of Río Janeiro bahía, bay

baile, m., dance

bailoteo, awkward dancing bajâ, m., pasha

bajar, to lower, let down; to descend, go down

bajío, shoal

bajo, -a, low

bajo, under; underneath bala, bullet

baladro, bellowing, cry balanza, scales balazo, shot

balbucear, to mutter, stamner balcón, m., balcony

Báltico, Baltic Sea baluarte, m., bulwark, fort banco, bench; bank; shoal bandera, banner, flag; party bandido, bandit

bando, faction, party ; band bandolero, highwayman, thief banquero, banker banquete, $m$., banquet bañar, to bathe, suffuse baqueano, $V$. baquiano baquía, also written vaquía, dexterity, expertness baquiano, Arg., guide, pathfinder; also spelt baqueano báquico, -a, bacchic barba, beard, chin barbarie, $f$., savagery bárbaro, -a, savage, fierce barbirrucio, -a, graybearded barca, boat, barge barco, boat bardo, bard, singer barège, barège, fabric of worsted and silk barra, bar, gallery barranca, ravine, cliff barranco, $V$. barranca barrer, to sweep, clear barrial, m., puddle barrio, quarter of a city, district

barro, mud 
basalto, basalt, name of a beso, kiss species of marble base, $f$., base bastante, enough, rather bastar, to suffice bastión, $m$., bastion batalla, battle, encounter batear, $A r_{\text {g., }}$ to roast whole, barbecue

batir, to fashion, beat; - - se, to fight; - en brecha, to batter a breach

bayeta, flannel; cloak worn by students in the Middle Ages

bayoneta, bayonet beber, to drink

Belial, Belial, one of the fallenangels in Milton's Paradise Lost

bélico, $-\mathbf{a}$, warlike

belicoso, -a, bellicose

belleza, beauty

bellísimo, $-\mathrm{a}$, very beautiful bello, $-a$, handsome, beautiful bendición, blessing, benediction

bendito, - a, blest

beneficiar, to benefit

beneficio, bencfit

benéfico, $-\mathrm{a}$, beneficent

benévolo, $-\mathrm{a}$, benevolent

benignidad, kindness, benignity

bergantin, $m$., brig

besar, to kiss

bestia, beast, animal bíblico, -a, biblical bibliografía, bibliography bien, well; no - , as soon as; si -, although; antes -, rather, on the contrary bien, m., property, possession, treasure; - público, public weal

bienestar, m., well-being bienhechor, benefactor bienvenido, - $a$, welcome bifurcar, to branch off, bifurcate biografia, biography

bipedo, biped

bizarro, -a, gallant, brave, bizarre

bizco, -a, cross-eyed

blanco, $-\mathbf{a}$, white

blancura, whiteness

blandengue, soldier, armed with lance, who policed province of Buenos Aires

blandir, to brandish.

blanquear, to whiten; appear white

blanquecino, $-\mathrm{a}$, whitish

blanquizco, $-\mathbf{a}$, whitish

blasonar, to boast

bloqueo, blockade

boca, mouth

bocacalle, $f_{\text {., outlet, entrance }}$ (1) a street

bocado, tit-bit, mouthful 
bocina, horn; - de meleadas, horn used in honey-gathering

boda, wedding

bofetada, slap; dar de $-\mathrm{s}$, to slap

boina, cap worn in Navarra and Biscay

bolear, to bring down with bolas; $c f$. note, 64,5

boliche, Arg., small store

bolsillo, pocket

bombardeo, bombardment

bonaerense, pertaining to

Buenos Aires

bonanza, clear weather, pros-

perity

bondad, kindness

bondadoso, $-a$, kind

bonito, -a, pretty

borda, gunwale, rail

borde, m., edge, border

bordo, board; a -, on board borlôn, m., tassel

borracho, -a, drunk, intoxicated

borrar, to erase, do away with bosque, m., wood

bosquecillo, small wood bota, boot; - de potro, horsehide boot

bote, m., boat

botijilla, little bottle, flask

boya, buoy

Brasil, Brazil

brasileño, -a, Brazilian bravio, -a, wild, unpolished bravo, -a, brave, courageous bravura, bravery

brazo, arm; a - partido, arm

to arm, openly; pl., hands, employees

brecha, breach

breña, wild, craggy ground

Bretaña, Britain; $V$. Gran

Bretaña

breve, brief, short

brigada, brigade

brillante, brilliant

brillar, to shine

brillo, luster, splendor

brin, m., duck, sailcloth

brincar, to leap, jump

brindar, to toast, offer a toast

brio, dash, courage, eagerness

brioso, -a, spirited, courageous

brisa, breeze

británico, -a, Britannic

broma, joke; en -, jokingly bromista, droll

brotar, to bud; to gush, issue bruja, witch

brujo, enchanter, necromancer bruma, haziness, fog

brumoso, -a, foggy, gloomy

bruscamente, abruptly

brusco, -a, brusque

bruto, animal, brute

bueno, - a, good; a las buenas

o las malas, willy-nilly

buey, ox

búfalo, buffalo 
buho, owl

buitre, $m$.. vulture

bulevar, m., boulevard

bulliciosamente, noisily

bullir, to boil

buque, m., vessel, ship

burgués, -zsa, bourgeois, mid-

dle class

burla, mockery, fun

burlar, to mock, scorn, deceive busca, search

buscador, searcher

buscar, to look for

busto, bust

\section{C}

cabalgador, rider

cabal zar, to ride on horseback

caballar, equine

caballería, cavalry; chivalry

caballero, knight, gentleman

caballerosidad, magnanimity, chivalry

caballo, horse

cabaña, hut

cabeceante, swaying, nodding cabecear, to sway, nod

cabellera, head of hair

cabello, hair

caber, to be contained in, fit, befall

cabeza, head

cabildo, town council, town liall

cabizbajo, -a, crestfallen, pensive cabo, end; cape; chief, corporal; al -, finally; - de guardia, corporal of the guard

cacique, cacique, Indian chief cactus, $m$., cactus

cada, each

cadalso, scaffold

cadáver, m., corpse

cadena, chain

cadencia, cadence

cadete, commercial apprentice, cadet

caduco, $-\mathbf{a}$, worn out, decrepit caer, to fall, happen

café, coffee, café

caída, fall

Cain, Cain, son of Adam and Eve

caja, box, chest, treasury

cajetilla, m., Argentine locution used by a gaucho to show his contempt for a city man; fop, dandy

cal, $f$., lime

calabaza, pumpkin

calamidad, calamity

calamitoso, $-\mathbf{a}$, calamitous

calar, to pierce, fix a bayonet

calcular, to calculate

cálculo, calculation, estimate

caldear, to heat, foment

caldera, boiler, kettle

calibre, m., caliber

calidad, guality

cálido, - a, warm 
caliente, warm

calificación, qualification

calificar, to qualify

calizo, -a, limy

calma, calm

calmar, to calm, pacify

calor, m., heat, passion, zest

calumniar, to calumniate

calurosamente, warmly

calzada, causeway, paved road callado, $-\mathrm{a}$, silent

callar, to quiet; to keep silence

calle, $f$, street

callejón, m., lane

callejuela, alley

cama, bed

cámara, chamber, hall

camarada, m., comrade

cambiar, to change

cambio, change, exchange; en -, on the other hand caminante, wayfarer, traveler caminar, to walk

caminito, byway

camino, road; - $\mathrm{s}$ públicos, public highways; - de encrucijada, crossroad

camote, $m$., sweet potato

campamento, camp

campaña, campaign; Arg.,

field, country

campechano,-a, frank, hearty

campeón, $m$., champion

campesino, -a, a. and s., rural ;

farmer campestre, rustic

campiña, flat arable land, plain

campo, field, country

canción, song

Candelaria, Candlemas

candorosamente, candidly, unwittingly

candoroso,-a, frank, candid, naive

canoa, canoe

cansancio, fatigue

cansar, to tire

cantar, to sing

cantar, m., song

cántico, hymn

cantidad, quantity

canto, song

cantor, singer, bard

cañada, dale

cañón, cannon, barrel of a gun, tube; - de batir, siege gun; - de diez y ocho, eighteen pounder; - de chimenea, chimney flue

cañonero, -a, gun-bearing; lancha cañonera, gunboat capa, cape, mantle, cloak. capacidad, capacity caparazón, m., caparison, shell capataz, m., overseer capaz, capable

capellán, chaplain

capital, f., capital; m., money

capitalismo, capitalism

capitalista, m., capitalist 
capitán, captain

capítulo, chapter

capote, $m$., cloak with a cape capricho, caprice, whim

capucha, cover

cara, face; volver -s, to face about

carácter, m., character, feature

característico, -a, characteristic

caracterizar, to characterize carancho, bird of prey, peculiar to Argentina

carbón, m., coal

carbonera, coal-bin

cárcel, $f$, prison

carcomido, -a, gnawed, tottering

cardal, m., Arg. for cardizal,

field covered with thistles

cardinal, cardinal, basic

cardo, thistle

cardón, m., cactus

carencia, lack, absence

carecer, to lack

carestia, lack, scarcity

carga, charge, load

cargamento, cargo, load

cargar, to charge, load

cargo, charge, trust; office,

rank; accusation; a -

de, in charge of

caricia, caress

caridad, charity

cariñoso, -a, loving carnavalesco, -a, carnival-like carne, f., flesh, meat

carnero, ram, sheep

carnestolendas, carnival last-

ing three day's before Ash

Wednesday

caro, $-a$, dear

carozo, kernel, seed

carrera, race, course, career

carreta, cart

carretón, $m$., large wagon

carril, $m$, road, rut, rail of

railway

carro, wagon

carruaje, m., carriage

carta, letter

cartabón, m., size-stick ;

standard

cartera, pocketbook, leather

case

cartón, m., pasteboard

cartucho, cartridge

casa, house, home

casar, to marry a person off ;

- se con, to marry

casco, hull; hoof of a horse

casería, country house; $A r g$,

customers

caserio, group of houses

casero, -a, homely, domestic

casi, almost

caso, case; hasta el - que,

as long as, until

castañuela, castanct

castellano, a, Castilian

castigar, to punish 
castigo, punishment

castillo, castle

castizo, -a, chaste, noble;

racy; idiomatic

casto, $-a$, chaste

casualidad, chance

catalán, -ana, Catalan, pertaining to Spanish province of Catalonia

Catamarca, province of Argentina, $l$. map

catarata, falls

catástrofe, f., catastrophe, death

cátedra, class, chair

categoria, rank, category

catolicismo, catholicism

católico, -a, catholic

catorce, fourteen

cauce, m., bed of a river, channel

caudal, $m$., wealth, fund

caudaloso, -a, voluminous, used of rivers having great volume, copious

caudillejo, upstart chief, leader

caudillo, chief, leader

causa, cause; por - de, on account of

causar, to cause

cautelosamente, cautiously, quietly

cautiverio, captivity

cautividad, captivity

cautivo, -a, captive cauto, $-\mathrm{a}$, cautious

cavatina, aria

caverna, cavern

cavilación, deep thought,

caviling

cavilar, to think, meditate

cazador, hunter

cazar, to liunt

ceder, to yield

cedulilla, small slip of paper;

lottery ticket

céfiro, zephyr

ceibo, silk-cotton tree of the

Plata basin, about one hundred feet in height, broad crowned, witl red leaves and flowers. Its fruit is conical shaped, about one foot long, and it contains six seeds wrapped in a thick cottonlike substance used to pad pillows

ceja, eyebrow

celebración, celebration

celebrar, to celebrate, hold

célebre, famous

celeste, heavenly

celo, zeal, jealousy

celoso, $-\mathbf{a}$, zealous, jealous

cenagoso, $-\mathbf{a}$, muddy

cendal, $m$., crape, veil

ceniza, ashes

centellante, sparkling

centelleo, sparkle, flashing

centenario, centenary 
centenar, $m$. , hundred centinela, sentinel central, central centralista, centralist céntrico, $-\mathbf{a}$, centric centro, center, domain, power centuplicado, $-\mathrm{a}$, bundredfold ceñir, to gird, grasp ceño, frown, supercilious look c eñudo, $-a$, frowning cerca, near cercanía, neighborhood cercano, -a, near cercar, to surround cerciorar, to ascertain, assure cerco, ring, circle, fence, inclosure

ceremonia, ceremony

cerrar. to shut; - - se, to come to an end

certidumbre, $f$, certainty certamen, $m$., competition cerviz, $f$, cervix, nape of the neck

cesar, to cease cicatriz, $f$., scar ciego, $-\mathbf{a}$, blind; a ciegas, blindly

cielito, name of dance peculiar

to gauchos, corresponding to. Andalusian jaleo cielo, sky; song, dance cien, one hundred ciénago, m.. swamp, mud ciencia, science, art, knowledge científico, $-\mathrm{a}$, scientific cierto, -a, certain, sure, true; por -, surely, of course cilindrico, -a, cylindrical cilindro, cylinder, roll cima, top, summit cimiento, cement, foundation cinco, five

cincuenta, fifty cintillo, band cinto, belt circo, circus, circle, arena circulación, circulation circular, to circulate circular, circular círculo, circle circunferencia, circumference circunscribir, to limit, circumscribe

circunscripción, circumscription, political district circunspecto, $-a$, cautious circunstancia, circumstance circunstante, standing about circunvalar, to encircle cirio, cereus, genus of plants of the cactus family cita, call, appointment ; darse -, to have a rendezvous citar, to quote, cite, appoint, call ciudad, city ciudadano, citizen cívico, $-\mathbf{a}$, civic civil, civil, polite civilización, civilization 
civilizar, to civilize

cizaña, darnel

clamor, noise, clamor

claridad, clarity, clearness, light

clarin, $m$., bugle

claro, gap

claro, - a, light, clear, manifest clase, class, condition

clásico, $-\mathrm{a}$, classic

clasificar, to classify

clausurar, to adjourn, close

clavar, to nail, rivet

clave, $f$., key

clavo, nail, clove

clêrigo, clerk, i.e., man of letters; priest

clienta, patroness, customer; Arg. for parroquiana

clima, m., climate

coaligado, $-\mathbf{a}$, joined, allied

cobertizo, cover, shelter

cobijar, to protect, shelter

cobro, collection

cocina, kitchen

cocinar, to cook

cocinera, cook

cocotero, coconut tree

codicia, cupidity

codiciar, to covet, envy

codicioso, $-\mathrm{a}$, covetous

codo, elbow

coexistir, to coexist

cohesiôn, cohesion, contiguity cohete, $m$., firecracker, rocket cohibido, -a, restrained coincidencia, coincidence coincidente, coincident cola, tail

colaboración, collaboration colaborador, collaborator colar, to filter, pass through colcha, coverlet colchôn, m., mattress colchoneta, quilt colectivo, $-\mathbf{a}$, collective colega, m., colleague coleto, jacket; - de ante, buff doublet colgar, to hang colina, hill

colindar, to be contiguous, border on

colmena, hive

colmillo, eye-tooth, tusk

colocación, position

colocar, to place

Colón, Columbus

colonia, colony

coloniaje, m., period during which Spanish-American colonies were under Spanish rule; colonial system

colonial, colonial colonización, colonization colono, settler, farmer color, m., color colosal, colossal columbrar, to discern, perceive

columna, column

columpio, swing 
comandante, commander; in Argentine army, lieutenantcolonel; - general de armas, commander-in-chief comarca, district

combate, m., struggle, combat combatiente, combatant combatir, to fight combinación, combination, chance, preparation, plan combinar, to combine comenzar, to begin comer, to eat comercial, commercial comercio, commerce cometa, m., comet cometer, to commit comisaría, commissariat, police court; - de guerra, office of paymaster general como, as; like

cómo, how; $i-1 \mathrm{e}$ va? how goes it with you? ¿- me ha de ir? how do you suppose?

cómodamente, comfortably cómodo, $-a$, comfortable compacto, $-\mathbf{a}$, firm, unswerving. compact

compadrito, the Argentine correspondent of majo; $c f$. slan, show-off, swell, showy gent

compañero, companion compaña, company comparación, comparison comparado, $-a$, comparative comparar, to compare compartir, to share compasión, compassion compatible, compatible compatriota, compatriot, fellow-citizen

compenetración, compenetration, infiltration

competencia, fitness, competition

competente, competent, able complacerse, to take delight complejo, $-\mathrm{a}$, complex completamente, completely completar, to complete completo, -a, complete, accomplished complicado, $-\mathbf{a}$, complicated cómplice, accomplice complicidad, complicity componente, m., component componer, to compose comportar, to cause, suffer ; -se, to behave composición, composition compositor, composer comprador, buyer comprar, to buy comprender, to understand, arasp

comprobar, to verify, compare, test

comprometer, to compromise, endanger

compromiso, engagement, 
contract, compromise, difficulty

compulsivo, -a, compulsory

común, common

comuna, commune, community

comunicación, communication comunicar, to communicate

con, with; - tal que, pro-

vided that

cóncavo, - a, concave

concebir, to conceive

conceder, to concede

concentrado, $-\mathbf{a}$, concentrated,

self-possessed

concentrar, to concentrate;

to consolidate

concepción, conception

concepto, concept

conceptuar, to conceive

conciencia, conscience, con-

sciousness; obligado en -, in duty bound

concienzudo, $-\mathbf{a}$, conscientious concierto, concert, agreement conciliar, to conciliate

concitar, to excite, invite

conciudadano, fellow-citizen

concluir, to end

conclusión, conclusion

concorbarse, to bend down

concordancia, concordance,

harmony

concreto, $-\mathbf{a}$, concrete

concurrencia, competition ;

gathering concurrir, to gather, contribute

concurso, concourse, gathering, aid

concha, conch, shell

condenar, to condemn

condensar, to condense

condición, condition, state

condolido, $-a$, grieving

cóndor, $m$, condor

conducción, bringing, guidance

conducir, to lead, transport

conducta, conduct

conductor, conductor, leader,

driver

conexión, connection

conferencia, conference, inter-

view

conferir, to confer

confesar, to confess

confesiôn, confession

confianza, confidence

confiar, to intrust, confide

confidencia, faith, confidence

confidencial, confidential

confidente, confidant

configuración, configuration,

lay

confín, $m$., confine

confirmar, to strengthen, con-

firm

conflagración, conflagration

conflicto, conflict

confraternidad, brotherhood

confundir, to confuse, mix, fuse, join 
confusión, confusion confuso, $-\mathrm{a}$, confused congreso, congress cónico, -a, conic conjunto, whole, ensemble: milieu

conjuro, conjury, spell conmemorar, to commemorate conminación, threat conmoción, uprising, commotion

conmover, to move, excite connaturalizarse, to have the same nature, become one

conocedor, -ora, $a$, and s., connoisseur, expert; knowing

conocer, to know, be acquainted

conocimiento, knowledge conquista, conquest conquistador, conqueror conquistar, to conquer consagrar, to consecrate, put on record

consecuencia, result, consequence

consecutivo, $-\mathbf{a}$, consecutive conseguir, to obtain, bring about

consejo, adrice; council consentimiento, consent consentir, to consent, tolerate conservar, to save, preserve considerable, considcrable consideración, consideration, esteem considerar, to consider consigna, watchword, order, password consiguiente, result; por consequently

consistir, to consist, lie consolador, -ora, consoling consonancia, harmony consorte, consort conspicuo, $-\mathbf{a}$, conspicuous constaniia, constancy constante, constant constantemente, constantly Constantinopla,

Constantinople constar, impers., to be clear; - de, to consist of constelación, constellation constitución, constitution constitucional, constitutional constituir, to constitute, establish constreñir, to bind construcción, construction, building constructivo, $-\mathbf{a}$, constructive consuelo, consolation consumado, $-\mathbf{a}$, consmmmate contacto, contact contar, to count, relate, expect; - con, to rely upon contemplación, contemplation contemplar, to contemplate 
contemporáneo, -a, contemporary

contener, to contain, restrain contentar, to content

contertuliano, social friend, of the same social set

contestación, reply

contestar, to reply

continental, continental

continente, $m$., continent

contingente, contingent

continuar, to continue

continuo, -a, continuous; acto

-, at once

contorno, outline

contra, against

contrabandista, m., smuggler contradicción, contradiction

contradictorio, -a, contradic-

tory

contraer, to contract, bring

together

contrafuerte, spur

contraponer, to set against

contrapunto, counterpoint ;

Arg., repartee; $V$. note,

79, I $6 ; 88,3$

contrariar, to deny, vex, dis-

appoint

contrario, -a, contrary; al -

on the contrary

contraseña, countersign

contraste, $m$., contrast, check,

setback

contratar, to treat, contract

contrato, contract contravenir, to contravene, violate

contribución, contribution

contribuir, to contribute

contrición, contrition

control, m., control

controlar, to control

controversia, controversy

conturbar, to arouse, excite

convencer, to convince

conveniencia, need, use, con-

venience, comfort

conveniente, suitable, ex-

pedient, convenient

convenir, to behoove, be

necessary; - en, to agree

upon

convento, convent

convergente, converging

conversar, to talk

convertir, to convert

convidar, to invite

convocar, to convoke

convoy, m., convoy

convulsión, convulsion

convulsivo, $-\mathrm{a}$, convulsive,

trembling

conyugal, conjugal

cooperar, to coöperate

copa, cup, glass; crown, top

(of a tree)

copiosísimo, -a, very abundant

copista, m., copyist

copla, couplet, verses

copo, snowflake 
co-redactor, fellow-editor coraje, m., courags., anger coral, $m$, coral corazón, $m$, heart corbata, tie, cravat corcel, m., charger, steed cordaje, $m$., cordage cordero, lamb cordial, cordial cordialidad, cordiality cordillera, mountain range Córdoba, province of Argentina, also capital of said province: $l$. map coro, chorus, refrain corona, crown coronar, to crown, honor coronel, colonel

corpulento, -a, stout, corpulent

corral, m., corral, pen for animals

corrección, correctness, correction

corredizo, -a, running, lose correligionario, co-religionist, co-religionary

Correo, El, name of a newspaper: The Mail

correr, to run, flow, traverse; —se, to spread, extend correria, raid, travel correspondencia, correspondence.

corresponder, to correspond, match, respond corriente, current, stream; with dates, instant

Corrientes, name of street in Buenos Aires; also province of Argentina

corrupción, corruption

cortar, to cut, destroy, curtail corte, $m_{\text {., cut }}$, edge

corte, $f$., court

cortejo, following, retinue

cortesanía, courtliness

cortesía, courtesy

corteza, bark, rind, exterior of anything cortijo, farm, estate cortina, curtain corto, -a, short, brief corvo, hook; curved sword used by grenadiers of San Martín

cosa, thing

cosecha, harvest

cosechar, to gather, reap

cosmogónico, -a, cosmic, starry

cosmopolita, cosmopolitan cosmopolitismo, cosmopolitanism

costa, coast, cost

costado, side, aspect

costar, to cost

costear, to defray, pay expense's; coast along costumbre, f., custom ; como de -, as usual creación, creation 
creador, -ora, a. and s., creative; creator

crear, to create crecer, to grow crédito, credit, money accredited, loan credo, creed, belief credulidad, credulity crédulo, $-\mathbf{a}$, credulous creencia, belief creer, to believe crepúsculo, twilight, sunset, evening crespo, -a, curly creyente, believer cria, brood of animals criado, servant criar, to grow, develop, rear criatura, creature crimen, $m$, crime crin, $f$. mane

crinado, -a, maned, crested crinolina, hoop-skirt, crinoline criollo, -a, creole; Arg., native

crisis, $f$, crisis

crisol, $m$. , crucible cristal, m., crystal cristalino, - a, crystalline cristiano, $-a$, Christian criterio, criterion, appreciation, judgment critica, criticism criticar, to criticize crónica, chronicle crucificar, to crucify crudeza, crudity crudo, - a, crude cruel, cruel

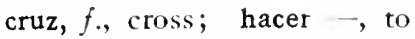
intersect

Cruzada, Crusade; one of a series of attempts to win back the Holy Land cruzado, crusader cruzar, to cross cuadra, block cuadrado, $-\mathrm{a}$, square cuadro, square; picture, frame cuadrúpedo, quadruped cuádruple, fourfold cuajada, curd of milk cual, as, like; el -, that, which, who

¿cuál? which ? what? cualidad, quality cualquiera, whatever, any cuan, shortened form of cuanto cuán, shortened form of cuánto cuando, when; - más, at most

cuanto, -a, as much as, all that; en - a, with regard to; en - que, in so far as ¿cuánto? how much ? how? cuarenta, forty cuartel, m., quarter, barrack cuarteta, quatrain cuarto, $-a$, fourth cuarto, quarter, room cuatro, four cubierta, deck, cover, roof 
cubierto, cover

cubrir, to cover; p. p. cubierto; voz cubierta, soft voice

cucuyo, glowworm cuchilla, Arg., stretch, knoll, slope

cuchillo, knife

cuello, neck, collar

cuenca, basin of a river

cuenta, account, bill; darse

-, to become aware

cuerda, cord, string

cuero, leather, hide, skin

cuerpo, body, corps

cuervo, raven

cuesta, hill

cuestión, question, problem

cueva, cave

cuidado, care

cuidadoso, $-\mathbf{a}$, careful

cuidar, to take care

cultivar, to cultivate

culto, -a, cultured, learned

culto, cult, religion

cultura, culture

cumbre, $f$., summit

cumplido, -a, courteous, ac-

complished

cumplimiento, fulfiment cumplir, to fulfil, carry out ;

- con, to satisfy

cuna, cradle

cúpola, cupola

curiosamente, curiously

curiosidad, curiosity curioso, $-\mathbf{a}$, curious, queer

curso, course

curva, curve

custodia, custody

custodiar, to guard

cuyano, - a, from old Argen-

tine province of Cuyo, which included the present provinces of Mendoza, San Juan, and San Luis

cuyo, $-\mathrm{a}$, whose

¿ cúyo, $-a$ ? whose?

cuzqueño, -a, from Cuzco, capital of Peru

\section{$\mathrm{Ch}$}

chacra, Arg., farm

charco, pool, marsh

charlatán, charlatan, faker

charlatanismo, charlatanism, gossip

charro, stream, trickle

chileno, -a, Chilean

chillido, shriek

Chimborazo, mountain in Ecuador

chimenea, chimney, smokestack

chiquillo, $-a$, child

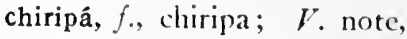
270,4

chirrido, chirp, screech, chattering

chispa, spark

chispeante, sparkling

chisporrotear, to crackle 
chisporroteo, sparkling, gleam i chitón! hush!

chivo, goat

chocar, to clash

choque, $m$., shock, clash

choza, hut

chubasco, squall

chúcaro, -a, savage

Chuquisaca, province of Bolivia, also ancient name for Sucre, present capital of Bolivia

churriador, Arg., a gaucho who takes delight in murder

D

dado, die

dama, lady

damasco, plum

danza, dance

dar, to give; - lugar, to

give rise; - que hacer, to

cause trouble; - - se, to surrender; - a, to face;

- con, to meet; - una

vuelta, to take a stroll;

- en, to hit, strike

dársena, dock, basin, anteport

dato, fact, information

de, of, from, by, with

debatir, to argue; - $\mathrm{se}$, to struggle

deber, m., duty

deber, to owe, be obliged to debido, -a, due, proper dẻbil, weak

debilidad, weakness

debilitar, to weaken

decaîdo, -a, fallen down, de-

pressed

decano, dean

decepción, deception

decidir, to decide

décima, stanza of ten verses

decir, to say, tell

decisión, decision

decisivo, $-a$, decisive

declaración, declaration

declarar, to declare

declaratoria, declaration

declive, m., decline, declivity

decoración, decoration

decorar, to decorate

decoro, decorum, self-respect

decretar, to decree

dédalo, labyrinth

dedicar, to dedicate

dedo, finger, toe

defecto, defect, fault

def ender, to defend

defensa, defense

defensor, defender

definido, -a, definite

definir, to define

definitivamente, definitely

definitivo, $-a$, decisive, defi-

nite; en - finally

deformado, -a, deformed

defraudar, to defraud

degenerar, to degenerate

degollar, to behead 
degradador, -ora, degrading degradar, to degrade deismo, deism, belief in God without belief in the Scriptures

dejar, to leave. cease: - de,

to fail; to stop; - caer, to drop

delante, before, in front delantero, leading, going in front

delegado, delegate

delegar, to delegate

deleitar, to delight

deleite, m., delight

deleznable, fragile, slippery, mean

deliberante, deliberating deliberar, to deliberate delicadeza, nicety, delicacy delicado, - a, refined, subtle, weak

delicia, delight

delicioso, $-\mathrm{a}$, delicious

delincuente, m., criminal

delirante, raving

delirar, to rave

delito, crime

delta, clelta

demagogia, demagogy

demanda, demand, need

demandable, liable, subject $(0)$ prosecution

demás, other (alicays used with lo, los, or las); por lo -, as for the rest demasiado, too, very

demencia, madness

democracia, democracy

demócrata, m., democrat democrático, $-\mathbf{a}$, democratic demoler, to demolish

demonio, demon

demostrar, to show

denegatorio, - a, contrary, demolishing, counter

denodado, -a, bold, intrepid denominación, name, title, denomination

denso, $-a$, dense

dentro, within

denunciar, to denounce, claim depender, to depend deplorable, deplorable deponer, to put down, settle, depose

deposición, deposition depravado, -a, depraved depreciar, to depreciate depurar, to purify, filter derecera, straight road, line derecho, $-\mathbf{a}$, right

derecho, right; de - , by right

derivar, to derive, emanate derramar, to pour, sbed; - se, to be lost

derredor, vicinity: en -. round about derretir, to melt derribar, to throw down, werwhelm, kill 
derrota, rout

derrotar, to rout

desacreditado, $-\mathbf{a}$, discredited desafiar, to defy, challenge desafio, challenge

desahogo, vent, outlet desairado, -a, graceless, charmless

desaliento, dejection desaliñado, - a, careless, artless

desaliñar, to disorder, disarrange

desaliño, $m$., negligence, disorder; con -, riotously, aimlessly

desalmado, -a, soulless, merci-

less

desalojar, to dislodge

desaparecer, to disappear

desarreglado, -a, irregular, lacking orderliness desarrollar, to develop desarrollo, development desarrugar, to unwrinkle, smooth

desasirse, to break loose desasociación, dissociation desastre, $m$., disaster desatar, to untie, unwind desavenencia, discord desbaratar, to interrupt, upset descalabro, misfortune descansar, to rest descanso, rest descarga, discharge

descargar, to fire; to unload descender, to descend descollar, to excel descomponer, to upset descomposición, disintegration, change desconcertante, disconcerting, puzzling desconfiar, to distrust desconocido, $-a$, unknown desconocimiento, lack of knowledge, ignorance descontento, $-\mathbf{a}$, discontented descrédito, discredit descreído, -a, incredulous, skeptical

describir, to describe descripción, description descriptivo, $-a$, descriptive descuajar, to clear away descubridor, discoverer descubrimiento, discovery descubrir, to discover, reveal

descuido, carelessness, negligence

desde, from

desdén, $m$., disdain

desdeñar, to disdain

desdeñoso, - a, disdainful desdichado, $-\mathbf{a}$, unhappy deseable, desirable desear, to desire desechar, to cast off, drive away 
desembarcadero, landing place

desembarcar, to disembark desembarco, disembarkation desembocadura, mouth of a river

desembocar, to empty; to debouch

desembozar, to unmask, unmuffle

desempeñar, to perform, play desencadenar, to unchain desenfrenado, -a, unbridled desengaño, disillusion, disappointment desenvainar, to unsheath desenvolver, to develop, open out desenvolvimiento, development

deseo, desire deseoso, $-\mathbf{a}$, desirous desertar, to desert desertor, deserter desesperación, despair desesperado, - a, desperate desesperar, to despair desfavorecer, to contemn, injure

desflgurar, to disfigure desfilar, to march, defile desgajar, to break, lop off, rend

desgarrar, to rend, tear desgracia, misfortune, death desgraciadamente, unhappily. desgraciado, -a, unfortunate desgraciarse, to incur misfortune, kill deshacer, to undo; - se de, to get rid of deshonrar, to dishonor desierto, desert designar, to designate, plan designio, design desigual, unequal, uneven, difficult

desigualdad, inequality, unevenness

desinterés, $m$., disinterestedness

desinteresado, -a, disinterested

deslizar, to pass by, slip, glide

deslumbrador, -ora, dazzling deslumbrar, to dazzle, puzzle desmandar, to rebel, go beyond the bounds of reason desmayar, to dismay, depress ; - se, to swoon

desmejorar, to deteriorate desmelenar, to dishevel desmentir, to belie, give the lie

desmontar, to dismount desmoronar, to destroy, fall to pieces

desnudez, nakedness, lack of shelter against the rigors of the weather

desnudo, a, naked, deprived 
desocupación, disoccupation desocupado, -a, idle desolar, to desolate desorden, $m$., disorder desorganización, disorganization

desorganizar, to disorganize desorientar, to confuse, cause to lose one's bearings despacio, slowly

despachar, to send off, hurry off

despacho, hurry; office; settlement

desparramar, to scatter, overspread

despecho, spite; a - de, in spite of

despedazar, to tear to pieces despedida, departure, leavetaking

despedir, to send off; - se,

to take leave

despegar, to detach

despertar, to awaken despierto, -a, wide-awake, keen

desplegar, to unfold, display desplomarse, to get out of plumb, collapse despoblado, uninhabited place despojar, to despoil despojo, despoliation, remnant

déspota, m., despot despótico, -a, despotic despotismo, despotism

despotizado, -a, tyrannized, lorded over despreciar, to scorn desprecio, scorn; lowering in value desprendimiento, disinterestedness

desprevenido, $-\mathbf{a}$, unaware desprovisto, $-\mathbf{a}$, deprived of después, afterwards; $\mathrm{y}-$, besides

destacamento, detachment destacar, to detach, send forth; - se, to stand out destello, flash

desterrar, to exile destinar, to destine destino, destination; fate destituir, to deprive destrenzar, to undo, unbraid destreza, skill, dexterity destronar, to dethrone destrozar, to tear to pieces destructor, -ora, destructive destruir, to destroy desunido, $-\mathbf{a}$, disunited desvalido, $-\mathbf{a}$, helpless desvanecer, to vanish; to dispel; - -se, to faint desventaja, disadvantage desventura, misfortune desventurado, $-\mathbf{a}$, hapless desvio, deviation, aberration detención, detention, delay detener, to detain 
determinante, determining determinar, to determine detestable, detestable detonación, detonation, report detractor, detractor, decrier detrás, behind deuda, debt devolver, to return devorar, to devour día, m., day diablo, devil diabólicamente, diabolically diabólico, -a, diabolical diálogo, dialogue diametral, diametrical diario, -a, daily dibujar, to draw, sketch diccionario, dictionary diciembre, December dictadura, dictatorship dictar, to dictate dictatorial, dictatorial dicha, happiness dicho, saying dichoso, - a, happy dieciséis, sixteen diecisiete, seventeen diente, $m$, tooth diez, ten

diezmar, to decimate diferencia, difference diferenciar, to differentiate diferente, different diferir, to delay, postpone difícil, diticult, critical, untractable dificultad, difficulty, stress difunto, $-a$, dead, late dignamente, worthily dignidad, dignity dignificar, to dignify dignísimo, -a, very worthy digno, -a, worthy, dignified dilatación, expansion, increase dilatado, - a, wide, vast dilatar, to spread diligencia, errand, diligence dimanar, to spring, flow dimensión, dimension diminuto, -a, small, diminutive dinero, money

Dios, God diplomacia, diplomacy dique, m., dike, barrier direcciôn, direction, address directamente, directly directo, -a, direct, immediate directorial, pertaining to a directory, directing directorio, directory dirigir, to direct, control; - se, to turn disciplina, discipline disciplinar, to discipline discípulo, pupil, student disco, dis $\mathrm{k}$

discreción, discretion: rendirse a -, to surrender unconditionally

discreto, - a, cautious, wise discurso, speech, discourse 
discusión, discussion

discutir, to discuss

diseminar, to disseminate

diseñar, to design, outline

disertación, speech, dissertation

disfrazar, to mask, hide

disfrutar, to enjoy

disimuladamente, dissem-

blingly

disimulado, $-a$, dissembling, hidden, sly

disipar, to dissipate, scatter, destroy

disnea, dismay, difficulty in breathing

disolver, to dissolve

disparar, to shoot, fire

dispersar, to disperse

disperso, refugee

disponer, to dispose

disponible, available

disposición, disposition, aptitude; measure

disputa, dispute

disputar, to dispute

distancia, distance

distante, distant

distención, stretching

distinción, distinction

distinguidisimo, $-\mathbf{a}$, very distinguished

distinguir, to distinguish

distintivo, $-\mathbf{a}$, distinctive

distinto, -a, distinct, different,

separate distraer, to distract

distribuir, to spread, distribute

diva, goddess

diverso, $-a$, diverse, different

divertir, to amuse, divert

dividir, to divide, sever

divinizar, to make divine

divisar, to catch sight of, descry

división, division

divorciar, to divorce

do, poetical for donde, where

doblar, to bend, double

doble, $a$. and s., double

doblez, doubleness, duplicity ;

fold

doce, twelve

docilidad, meekness

doctor, physician

doctrina, doctrine, teaching,

learning

documento, document

dogma, m., dogma

dolencia, pain, ache

doliente, grieving

dolor, m., pain, grief, hardship

doloroso, -a, painful

domar, to tame

doméstico, $-\mathbf{a}$, domestic

dominación, dominion, domination

dominante, dominant, overbearing

dominar, to dominate, overcome 
domingo, Sunday dominio, dominion

don, Mr., used with first name only

don, $m$., gift

donativo, donation

doncella, damsel

donde, where

¿dónde? where?

dondequiera, wherever

doña, lady, fem. of don

doquier, poetical for donde-

quiera

dorado, -a, gilt; golden;

splendid

dorar, to gild

dormido, -a, asleep

dormir, to'sleep

dos, two

doscientos, two hundred

dosel, m., canopy

dosis, $f$., amount, dose

dotar, to endow

dote, $f$., gift, dowry

dragón, dragon

drama, m., drama, struggle

dramático, -a, dramatic

druídico, -a, Druid, Druidic

duda, doubt

dudar, to doubt, hesitate

duende, $m$., demon

dueño, lord, master

dulce, sweet, fresh

dulcemente, sweetly

duplicar, to double

durante, during durar, to last

duraznero, peach tree

durazno, peach

duro, $-a$, hard

\section{E}

e, and

ebrio, $-a$, intoxicated, drunk

eclipsar, to eclipse

eco, echo

economia, economy; devel-

opment, regulation

económico, -a, economic

economizar, to spare, econo-

mize

ecuador, equator

ecuanimidad, fairness, equanimity

echar, to throw, drive out;

- a pique, to sink; -

mano de, to avail oneself

of ; - se a, to begin

edad, age; Edad Media,

Middle Ages

edecán, m., aide-de-camp

edificación, construction

edificio, building

educación, education, training

educar, to instruct, lead, train, direct

ef ectivo, $-\mathfrak{a}$, cffective

efecto, effect, purpose; en

-, indeed, in fact

efectuar, to carry out, effect;

- se, to take place 
eficacia, efficacy

eficaz, efficient, effective

eficazmente, efficiently

eficiente, efficient, powerful

efímero, -a, ephemeral, shortlived

efusivo, -a, effusive

Egipto, Egypt

egoísmo, egoism

egoísta, $m$., egoist

egoista, selfish

ejecución, execution

ejecutar, to execute; - - se, to take place

ejecutivo, executive

ejecutor, executor

ejemplar, exemplary, model

ejemplo, example

ejercer, to practice, exert

ejercicio, exercise

ejercitar, to exercise

ejército, army

él, he

el, the

elasticidad, elasticity

elección, election

electricidad, electricity

eléctrico, -a, electric

elefante, $m$., elephant

elegante, elegant

elegía, elegy

elegir, to choose

elemento, element, environment

elevación, lof tiness, elevation elevado, -a, lofty, high elevador, elevator

elevar, to raise

eliminar, to eliminate

elocuencia, eloquence

elocuente, eloquent

ello, it, that; por - on that account

emanación, emanation

emanado, -a, emanating, derived

emancipación, emancipation

emancipar, to free

embalsamar, to embalm

embarcación, embarking;

vessel; - a vela, sailboat

embarcar, to embark

embargo, sequestration; sin

-, nevertheless

embarque, $m$., shipment, passage, embarkation

embellecer, to beautify

embolar, to bring down with

bolas

embudo, funnel

emigrante, emigrant

emigrar, to emigrate

eminente, eminent

eminentemente, eminently

emoción, emotion, sorrow

emocionante, emotional, moving

empalme, $m$. junction, splic-

ing

empañar, to darken, cloud

emparedar, to wall in

empedrar, to pave 
empeñar, to pawn; to begin an action; - se, to bind oneself

enıpeño, pledge, eagerness empero, but, nevertheless empezar, to begin empleado, employee emplear, to employ, spend empleo, task, employment emplumado, $-a$, feathered emplumecer, to take on

feathers empozarse, to stagnate emprender, to undertake, begin

empresa, undertaking empréstito, loan

empujar, to drive, push empuñar, to seize, take up en, in, on, among enamorado, $-a$, enamored enarbolar, to hoist enardecer, to fire up, kindle encabezar, to head, lead encadenar, to chain encajar, to place, inclose encaje, $m$., lace encaminar, to put on the

road; - -se, to set out encantar, to enchant encanto, enchantment encantonar, to intrench encargado, agent encargar, to intrust, charge: se de, to take charere of encarnación, incarnation encarnarse, to become incarnate

encender, to kindle encerrar, to shut in encima, above; - de, above, upon encomendar, to recommend, intrust encono, rancor, ill-will encontrar, to meet, find encontrón, m., collision, meeting encorvar, to bend encrespar, to wave, curl encrucijada, crossway encuadrar, to frame, fit in encubrir, to hide, disguise encuentro, encounter, meeting

encumbramiento, rise, elevation

endecasilabo, verse of eleven syllables, hendecasyllabic endecha, dirge, stanza endilgar, to turn, direct, send enemigo, $-\mathbf{a}, a$. and s., hostile; enemy enemistad, enmity energía, energy enérgico, $-a$, energetic, strong enero, Jamuary enervado, $-a$, weakened, dull enfardar, to pack enfermo, $-a$, sick enfilar, to pierce, enfilade; (c) march 
enflaquecer, to become thin, weaken

enfrente, before, in front; de, in front of

enfriamiento, cooling, chill

enfurecer, to madden

engalanar, to deck, adorn

engañar, to deceive

engañoso, -a, deceitful, deceptive

engendrar, to engender

engolosinar, to whet one's desire

engrosar, to enlarge

enjaezar, to caparison

enjambrar, to breed a hive of bees

enjambre, $m$., colony of bees; bees

enjuiciar, to pass judgment; to try in court

enlazar, to lasso

enloquecedor, -ora, maddening

enmascarar, to mask

enmendar, to mend, improve

enmienda, amendment

enmudecido, $-a$, mute

ennegrecer, to blacken

enojo, anger

enorme, enormous

enormidad, enormity

enredar, to twine, knot

enrojecer, to redden

enronquecer, to become hoarse

ensalzar, to exalt, extol ensanchar, to widen, swell

ensangrentar, to stain with

blood

ensayar, to try

ensayo, essay, trial

enseñanza, teaching

enseñar, to teach, show

enseñorearse, to lord it over,

get control of

ensillar, to saddle

ensopar, to dip, wet

ensortijado, - a, curly

ensueño, dream

entender, to understand, hear entendimiento, understanding enteramente, entirely

enterar, to inform

enternecido, -a, moved, sof-

tened

enternecimiento, tenderness

entero, $-\mathbf{a}$, entire

enterrar, to bury

entidad, entity, import ; - es

dominantes, ruling spirits

entonar, to sing, intone

entonces, then; desde -

ever since

entrada, entrance

entraña, bowel; depth; core,

heart; vein. (Seldom used

in the singular)

entrañable, affectionate, deep entrar, to enter; no -- para

nada, to be of no account

entre, between, among; -

tanto, meanwhile 
entreabrir, to open partly entregar, to give over, surrender, deliver entrelazar, to interlace entrever, to discern, glimpse entrevista, interview entusiasmo, enthusiasm entusiasta, enthusiastic enunciar, to enunciate, proclaim

envenenar, to poison enviado, messenger enviar, to send envidia, envy, jealousy envidiable, enviable envidiar, to envy envilecer, to degrade envolver, to wrap, involve épico, -a, epic episodio, episode epitafio, epitaph epiteto, epithet época, epoch, period epopeya, epic poem equidad, equity, justice equilibrar, to balance equilibrio, balance, equipoise equipaje, m., bagrage equitación, horsemanship equívoco, -a, equivocal, concealed

erguir, to raise, elevate erial, $m$., uncultivated land erigido, -a, erected, bised erizar, to set on end, bristle; erizado de, bristling with errante, wandering erróneo, $-\mathrm{a}$, erroneous erudición, erudition esbeltez, elegance esbelto, -a, stately; sprightly escala, scale, stage, ladder, dock; hacer-, to stop escalar, to scale escama, shell, scale escándalo, scandal escapar, to escape escape, m., escape; a todo at full speed escapulario, scapulary escarchado, -a, frosty escasear, to give sparingly;

to be scarce, lacking escasez, scarcity escaso, -a, scarce, occasional, few escena, scene, environment, foreground escenario, scene, stage escenográfico, -a, scenic, picturesque escepticismo, scepticism esclavitud, slavery esclavo, slave escoger, to select escolar, student escolástico, -a, scholastic escombro, rubbish, ruins esconder, to hide escribir, to write escrito, writing escritor, writer 
escritorio, office, writing-desk escritura, Scripture escrupuloso, $-\mathbf{a}$, scrupulous escrutador, -ora, scrutinizing escuadra, fleet

escuadrón, $m$. , squadron

escuchar, to listen

escudo, shield

escud iñador, -ora, searching escuela, school

escueto, -a, unincumbered, bare

escupir, to spit, belch

ese, that

ése, that one, that

esencialmente, essentially

esfinge, $f$., sphinx

esforzado, -a, strong, valiant

esforzarse, to strive

esfuerzo, effort

esfumarse, to disappear, fade away

esgrima, art and rule of fencing

esgrimir, to wield

esmerado, -a, careful

esmeralda, emerald

espaciarse, to roam

espacio, space, distance

espada, sword

espalda, back, shoulder; a la

- , in the rear, behind

espantar, to frighten

espanto, fright

espantoso, -a, frightful

España, Spain español, -ola, Spanish

esparcir, to scatter

Esparta, Sparta, one of former independent Greek states, whose citizens were renowned for manliness

especial, special

especialidad, specialty, peculiarity

especie, $f_{\text {., kind, class }}$

espectáculo, spectacle, sight

espectador, spectator

espectativa, expectation

espejismo, mirage, deception espejo, mirror

espera, wait, waiting

esperanza, hope

esperar, to hope, expect

espesísimo, $-a$, very thick

espeso, $-a$, thick

espesor, $m$., thickness, density

espesura, thickness, forest

espiar, to spy

espinillo, thorn, prickly tree

espinoso, -a, thorny, prickly

espiral, $m$. , curl, spiral

espiritu, spirit, mind

esplendidez, splendor

espléndido, $-\mathbf{a}$, splendid

esplendor, $m$., splendor

esplorador, scout, explorer

espoleta, bomb fuse

esponjazo, blow with a

sponge, shower

espontáneamente, spontaneously 
espontåneo, -a, spontaneous esposa, wife

esposo, husband

espuela, spur

espuma, foam

esquina, corner

esquisito, $-a$, exquisite

establecer, to establish

establecimiento, establishment

estación, station; season

estacionar, to station

estado, state, condition; -

mayor, staff

estallar, to burst

estampa, stamp, appearance

estampar, to print, stamp

estampido, crash

estancia, large tract of land

for raising stock; ranch

estanciero, rancher

estandarte, standard, banner

estar, to be, stand, lie; $\rightarrow$

en, to know

estatuaria, statuary, statues

estatura, stature

este, this

éste, this one, the latter

estepa, steppe

estereotipar, to stereotype

estéril, sterile, barren

estero, marsh, lake

estertor, throat rattle

estético, a, iesthetic

estimación, estecm, estimation estimular, to stimulate estímulo, stimulant, stimulus estirar, to stretch

estirpe, m., stock, family

esto, this; por -, on this

account

estoico, $-a$, stoic

estopin, $m$., quick-match

estorbar, to hinder

estorbo, hindrance

estrangular, to strangle

estrategia, strategy

estratégicamente, strategi-

cally

estratégico, -a, strategic

estrato, layer, level

estrechar, to squeeze, clasp,

press, shut in

estrechez, narrowness, penury estrecho, -a, narrow, closely

bound

estrechura, narrowness

estrella, star

estrellado, -a, starry

estrellar, to clash, smash

estremecer, to shake, agitate

estremecimiento, trembling, shudder

estrépito, noise, din

estribor, m., starboard

estro, inspiration

estrofa, stan\%a

estruendo, ro:ır, thunder

estruendoso, -a, noisy, thunderous:

estuario, estuary

estuche, m., casing 
estudiante, student estudiar, to study estudio, study estudioso, -a, studious estupefacto, $-\mathbf{a}$, stupefied estupendo, $-\mathrm{a}$, stupendous estúpido, -a, stupid etapa, stop, station etéreo, $-\mathbf{a}$, ethereal, unsullied eternamente, eternally eternidad, eternity eterno, -a, eternal ético,-a, hectic, weak, panting

Europa, Europe europeo, -a, European

Eva, Eve

evacuar, to evacuate evangelio, gospel evasión, escape, evasion evidencia, evidence evidenciar, to give evidence of

evidente, evident evitar, to avoid evocador, -ora, evoking evocar, to evoke evolución, evolution exactamente, exactly exactitud, exactness exacto, $-a$, exact exagerar, to exaggerate exaltación, loftiness, exaltation

exaltar, to exalt examen, m., examination examinar, to examine

exánime, lifeless excelente, excellent

excelentísimo, -a, very excellent excepcional, exceptional excepto, except; - en cuanto, except in so far as excesivo, $-\mathbf{a}$, excessive exceso, excess excitar, to excite exclamar, to exclaim exclusivamente, exclusively exclusivo, $-\mathbf{a}$, exclusive excursión, excursion excusado, -a, excused, old, useless

excusar, to excuse, shun exento, $-a$, exempt exhalar, to exhale exhausto, $-\mathbf{a}$, exhausted exhibición, exhibition, portrayal

exhibir, to exhibit exigencia, exigency, need exigir, to demand, require, arouse

exiguo, -a, scarce, small

existencia, existence

existir, to exist

éxito, outcome, success

Excmo., abbreziation for $\mathbf{E x -}$ celentísimo éxodo, exodus exorbitante, exorbitant 
exótico, -a, exotic

expansión, expansion

expansivo, $-\mathrm{a}$, expansive, ex-

pansionist

expedición, expedition

expedicionario, -a, expedi-

tionary

expediente, m., expedient, measure

expedir, to issue, send, expedite

expeditivamente, expeditely, expeditiously

expeditivo, $-\mathrm{a}$, expeditious

expeler, to expel

experimentar, to undergo, experiment

experto, -a, expert, clever

explicar, to explain

explicativo, $-\mathbf{a}$, explanatory

exploración, exploration

expolio, spoliation

exponente, exponent

exposición, exposition

expresar, to express

expresión, expression

expresivo, $-\mathrm{a}$, expressive

exquisito, -a, exquisite

extasiado, -a, ecstatic, in

ecstasy

extender, to extend

extensión, space, extent

extenso, - a, extensive

extenuar, to wear away,

weaken

exterior, exterior, outer exterior, m., exterior, outside; en el -, abroad exteriorizar, to show, manifest, bring to the surface exterminador, exterminator exterminar, to exterminate externo, -a, external, foreign extinguir, to extinguish extramuros, outside the city limits

extranjero, foreigner, stranger extrañar, to wonder at, alienate, miss

extrañeza, strangeness

extraño, -a, strange

extraordinario, -a, extraordinary

extraviar, to lose, put off the track

extremo, extreme

exuberante, exuberant, overflowing

\section{F}

fábrica, manufactory, factory fabricación, manufacture

fabricante, $a$. and s., making; maker

fabricar, to construct, make fabril, manufacturing, textile fabuloso, -a, fabulous facción, feature, faction, act fácil, casy

facilidad, facility

fácilmente, easily

facticio, $-a$, artificial, sham 
facultad, power, faculty

faena, task, work

f $\lrcorner$ ja, sash, belt, strip

falaz, deceitful

falda, slope, skirt

falsificado, $-a$, falsified

falta, absence, fault, lack

faltar, to be lacking, fail;

- a una cita, to break an

appointment

falto, -a, lacking; - de, lacking in

fallar, to pass sentence

fallo, sentence, decree

fama, fame

famélico, -a, hungry

familia, family

familiar, familiar

familiarizar, to familiarize

familiarmente, familiarly

famoso, -a, famous

fanático, $-a$, fanatic

fanatismo, fanaticism

fanatizar, to fanaticize

fanfarronamente, swaggeringly

fantasear, to fancy, imagine

fantasía, fantasy

fantasma, $m$., phantom

fantasmagoría, illusion

fantástico, $-\mathbf{a}$, fantastic

fardo, weight, pack

farol, m., lamp, lantern

farola, big lantern

fascinación, fascination, bewilderment fascinador, -ora, fascinating

fascinar, to fascinate

fase, $f$., phase, aspect

fastidiar, to bore, disgust, weary

fatal, fatal

fatalidad, fatality

fatalismo, fatalism

fatalista, $m$., fatalist

fatídico, $-a$, fateful

fatigar, to fatigue, tire

fatigoso,-a, fatiguing, tedious, tiresome

favor, m., favor; a $-\mathrm{de}$, favored by

favorecer, to favor, aid

favorito, $-a$, favorite

faz, $f$., face, appearance, phase, surface

fe, f., faith; hacer -, to constitute evidence

febrero, February

febril, feverish

fecundante, life-giving, fertile

fecundidad, fertility

fecundo, $-a$, fertile

fecha, date

federal, federal

feísimo, $-a$, very ugly

felicidad, happiness

felicitar, to congratulate

feliz, happy

felizmente, happily

fenómeno, phenomenon

feraz, fruitful

féretro, coffin, hearse 
ferocidad, fierceness

feroz, fierce, wild

férreo, $-a$, of iron, firm

ferrocarril, m., railroad

fértil, fertile

fertilidad, fertility

festín, m., feast, entertainment

feudalismo, feudalism

fiado, -a, trusting

fiambre, $m$., cold meats

fiambre, cold-served

ficticio, $-a$, fictitious

fidelidad, faithfulıess

fiebre, $f$, fever

fiel, faithful

fielmente, faithfully

fiera, wild beast

fiero, $-\mathbf{a}$, fierce, wild

fiesta, holiday, feast

figura, shape, form, appear-

ance

figurar, to figure, shape; --se, to imagine

fijamente, assuredly, fixedly, exactly

fijar, to fix, set, allot

fijeza, accuracy, firmness

fijo, $-\mathbf{a}$, fixed, inflexible

fila, file, row

filosofia, phitosophy

filosófico, a, philosophical

filtrar, to percolate, filter

fin, m., end; al , finally

finado, -a, dead, deccased, late final, last final, $m$. , end

financiero, $-a$, financial

finanza, finance

fingir, to feign, pretend

fino, $-a$, fine, keen, polite

fiord, $m$., fiord

firmar, to sign: to strengthen

firme, firm, strong

firmeza, firmness

fisga, harpoon

fisica, physics

físico, $-\mathbf{a}$, phyrsical

fisonomía, physiognomy, as-

pect, character, figure, features

flamear, to wave, flame, gleam flanco, flank, side

flaquear, to become weak

flauta, flute

flecha, arrow

flexibilidad, flexibility

flexible, Alexible

flor, $f$., Hower

flora, Hora

flordelisado, - a, adorned with fleur-de-lis

florecer, to flower, bloom

florido, a, Howering, blossoming

flota, flcet

flotante, floating

flotar, to Hoat

flotilla, Hotilla

flúido, fluicl

fluvial, Huvial, pertaning to a rive't 
foco, center, focus

fogoso, -a, fiery

follaje, $m$., foliage

fomentar, to encourage, foment

fondear, to anchor

fondo, bottom, depth, fund, background; de - , of importance; en el-, at bottom

forastero, -a, strange, foreign forense, forensic

forjar, to forge, create, shape forma, form, formality, means, outline, feature, manner formación, formation

formal, serious, grave, solemn, dignified

formar, to form, create, line up

fornido, $-\mathrm{a}$, robust, thickset

fórmula, formula

fortalecido, -a, strengthened

fortaleza, strength, fortification

fortuna, fortune; por luckily

forzar, to force, violate, overthrow

forzosamente, necessarily

forzoso, -a, necessary, unavoidable, exacting

fosco, -a, frowning, dark, sullen

fosforescer, to be visible, phosphorescent fracasar, to shatter, fail, break fragata, frigate

fragor, $m$., roar

fraguar, to forge

fraile, friar

francés, -esa, French

Francia, France

franco, -a, frank, open

franqueza, sincerity, frankness frase, $f$., sentence, expression fraternal, brotherly

fraternizar, to fraternize

fratricida, $a$. and s., fratricidal; fratricide

fray, contraction of fraile, title used before the name of a monk, brother

frecuencia, frequency

frecuente, frequent freno, bridle; restraint frenología, phrenology frente, $f$., forehead, brow; hacer - a, to face; - de, Arg., in one's face fresco, - a, fresh, cool frescura, coolness fríamente, coldly frigio, -a, Phrygian frío, $-a$, cold frio, cold frondosidad, leafiness frondoso, -a, leafy frontera, frontier, boundary frotar, to rub, stroke fruta, fruit fruto, fruit; produce 
fuego, fire, discharge

fuente, $f$., fountain

fuera, outside, beyond; $\tan$ - de, so far or entirely beyond

fuerte, strong

fuerte, $m$., fort

fuertemente, strongly

fuerza, strength, violence; en or a - de, by dint of

fuga, flight

fugaz, fleeing, fleeting

fugitivo, fugitive

fulgor, $m$, brilliancy

fulminante, thundering, fulminating

fulminar, to fulminate, strike down

fumar, to smoke

función, function, entertainment

fundación, settlement, foundation

fundador, founder

fundamental, fundamental

fundamento, foundation

fundar, to found

fundir, to cast, melt, fuse

funeral, $m$., funeral

funesto, -a, fatal, sad, dismal

furia, fury, excitement

furioso, $-\mathrm{a}$, furious

furor, m., fury

furtivamente, furtively

fusil, $m$., gun, rifle

fusilar, to shoot fusileria, musketry

futuro, $-a$, future

G

gabinete, m., office, cabinet; hombre de -, administrator

gala, gala

galante, gallant

galante, $m$., gallant

galanteria, gallantry

galeria, gallery

galo, Gaul, Frenchman

galopar, to gallop

galope, m., gallop; a -

tendido, at full gallop

galpón, m., Arg., shed, warehouse

galvanizar, to galvanize, quicken into life

gallardamente, gracefully, bravely

gallardia, deed of bravery, gallantry

galleguito, diminutive "f

gallego, inhabitant of the province of Galicia in northwestern Spain

gamo, buck

ganado, stock, cattle

ganar, to gain, win

garantia, guaranty, assurance garantizar, to guarantee, protect

garbo, gracefulness, cleverness garganta, throat; gorge 
garra, clutch, claw

garrote, $m$., stick, cudgel

gas, $m$., gas

Gascuña, Gascony

gasto, expense

gato, cat

gauchaje, m., collective for

gauchos, gathering of gau-

chos

gauchesco, -a, pertaining to

the gaucho

gaucho, cowboy of the pam-

pas; - malo, outlaw gau-

cho, "bad man"

gaveta, draver

gaviota, sea gull

gayo, -a, gay, festive; gaya

ciencia, minstrelsy

gemelo, twin

gemido, groan

gemir, to moan, grieve

generación, generation

general, general

general, $m$., general

generala, the general (a roll

of the drum); se tocó -

the general was sounded

generalmente, generally

género, kind; gender; stuff

generosidad, generosity

generoso, $-\mathbf{a}$, generous

Génesis, m., Genesis

genial, genial

genio, genius, temper, mind

gente, $f$., people

gentio, crowd genuino, $-\mathbf{a}$, genuine geografía, geography geográîco, -a, geographical germen, $m$., germ, source gestión, effort, negotiation gesto, military feat; face,

grimace; turn

gigante, $m$, giant

gigantesco, $-\mathbf{a}$, gigantic

gimnasia, exercise, gymnastics girar, to sweep about, look or turn around

glauco, -a, sea-green

globo, globe

gloria, glory

gloriosamente, gloriously

glorioso, $-\mathbf{a}$, glorious

gobernación, territory

gobernador, governor

gobernante, governing

gobernar, to govern

gobierno, government

goce, $m$., enjoyment

goleta, schooner

golfo, gulf

golondrina, swallow

golpe, m., blow; de un --

at a blow, at one stroke

goma, gum, rubber

gordo, $-a$, fat

gorro, cap

gota, drop

gótico, $-\mathrm{a}$, Gothic

gozar, to enjoy

gozo, joy

gozoso, $-\mathbf{a}$, joyous 
grabar, to engrave

gracia, grace, pardon; pl., thanks; en - de, in exchange for

grada, step

grado, degree, step

gradual, gradual

gradualmente, gradually

granada, grenade

granadero, grenadier; - de

a caballo, mounted grenadier

Gran Bretaña, Great Britain grande, great, broad

grandeza, greatness

grandiosidad, grandeur

grandioso, -a, grandiose, great, marvelous

granito, granite

grasoso, -a, greasy, fatty

gratitud, gratitude

grato, -a, pleasing

grave, serious, grave

gravitación, weight, gravitation

gravitar, to weigh down, gravi-

tate

Grecia, Greece

gris, gray

grita, shouting, clamor

gritar, to shout

grito, cry, shout: decir or

llamar a - s, to shout

grosero, -a, coarse

grủa, crane, derrick

grueso, -a, thick grupa, croup, rump of a horse grupo, group guanaco, guanaco, an animal

like the llama guantelete, m., glove used for protection, gauntlet guardar, to keep, guard guardia, guard, watch guarecer, to shelter guarida, den, lair, shelter guarnición, garrison gubernamental, governmental guedeja, long lock of hair guerra, war guerrero, -a, warlike guerrero, warrior guerrilla, diminutive of guerra, guerrilla

guerrillero, guerrilla, one who takes part in guerrilla warfare

guia, $m$. or $f$. guide, scout guiar, to guide

guijarro, pebble, smooth stone guiñar, to wink

guirnalda, garland, wreath guisa, manner, guise

guitarra, guitar

gustar, to taste; me gusta, I like

gusto, taste, pleasure

$\mathrm{H}$

habano, Ilavana cigar; person from llavana

haber, to have 
haber, $m$. , possession

hábil, able, clever

habilitado, paymaster

habitación, roon, dwelling

habitante, inhabitant

habitar, to live in, inhabit

hábito, habit ; dress ; characteristic

habituado, $-\mathbf{a}$, accustomed

habitual, habitual

habitud, habit

habla, speech

hablar, to speak

hacer, to do, carry on;

que, to bring about that;

- mal, to harm; - se

paso, to cut one's way through; - de, to act as; - se, to become

hacia, toward

hachazo, blow with an ax hada, fairy

halagador, -ora, flattering,

pleasing

halagar, to Hatter

halagüeño, -a, alluring, charming

hallar, to find; - -se, to be

hambre, $f$, hunger

hambriento, -a, hungry, famished

harto, very, excessively, more than

hasta, up to; even

hato, bundle

haz, $f$., surface, face hazaña, exploit, feat

he, behold; - - aquí, here is ;

- me aqui, here I am

hebreo, -a, Hebrew

hechicera, enchantress, witch

hecho, deed, fact

helada, frost, chill

helar, to freeze

hélice, $f$., propeller

hembra, woman, female

hemisferio, hemisphere

hender, to cleave

hercúleo, -a, Herculean

Hércules, Hercules, character

of Greek mythology, fa-

mous for his strength

heredad, domain, estate

heredar, to inherit

hereditario, - $a$, hereditary

herencia, inheritance

herir, to wound, strike

hermana, sister

hermandad, brotherhood; i.l

the Spanish world, a so-

ciety which banded to-

gether to restrain crime

hermano, brother

hermosamente, beautifully

hermoso, - a, beautiful

hermosura, beauty

héroe, hero

heroicamente, heroically

heroico, $-\mathrm{a}$, heroic

heroísmo, heroism

herrado, - a, iron-shod

herradura, horseshoe 
herramienta, tool

herrumbrado, $-a$, rusty

heterogéneo, -a, heterogeneous

hibrido, $-a$, hybrid

hidalgo, nobleman, hidalgo

hidalguia, nobility, chivalry hidromiel, $f_{\text {., }}$ a fermented drink from honey and water hiel, $f$., gall, bile; bitterness hierba, grass, verdure

hierro, iron

hija, daughter

hijo, son

hilar, to spin

hilo, thread

himno, hymn

hincadito, $-\mathbf{a}$, diminutive of

hincado, kneeling, huddling hinojo, fennel

hipócrita, $m$. or $f$., hypocrite, dissembler

hirviente, boiling

hispanoamericano, -a, Spanish-American

historia, history, story

historiado, -a, storied

historiador, historian

histórico, $-\mathrm{a}$, historic

hocico, snout, murzle

hogar, $m$, home, hearth

hoguera, fire

hoja, leaf

holgazán, -ana, indolent

holgazanería, indolence

holgorio, jollity hollar, to trample under foot hombre, man

hombro, shoulder

hombrón, big, lusty man

homenaje, $m$., homage

homicida, a. and s., homicidal; murderer

homogéneo, $-a$, homogeneous hondamente, deeply

hondo, -a, deep

hondonada, dale, deep valley honor, $m$., honor

honra, honor, good name

honrado, $-\mathbf{a}$, honored, honest

hora, hour

horadar, to bore

horda, horde

horizontalidad, horizontality

horizonte, $m$., horizon

Hornos, Horn (Cape)

horqueta, fork, crossing of

two branches

horrible, horrible

horror, $m$, horror

horroroso, $-\mathbf{a}$, horrible

hortaliza, Ars., vegetable gar-

den; vegetables

hosanna, m., hosanna

hospitalario, -a, hospitable

hospitalidad, hospitality

hostigar, to vex, harass

hostil, hostile

hostilidad, hostility

hostilizar, to harass

hoy, today

hueco, -a, hollow, empty, vain 
hueco, hollow, gap

huelga, rest, repose; strike;

a la -, in idleness

huella, trace, footprint

huérfano, $-\mathbf{a}, a$. and s., orphan huerto, garden

hueso, bone

huésped, $m$., host

huída, flight

huído, $-\mathbf{a}, a$. and s., fugitive

huir, to flee

hulla, soft coal

humanidad, humanity

humanitario, $-\mathrm{a}$, humanitarian

humano, $-\mathrm{a}$, human

humedad, humidity

húmedo, -a, humid

humildad, humility

humilde, humble

humillación, humiliation

humillar, to humiliate

humo, smoke

humor, humor, disposition

humorístico, $-\mathrm{a}$, humoristic

hundir, to sink

huracán, $m$., hurricane

huronear, to pry, ferret out, scrutinize

husmear, to scent

\section{I}

ibérico, -a, Iberic, Iberian

ibero, $-\mathbf{a}, a$ and s., Iberian

idea, idea, thought

ideal, ideal

ideal, $m$., ideal idealismo, idealism

idealista, idealistic

idealista, $m$., idealist

idealización, idealization

identidad, identity

identificar, to identify

idolatría, idolatry

iglesia, church

ígneo, -a, fiery, igneous

ignominia, infamy

ignominioso, $-\mathrm{a}$, ignominious

ignorancia, ignorance

ignorante, ignorant

ignorar, to be ignorant of, not

to know

ignoto, $-\mathbf{a}$, unknown

igual, equal, similar, even

igualar, to equalize

igualdad, equality

igualmente, equally

ijar, $m$., flank, side

ilimitado, -a, unlimited

iluminación, illumination, gleam, brilliancy

iluminar, to illuminate, light

ilusión, dream, illusion

iluso, -a, deluded, ignorant

ilustración, wisdom; explana-

tion; fame; illustrious man

ilustrarse, to become famous

ilustre, famous

imagen, $f$, image

imaginación, imagination, mind

imaginar, to imagine, conceive imaginativo, $-a$, imaginative 
imborrable, ineradicable

imitar, to imitate

impaciencia, impatience

imparcial, impartial

impedir, to prevent

impenetrable, inscrutable, impenetrable

imperar, to hold sway

imperceptible, imperceptible

imperfectamente, imperfectly imperio, empire, control, sway imperioso, -a, imperious impersonal, impersonal impetu, $m$., impetus, impulse impetuosidad, impetuousness impetuoso, $-\mathrm{a}$, impetuous implacable, implacable implicitamente, implicitly implorar, to implore imponente, imposing imponer, to impose, place upon

importancia, importance importante, important importantísimo, -a, very important

importar, to be of importance, import

importe, m., amount

importuno, a, importunate, vexatious

imposibilidad, impossibility imposible, impossible imposición, impersition impotencia, incapacity, inpotence imprecación, imprecation imprenta, printing press impresión, impression impresionable, impressionable impresionar, to impress imprevisor, -ora, unforeseein , careless

imprimir, to impress, print improbable, improbable improvisación, improvisation improvisador, improviser improviso, -a, unforeseen; de -, unexpectedly imprudente, imprudent impulsar, to impel, force; to foster

impulso, impulse; a $-\mathrm{s}$ de, impelled by

inabarcable, incomprehensible inaccesible, inaccessible inagotable, inexhaustible inalterable, impassible, unchanging, inalterable inapelable, beyond appeal, withoat appeal inapreciable, inestimable inaudito, $-a$, unheard of inavertido, $-\mathbf{a}$, unnoticed; unwary, careless incapaz, incapable incásico, $-a$, pertaining to the Incas incendiarse, to catch fire incendio, fire

incertidumbre, $f$, incertainty incesante, incessant 
incidente, $m_{.}$, incident incienso, incense

incierto, $-\mathrm{a}$, uncertain inclemente, inclement inclinación, inclination inclinar, to bow down, incline ínclito, $-\mathrm{a}$, famous, glorious incógnito, $-\mathbf{a}$, unknown incoloro, $-\mathbf{a}$, colorless incómodo, $-\mathbf{a}$, uncomfortable, oppressive

incomparable, matchless incompatible, incompatible incomprensible, incomprehensible

inconciliable, irreconcilable inconcluso, $-\mathbf{a}$, unfinished inconmensurable, limitless inconmovible, immovable incontaminado, -a, uncontaminated

incontrastable, irresistible inconveniente, $m$., difficulty, objection, trouble incorporarse, to unite, join; to sit up

increíble, incredible incrustar, to incrust inculto, $-\mathbf{a}$, uncultivated, uneducated

incuria, negligence

incurrir, to incur

indecisión, indecision indeciso, $-a$, undecided indefenso, $-\mathbf{a}$, defenseless indefinible, undefinable indefinido, $-a$, indefinite indeleble, indelible, indestructible independencia, independence independiente, independent indestructible, indestructible indicar, to show, point out indice, $m$., index finger, index indiferencia, indifference indiferente, indifferent indiferentemente, indifferently

indigena, s. and a., native; indigenous

indignar, to make indignant, excite

indigno, -a, unworthy indio, -a, Indian indirectamente, indirectly indiscutible, unquestionable indispensable, indispensable indistintamente, indistinctly, indiscriminately individual, individual individualidad, individuality individualismo, individualism individuo, individual, person indolencia, indolence indolente, indolent, indifferent indómito, $-\mathbf{a}$, untamed, wild indudable, undoubted, undeniable

indulgencia, indulgence indulto, amnesty, pardon indumentaria, clothing industria, industry 
ineducado, -a, uneducated, ill-bred

inercia, inertia

inerte, inert, lifeless

inevitable, inevitable

inexplicable, inexplicable

in extinguible, unextinguishable

infalible, infallible

infaliblemente, infallibly

infamia, infamy

infancia, infancy

infanteria, infantry

infeliz, a. and s., unlappy; wretch

inferior, lower, inferior

infernal, infernal

infiel, $a$. and s., faithless, un-

faithful, infidel

infinidad, infinity

infinito, $-a$, endless; al -, to infinity

inflamado, $-a$, passionate, in-

flamed

inflar, to swell, inflate

inflexión, inflexion

inflexible, inflexible

influencia, influence

influjo, influence

influyente, influential

informe, $m$., notice, information

infructuoso, $-a$, fruitless

infundir, to inspire, cause

ingeniero, engineer

ingenio, genius, mind ingenioso, $-a$, ingenious

ingenuamente, ingenuously ingenuidad, ingenuousness,

openness

ingenuo, $-a$, ingenuous, naive ingertar, to ingraft

Inglaterra, England inglés, -esa, $a$. and s., English ingrato, -a, thankless, ungrateful, unpleasant

inherente, inherent

inhibir, to inhibit, prevent

inicial, first, initial

iniciar; to initiate, begin

iniciativa, initiative, enterprise

iniquidad, iniquity

injusticia, injustice

injusto, $-\mathbf{a}$, unjust

inmaculado, $-\mathbf{a}$, immaculate,

holy

inmediación, contiguity, con-

tact; a -es de, close by, in the vicinity of

inmediatamente, immedi-

ately; - que, as soon as

inmediato, $-a$, inmediate, near by

inmensidad, immensity

inmenso, $-a$, immense

inmigración, immigration

inmolar, to sacrifice

inmortal, immortal

inmóvil, motionless

inmovilidad, immobility

innecesario, -a, unnecessary

innoble, ignoble 
innumerable, numberless inocencia, innocence inocente, innocent inocular, to inoculate inofensivo, $-a$, inoffensive inopinadamente, unexpectedly, thoughtlessly inquieto, $-\mathrm{a}$, restless inquietud, anxiety, restlessness insaciable, insatiable insecto, insect insensible, unaware, senseless inseparable, inseparable insigne, famous insignificante, insignificant insinuar, to insinuate, hint, whisper, try

insipido, $-\mathbf{a}$, insipid insipiencia, ignorance insistir, to insist insolvencia, insolvency insostenible, untenable inspeccionar, to inspect inspiración, inspiration inspirar, to inspire; -se en, to be inspired by instalación, installation, establishment

instalar, to install instancia, instance, urgent request

instante, $m$., instant instaurar, to set up instintivo, $-a$, instinctive, innate instinto, instinct institución, institution instituir, to set up, institute instrucción, instruction insirumentista, m., player upon a musical instrument, virtuoso instrumento, instrument insultar, to insult insurreccionado, $-a$, rebellious, in arms intacto, $-\mathbf{a}$, intact integrante, $f$., integral part integrar, to integrate, fuse integridad, integrity, honesty intelectual, intellectual inteligencia, intelligence, mind; buena - good will inteligente, intelligent intemperie, $f$., rough weather; a la -, without shelter, under the open sky intempestivo, -a, abortive, untimely

intención, intention

intendente, intendant, subtreasurer of the government

intentar, to try, plot intercambio, exchange interés, $m$., interest interesante, interesting interesar, to interest interior, $m$., interior interior, interior, inner, internal 
interminable, endless internacional, international internar, to intern interno, $-\mathrm{a}$, internal, inner interponer, to interpose interposición, interposition interpretar, to interpret interrogar, to question, ask interrumpir, to interrupt interrupción, interruption intervalo, interval intervención, intervention intervenir, to intervene intestino, $-\mathrm{a}$, internecine, internal

intimación, intimation intimar, to intimate intimidar, to intimidate, frighten intimo, $-a$, intimate, internal intrépido, $-\mathbf{a}$, intrepid, fearless

intriga, intrigue intrínseco, $-\mathbf{a}$, intrinsic introducir, to introduce inundación, flood inundar, to flood inusitado, -a, unwonted inútil, useless inutilidad, uselessness inutilizar, to make uscless inútilmente, usclessly invadir, to invade invariable, invariatle, unmovable

invasión, invasion invasor, -ora, a. and s., conquering, invading; invader

invencible, invincible invención, invention inventar, to invent invernal, of winter, wintry invertir, to take up, invest investidura, investiture investigación, investigation investigador, investigator inveterado, $-a$, inveterate invierno, winter invisible, invisible invitación, invitation invitar, to invite invocar, to invoke involucrar, to involve, take in, envelop

involuntario, $-\mathbf{a}$, involuntary ir, to go ira, wrath, anger iris, m., rainbow ironía, irony irreal, unreal irreconciliable, irreconcilable irregular, irregular irreparable, beyond repair, irreparable

irresistible, irresistible

irrevocable, beyond recall, irrevocible

irritar, to initate, excite

irrupción, cruption, breaking forth; hacer - en, to rush into 
isba, Russian log-cabin, peasant's house

isla, island

islote, $m$., islet

Italia, Italy

italiano, - a, a. and s., Italian

izar, to raise, hoist

izquierdo, $-a$, left

\section{$\mathrm{J}$}

jabonoso, $-\mathbf{a}$, soapy, lathery

jactar, to praise; - se, to

boast

jaguar, m., jaguar, American

tiger

jaleo, Andalusian dance

jamás, never

jardin, $m$., garden

jazmin, m., jasmin

jefe, chief, leader

jerarquia, hierarchy, rank

jerez, $m$., sherry wine

Jerusalén, Jerusalem

jilguero, linnet

jinete, rider, horseman

Job, Job

jornada, day, journey, day's

march, stopping place

jornal, $m$., wage, earning

jorobado, -a, a. and s., hump-

backed ; hunchback

Josê, Joseph

joven, young

juanete, $m$., cheek bone

judicial, judicial

judio, Jew juego, play, game; gambling juez, judge

jugar, to play; to gamble

juguetear, to gambol, leap, frolic

juicio, judgment

julio, July

junco, rush, weed

junio, June

junta, junta, council, governing body

juntar, to amass, get together, join

junto, $-\mathrm{a}$, together

juramento, oath

jurar, to swear

justa, joust, tourney

justicia, justice; police; court of justice

justicieramente, justly, according to justice

justiciero, -a, justice-dealing, just

justificar, to justify, prove

justo, $-a$, just

juvenil, young, juvenile

juventud, youth

juzgar, to judge

\section{K}

kakuy, Quichua Indian name for owl

kilómetro, kilometer, nearly five-eighths of a mile

Korán, m., Koran, sacred book of the Mohammedans 


\section{L}

laberinto, labyrinth, maze labio, lip

labor, $f$., work; hardship laboratorio, laboratory

laboriosidad, laboriousness, industry

labrador, tiller of the soil

labranza, tillage

labrar, to create, bring about

labriego, tiller of the soil

laconismo, laconism, brevity

lácteo, -a, milky

ladera, slope, declivity

lado, side

ladrillo, brick

ladrón, m., thief

lago, lake

lágrima, tear

laguna, pool, pond

lamentable, lamentable

lana, wool

lance, m., opportunity ; cast, throw

lancha, boat, launch

lanchero, boatman

landa, heath, moorland

languidecer, to languish

lánguido, $-\mathrm{a}$, languid

lanudo, a, woolly

lanza, lance

lanzada, lance-thrust

lanzafuego, linstock

lanzar, to hurl, cast, pour out lapacho, a South American tree

largamente, at length

largo, -a, long; a lo -, along

lástima, pity, hurt

lastimar, to hurt

lastimero, $-a$, sad, doleful

lastimoso, -a, pitiable, pitiful

latente, latent

latido, beating, beat

látigo, whip

latinoamericano, -a, a. and s., Latin-American

latir, to throb, beat

latitud, latitude

laurel, m., laurel, praise; laurel tree

lavandera, washerwoman

lavar, to wash

lazo, trap; lasso

leal, loyal, frank, trustworthy lealtad, loyalty, magnanimity

lección, lesson

lector, m., reader

lectura, reading

leche, $f$., milk

lechero, milkman

lechiguana, wasp

lecho, bed

leer, to read

legendario, -a, legendary

legión, legion

legislación, legislation

legislador, legislator

legislativo, $-a$, legislative 
legislatura, legislature

legítimo, -a, legitimate

legua, league, abeut three miles

lejano, -a, distant, past

lejos, far; a lo - , in the distance, from afar

lengua, tongue

lentamente, slowly

lentitud, lentitude, slowness

lento, $-\mathbf{a}$, slow

león, m., lion

leonado, $-\mathrm{a}$, lion-like

lerdo, -a, heavy, slow

letanía, litany

letra, letter

letrero, sign, poster

leva, levy

levadizo, $-\mathbf{a}$, capable of being lifted

levantar, to raise; - se, to arise, get up

leve, light, gentle

leviatán, $m$., leviathan

ley, $f$., law

leyenda, legend

liberal, liberal, free

libertad, liberty

libertador, -ora, a. and s., liberating; liberator

libertar, to liberate

librar, to free, deliver, occur, engage in

libre, free, unhampered

licor, $m$. , liquor, cordial

lid, $f$., fight, strife lienzo, cloth, linen, canvas

ligadura, bond, knot

ligar, to bind, join

ligereza, lightness, speed, trifle

ligero, - a, light, fast

limitar, to limit, confine

límite, $m$., limit, boundary

limitrofe, limiting, bounding

limosna, alms, charity

limpiar, to clean out

lincolniano, - a, of Lincoln

lindero, boundary, confine

lindero, - a, contiguous, bordering upon

lindo, $-a$, pretty

linea, line

lineamento, lineament, feature

linfa, water

linternilla, small lantern

liquidación, liquidation, settlement

lira, lyre

lírico, -a, lyric

Lisboa, Lisbon

liso, $-\mathrm{a}$, smooth

listo, -a, ready, clever

literalmente, literally

literario, -a, literary

literato, litterateur, man of

letters

literatura, literature

lives: boleada a -., brought down with light bolas; $V$.

note, 64,5

liviano, $-a$, light

livido, - a, livid 
lóbrego, -a, dark, dismal

local, local

local, m., place; - de esquina, corner-house

localidad, locality

loco, -a, mad

locomotiva, Arg. for locomotora, locomotive

locro, Arg., stew made with meat and vegetables, especially corn

locura, madness

lógica, logic

lógico, -a, logical

lograr, to succeed, obtain

lomo, loin, back

lona, canvas

longevidad, longevity

loor, m., praise

lote, $m$., lot, amount

lotero, lottery agent

loza, china, porcelain

lozamía, luxtiriance, vigor

lozano, -a, luxuriant, sprightly

lucero, star

lucido, -a, fimors, shining

luctuoso, -a, sad, mournful

lucha, struggle, fight

luchar, to struggle, fight

luego, soon, after, then; desde -, at once, from now on

lugar, m., place

lugarteniente, licutemant

ligubre, lugubrious, dismal

lajo, luxury
Lules, Indian tribe formerly inhabiting central Argentina

luminoso, $-\mathrm{a}$, luminous

luna, moon

lustroso, $-\mathrm{a}$, lustrous

luto, mourning, grief

luz, f., light, luster; pl., enlightenment

\section{L1}

llamar, to call

llano, plain

llanto, wail, sorrow

llanura, plain

llegar, to arrive, reach; - a, to arrive at, succeed in, happen

llenar, to fill

lleno, -a, full

llevar, to carry, wear; - se, to carry away

llorar, to weep, lament lluvia, rain

\section{M}

machete, m., cutlass madera, wood, timber madero, beam, timber madrasta, stepmother madre, mother madrigal, m., madrigal madurar, to ripen madurez, maturity maestria, mastery, skill maestro, master, teacher 
magallánico, -a, of Magellan mágico, $-\mathbf{a}$, magic

mágico, magician

magistrado, magistrate, official

magnanimidad, magnanimity magnánimo, -2 , magnanimous magnético, -a, magnetic magnificencia, magnificence magnífico, -a, magnificent magnitud, magnitude magno, $-a$, great mago, wise man, magus magro, -a, meager, lean Mahoma, Mahomet maíz, $m$., corn majestad, majesty majestuosamente, majestically

majestuoso, -a, majestic majo, Andalusian type, vain and ostentatious in his dress. Cf. compadrito mal, evilly, badly mal, m., evil, disease maldecir, to curse maldición, curse maldito, $-\mathbf{a}$, cursed maléfico, -a, evil malévolo, evildoer maleza, thicket, brush malhechor, evildoer maligno, -a, malignant malísimo, $-a$, very bad malogrado, -a, unfortunate, ill-fated malón, m., Arg., Indiann raid malvado, $-\mathbf{a}$, wicked, vicious mamá, mother, mamma manada, herd, drove manantial, $m$., spring, fountain manar, to run forth, distill, spring forth

mancebo, youth

mancha, spot, stain

mandar, to order, send

mandatorio, agent

mando, command, order, power

mandolina, mandolin

manejar, to manage, wield

manejo, management

manera, way, manner

maniatar, to bind, trip, shackle, manacle

manifestación, sign, manifestation

manifestado, -a, manifest, open

manifestar, to make clear, show

maniobra, maneuver

mano, f., hand; - a amicably

mansión, mansion

manso, -a, mild, tame

manta, mantle, blanket, cover mantener, to maintain, suffer, support

mantenimiento, maintenance manuscrito, manuscript manzana, apple; city block 
mañana, morning; por la in the morning mañana, tomorrow mapa, $m$., map máquina, machine mar, $m$. or $f_{.}$, sea maraña, brier thicket maravilla, wonder maravillosamente, marvelously

maravilloso, $-\mathrm{a}$, marvelous marca, mark, brand marcar, to mark, brand, delineate marco, frame marcha, march, course, progress

marchanta, Arg. for parroquiana, customer, patron marchar, to march narchito, $-a$, wilted, withered marea, tide mareo, seasickness margen, $f$., margin, bank marido, husband marinero, sailor marino, $-\mathbf{a}, a$. and s., marine; sailor mariposa, butterfly mariscal, m., marshal marisco, shellfish marítimo, a, maritime mármol, m., marble Marte, Mars mártir, m., martyr martirio, martyrdom marzo, March mas, but mâs, more; - bien que, rather than; a - besides masa, mass, multitude, power; en -, in a body mascar, to chew máscara, mask mástil, m., mast mata, shrub matar, to kill mate, m., South American a, drunk from a gourd with a tube called bombilla materia, matter material, material material, $m$. , material, stuff matiz, m., color matorral, m., brier thicket matrimonio, matrimony matrona, matron mayo, May mayor, greater, older mayoría, majority mayormente, specially, mostly inazorca, ear of corn mecánica, mechanics mecer, to stir, mix mediados, restricted to the expression a - de, about, toward the middle of mediano, $-\mathrm{a}$, middle mediar, to measure, stretch, be at the middle medida, measure; a - que, in proportion as 
medio, way, means, environment; en - de, in the midst of

medio, $-\mathrm{a}$, half

mediodia, m., midday, south

medioeval, medieval

medir, to intervene, lie; measure

meditabundo, $-\mathrm{a}$, pensive meditación, meditation meditar, to meditate meditativo, $-a$, meditative Mediterráneo, Mediterranean Sea

mediterráneo, $-a$, of the Mediterranean

medroso, $-a$, fearful, timid mefítico, -a, obnoxious, mephitic

megaterio, megatherium, extinct species of prehistoric animals, remains of which are found in the Pampas Méjico, Mexico mejilla, cheek mejor, comp. of bueno, better mejora, amelioration, progress

mejoramiento, betterment mejorar, to better melancolia, melancholy melancólico, -a, sad, melancholy melena, mane, shock of hair melero, $-\mathbf{a}$, of honey, honeylike melodía, melody memorable, memorable memoria, memory, mind mendigo, beggar menester, $m$., necessity; ser -, to be necessary

menor, comp. of pequeño, smaller

menos, less; a - que, unless; por lo - , at least menoscabo, discredit, lessening mensaje, $m$., message mensajero, messenger mentalmente, mentally mente, $f$., mind mentir, to lie, tell a lie mentira, lie, fiction menudeo, retail; comercio al -, retail trade

meollo, substance, inside, heart of anything, marrow mercader, merchant, shopkeeper mercadería, merchandise mercado, market mercancía, merchandise merced, f., mercy, grace; a, thanks to mercenario, mercenary merecer, to deserve mérito, merit meritorio, $-\mathbf{a}$, meritorious mes, m., month mesa, table mesana, mizzen; pena de la -, peak of the mizzen 
meseta, plateau, landing place mesita, small table mestizo, half-breed meta, terminus, end metafísico, -a, metaphysical metafórico, -a, metiphorical metal, $m$., metal

metamorfosis, $f_{\text {., }}$ metamorphosis

meter, to put, place, drive metódico, -a, methodical metralla, grapeshot metro, meter metrópoli, $f_{\text {., }}$ metropolis, mother country

mezcla, mixture

mezclar, to mix, confuse mezquino, -a, mean, niggardly

microscópico, -a, microscopic miedo, fear miel, $f$., honey miembro, member mientras, while; - tanto, meanwhile; - que, while miguelete, $m$., rural guard mil, a thousand milagro, miracle milagrosamente, miraculously milicia, militia, military affairs

militante, militant, agrgressive

militar, to serve in an army militar, military militar, soldicr milla, mile millar, a thousand millonario, millionaire mimar, to take care of, caress, fondle, pamper mina, mine

Mingo, tribe of Indians mentioned in The Last of the Mohicans

ministro, minister, servant minuto, minute miñôn, m., light infantry; soldier of same miquilo, Indian name for nutria, otter

mira, intention, purpose, point mirada, look, glance mirar, to look at, regard misa, mass misántropo, misanthrope, man-hater miserable, miserable, pitiful miseria, misery mísero, -a, wretched, mean misión, mission misionero, missionary misiva, missive, note mismo, -a, self, same, even; lo - que, the same as misterio, mystery misterioso, - a, mysterious mistol, m., jujube, name of a fruit mitad, half mi 0, myth mixto, explosive 
modal, m., generally used in the plural, manners

modalidad, manner of being, modality, manifestation moderación, moderation, restraint

moderar, to moderate moderno, $-\mathbf{a}$, modern modesto, - a, modest, unassuming

modificación, modification modificar, to modify modo, manner, fashion; de - que, so that; de tal -, in this manner, in such manner; de todos $-s$, in any case; de otro --, otherwise

molestar, to molest, disturb molestia, bother, discomfort molesto, -a, bothersome, uncomfortable

momentáneamente, momentarily momentáneo, -a, momentary momento, moment, instant monarca, $m$., monarch monarquía, monarchy monarquista, monarchist, monarchical monástico, --a, monastic moneda, coin, money morje, monk monosílabo, monosyllable monotonía, monotony monótono, $-\mathbf{a}$, monotonous monstruo, monster

monstruoso, - a, monstrous, tremendous montaña, mountain montar, to mount monte, m., mountain, wood montés, -esa, of the mountain; gatos -eses, wildcats montesino, -a, mountainous, wild,

monto, sum, amount

montón, m., pile

montonera, Arg., mounted insurgent band

montonero, member of a montonera

montura, saddle, trappings, mount

monumento, monument morado, house, dwelling moral, moral moral, $f$., morale, morality moralmente, morally, practically

morar, to live, dwell morder, to bite, gnaw moreno, -a, dark-complexioned

moribundo, -a, dying morir, to die; - se, to be dying

moro, -a, a. and s., Moorish ;

Moor; $A r g .$, blue-roan morocho, $-\mathrm{a}$, brunette, darkcomplexioned morro, bowlder, cliff 
mortal, a. and s., mortal

morueco, ram

mostrador, m., counter, demonstrator

mostrar, to show

motejar, to ridicule, censure

motín, $m$, riot, uprising

motivar, to cause

motivo, motive; con - de,

with regard to

mover, to move, excite

móvil, varying

móvil, m., cause, motive

movimiento, movement, motion

mozo, youth, attendant;

de mula, stableboy

muchacha, girl

muchacho, boy

muchachuelo, small boy

muchedumbre, $f$., crowd

mucho, $-\mathrm{a}$, much

mucho, adr., much

mudanza, change, step of a dance

mudar, to change, move

mudo, $-a$, mute

muelle, m., pier, fuay, dock

muerte, $f_{\text {., death }}$

muerto, -a, dead

mugir, to bellow, roar

mugir, m., bellow, roar

mujer, woman, wife

mula, mule

mulato, -a, mulatto

mulita, armadillo; little mule multiforme, multiform, of many forms

multiplicar, to multiply

multitud, multitude

mundial, of the world, world-

wide

mundo, world

munición, ammunition

municipal, municipal

muralla, wall

murallón, m., battlement

murmullo, whisper, murnur.

murmurar, to murmur, grum-

ble

muro, wall

musa, muse

muscular, muscular

muselina, muslin

música, music, band

músico, musician

músico, -a, musical

musitar, to whisper, chant

mutuamente, mutually

muy, very

$\mathrm{N}$

nácar, $m$., mother-of-pearl

nacer, to be born

naciente, rising

nacimiento, birth

nación, nation

nacional, national

nacionalidad, nationality

nada, nothing

nada, not at all

nada, $f$, nothingness 
nadar, to swim

nadie, no one

naipe, $m$. playing card

napolitano,-a, Neapolitan

naranja, orange

naranjo, orange tree

nariz, $f$., nose

narrador, narrator

narrativo, -a, narrative

natal, native, natal

nativo, $-a$, native

natural, a. and s., natural; native

naturaleza, nature, natural scenery

naturalidad, naturalness

naturalmente, naturally

naufragar, to come to grief, shipwreck

náufrago, -a, shipwrecked

nave, $f$., ship

navegación, navigation

navegante, navigator

navegar, to navigate

navio, ship

náyade, $f$., naiad

neblina, fog, mist

nebuloso, $-\mathbf{a}$, nebulous

necedad, foolishness

necesariamente, necessarily

necesario, $-\mathbf{a}$, necessary

necesidad, necessity, need

necesitar, to need

néctar, $m$., nectar

nefasto, $-a$, ill-fated

negar, to deny negativo, -a, negative

negligencia, negligence

negocio, business, affair

negro, -a, black, gloomy

negrusco, $-\mathbf{a}$, blackish

neófito, neophyte, beginner, convert

nervioso, -a, nervous, eager, strong

netedad, clarity, conciseness

neumático, $-a$, pneumatic

nevado, -a, snowy, snowladen

ni, nor

nido, nest

niebla, mist, cloud

nieve, $f$., snow

ninfa, nymph

ninguno, -a, not any, no;

no one

niña, girl

niño, child, boy

nitidez, neatness, sharpness

nivel, $m$., level

nivelar, to level

no, no, not

noble, noble

noblemente, nobly

nobleza, nobility

noción, notion

nocturno, -a, nocturnal

noche, $f$., night; en la cerrada, in the thick of night

nómada or nómade, adj.: nomad 
nombradia, renown

nombre, $m$., name

nomenclatura, nomenclature nominal, nominal, titular nordeste, $m$., northeast norma, norm, standard normal, normal

noroeste, $m$., northwest norte, m., north; guide norteamericano, -a, North American

noruego, -a, Norwegian nota, note notable, notable notar, to note, remark noticia, notice; pl., news notorio, $-\mathbf{a}$, well-known novedad, novelty novel, novel, new novelesco, $-\mathrm{a}$, novel-like noventa, ninety nube, $f$, cloud núcleo, nucleus nudo, knot nuestro, $-\mathrm{a}$, our nuevamente, again, ancw nueve, nine nuevo, -a, new; de nuevo, again

numen, m., musc, poctic inspiration

número, number

numerosísimo, -a, very numerous

numeroso, -a, numerous, prolific nunca, never

nupcial, nuptial

nutrir, to nourish

O

o, or, either

oasis, m., oasis

obedecer, to obey

obediencia, obedience

obispo, bishop

objeción, objection

objeto, object, article, aim

oblicuo, -a, oblique

obligación, obligation, duty

obligado, -a, necessary, obliged, inevitable

obligar, to oblige

obligatorio, -a, obligatory

obra, work

obrar, to work; - se, to take place

obrero, workman

obscuridad, darkness

obscuro, -a, dark

obsequiar, to entertain ; to show cordiality

obsequioso, -a, obsequious, officious

observación, observation, remark

observador, observer

observar, to observe, remark

obstáculo, olstacle

obstante, withstanding: used generally weith no, no notwithstanding 
obstinación, obstinacy

obtener, to obtain

obús, m., howitzer

ocasión, occasion

ocasional, accidental

ocasionar, to cause

ocaso, sunset

occidente, $m_{\text {., west }}$

oceánico, -a, oceanic

ociosidad, laziness

octava, stanza of eight verses

octosilábico, -a, octosyllabic, of eight syllables

octosílabo, verse of eight syllables

ocultar, to hide

oculto, $-\mathbf{a}$, hidden

ocupaciôn, occupation

ocupar, to occupy, employ

ocurrencia, occurrence, unexpected thought

ocurrir, to occur; to hasten

ochenta, eighty

ocho, eight

odio, hatred

oeste, $m$., west

ofender, to offend

oficial, official

oficial, officer, official

oficina, office, bureau

oficio, office, occupation, service, duty

ofrecer, to offer

ofrecimiento, offer

ofuscación, bewilderment, confusion ofuscar, to bewilder, confuse oido, ear, sense of hearing oír, to hear ojiva, ogive, vaulted arch ojo, eye

ola, wave

oleada, surge, swell

oleaje, m., wave motion, waves

oler, to smell

olímpico, -a, olympic, gigantic

olor, $m$., odor

olvidar, to forget

olla, kettle, pot

ollita, diminutive of olla

ombú, m., ombú, tree of the

Pampas

omitir, to omit

omnipotente, all-powerful

once, eleven

onda, wave

ondulación, undulation

ondular, to undulate, sway

oneroso, -a, burdensome

onza, ounce

opaco, -a, opaque

operación, operation

operar, to operate; Arg. for

obrar, to act

opinar, to think, opine

opinión, opinion

opio, opium

oponer, to oppose

oportunamente, opportunely

oportunidad, opportunity, 
time; de -, opportune, befitting the occasion oportuno, -a, timely, oppor-

tune oposición, opposition opresión, oppression opresor, oppressor oprimir, to oppress oprobio, shame, opprobrium optimismo, optimism optimista, a. and s., optimistic; optimist opuesto, -a, opposed, contrary oración, prayer orden, $f_{\text {., order, command }}$ orden, m., orderliness, order (rotation), class; en-a, in order to ordenado,-a, orderly, peaceful ordenanza, $f$., order ordenanza, m., orderly ordenar, to order ordeñar, to milk ordinario, $-\mathrm{a}$, ordinary; de -, ordinarily

oreja, ear orejano, -a, Arg., unbranded organismo, organism, social order organización, organization, arrangement . organizador, organizer organizar, to organize órgano, organ, moutlipiece, means orgía, orgy orgullo, pride orgullosamente, proudly orgulloso, -a, proud oriental, a. and s., Oriental; Uruguayan orientar, to orient, orientate; - se, to take one's course, get one's bearings oriente, m., Orient; luster (of pearls) origen, $m$, origen original, original, primitive, odd originalidad, originality originalmente, originally, in an original manner orilla, border, margin, shore; suburb orillero, -a, a. and s., Arg., pertaining to the suburbs of a city; suburban dweller Orinoco, river in northern South America orla, fringe, hem, border oro, gold; - de buena ley, genuine gold, warranted gold, gold of standard weight osadía, boldness osado, -a, daring osamenta, bones, skeleton osar, to dare oscilación, oscillation oscurecer, to darken ostentación, ostentation 
otomano, -a, Ottoman

ostracismo, ostracism

otro, -a, other, another

ovación, ovation

ovalado, -a, oval

óvalo, oval

\section{P}

pabellón, m., standard, banner pacer, to feed, graze paciencia, patience paciente, patient pacientemente, patiently pacíficamente, peacefully pacificar, to pacify pacífico, -a, peaceful Pacífico, Pacific Ocean pacto, pact padre, father pagar, to pay; - una visita, to return a visit página, page pago, payment pago, $A r g$., haunt, district país, $m$., country paisaje, $m$., landscape paisano, civilian, fellowcountryman; Arg., countryman

pájaro, bird palabra, word palacio, palace paladar, m., palate paladín, $m$., paladin palanca, bar, lever; - corrediza, pulley palenque, $m$. palisade paleta, palette; shoulder blade

paletada, blow dealt with a palette

palidecer, to become pale pálido, $-a$, pale palma, palm tree, palm palmo, unit of measure, span; - a - inch by inch palo, pole, stick, mast palpable, palpable palpar, to feel, grope along palpitante, quivering palpitar, to beat, palpitate palla, countrywoman Pampa, name given to the plains of Argentina pampeano, $-\mathbf{a}$, of the Pampa pan, $m$., bread; tierras de llevar, grain-producing lands panaderia, bakery panal, $m$., honeyconb panamericano, -a, Pan-American pangaré, m., Arg., bay horse panorama, $m$. , panorama pantano, puddle, marsh panteísmo, pantheism pantera, panther pantorrilla, calf of the leg pañuelo, handkerchief papal, papal papel, m., paper; rôle far, m., pair; a la -, to- 
gether, jointly, at the same time

para, for, in order to; con, toward

Paraguay, m., river in South

America, tributary of the

Paraná

paraíso, paradise

paraje, m., place, stopping-

place

paralizar, to paralyze

parapeto, parapet

parar, to stop, ward off

parásito, -a, parasitic

parcial, partial

parecer, to seem, appear;

-se, to resemble

parecido, -a, similar

pared. f., wall

pareja, pair, couple; partner parejero, Arg., courser, fast

horse

paréntesis, m., parenthesis, interval

pariente, $m_{\text {. }}$, relative

parlamentarjo, -a, $a$. and s.,

parliamentary ; envoy

parquedad, paucity, parsimony

parroquia, parish

parroquiano, patron, cus-

tomer

parte, f., part, direction, side;

por otra-, on the other

hand: por una -, on the

one hand participar, to participate, share, inform

particular, m., individual;

topic, detail

particular, special, private

particularmente, particularly partida, squad, rural patrol, departure, group

partidario, commander, partisan

partido, side; tomar -, to decide

partir, to leave; to split

párvulo, -a, a. and s., small;

child

pasacana, cactus fruit

pasado, past

pasaje, $m$., passage, deed

pasajero, $-\mathbf{a}, a$. and s., pass-

ing; passenger

pasar, to pass; to happen

pasatiempo, pastime

pasear, to stroll

pasión, love, passion, anger

pasivo, - a, passive

paso, step, way, pace; de-,

in passing; a or en -, on

the way; a - de carrera,

on the rum; al - que,

at the same time that, as

pasta, paste

pastar, to feed, grime

pastizal, m., pasture land

pasto, griss

pastor, shepherd 
pastor, pastoral

pastora, shepherdess

pastoril, pastoral

pata, foot, hoof

patada, kick

patán, -ana, a. and s., churlish ; lout, "hayseed"

patentemente, openly

paternalismo, paternalism

paternalmente, paternal $y$

paterno, -a, paternal

patético, - a, pathetic

patio, courtyard

patria, fatherland

patriarca, $m$. , patriarch

patricio, -a, patrician

patrimonio, patrimony, heri-

tage

patriota, m., patriot

patriotismo, patriotism

patrón, owner, master, "boss" patrona, housewife, mistress

pausa, pause

pava, turkey hen

pavor, $m$., fear

pavoroso, -a, fearful, awful payada, $A r_{s}^{g}$., improvisation ;

- de contrapunto, contest

in improvisation

payador, improviser, minstrel payar, to improvise

paz, $f$., peace

pecado, sin

pecar, to sin

peculiar, peculiar

peculiaridad, peculiarity peculio, stock, capital, allowance

pecho, chest, breast

pedazo, piece; hacer-s, to

break to pieces

pedestre, pedestrian

pedido, demand, asking

pedigüieño, -a, alms-seeking, beggarly

pedir, to ask

pedregoso, -a, rocky

Pedro, Peter

pegar, to stick, to strike

pelambrera, hair

pelear, to fight

peligro, danger

peligroso, -a, dangerous

pelo, hair, color of horse

pelota, ball

pelotón, m., platoon; en pslo-

tones, in platoon formation peludo, -a, hairy

pena, punishment, pain

penalidad, penalty, hardship

pendenciero, $-\mathrm{a}$, quarrelsome

pendiente, $f$., slope

pendón, m., flag, pennant

penetrar, to pierce, pene-

trate

península, peninsula ; Península, Spain

peninsular, peninsular, Spanish

penosamente, slowly, pain-

fully

pensador, thinker 
pensamiento, thought

pensar, to think; - en, to

think of

pensativo, $-a$, pensive

pensil, hanging, supported pensil, $m$., enchanted garden penumbra, penumbra, gloaming

penuria, penury

peñón, $m$., rock, cragr

peón, $m$., peon, laborer;

de arria, drover

peor, comp. of malo, worse

pequeñez, smallness

pequeño, $-a$, small

pequeñuelo, $-\mathbf{a}$, dim. of pe-

queño, smallish

pequín, $m$., silk from Pekin

peral, $m$., pear tree

percal, $m$. , percale

percatarse, to be aware

percibir, to perceive

perder, to lose, ruin

pérdida, loss, destruction

perdiz, f., partridge

perdón, m., pardon

perdonar, to pardon

perdurar, to last

perecer, to perish

peregrinación, pilgrimage

peregrinar, to wander

peregrino, wanderer

perezoso, $-\mathrm{a}$, lazy

perfección, perfection

perfeccionarse, 10 beconc perfect perfectamente, perfectly perfecto, $-a$, perfect perfil, $m$., outline, profile perfumar, to perfume perfume, $m$., perfunse perifêrico, -a, peripheric, superficial periódico, newspaper periodístico, $-a$, journalistic periodo, period peri, $f_{\text {, }}$ peri, fairy in Persian mythology peristilo, colonnade perjuicio, damage, detriment perla, pearl

permanecer, to remain permanente, permanent permitir, to permit

Pernambuco, seacoast city of Brazil pero, but

perpendicular, perpendicular perpendicular, $f_{\text {., }}$ perpendicular

perpetuo, $-\mathrm{a}$, perpetual

persecución, persecution

perseguidor, persecutor, pursucr

perseguir, to persecute, pursue

persistir, to persist

persona, person

personaje, m., personage, character, hero

personal, personal

personalidad, personality 
personalismo, personal pride, individuality, personality personificación, personification perspectiva, perspective, prospect

persuadir, to persuade, convince

pertenecer, to belong perteneciente, belonging pertinacia, perseverance, tenacity pertinaz, obstinate, tenacious peruano, -a, Peruvian perversidad, perversity perverso, $-\mathbf{a}$, perverse pervertidor, -ora, perverting pesadez, gravity, weight, heaviness pesadilla, nightmare. pesado, -a, heary pesar, to weigh, cause sorrow pesar, m., sorrow; a de, in spite of pescador, fisherman pescar, to fish, catch pesebre, $m$., manger, christening, feast peso, dollar (the Argentine peso is worth about 45 cents in American money); weight

pesquisa, inquiry, search peste, $f$., pestilence pestífero, -a, pestiferous, venomous pétalo, m., petal piadoso, -a, pious, tenderhearted piano, piano picaflor, $m$., humming bird picaro, rascal, rogue pico, pick; beak; small amount; peak

Pichincha, m., volcano in Ecuador pie, $m$., foot piedad, pity piedra, stone piel, $m$., skin pierna, leg pieza, piece of furniture, piece of cloth; part piloto, pilot pinar, $m$. , pine grove pincelada, stroke with a brush, line pinchar, to pinch, prick pingüelo, depreciative diminutive for pingo, which is an Argentinism for "horse", nag

pino, pine pintar, to paint pintarrajeado, -a, painted, daubed

pintura, picture, painting piquete, m., picriet pirámide, $f$, pyramid pisada, footprint pisar, to tread; - con la punta del pie, to tread on tiptoes 
piso, pavement, floor;

bajo, ground floor

pista, trace, trail

pitón, $m$., python

placer, m., pleasure; placer

placidez, placidity

plácido, -a, placid, gentle

plagiar, to plagiarize, copy

plan, $m$., plan

planetario, -a, planetary

planicie, $f$., plain

plano, plan, design

plano, -a, level

planta, plant, foot, step

plantador, planter

plantar, to plant

plantear, to establish, enact

plañidero, $-a$, mournful

plañir, to mourn

Plata, $m$., river in Argentina

plata, silver; Arg., money

playa, shore, heach

plaza, square, stronghold;

Plaza de Toros, Bull Ring plazoleta, dim. of plaza

plebe, $f$., populace

plegaria, prayer

pleito, lawsuit

plenamente, fully

plenitud, fullness

pleno, $-a, f u l l$

pluma, feather; pen

pluvioso, - a, miny

población, town, population, settement

poblado, a, thick, populous poblado, inhabited place, town, village

poblador, settler

poblar, to populate

pobre, poor

pobreza, poverty

poco, m., small part, little;

pl., few

poco, ads, little, in a small

degree

poco, -a, little, scanty

poder, to be able

poder, $m$., power, ability

poderio, power, influence

poderoso, $-\mathbf{a}$, powerful

poema, $m$., poem

poesía, poetry, poem

poeta, m., poet

poético, -a, poetic

polarizar, to polarize, turn

policia, police

policromo, -a, many-colored

política, policy, politics

políticamente, politically

político, -a, political

polo, pole

polvo, dust

polvoriento, $-\mathbf{a}$, dusty

pollo, chicken

pompa, pomp

pomposo, a, pompous

poncho, poncho

poner, to place, locate; -se

en 1$)$ de pie, to stand up;

- se, to put on; to be-

conte; - se a, to begin 
popa, poop, stern

popular, popular

popularidad, popularity

popularizar, to popularize

por, in order to, by, on account of, through, for ;

- ... que, however ...;

¿- qué? why?

porción, portion

pormenor, $m$., detail

porque, because

porte, m., bearing, carriage

portentoso, $-\mathrm{a}$, wonderful

porteño, -a, pertaining to

Buenos Aires, inhabitant

of Buenos Aires

portezuela, door

pórtico, portico

portillo, lane

porvenir, $m$. , future

posar, to rest, lay

poseer, to possess

posesión, possession

posibilidad, possibility

posible, possible

posición, position

positivo, -a, positive, definite,

binding, efficient

posteridad, posterity

posterior, later

postrarse, to prostrate oneself

postrero, $-\mathrm{a}$, last

póstumo, $-\mathrm{a}$, posthumous

postura, posture

potencia, power

potente, potent, powerful potro, colt, unbroken or wild

horse

poyo, bench

pozo, well

práctica, practice

practicar, to practice, use

práctico, -a, practical, ex-

perienced

pradera, meadow

preboste, m., leader, chief

precaución, precaution

precedente, $m$., precedent

preceder, to precede

precio, price

precioso, $-\mathrm{a}$, precious

precipicio, precipice

precipitación, precipitation

precipitadamente, precipi-

tously

precipitar, to precipitate, rush precisamente, necessarily ;

exactly, precisely

preciso, $-\mathrm{a}$, necessary, precise precoz, precocious

predecesor, predecessor:

predicación, preaching, ser-

mon, prayer

predicar, to preach

predilecto, $-\mathbf{a}$, favorite

predisponer, to predispose,

prepare

predisposición, predisposition, inclination

predominante, predominant.

dominant

predominar, to predominate 
predominio, predominance prefacio, preface preferencia, preference preferente, preëminent, favorite preferir, to prefer preguntar, to ask prehistórico, $-\mathbf{a}$, prehistoric prematuro, -a, premature premio, reward prenda, jewel, token, ornament, endowment; $A r g$, sweetheart

prendar, to infatuate, captivate

prender, to seize, take hold, imprison

prensa, press

preñado, -a, pregnant, full preocupación, preoccupation;

fancy, notion; prejudice preocupar, to preoccupy, disturb

preparar, to prepare preparativo, preparation presciencia, prescience, foreknowledge

prescindir, to do without; to

omit ; to pass over presencia, presence, appear-

ance

presenciar, to witness presentar, to present presentimiento, presentiment, forcboding presidencial, presidential presidente, president presidir, to preside presión, pressure, restraint prestar, to lend prestidigitador, juggler, prestidigitator prestigio, prestige prestigioso, -a, deceitful; famous

presunción, presumption presuroso, -a, hurried, in a hurry

pretender, to pretend, woo, claim, expect prevalecer, to prevail prevención, foresight, disposition, prejudice prevenir, to forewarn, prepare

prever, to foresee previsión, foresight previsor, -ora, foreseeing prieto, -a, compressed; dark prima, treble string; cousin (girl)

primar, $A r g$, to stand out, take precedence over primario, -a, primary primavera, spring primaveral, springlike, vernal primeramente, first primero, $-a$, first primitivo, - a, primitive primordial, primitive, fundamental principal, principal 
principalmente, principally príncipe, prince principiar, to begin

principio, principle, beginning prisa, hurry prisiôn, prison; pl., chains, fetters prisionero, -a, prisoner privación, privation privado, confidant privado, -a, deprived; pri-

vate

privar, to deprive privativo, -a, exclusive, peculiar

privilegiar, to grant a privilege proa, prow, bow probabilidad, probability probablemente, probably probar, to prove, try problema, $m$., problem proceder, to proceed procedimiento, process, procedure, act

prócer, m., hero, personage, great man procesión, procession proceso, process, procedure proclamar, to proclaim, an-

nounce

procurar, to procure, try prodigalidad, prodigality prodigio, prodigy prodigioso, -a, prodigious producción, production, product producir, to produce; - - se, to emerge, rise producto, product, result proeza, prowess profano, -a, profane, lay profesar, to profess profesión, profession profesional, usual, professional

profeta, prophet próf ugo, fugitive profundamente, deeply profundidad, depth profundo, -a, deep, profound programa, m., program progresivo, $-a$, progressive progreso, progress prohibir, to prohibit prohombre, leader, notable person

prójimo, fellow-being. Cf. próximo

proligidad, prolixity, minute detail, nicety

prolongar, to prolong promesa, promise prometer, to promise prominente, prominent promontorio, promontory, abutment promotor, promoter promover, to promote, advance promulgar, to promulgate pronóstico, omen pronto, -a, ready 
pronto, immediately, soon; proteger, to protect

de -, suddenly protestar, to protest

pronunciar, to pronounce, de- provecho, advantage, profit,

clare

gain

propicio, -a, propitious

propiedad, propriety, prop-

erty, land; - raiz, real

estate

proveedor, purveyor

proveer, to provide

provenir, to come from, be derived

propietario, -a, $a$. and s., provenzal, Provençal, from

landowning: landowner, old French province of

proprietor

propio, -a, proper, own, pe-

culiar

proponer, to propose

proporción, proportion

proporcionar, to apportion,

furnish

proposición, proposition, plan propósito, proposition, pur-

pose: fuera de -, out of

place; $\mathbf{a}-$, appropriate;

by the way

prorrumpir, to break forth

prosa, prose

prosaico, -a, prosalic

Provence

próvido, -a, provident, diligent

provincia, province

provincial, provincial

provisión, provision

provocación, provociation

provocar, to provoke

proximidad, proximity

próximo, -a, next, near

proyecto, project

prudencia, prudence

prudente, prudent

prueba, trial, proof; a -,

proven, tested

proscribir, to proscribe, out- púa, barh, sharp point

law

prosperar, to prosper

prosperidad, prosperity

prosternarse, to prostratc onesclf

protagonista, m., protagonist,

chicf character in a narra-

tive or dramia

protección, protection

protector, putector

publicar, to publish

publicista, m., publicist, au-

thority on international law público, a, public

pueblo, people, town

puente, m., bridge, gangplank; levadizo, draw-

bridge

pueril, loyish

puerilizarse, to become boy ish 
puerta, door, gate

puerto, port, harbor, haven; tomar el -, to make port pues, therefore, then, well, but puesto, place, post, watch pugnar, to fight, strive pujante, powerful, rampant pulgar, $m$., thumb pulido, $-\mathrm{a}$, polished pulmón, m., lung pulpería, Arg., country store and bar

pulsar, to strike, beat puma, m., puma, American lion

punta, point

punto, point, place; de todo 一, entirely

punzante, sharp, bitter

punzantemente, poignantly, keenly

puñado, handful

puñal, $m$. , dagger

puñalada, dagger-thrust puño, fist

purgar, to purge, clear purísimo, $-\mathrm{a}$, very pure puro, -a, pure, sweet purpúreo, -a, purple

\section{Q}

que, that, which, who; a que, to the fact that; de que, of the fact that ¿qué? which? what? ¿ por-? for what reason? why? quebrada, ravine, opening quedarse, to remain quemar, to burn querencia, haunt, den querer, to wish, will querida, mistress querido, - a, dear, beloved quichuo, -a, pertaining to

Indians of Perú and northwestern Argentina; also applied to their lansuage

quiebra, crack, gap quien, who ¿quién? who? quienquiera, whoever quietamente, quietly quietito, -a, diminutive of quieto, -a, quiet quietud, quiet quilate, m., carat quimera, fancy, illusion quince, fifteen quinientos, five hundred quinta, farm, orchard quintilla, stanza of five verses quirquincho, armadillo quiste, m., cyst; apathy ;

stratum

quitar, to remove

Quito, capital of Ecuador quizâs, perhaps; also written quizá

\section{R}

rabioso, $-\mathrm{a}$, mad

ración, ration 
radiante, radiant

radicar, to take root

radio, radius

radioso, -a, radiant, beautiful

raiz, $f$. , root; propiedad -, real estate

ralear, to thin, diminish

rama, branch

ramaje, $m$., foliage, branches

rampa, slope

rancho, hut, food, mess

ranquel, $m$. , an Indian of the

Pampas of Argentina; generally used in the pl., and said of the tribe

rápidamente, rapidly

rapidez, rapidity

rapidisimo, $-a$, very rapid

rápido, -a, rapid

rapsodia, rhapsody

rapto, abduction, flight

raptor, thief, abductor

raquítico, -a, flimsy, nig-

gardly, consumptive

raro, -a, rare; rara vez,

rarely

rasar, to glide by, skim, hug rasgado, -a, large, full rasgar, to tear, rend rasgo, feature, trait rasgueo, twang rastreador, tracker, tracer rastrear, to trace, trail rastro, trace, trail ratificar, w) ratify rato, while, moment raudal, $m$., torrent, river rayo, ray, thunderbolt ; means raza, race

razón, $f$., reason; cambiar razones, to exchange words reaccionar, to react real, royal; real real, m., camp; coin of different values; in Argentina, a ten-cent piece

realidad, reality; caer en la -, to realize the truth

realista, royalist

realizar, to realize, carry into execution; -se, to take place

realzar, to heighten reanudar, to renew, resume reaparecer, to reappear reasumir, to reassume rebaño, flock

rebelde, a. and s., rebellious; rebel

rebosante, overflowing ebotar, to rebound, strike against

rebullir, to boil, seethe recaer, to fall back recalcitrante, recalcitrant recelo, suspicion, misgiving receloso, -a, suspicious recepción, reception receta, recipe, formula recibir, to receive reciente, recent 
recientemente (reciên before p. p.), recently, just

recinto, district, room

reciprocamente, reciprocally

recitado, recitative

recitar, to recite, chant

reclamación, claim, reclamation

reclamante, $a$. and s., claiming; claimant

reclamar, to claim

reclinar, to recline

reclutor, -ora, recruiting

recodo, bend

recoger, to seize, gather;

- se, to gather one's thoughts, meditate, retire

recogimiento,

meditation

recolección,

gathering

recomendación,

dation

reconcentrar, to concentrate,

survey, scan; -se, to

gather one's thoughts

reconocer, to recognize, re-

connoiter, examine, ac-

knowledge

reconocimiento, acknowledg-

ment, recognition

reconquista, reconquest

reconquistar, to reconquer

reconvención, reproach

recordar, to recall

recorrer, to traverse, cross recostar, to lean, recline

rectificar, to rectify

rectitud, rectitude

recto, -a, upright, direct

recuerdo, memory, remem-

brance

recurso, recourse, resource,

means

rechazar, to repulse

redactar, to draw up

redactor, editor

redimir, to redeem

redoblar, to double; a marcha

redoblada, at double quick

redoble, m., beat, rolling

redondo, $-a$, round

reducir, to reduce

reemplazar, to replace

referir, to tell, refer, connect

refinado, -a, refined

reflejar, to reflect

reflejo, reflection

reflección, reflection

refleccionar, to reflect

reflexivo, $-a$, reflexive

reforzar, to strengthen

refrenar, to curb, restrain

refrescante, cool, refreshing refriega, fray, combat

refrigerio, refreshment, food

regalarse, to regale oneself

regalo, present, pleasure, re-

galement

regar, to water

régimen, $m$., régime, order

regimiento, regiment 
regio, - a, royal

región, region

regir, to govern

registrar, to register, examine, check

regla, rule

regresar, to return

regular, regular, mediocre

rehacer, to make over; -se,

to recover

rehusar, to refuse

reinar, to reign

reincidir, to relapse

reír, to laugh: —se (de),

to make fun (of)

rejuvenecimiento, rejuvenation

relación, narrative, relation, connection

relacionar, to relate, connect relajar, to relax, become lax

relámpago, flaslı, lightning relativo, - a, relative relevar, to relieve

relieve, $m$., relief; de - , in relief

religión, religion

religioso, -a, religious

relincho, neigh, snort

reliquia, remain, relic

relleno, $-\mathrm{a}$, replete

remanso, stamnant water

remedar, to imitate, resemble remediar, to remedy

remo, war: hind- or forclegs of a beast (in this sense usually plural)

remolcador, $m$., tugboat

remontar, to remount, supply,

climb

remordimiento, remorse

remoto, $-\mathrm{a}$, remote

remover, to remove

remuda, relief, relay

remuneración, remuneration

rencor, rancor, hatred

rendija, opening, slit

rendir, to surrender, vanquish

renegar, to deny

renegrido, - a, blackened

renombre, $m$., renown

renovar, to renew

renta, rent, income

renuncia, renunciation

renunciar, to renounce

reo, $m$. and $f_{\text {., criminal }}$

reo, $-a$, guilty

repartir, to deal, distribute,

scatter

repeler, to repel

repente, m., mnexpected

event; de -, unexpectedly

repertorio, repertoire

repetición, repetition

repetir, to repeat

repiqueteo, beat, roll, jingle

replegar, to fold; - se, to

fall back

repleto, $-a$, replete

replicar, to reply

repoblación, repopulation 
repoblador, one who settles again

reponer, to repose, replace; - se, to recover

reposado, -a, restful, snug reposar, to rest, lie

reposo, repose

representación, representation

representante, $a$. and s., representative

representar, to represent

representativo, $-\mathbf{a}$, representative

represión, repression

reprimir, to repress

reproche, $m$., reproach, blemish

reproducir, to reproduce república, republic

republicano, $-\mathbf{a}, a$. and s., republican; citizen

repugnante, repugnant

reputación, reputation

requerir, to require

requiebro, compliment; echar

- s, to compliment

requisito, requirement res, $f$., beast, head of cattle resabio, vice, evil effect rescatar, to redeem, ransom resentimiento, resentment reseñar, to review, point out reserva, reserve reservado, - a, reserved reservar, to reserve resfuerzo, reënforcement residencia, residence residente, $a$. and s., residing; resident residir, to reside resignación, resignation resignar, to resign resistencia, resistance resistir, to resist resolución, resolution resolver, to resolve, solve resonar, to resound resorte, $m$., motive, resource respectivamente, respectively respectivo, $-a$, respective respecto, respect, relation; a este - , with respect to this; - de, with respect to

respetar, to respect respeto, respect respetuoso, -a, respectful respiración, respiration respirar, to breathe resplandecer, to shine resplandeciente, resplendent resplandor, m., gleam, splendor responder, to reply; to be responsible for, guarantee responsabilidad, responsibility

responsable, $a$. and s., responsible; responsible person

respuesta, reply 
resquicio, opening, rift, op- / retumbar, to resound

\section{portunity}

restante, remaining

restañar, to stop the flow of

blood, staunch

restar, to remain

restaurar, to restore

resto, rest, remnant

restregar, to rub

resueltamente, resolutely

resuelto, $-\mathrm{a}$, resolute

resultado, result, outcome

resultante, $f_{\text {., }}$ resultant

resultar, to result, come about resumir, to resume; en re-

sumidas cuentas, in brief resurrección, resurrection retaguardia, rear, rear guard retardar, to delay, postpone retemplar, to encourage, give

fire to

retener, to hold back, retain retina, retina, eye

retintín, m., tinkling, ring

retirada, retreat

retirarse, to retite

retiro, retirement, retreat

reto, challenge

retoño, sprout, shoot

retorno, return

retratar, to portray, depict

retrato, portrait

retrogradar, to degencrate,

lapse, fall back

retrógrado, -a, retrograde,

backivard reunión, reunion, gathering reunir, to unite, add, combine revelación, revelation

revelar, to reveal

rêver, from the French, to

dream

reverbero, street lamp, arc light

reverso, reverse side of a coin revés, m., opposite; al -, contrariwise

revestir, to clothe, cover, invest

revistar, to review

revivir, to live again, be renewed

revocar, to revoke

revolar, to Hy about

revolotear, to futter

revoltear, to revolve, wheel about

revolución, revolution

revolucionar, to revolutionize, convulse

revolucionario, $-a$, revolutionary

revolver, to turn about, envelop

revuelta, vicissitude, tevolt

rey, king

rezar, to pray

rico, $-a$, rich

ric-ric, onomatopaic syllables imitating noise produced by friction 
ridiculo, -a, ridiculous

riego, sprinkling, watering rienda, rein; - suelta, loose rein

riesgo, risk, danger rígido, $-\mathbf{a}$, rigid, inflexible rigurosamente, rigorously riguroso, $-\mathrm{a}$, rigorous rinconada, corner, nook, bend riña, fight río, river

Río Janeiro, capital of Brazil riqueza, wealth, riches risa, laugh, smile risotada, loud laughter ristra, string, row risueño, $-a$, smiling ritmo, rhythm rival, a. and s., rival rivalizar, to rival; - con, to vie with rivera, shore, bank rizado, $-a$, curly robar, to steal robo, theft robustecer, to make strong robusto, $-a$, robust, strong roca, rock rocalloso, -a, rocky roce, $m$., friction; intercourse rociado, $-\mathbf{a}$, bedewed rocío, dew rodar, to roll rodear, to surround rodilla, knee roedor, -ora, gnawing rogar, to beseech, entreat rojizo, $-\mathbf{a}$, reddish rojo, $-a$, red Roma, Rome romance, $m$., novel, romance, story

romancista, $m$., romancer romano, $-a$, Roman romántico, $-a$, romantic romper, to break; - marcha, to set out

ropa, cloth; clothes rosa, rose rosado, $-a$, rosy rosario, religious procession rostro, face, rostrum rótulo, title, inscription rozar, to scrape rubicundo, -a, rubicund, tawny

rubio, $-\mathbf{a}$, golden rudeza, coarseness rudimentario, $-\mathbf{a}$, rudimentary rudimento, rudiment, beginning

rueca, distaff

rueda, circle, wheel

ruego, prayer, entreaty

rugir, to roar, bellow

ruido, noise

ruidoso, $-a$, noisy

ruina, ruin

rumbo, direction, course; con - a, bound for rumiar, to ruminate, think rumor, $m$., rumor, news 
ruso, $-\mathrm{a}$, Russian

rutilante, shining, sparkling rutinario, $-\mathbf{a}$, routinary

\section{$\mathrm{S}$}

sábado. Saturday

sábalo, shad

sabana, plain

saber, to know how; a -, to wit

sabiduria, wisdom

sablazo, saber blow; a $-\mathrm{s}$,

by dint of sabering

sabor, m., taste

sabroso, -a, savoury, swee:

sacar, to take out

sacerdote, priest

sacerdotisa, priestess

saciar, to satiate, satisfy

saco, coat

sacramental, sacramental

sacrificar, to sacrifice

sacrificio, sacrifice

sacrílego, - a, sacrilegious

sacudir, to shake, stir up

sachasombrero,

brimmed straw hat

saetazo, arrow blow, arrow

wound

sagacidad, salaacity

sagaz, sagacions, fiecn

sagrado, a, sacred

sajón, ona, Siscon

Sajonia, Saxony

sala, lall, romin; - de armas, arunory salado, -a, salty, salted

Salamanca, Salamanca, city in Spain. $V$. notes, $78, \mathrm{I}_{5}$ salero, gracefulness

salida, exit, departure, raid

salir, to go out, leave

salobre, briny, salty

salomónico, -a, pertaining to

Solomon, wise, solomonic

salón, m., salon, parlor, hall

Salónica, city in Greece

salpicar, to bespatter

saltar, to leap, jump over

salteador, highwayman

salubre, salubrious, wholesome

salud, health

isalud! hail!

saludable, salubrious, healthful

saludar, to greet, salute

saludo, salute, greeting

salva, salvo, gun salute

salvación, salvation

salvaje, savage

salvar, to save, leap over, cover, pass

salvo, save, except

salvo, - a, salfe

sangrar, to bleed

sangre, f., hlood

sangriento, -a, gory, cruel

sanguinario, $-a$, bloolthirsty

sano, - a, safe, healthy

santo, -a, holy.

santuario, sanctuary 
saña, anger, rage

sarcasmo, sarcasm

sarcástico, -a, sarcastic

sargento, sergeant

sarta, wreath, string

things), series

sastre, tailor

sátiro, satyr

satisfacción, satisfaction

satisfacer, to satisfy

satisf echo, - a, satisfied

saturado, -a, saturated

sauce, m., willow

sauco, elder tree

savia, sap

sazón, f., time, season, occasion

sazonado, - a, ripe, seasoned

se, himself, herself, themselves, yourself, yourselves seco, $-\mathrm{a}$, dry

secretamente, secretly

secretario, secretary

secreto, secret

secreto, $-\mathbf{a}$, secret

secuaz, m., follower

secuela, sequel, result

secular, century-old, secular

secundario, $-\mathbf{a}$, secondary, subordinate

sed, $f$., thirst

seda, silk

sede, $f$., seat, headquarters

sedentario, - a, sedentary

sedición, sedition

sediento, $-\mathbf{a}$, thirsty seducir, to seduce

seductor,-ora, seductive, enticing

segar, to mow, cut down

seguida: en -, at once

seguir, to follow, continue

según, according to; as

segundo, $-\mathbf{a}$, second

seguridad, security, assurance seguro, -a, secure; sure, cer-

tain

seis, six

selva, forest

selvático, -a, wild, sylvan

sellar, to seal

sello, seal, stamp

semana, week

semblante, m., appearance, face

sembrar, to sow

semejante, s. and a., fellow-

being; similar

semejanza, resemblance

semejar, to resemble

semibárbaro, -a, semi-bar-

barous

semibarbarie, $f_{\text {., }}$ semi-barbarity

semiborrar, to half wipe away semilla, seed

semitropical, semitropical

sencillez, simplicity

sencillo, $-\mathbf{a}$, simple, frank

senda, byway

sendero, natrow path

sendita, diminutive of senda 
sendos, -as, used in the pl., strictly, to each of a specified number, one each; more freely, many, several seno, bosom sensación, sensation sensible, appreciative, sensible, sensitive sentar, to fit, agree, set; - se, to sit down

sentencia, sentence sentido, -a, heartfelt sentido, meaning, feeling, sense, direction sentimental, sentimental sentimiento, sentiment, emotion sentir, to feel, hear seña, sign, mark señal, $f .$, sign señalar, to point out, show señor, gentleman, Mr., sir señora, lady, Mrs., madam señorita, young lady, Mliss, madam

señorito, young gentleman separación, separation separar, to separate separatista, separatist septentrional, northern septiembre, m., September sepulcro, grave, tomb) sepultar, to hury, ameulf sequedad, barrenness, dryness sequia, drought séquito, $m$. , following ser, to be ser, $m$., being, creature ; modo de -. manifestation, mode of life

serenar, to soothe, calm serenata, serenade serenidad, serenity sereno, -a, serene, clear seriamente, seriously serie, $f$., series serio, -a, serious serpiente, $f$., serpent servicio, service, use, payment, installment servidor, servant servidumbre, f., colict., servants servil, servile servir, to serve, owe allegiance sesenta, sixty sesión, session seso, used in the pl., brains setenta, serenty severidad, severity severo, -a, severe, grave sexo, sex

sí, prep. form of se

sí, res, indeed si, if siempre, always; - que, whenever, provided sien, $f_{\text {., temple }}$ sierra, mountain range siesta, nap taken in the afternoon 
siete, seven

sigilo, secret; seal

sigilosamente, secretly

siglo, century

significado, meaning

significar, to mean, signify

significativo, -a, significant

signo, sign

siguiente, following

silbar, to whistle

silbido, hiss, whistle

silbo, whistle

silencio, silence

silencioso, $-\mathrm{a}$, silent

silvestre, of the forest, sylvan silla, chair, saddle; $-\mathrm{de}$

posta, post-chaise

símbolo, symbol

simétrico, -a, symmetrical

simiente, $f$., seed

simpatía, sympathy, attraction

simpático, -a, attractive, charming

simple, simple

simplemente, simply

simulacro, pretense; image

simular, to counterfeit, feign

sin, without

sincero, $-\mathrm{a}$, sincere

singladura, day's run on the sea

singular, singular

singularizar, to set apart,

make conspicuous

siniestro, $-\mathbf{a}$, sinister, evil sino, except, but

sintesis, f., synthesis

sinuosidad, sinuosity, undulation

sinuoso, -a, sinuous, undulating

Siôn, Zion

siquiera, at least; although, even if

sirena, siren, whistle

sistema, m., system

sistemado, -a, systematizea, systematic

sitio, place, siege; Arg., city lot

situación, situation, state

situar, to locate

soberanía, sovereignty

soberano, -a, sovereign

soberbio, -a, haughty

sobra, excess

sobrado, -a, sufficient, more

than enough

sobre, upon

sobrecoger, to surprise, alarm

sobrehumano, -a, superhuman

sobrenatural, supernatural

sobresalir, to rise, appear, stand out

sobreviviente, surviving

sobrevivir, to survive

sobrino, nephew

sobrio, $-a$, sober

social, social

socialmente, socially 
sociedad, society, social group $\mid$ son, $m$., sound; en - de, i i sociológico, $-\mathrm{a}$, sociological sociólogo, sociologist socorro, help sofocar, to stifle sol, $m$., sun solamente, only soldado, soldier soledad, solitude, waste solemne, solemn solemnidad, solemnity soler, to be wont solicitar, to solicit, importune, seek

solicito, -a, careful, anxious, discriminating solicitud, care, solicitude sólido, $-\mathrm{a}$, solid solitario, -a, solitary, lonely soliviantar, to lift, raise soliviar, to raise, lift solo, $-\mathrm{a}$, alone, single sólo, only soltar, to let loose soluc:oón, solution sollado, orlop, lower deck of a vessel

sollozar, to sob sollozo, sob sombra, shadow; ghost sombrear, to shade sombrero, hat sombrio, $-\mathrm{a}$, somber someter, to submit sometido, -a, submitted, submissive the manner of sonar, to sound, roll sondar, to sound, fathom sondear, to sound, fathom soneto, sonnet sonido, sound, note sonoridad, sonority sonoro, -a, sonorous, sounding

sonreir, to smile sonriente, smiling sonrisa, smile soñador, dreamer soñar, to dream soplar, to blow sorbo, sip, draught sordo, -a, dull, dumb, silent sorprendente, surprising sorprender, to surprise, overcome sorpresa, surprise sospecha, suspicion sospechar, to suspect sospechoso, -a, suspicious sostener, to sustain, support su, his, her, its, their, your suave, gentle, mild suavizar, to smooth, soften súbdito, subject subdividir, to subdivide subir, to dimb, ascend súbito, $-\mathrm{a}$, sudden; de suddenly sublevación, uprising sublevado, rebct 
sublevar, to excite to rebel-' sufrir, to suffer, endure lion, raise

sublime, sublime

subordinación, subordination

subordinado, - a, subordinate

subsiguiente, following, subsequent

subsistencia, sustenance, food, provision

substancia, substance

subterráneo, -a, subterranean, underground

suburbio, suburb, outskirt

subyugar, to conquer, subjugate

suceder, to follow, happen

sucesión, succession

sucesivamente, successively

suceso, event; success

sucesor, successor

sucio, -a, dirty

suculento, $-\mathbf{a}$, succulent

sucumbir, to succumb

sud, $m$., south

sudamericano, -a, South

American

sudario, shroud, handkerchief sudor, $m$., perspiration, sweat suelo, soil, ground suelto, - a, free, loose sueño, dream, sleep suerte, $f$., lot, fate, luck suestada, southeaster suficiente, sufficient sufrido, -a, patient sufrimiento, suffering sugerir, to suggest, prompt sugestión, suggestion sugestivo, -a, suggestive suicidio, suicide sui generis, from the Latin, peculiar to itself sujeción, subjection sujetar, to subject sujeto, subject sultán, sultan suma, sum; en -, in short sumamente, excessively suministrar, to supply, lend sumir, to plunge, sink sumisión, submission sumiso, - a, submissive sumo, -a, supreme; a lo at the most suntuosidad, sumptuousness superficie, $f_{\text {., }}$ surface superhombre, superman superior, superior superioridad, superiority superponer, to place upon, compare

supersticioso, $-a$, superstitious suplantación, supplanting, substitution súplica, supplication, request suplicante, suppliant suplicio, punishment, execution suplir, to supply, serve instead of suponer, to suppose 
supremo, -a, supreme, critical supresión, suppression supuesto, $-\mathbf{a}, p$. p. of suponer; por supuesto, of course sur, m., south

surcar, to furrow, sail

surco, furrow

surgir, to surge, arise

surtir, to provide, supply

suspender, to suspend, cease

suspensión, suspension, sus-

pense

suspicaz, suspicious, jealous suspiro, sigh

sustentar, to bear, support

sustento, sustenance

sustituir, to substitute, take the place of

sustraer, to take away ; - - se,

elude, withdraw

susurro, murmur, swish

\section{$\mathrm{T}$}

tabaco, tobacco

tabla, hoard

tablada, octroi or custom-

house in the outskirts of a town

tablilla, small strip of wood about which fabries are wrapped

Tácito, lacitus, Roman historian who lived from 55

to 120 A.1).

táctica, tactics

tacto, sense of rouch tahur, gambler

taimado, -a, sly, crafty

tajada, cut, slash

Tajo, river in Spain, the Tagus; Toledo is built on its banks

tal, such a; - cual, such as, just as; con - que, provided that

talento, talent

talla, height, stature

tamaño, size

también, also

tambor, $m$. , drum

tamboril, m., tambourine, drum

tampoco, neither, either, and not

tan, so; - . . como, as . . . as

Tántalo, m., Tantalus, punished according to Greek mythology to suffer everlasting thirst and hunger though almost within reach of food and water

tantear, to feel, try

tanto, -a, such, so much; en - que, while; por $10-$, therefore; - más ... cuanto que, the more... since; tantos ... cuantos, as many... as

tapar, to cover, dam

tapera, Arg., abandoned house; de - en galpón, from place to place 
tapia, mud wall, fence

tapizar, to upholster

tardar, to delay

tarde, $f$, afternoon

tarde, adv., late; de - en-, occasionally

tardo, - a, slow

tarea, task, labor

tártaro, -a, Tartar

tasa, charge, fee

tasar, to tax, appraise

taumaturgo, magician, prodigy

te, thee

te, $m$. , tea

teatral, theatrical

teatrillo, dingy little theater

teatro, theater, field of action

técnica, technique

techo, roof, house

tejado, roof

tejer, to weave, regulate

tela, cloth

telar, m., loom

telegrama, m., telegram

telón, $m$, curtain, film

temblar, to tremble

temblón, -ona, trembling

tembloroso, -a, quivering

temer, to fear

temeroso, -a, fearful, afraid

temible, fearful

temor, m., fear

temperamento, disposition, climate

tempestad, tempest, turmoil tempestuoso, -a, tempestuous templado, -a, tempered, cool templar, to tune, temper temple, m., disposition, temper

temporada, interval, period of time

temporal, m., storm, bad weather

temporalmente, temporarily

temprano, soon, early

tenacidad, tenacity

tenaz, tenacious, unrelenting

tendencia, tendency

tender, to stretch out, cast, level, attempt

tendero, salesman, clerk

tendiente, $m_{\text {. }}, A r_{g}$., attendant, clerk

tendiente, tending tenebroso, - a, dark

iener, to have, possess, hold - se por, to consider oncself as; - presente, to bear in mind; - en cuenta, to take into account; -.- a pecho, to hold dear, love tentación, tempitation tentar, to tempt, try tentativa, attempt, conspiracy tenue, tenuous, thin teñir, to tinge, dye tercerola, carbine terciana, intermittent fever terciar, to sling across 
terminar, to bring to a close, end

término, time, term, limit

ternera, calf, heifer; lomo de -, loin of veal

ternura, tenderness

terreno, ground, soil

terreno, $-\mathrm{a}$, earthy, worldly, earthly

terrestre, earthly, terrestrial terrible, terrible

territorial, territorial

territorio, territory

terrón, $m$., lump of earth

terror, $m$., terror

terruño, native soil

tertuliano, frequenter, ha-

bitué, nember of a club

or social circle

tesorería, treasury

tesoro, treasure

testificado, - a, attested to,

witnessed

testigo, witness

testimonio, testimony

tétrico, $-\mathbf{a}$, gloomy

texto, text, hasis

tez, $f$., complexion, skin

tibio, -a, lukewarm

tiempo, time

tienda, shop, tent

tienta, probe; a $-\mathrm{s}$, gropingly'

tiernamente, tenderly

tierno, - a, tender

tierra, land, eartlı; adentro, inland; $-\mathrm{s}$ de pan llevar, grain-producing lands

tigre, $m$., tiger

tijera, scissors

timbre, $m$. , timbre, pitch

timidez, timidity

tímido, -a, timid

tiniebla, generally used in the

plural, gloom, darkness

tino, skill, tact

tinta, tincture, ink

tinte, $m$., tint, color

tintura, tincture, tinge

tipo, type, figure, trait

tirado, -a, drawn along, led

tirador, marksman

tirania, tyranny

tirano, tyrant

tirante, taut, tense, stringent

tirar, to pull, throw, shoot

tiritar, to shiver

tiro, musket shot, range;

hasta - y medio de fusil, within range of once and a half rifle distance

tirón, m., stroke, pull

titánico, - a, titanic

titulado, -a, entitled

título, title, right

tocado, headgear, coiffure

tocar, to touch, play; me

toca, it is my turn

todavia, still, yet

todo, $-\mathrm{a}$, every, entire; con

-, neverthicless; del -.., 
wholly, at all; en or de punto, in every respect toma, capture tomar, to take, assume; partido, to take sides tono, tone; de -, stylish, fashionable; de buen -., in good taste topógrafo, topographer toque, $m$., sounding, ringing; - de las ánimas, ringing of bells in the evening when the faithful pray for souls in purgatory

torada, herd of bulls torbellino, whirlwind torcaza, cushat dove tormenta, storm tormento, torment tornar, to turn, return; - - se,

to become torneo, tournament torno, wheel; en -, round

about; en - de, about toro, bull torpe, stupid, infamous torre, $f$., tower torrente, m., torrent; a in torrents

torreón, m., bastion, tower tortuoso, -a, tortuous, en

tangled torvo, $-a$, scowling, forbidling tosco, $-\mathrm{a}$, rough, rude tostar, to brown, roast total, total, entire total, m., total, sum traba, hindrance, ligament trabajar, to work, suffer trabajo, work, hardship trabar, to begin, tie; to engage in

trabazón, $f$., coherence, bond tradición, tradition tradicional, traditional traducción, translation traducir, to translate, interpret, articulate traductor, translator traer, to bring, wear traficar, to barter, traffic, travel

tráfico, business, intercourse tragadero, esophagus ; devourer

tragedia, tragedy trágicamente, tragically trágico, -a, tragic traición, treachery traidor, traitor traidoramente, treacherously traje, $m$., suit, garment tramar, to weave; to plot trance, $m$., critical moment, danger, cost

tranco, stride, trot; al -, on the trot

tranquilamente, tranquilly tranquilizar, to set at ease, calm tranquilo, -a, tranquil, quiet transacción, transaction 
transatlántico, steamer transatlántico, -a, transatlantic transcurrir, to elapse transeunte, $a$. and s., passing; passer-by

transformación, transformation

transformar, to transform transido, $-\mathrm{a}$, pierced transigir, to yield, compromise

transitar, to roam transitorio, -a, transitory, temporary

transmitir, to transmit, forward

transparencia, transparency, clearness

transparente, transparent transportador, transporter, carrier

transportar, to transport, carry

tranvía, m., trolley-car tras, behind, after trascendental, transcendental trasladar, to move traslucir, to shine through traspasar, to go beyond trasplantar, to transplant trasponer, to put behind trastienda, rear shop tratar, to treitt; + infin., to try; - se to be a matter of trato, intercourse, dealing, relation través, m., bias, inclination; al -, across

travesía, crossing, journey across

travieso, $-\mathbf{a}$, mischievous trazar, to trace, design trecho, distance treinta, thirty tremendo, -a, tremendous tremolar, to wave, flutter, beat

tren, m., train

trenzar, to braid, twine

trepar, to climb, crawl on tres, three

tribu, $f$., tribe

tribuna, speaker's platform tribunal, m., tribumal, court tributar, to pay tribute, offer trigo, wheat trillar, to thresh, cut trinchera, trencher, banquet, feast tripe, m., plush, shag triplemente, triply, threefold triplicar, to triple triste, sad triste, $m_{\text {. }}$, Argentine song of that name tristeza, sadness triunfal, triumphal de, triunfante, triumpliant de, triunfar, to trimuph triunfo, triumph 
trofeo, trophy

trompa, proboscis, trumpet,

trunk

tronco, trunk

trono, throne

tropa, troop, herd; Arg.,

train of pack animals or $o x$ carts

tropel, $m$, hubbub, confusion tropezador, -ora, stumbling tropezar, to stumble

tropiezo, obstacle, difficulty, trouble

tropilla, Arg., troop, herd trote, m., trot

trotón, m., trotter

trova, ballad

trovador, troubadour, minstrel trueno, thunder

trueque, m., exchange; a - , in exchange

truncado, $-a$, truncated

Tucumán, province of Argentina; also name of capital of said province

tucumano, $-\mathbf{a}$, of Tucumán

tumba, tomb, grave

tumultuoso, -a, tumultuous

tuna, cactus pear, cactus plant

tunal, $m$., cactus, place where cactus grows

túnica, tunic

tupidisimo, -a, very dense, thick

turba, crowd turbación, agitation, disturbance

turbante, m., turban

turbar, to trouble, disturb

turbulento, -a, turbulent

turno, turn

tutela, guardianship, tutelage tutelar, tutelary, protecting

\section{U}

ubicar, to place, locate

ubicuo,-a, omnipresent, ubiquitous

ujier, usher

ulterior, later, ulterior, further ultimamente, lastly, in the end último, -a, last, final

umbral, $m$., threshold

umbroso, -a, shady

unánime, unanimous

undécimo, $-\mathbf{a}$, eleventh

únicamente, only

único,-a, only, sole, unique

unidad, unity

uniforme, uniform, constant

uniforme, m., uniform; de

grande --, in full uniform

unión, union

unir, to join, unite

unitario,-a, unitary, unitarian

universal, universal

universidad, university

uno, -a, one, pl., some; - y

otro, both; unos y otros, all

uña, nail, claw

urbano, -a, urban 
urbe, $f$., city

urgente, urgent

usar, to use

uso, use, usage

útil, useful

\section{V}

vaca, cow

vacilación, vacillation

vacilar, to waver, hesitate vacío, $-\mathbf{a}$, empty, unburdened vacio, hollow, void

vado, ford

vagabundo, $-a$, roaming, vag abond

vagamente, vaguely

vagar, to wander, roam

vago, $-\mathbf{a}$, rague

vago, idler

vajilla, table service

valer, to avail, be worth

valeroso, -a, valiant, brave valiente, $a$. and s., valiant; brave man

valioso, $-a$, valuable, powerful valor, m., valor, bravery, value valle, m., valley

vanagloria, vainglory

vandalaje, $m$. vandalism

vanguardia, vanguard

vanidad, vanity

vano, $-a$, vain

vapor, $m$., stean, steamer

vaporoso, $-\mathbf{a}$, misty

vaquía, also cerillen baquia, dexterity, expertness vara, yard, yardstick

variado, $-a$, varied

variante, $m$., variant

vario, -a, various, varied;

pl., several

varita, small stick

varôn, male, man

varonil, manly

vasallo, vassal

vasco, -a, Basque, pertaining

to the Basque provinces of

Spain

vaso, vessel, vase, glass

vástago, offshoot, branch, descendint vasto, $-a$, vast, immense vate, $m$., seer, poet

V. E., abbr. for Vuestra Excelencia, Your Excellency vecindad, vicinity

vecindario, vicinity, district; collect., neighbors

vecino, $-\mathbf{a}$, a. and s., neighboring; neighbor, inhabitant, denizen; m. pl., people, inhabitants

vedado, $-a$, forbidden

vedija, entangled lock of wool

vehemencia, vehemence

vehemente, velsensent, strong

veinte, twenty

veintidós, twenty-two

veintinueve, twenty-nine

veintitrés, twenty-three

vejez, old ane 
vela, vigil, watch; candle vela, sail

velar, to keep watch, watch veleidad, fickleness, levity, shilly-shally

velero, swift sailing vessel velo, veil

velocidad, velocity

velorio, vigil for the dead veloz, rapid

velozmente, rapidly

vencedor, victor

vencer, to win, conquer

vencimiento, victory, con-

quest; maturity

vendaval, $m$., wind from the sea

vendedor, salesman

vender, to sell

veneciano, $-\mathbf{a}$, Venetian

venerable, venerable

veneración, veneration

venganza, vengeance

vengar, to avenge

venir, to come

venta, inn

ventaja, advantage

ventana, window

ventilar, to ventilate

ventura, good fortune

ver, to see, notice; a - let's see

veracidad, veracity, truth

verano, summer

verbalmente, verbally

verbo, verb

verdad, truth verdaderamente, truly, indeed verdadero, -a, true, genuine, veritable, real

verde, green

verdugo, executioner, tormentor

verdura, verdure, greens

vereda, walk, path; Arg., sidewalk

verificación, verification

versificación, versification

versificador, versifier

verso, verse

vertiginosamente, rapidly, giddily

vertiginoso, $-\mathbf{a}$, giddy, swift vẻrtigo, giddiness

vespertino, $-\mathrm{a}$, pertaining to evening

vestíbulo, vestibule, lobby

vestido, dress

vestigio, trace, vestige

vestir, to wear, put on

veterano, $-\mathrm{a}$, veteran, seasoned vetusto, $-a$, old

vez, f., occasion, time; a la -.,

at the same time; tal-, perhaps; en - de, instead of; de - en cuando, from time to time; a su -, in one's turn; otras veces, at other times; hacer las veces, to play the part, take the place

vía, way

viajar, to travel 
viaje, m., voyage, trip; en on the way

viajero, traveler

vibrante, vibrating

vicio, vice, habit

vicioso, $-\mathrm{a}$, vicious, corrupt

vicisitud, vicissitude, lot

víctima, victin

victoria, victory

victorioso, $-\mathrm{a}$, victorious

vida, life

vidalita, gaucho song vidriera, show case, window

viejo, $-a$, old

viento, wind

vientre, $m$., stomach, belly

vigilancia, vigilance; - mari-

tima, harbor police

vigilante, watchful, alert

vigilia, vigil, nocturnal medi-

tation

vigor, m., vigor, strength

vigorosamente, vigorously

vigoroso, -a, vigorous, powerful

vihuela, guitár

vil, vile, low

villa, community

vino, wine

viña, vineyard

violación, violation

violencia, violence

violento, $-\mathrm{a}$, violent

violín, m., violin

virgen, virgin

virginidad, virginity, purity viril, virile, manly

virreinato, viceroyalty

virrey, viceroy

virtud, virtue, quality

virtuosísimo, -a, very virtuous

virulencia, virulence

visible, visible

visiblemente, visibly

visión, vision

visita, visit

visitar, to visit

viso, feature, aspect, outlook

vista, look, sight, view; a la

-, in sight

vitalidad, vitality

vitualla, food, victuals

viuda, widow

vivac, m., bivouac

vivamente, sharply, vividly

vivaque, $m$., bivouac

viveres, $m$. pl., provisions

viveza, vivacity, keenness

vivienda, dwelling

vivir, to live

vivísimo, - a, very keen, sharp

vivo, $-\mathbf{a}$, alive, vivid, eager

volador, ora, flying

volante, Hying, light; arti-

llería - field artillery

volar, to Hy

volcánico, $-a$, volcanic

volcar, to upset

voltear, to throw down, overpower

voltigero, voltigeur, lightarmed infantry soldier 
voluntad, will, mind voluntariamente, voluntarily voluntario, $-a$, voluntary voluntario, volunteer voluntarioso, $-\mathbf{a}$, willful volver, to return, turn; - a + infin., to do again; - en sí, to regain consciousness; - se, to become

vomitar, to vomit, belch votar, to vote voto, vote, ballot, vow voz, $f$., voice

V. S., abbr. for Vueseñoría, Your Lordship vuelo, flight; loftiness in discourse

vuelta, turn; dar una - , to take a stroll vulgar, vulgar, commonplace vulgarisimo, -a, very vulgar, commonplace vulgo, crowd, populace

$y$, and

\section{Y}

ya, already, even, now; with a negative, no longer; - ... -, whether...or yacer, to lie

yermo, -a, waste, desert yerto, -a, stiff, inert, lifeless yugo, yoke

yunta, pair, yoke

\section{Z}

zafar, to untie

zaga, rear of anything; ir en

-, to be behind, inferior

zagal, shepherd

zamarra, sheepskin coat

zanja, ditch

zanjón, $m$., deep ditch

Zaragoza, city in Spain

zarpar, to weigh anchor, set sail

zona, zone, belt

zoológico, -a, zoölogical

zorzal, $m$., thrush

zozobra, worry, anguish

zumbido, buzzing

Zupay, m., mythical character in the Quichua Indian traditions; represents the evil spirit of the forest 

. 







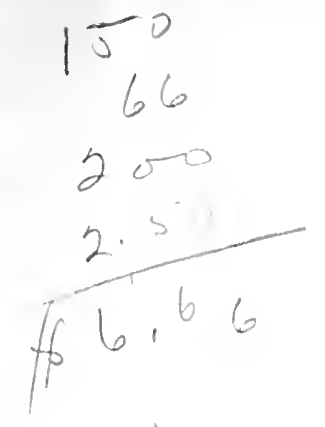




\section{•}





\section{UNIVERSITY OF CALIFORNIA LIBRARY}

\section{Los Angeles}

This book is DUE on the last date stamped below. 
UC SOUTHERN REGIONAL LIBRARY FACILITY

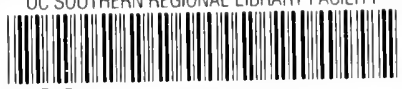
AA $000420766 \quad 8$ 


\section{(t)}

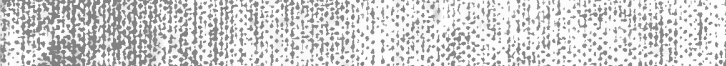

STh

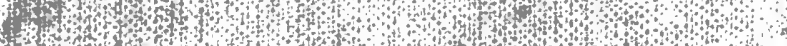
Shy Shof

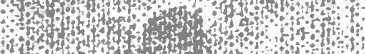
A 4 (2) Tit.

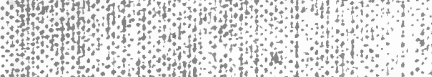

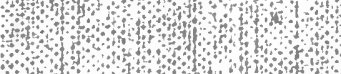

(1)

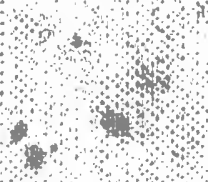

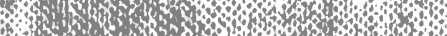

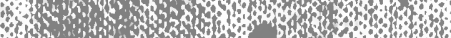

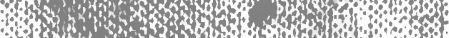

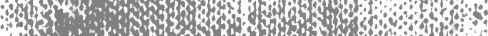

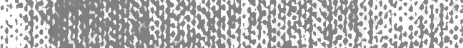

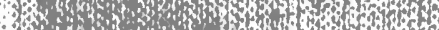
030 . 30,0 . 3030 o s.

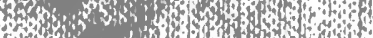

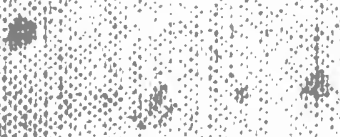

